Cochrane Database of Systematic Reviews

\title{
Telephone counselling for smoking cessation (Review)
}

Matkin W, Ordóñez-Mena JM, Hartmann-Boyce J

Matkin W, Ordóñez-Mena JM, Hartmann-Boyce J.

Telephone counselling for smoking cessation.

Cochrane Database of Systematic Reviews 2019, Issue 5. Art. No.: CD002850.

DOI: 10.1002/14651858.CD002850.pub4.

www.cochranelibrary.com 
TABLE OF CONTENTS

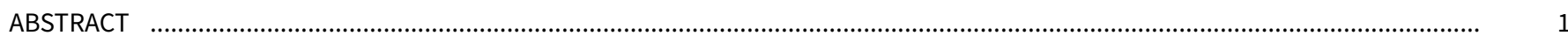

PLAIN LANGUAGE SUMMARY

SUMMARY OF FINDINGS

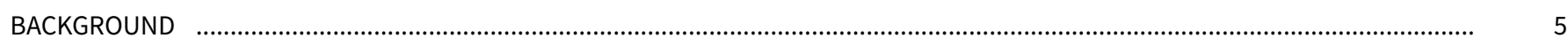

OBJECTIVES

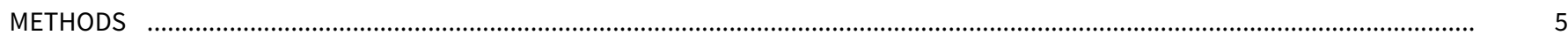

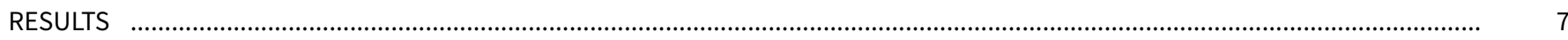

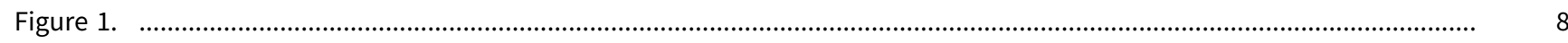

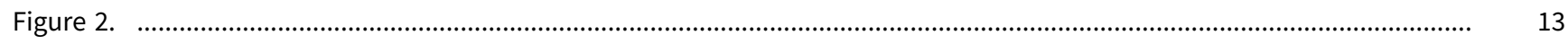

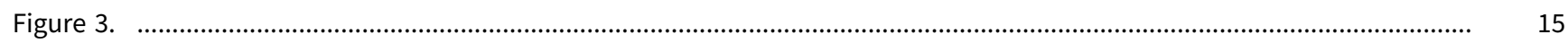

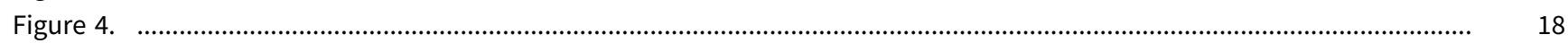

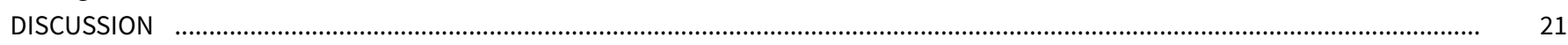

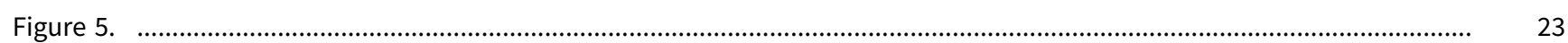

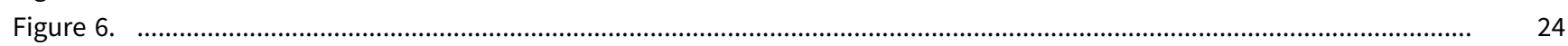

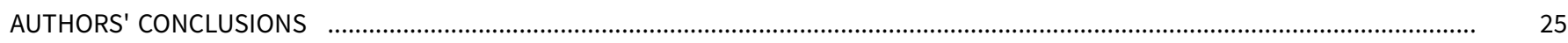

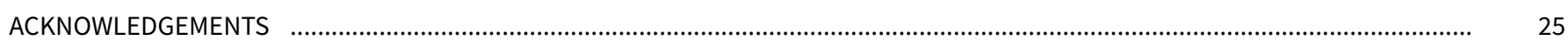

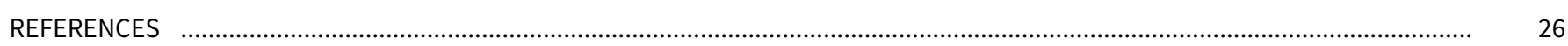

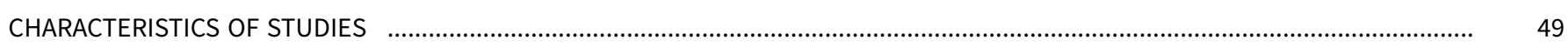

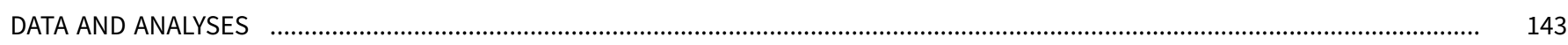

Analysis 1.1. Comparison 1 Interventions for callers to quitlines - effect of additional proactive calls, Outcome 1 Cessation at 143 longest follow-up.

Analysis 2.1. Comparison 2 Interventions for callers to quitlines - comparison of different intensities, Outcome 1 Cessation at longest follow-up.

Analysis 3.1. Comparison 3 Interventions for callers to quitlines - subgroups by counseling intensity, Outcome 1 Cessation at longest follow-up.

Analysis 4.1. Comparison 4 Interventions for callers to quitlines - comparison of different support at initial call, Outcome 1 Cessation at longest follow-up.

Analysis 5.1. Comparison 5 Offer of counselling via quitlines/helplines/hotlines, Outcome 1 Cessation at longest follow-up. ...

Analysis 6.1. Comparison 6 Interventions for smokers not calling quitlines - subgroups by baseline support, Outcome 1 Cessation at longest follow-up.

Analysis 7.1. Comparison 7 Interventions for smokers not calling quitlines - intense versus minimal telephone counselling, Outcome 1 Cessation at longest follow-up.

Analysis 8.1. Comparison 8 Interventions for smokers not calling quitlines - subgroups by counseling intensity, Outcome 1 Cessation at longest follow-up.

Analysis 9.1. Comparison 9 Interventions for smokers not calling quitlines - subgroups by motivation, Outcome 1 Cessation at longest follow-up.

Analysis 10.1. Comparison 10 Other studies, Outcome 1 Cessation at longest follow-up.

APPENDICES

WHAT'S NEW

HISTORY

CONTRIBUTIONS OF AUTHORS

DECLARATIONS OF INTEREST

SOURCES OF SUPPORT

DIFFERENCES BETWEEN PROTOCOL AND REVIEW

INDEX TERMS (1)

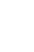
.

8

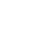
$(8-10$ .

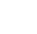

5

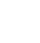

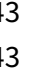


[Intervention Review]

\section{Telephone counselling for smoking cessation}

William Matkin1a, José M. Ordóñez-Mena²b, Jamie Hartmann-Boyce ${ }^{2}$

${ }^{1}$ Medical Sciences Division, University of Oxford, Oxford, UK. ${ }^{2}$ Nuffield Department of Primary Care Health Sciences, University of Oxford, Oxford, UK

${ }^{a}$ Equal contributions as first authors. ${ }^{b}$ Equal contributions as first authors

Contact: José M. Ordóñez-Mena, Nuffield Department of Primary Care Health Sciences, University of Oxford, Radcliffe Observatory Quarter, Woodstock Road, Oxford, Oxfordshire, OX2 6GG, UK. jose.ordonezmena@phc.ox.ac.uk.

Editorial group: Cochrane Tobacco Addiction Group.

Publication status and date: New search for studies and content updated (no change to conclusions), published in Issue 5, 2019.

Citation: Matkin W, Ordóñez-Mena JM, Hartmann-Boyce J. Telephone counselling for smoking cessation. Cochrane Database of Systematic Reviews 2019, Issue 5. Art. No.: CD002850. DOI: 10.1002/14651858.CD002850.pub4.

Copyright ( 2019 The Cochrane Collaboration. Published by John Wiley \& Sons, Ltd.

\section{A B S T R A C T}

\section{Background}

Telephone services can provide information and support for smokers. Counselling may be provided proactively or offered reactively to callers to smoking cessation helplines.

\section{Objectives}

To evaluate the effect of telephone support to help smokers quit, including proactive or reactive counselling, or the provision of other information to smokers calling a helpline.

\section{Search methods}

We searched the Cochrane Tobacco Addiction Group Specialised Register, clinicaltrials.gov, and the ICTRP for studies of telephone counselling, using search terms including 'hotlines' or 'quitline' or 'helpline'. Date of the most recent search: May 2018.

\section{Selection criteria}

Randomised or quasi-randomised controlled trials which offered proactive or reactive telephone counselling to smokers to assist smoking cessation.

\section{Data collection and analysis}

We used standard methodological procedures expected by Cochrane. We pooled studies using a random-effects model and assessed statistical heterogeneity amongst subgroups of clinically comparable studies using the $\mathrm{I}^{2}$ statistic. In trials including smokers who did not call a quitline, we used meta-regression to investigate moderation of the effect of telephone counselling by the planned number of calls in the intervention, trial selection of participants that were motivated to quit, and the baseline support provided together with telephone counselling (either self-help only, brief face-to-face intervention, pharmacotherapy, or financial incentives).

\section{Main results}

We identified 104 trials including 111,653 participants that met the inclusion criteria. Participants were mostly adult smokers from the general population, but some studies included teenagers, pregnant women, and people with long-term or mental health conditions. Most trials (58.7\%) were at high risk of bias, while $30.8 \%$ were at unclear risk, and only $11.5 \%$ were at low risk of bias for all domains assessed. Most studies (100/104) assessed proactive telephone counselling, as opposed to reactive forms.

Among trials including smokers who contacted helplines (32,484 participants), quit rates were higher for smokers receiving multiple sessions of proactive counselling (risk ratio (RR) $1.38,95 \%$ confidence interval $(\mathrm{Cl}) 1.19$ to $1.61 ; 14$ trials, 32,484 participants; $\mathrm{I}^{2}=72 \%$ ) 
compared with a control condition providing self-help materials or brief counselling in a single call. Due to the substantial unexplained heterogeneity between studies, we downgraded the certainty of the evidence to moderate.

In studies that recruited smokers who did not call a helpline, the provision of telephone counselling increased quit rates (RR $1.25,95 \% \mathrm{Cl}$ 1.15 to $1.35 ; 65$ trials, 41,233 participants; $\left.\right|^{2}=52 \%$ ). Due to the substantial unexplained heterogeneity between studies, we downgraded the certainty of the evidence to moderate. In subgroup analysis, we found no evidence that the effect of telephone counselling depended upon whether or not other interventions were provided $(P=0.21)$, no evidence that more intensive support was more effective than less intensive $(P=0.43)$, or that the effect of telephone support depended upon whether or not people were actively trying to quit smoking $(P=0.32)$. However, in meta-regression, telephone counselling was associated with greater effectiveness when provided as an adjunct to self-help written support $(P<0.01)$, or to a brief intervention from a health professional $(P=0.02)$; telephone counselling was less effective when provided as an adjunct to more intensive counselling. Further, telephone support was more effective for people who were motivated to try to quit smoking $(P=0.02)$. The findings from three additional trials of smokers who had not proactively called a helpline but were offered telephone counselling, found quit rates were higher in those offered three to five telephone calls compared to those offered just one call (RR $1.27,95 \% \mathrm{Cl} 1.12$ to $1.44 ; 2602$ participants; $\left.\right|^{2}=0 \%$ ).

\section{Authors' conclusions}

There is moderate-certainty evidence that proactive telephone counselling aids smokers who seek help from quitlines, and moderatecertainty evidence that proactive telephone counselling increases quit rates in smokers in other settings. There is currently insufficient evidence to assess potential variations in effect from differences in the number of contacts, type or timing of telephone counselling, or when telephone counselling is provided as an adjunct to other smoking cessation therapies. Evidence was inconclusive on the effect of reactive telephone counselling, due to a limited number studies, which reflects the difficulty of studying this intervention.

\section{PLAIN LANGUAGE SUMMARY}

\section{Does telephone counselling help people stop smoking?}

\section{Background}

There are a number of interventions available to help people stop smoking. One of them is using telephone calls to give smokers information, advice, and help to stop smoking. People can use these services by calling quitlines or by signing up to get calls from counsellors. We wanted to find out whether telephone counselling can help people quit smoking. Our most recent search for evidence was in May 2018.

\section{Study characteristics}

We found 104 studies (including 111,653 participants) testing the effect of any type of telephone counselling. The participants were mostly adult smokers from the general population, but some studies also looked at teenagers, pregnant women, and people with long-term or mental health conditions.

Some studies included participants who had called helplines that provide smoking counselling (quitlines). Other studies included people who had not called quitlines, but received calls from counsellors or other healthcare providers.

Some studies provided telephone counselling alone, but many others provided telephone counselling along with minimal support such as self-help leaflets, or more active support such as face-to-face counselling, or with stop-smoking medication. The number of calls offered ranged from a single call to 12 calls. Some studies only recruited people trying to stop smoking, while others offered support even to those not actively trying to stop.

Studies needed to compare groups whose participants had similar characteristics at the start of the study, to investigate whether the participants had stopped smoking for at least six months, and ideally would test whether people had quit with blood or urine tests.

We judged few studies to be well designed and conducted. Most had at least one issue that could have affected the results.

\section{Key results}

In people who had called helplines, providing additional telephone counselling increased their chances of stopping smoking from $7 \%$ to $10 \%$. In people who had not called a helpline, but received telephone calls from counsellors or other healthcare providers, their chances of stopping smoking increased from $11 \%$ to $14 \%$. In studies which directly compared more versus fewer calls, people who were offered more calls (three to five) tended to be more likely to quit than those who received only one call. Telephone counselling appears to increase the chances of stopping smoking, whether or not people are motivated to quit or are receiving other stop-smoking support.

\section{Certainty of evidence}

The overall certainty of the evidence was moderate, meaning that further research is likely to have an important impact on our conclusions. 
SUMMARY OF FINDINGS

Summary of findings for the main comparison. Interventions for callers to quitlines - effect of additional proactive calls for smoking cessation

Interventions for callers to quitlines - effect of additional proactive calls for smoking cessation

Patient or population: callers to quitlines

Intervention: additional proactive calls

\begin{tabular}{|c|c|c|c|c|c|c|}
\hline \multirow[t]{3}{*}{ Outcomes } & \multicolumn{2}{|c|}{ Illustrative comparative risks* $(95 \% \mathrm{Cl})$} & \multirow{3}{*}{$\begin{array}{l}\text { Relative effect } \\
(95 \% \mathrm{CI})\end{array}$} & \multirow{3}{*}{$\begin{array}{l}\text { No of Partici- } \\
\text { pants } \\
\text { (studies) }\end{array}$} & \multirow{3}{*}{$\begin{array}{l}\text { Quality of the } \\
\text { evidence } \\
\text { (GRADE) }\end{array}$} & \multirow[t]{3}{*}{ Comments } \\
\hline & Assumed risk & Corresponding risk & & & & \\
\hline & Control & Additional proactive calls & & & & \\
\hline \multirow{5}{*}{$\begin{array}{l}\text { Smoking cessation } \\
\text { Self-reported absti- } \\
\text { nence (majority) } \\
\text { Follow-up: } 6+\text { months }\end{array}$} & \multicolumn{2}{|c|}{ Study population } & \multirow{5}{*}{$\begin{array}{l}\text { RR } 1.38 \\
\text { (1.19 to } 1.61)\end{array}$} & \multirow{5}{*}{$\begin{array}{l}32,484 \\
\text { (14 studies) }\end{array}$} & \multirow{5}{*}{$\begin{array}{l}\oplus \oplus \oplus \ominus \\
\text { moderate } b, c\end{array}$} & \multirow[t]{5}{*}{-} \\
\hline & 72 per 1000 & $\begin{array}{l}\mathbf{1 0 0} \text { per } \mathbf{1 0 0 0} \\
(85 \text { to } 116)\end{array}$ & & & & \\
\hline & \multicolumn{2}{|l|}{ Low } & & & & \\
\hline & 50 per $1000^{a}$ & $\begin{array}{l}69 \text { per } 1000 \\
(59 \text { to } 81)\end{array}$ & & & & \\
\hline & \multicolumn{2}{|l|}{ High } & & & & \\
\hline
\end{tabular}

*The basis for the assumed risk (e.g. the median control group risk across studies) is provided in footnotes. The corresponding risk (and its $95 \%$ confidence interval) is based on the assumed risk in the comparison group and the relative effect of the intervention (and its $95 \% \mathrm{Cl}$ ).

Cl: Confidence interval; RR: Risk ratio

GRADE Working Group grades of evidence

High quality: Further research is very unlikely to change our confidence in the estimate of effect.

Moderate quality: Further research is likely to have an important impact on our confidence in the estimate of effect and may change the estimate.

Low quality: Further research is very likely to have an important impact on our confidence in the estimate of effect and is likely to change the estimate.

Very low quality: We are very uncertain about the estimate.

aLow control rate reflects lower end of range evident in trials; $4 / 14$ had control rates $<50$ per 1000 . High control rate likely to be applicable for smokers also using pharmacotherapy. 


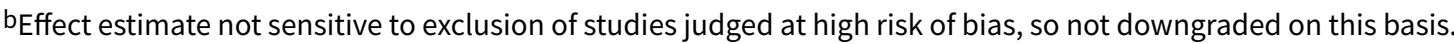

cDowngraded by one level due to unexplained statistical heterogeneity $(12=72 \%)$.

\section{Summary of findings 2. Interventions for smokers not calling quitlines - effect of proactive telephone counselling}

Proactive telephone counselling for smokers not calling quitlines

Patient or population: smokers not calling quitlines

Intervention: proactive telephone counselling

\begin{tabular}{|c|c|c|c|c|c|c|}
\hline \multirow[t]{3}{*}{ Outcomes } & \multicolumn{2}{|c|}{ Illustrative comparative risks ${ }^{\star}(95 \% \mathrm{Cl})$} & \multirow{3}{*}{$\begin{array}{l}\text { Relative effect } \\
(95 \% \mathrm{CI})\end{array}$} & \multirow{3}{*}{$\begin{array}{l}\text { No of Partici- } \\
\text { pants } \\
\text { (studies) }\end{array}$} & \multirow{3}{*}{$\begin{array}{l}\text { Quality of the } \\
\text { evidence } \\
\text { (GRADE) }\end{array}$} & \multirow[t]{3}{*}{ Comments } \\
\hline & Assumed risk & Corresponding risk & & & & \\
\hline & Control & Proactive telephone counselling & & & & \\
\hline \multirow{2}{*}{$\begin{array}{l}\text { Smoking cessation } \\
\text { Self-reported abstinence } \\
\text { (majority) } \\
\text { Follow-up: } 6+\text { months }\end{array}$} & \multicolumn{2}{|c|}{ Study population } & \multirow{2}{*}{$\begin{array}{l}\text { RR } \mathbf{1 . 2 5} \\
\text { (1.15 to } 1.35)\end{array}$} & \multirow{2}{*}{$\begin{array}{l}41,233 \\
\text { (65 studies) }\end{array}$} & \multirow{2}{*}{$\begin{array}{l}\oplus \oplus \oplus \ominus \\
\text { moderate }\end{array}$} & \\
\hline & 110 per $1000^{a}$ & $\begin{array}{l}\mathbf{1 3 7} \text { per } \mathbf{1 0 0 0} \\
\text { (127 to } 149)\end{array}$ & & & & \\
\hline
\end{tabular}

${ }^{\star}$ The basis for the assumed risk (e.g. the median control group risk across studies) is provided in footnotes. The corresponding risk (and its $95 \%$ confidence interval) is based on the assumed risk in the comparison group and the relative effect of the intervention (and its $95 \% \mathrm{Cl}$ ).

Cl: Confidence interval; RR: Risk ratio

GRADE Working Group grades of evidence

High quality: Further research is very unlikely to change our confidence in the estimate of effect.

Moderate quality: Further research is likely to have an important impact on our confidence in the estimate of effect and may change the estimate.

Low quality: Further research is very likely to have an important impact on our confidence in the estimate of effect and is likely to change the estimate.

Very low quality: We are very uncertain about the estimate.

${ }^{a}$ Based on crude average of events/total, with participants lost to follow-up assumed to be smoking. Interquartile range in trials 63 - 200 per 1000 . Higher baseline cessation rates typical amongst motivated populations receiving pharmacotherapy and some support. Relative additional benefit of telephone intervention may be smaller in this setting.

bEffect estimate not sensitive to exclusion of studies judged at high risk of bias, so not downgraded on this basis.

cDowngraded by one level due to statistical heterogeneity, which was only partially explained by differences in baseline support. In subgroup analyses, evidence of effect was clearer when telephone counselling was offered as an adjunct to print-based self-help, or brief face-to-face counselling. Effect smaller and less certain when telephone counselling was offered as an adjunct to pharmacotherapy. However, statistical heterogeneity ranged from small to substantial within the subgroups. 


\section{B A C K G R O U N D}

\section{Description of the condition}

Worldwide, tobacco smoking kills more than seven million people each year, shortening life by an average of 10 to 11 years in people who smoke their whole lives (Doll 2004; Pirie 2013; WHO 2018). This increase in mortality is primarily due to cardiovascular disease, lung cancer, and chronic obstructive pulmonary disease, but smoking is also causally associated with other cancer- and non-cancer-related health conditions (USDHHS 2014; WHO 2018). Smoking cessation reverses much of the damage, and most smokers who are aware of these health hazards wish to quit (Doll 2004; Mons 2015; Müezzinler 2015; Ordóñez-Mena 2016; WHO 2018).

\section{Description of the intervention}

Telephone counselling is a behavioural intervention to help people stop smoking. It can act as a stand-alone intervention or one that runs alongside other interventions (e.g. an added component to face-to-face counselling). It can be proactive (the counsellor initiates contact) or reactive (the smoker initiates contact) (Lichtenstein 1996). In many areas, reactive services are available through helplines or quitlines, which may be specific to smoking, as for example the California Smokers' Helpline (Zhu 2000a) and the Quitlines in Australia (Borland 2001), the UK (Owen 2000), Sweden (Lindqvist 2013), and Denmark (Skov-Ettrup 2016), or they may be embedded in broader health information services such as the Cancer Information Service in the USA (La Porta 2007). Quitlines may provide a regional or national service. They are often advertised in conjunction with population-wide campaigns such as No-Smoking Days. Helplines may also be provided on a smaller scale for a specific project or population. In some services, people may be enrolled in a formal smoking cessation programme, with further proactive calls from counsellors. Telephone counselling may also be provided as part of an integrated smoking cessation support service (e.g. Glasgow 1991). Access to hotlines or the opportunity to register to receive calls from a counsellor may also be offered as part of a cessation programme, including pharmacotherapy.

\section{How the intervention might work}

Behavioural and pharmacological interventions help people to quit smoking. Behavioural support can be given in individual counselling sessions (Lancaster 2017) or in group therapy (Stead 2017), where clients can share problems and derive support from one another. Standard self-help materials have at best a small effect in helping people to quit, while those tailored to the characteristics of individuals are more likely to be effective (LivingstoneBanks 2019a). Telephone counselling may supplement face-toface support, or be a substitute for it as an adjunct to self-help interventions or pharmacotherapy. Counselling may be helpful in planning a quit attempt, and in helping to prevent relapse during the initial period of abstinence (Livingstone-Banks 2019b). Although intensive face-to-face interventions increase quit rates, there are difficulties with scalability. Telephone counselling may be a more feasible way to provide individual counselling to large populations. In addition, telephone contact can be timed to maximise the level of support around a planned quit date, and can be scheduled in response to the needs of the recipient. In a proactive approach the counsellor initiates one or more calls to provide support in making a quit attempt or avoiding relapse. Reactive counselling, in contrast, is available on demand to people calling specific services; quitlines, helplines or hotlines. These services take calls from people who smoke, or their friends and family (Zhu 2006). These telephone services may offer information, recorded messages, personal counselling or a mixture of components (Anderson 2007; Ossip-Klein 2003).

\section{Why it is important to do this review}

Telephone counselling services have the potential to provide access to information for large numbers of people. Some services have reported reaching substantial proportions of the target population (Ossip-Klein 1991; Platt 1997). They have the potential to reach underserved populations such as ethnic minorities (Zhu 2000a) or younger people (Chan 2008; Gilbert 2005).

Telephone counselling is a widely used intervention for smoking cessation, and is often supported through public funds. It is therefore important to evaluate its effects, as well as different variations of telephone counselling that may impact on quit rates.

\section{O B JECTIVES}

To evaluate the effect of telephone support to help smokers quit, including proactive or reactive counselling, or the provision of other information to smokers calling a helpline.

We tried to address the following questions:

- Do telephone calls from a counsellor increase quit rates, compared to other brief non-pharmacological interventions or to no intervention?

- Do telephone calls from a counsellor offered together with other interventions increase quit rates, compared to other interventions alone?

- Does an increase in the number of telephone contacts increase quit rates?

- Do differences in counselling protocol related to the type or timing of support lead to differences in quit rates?

- Does the availability of a reactive helpline increase quit rates?

\section{METHODS}

\section{Criteria for considering studies for this review \\ Types of studies}

Randomised or quasi-randomised controlled trials (RCTs), with the unit of allocation being one of the following: the individual smoker; counsellor; group; intervention site; or geographical area.

\section{Types of participants}

Individuals who were current smokers at the time of inclusion in the trial. We included trials with a mixture of current smokers and recent quitters if the recent quitters were only a small proportion of the entire study population. The definition of recent quitters was that used by the trial recruitment protocols, or by the participants themselves. We excluded trials that exclusively recruited quitters or were focused on telephone counselling as an intervention for relapse, as they fall within the scope of a separate Cochrane Review on preventing relapse (Livingstone-Banks 2019b).

We included trials recruiting exclusively teenagers or pregnant women, but we considered them as a potential source of 
heterogeneity in meta-analyses. There are separate Cochrane Reviews for these population groups (Chamberlain 2017; Fanshawe 2017).

\section{Types of interventions}

Provision of proactive or reactive telephone counselling to assist smoking cessation, to any population. We excluded studies if the contribution of the telephone component could not be evaluated independently of another therapy. We included studies that compared a combination of telephone counselling and self-help materials versus no telephone counselling, as the effect of self-help materials alone is limited (LivingstoneBanks 2019a). We also included studies in which the effect of telephone counselling as an adjunct to another smoking cessation treatment was evaluated, e.g. print-based self-help, brief faceto-face intervention, pharmacotherapy, or incentives. We also included studies that compared different modalities or strategies of telephone counselling, and different theories of behavioural change.

\section{Types of outcome measures}

Long-term smoking cessation (i.e. at least six months after the start of intervention). We excluded trials with shorter follow-up. We used the strictest definition of smoking cessation available in a trial and biochemically-validated abstinence data whenever available.

\section{Search methods for identification of studies}

We identified studies from the Cochrane Tobacco Addiction Group Specialised Register (until May 3, 2018), World Health Organization (WHO) International Clinical Trials Registry Platform (ICTRP) and ClinicalTrials.gov (until July 30, 2018) using the MeSH term 'hotlines' or free-text terms telephone* OR phone* OR quitline* OR helpline. See Appendix 1 for the full search strategy. At the time of the search the Register included the results of searches of the Cochrane Central Register of Controlled trials (CENTRAL), issue 1, 2018; MEDLINE (via OVID) to update 20180404; Embase (via OVID) to week 201814; PsycINFO (via OVID) to update 20180212. See the Cochrane Tobacco Addiction Group website for full search strategies and a list of other resources searched.

\section{Data collection and analysis}

We identified trials where at least one of the arms included telephone contact. For this update, two review authors (WM and JMOM) extracted data from included studies, compared extraction and discussed disagreements with a third review author (JHB). We recorded the following information in the Characteristics of included studies tables:

- The country and setting of the trial

- The method of recruitment to the study

- The method of randomisation and allocation concealment

- Details of participants, including whether they were selected according to motivation to quit, and their age, gender and average baseline cigarette consumption

- Description of intervention and control, including the schedule of telephone contacts

- Definition of smoking abstinence used for the primary outcome, including timing of longest follow-up and whether quit status was based on recent behaviour (point prevalence abstinence, e.g. in the past seven days) or on abstinence for an extended period since a quit date or a previous follow-up (continuous or sustained abstinence)

- Description of method of any biochemical validation or other method used to confirm self-reported quitting

- Description of numbers lost to follow-up by treatment condition

In the Characteristics of excluded studies tables, we describe key trials that did not meet all inclusion criteria.

\section{Assessment of risk of bias}

We assessed each included study for risks of bias in the following domains: random sequence generation (allocation bias), allocation concealment (allocation bias), blinding of outcome assessor (detection bias), and incomplete outcome data (attrition bias). Following standard Cochrane guidance, we rated items in the 'Risk of bias' tables as being at low, unclear, or high risk of bias.

We judged studies to be at low risk of bias for sequence generation if an acceptable method for generating a randomisation sequence was described, at unclear risk if the study was described as 'random' but with no further information, and at high risk if it did not use a true randomisation method, e.g. alternation by calendar week. We judged the quality of the allocation concealment to be at low risk if the group to which a participant was to be allocated remained unknown to investigators and participant until enrolment was complete. We did not assess studies for performance bias, because blinding of participants and study personnel is not possible due to the nature of the intervention. We rated the quality of the blinding of outcome assessment at low risk if a biochemical verification of abstinence was carried out in the entire study population or in a random subsample, or if smoking status was measured by self-report but the intervention and control arms received similar amounts of person-to-person contact, and at high risk otherwise. We judged attrition bias to be at low risk if the percentage of loss to follow-up was less than $50 \%$ and if the difference between arms in percentage loss to follow-up was less than $20 \%$.

\section{Choice of outcome and treatment of missing data}

The primary outcome was the number of quitters at the longest follow-up, using the strictest measure of abstinence reported. We preferred sustained and biochemically-validated abstinence to point prevalence or to self-reported quitting. If a less strict definition of quitting seemed more appropriate for showing an effect of the intervention on recovery from lapses or relapses, we planned a sensitivity analysis.

Where possible and appropriate, we used as denominators the number randomised to each condition, with losses to follow-up assumed to be continuing smokers. We noted any exceptions in the 'Risk of bias' table for a study. Population-based studies typically have relatively high loss to follow-up, because of change of address or disconnected telephones. Non-response might be independent of both treatment condition and smoking status, although possibly associated with other variables such as age or socioeconomic status. Dropout might be related to smoking status but not to treatment condition. Imputing as smoking all those missing, irrespective of, for example, whether they could not be contacted, or declined to respond, may not be appropriate. For individual studies it is possible to use analysis methods such as generalised estimating equations (GEE) for imputing missing data 
(Hall 2001). We noted whether studies that explored alternative assumptions about missing data reported any impact on the conclusions. When proportions lost are similar across conditions, and trial arms are balanced, the choice of denominator does not alter the relative effect, although the percentage quit and the absolute difference between conditions will be conservative.

\section{Data synthesis}

We summarised individual study results as a risk ratio (RR), calculated as: (number of quitters in intervention group/number randomised to intervention group)/(number of quitters in control group/number randomised to control group). Where appropriate, we performed meta-analysis using a Mantel-Haenszel randomeffects model to estimate a pooled risk ratio with a $95 \%$ confidence interval $(\mathrm{Cl})$. When trials had more than one arm with a less intensive intervention we used only the most similar intervention without a telephone component as the control group in the primary analysis. We considered pooling of study results if both the intervention and control arms were sufficiently similar across trials. We assessed statistical heterogeneity between trials using the $1^{2}$ statistic which describes the percentage of total variation between studies that is due to heterogeneity rather than chance (Higgins 2003). We used threshold values of $50 \%$ and $70 \%$ as suggesting moderate and substantial heterogeneity respectively.

\section{Investigations of heterogeneity: meta-regression and subgroup analyses}

We ran a meta-regression in $\mathrm{R}$ version 3.5.0 ( $\mathrm{R}$ 2018) using the meta and metafor packages (Schwarzer 2007; Viechtbauer 2010) to test the moderation of the effect of telephone counselling on smoking cessation by telephone counselling intensity (continuous: defined as maximum number of calls offered as part of the telephone counselling intervention), trial selection of participants that were motivated to quit (binary: yes/no), and type of baseline support offered in both the intervention and control arms (categorical: print-based self-help, brief face-to-face counselling, pharmacotherapy, or financial incentives). In meta-regression, the effect size was summarised using the trial-specific (natural) logarithm of the RR with its standard errors as weights. We fitted these trial characteristics separately in univariate models, and also together in a multivariate model to adjust for each moderator simultaneously.

We did not combine proactive and reactive approaches to counselling, so studies that provided access to a telephone helpline but did not call participants form a separate category. In earlier versions of this review we noted heterogeneity between studies of proactive telephone counselling, which was not explained by using subgroups based on the amount of support given for the control group. Lichtenstein 2002a has suggested that studies recruiting smokers who call quitlines should be considered separately. These studies share the characteristics that participants were actively seeking support at the time of their call, and that telephone counselling was the primary intervention. We therefore distinguish between trials in quitline callers and trials in smokers not calling a quitline.

We expected differences between the relative effect of telephone support, depending on whether it was being tested as the main intervention to aid cessation, or as an extra part of a multicomponent cessation programme. We therefore conducted a priori defined subgroup analysis to distinguish those studies in which telephone counselling was the most intensive component of a minimal contact intervention (print-based self-help was provided), from studies in which telephone counselling was assessed as an adjunct to a brief face-to-face counselling, or to pharmacotherapy. Where results of studies differed within the broad groupings described above we considered the following possible explanations: the difference between the intensity of the counselling based on the number of calls (two sessions or fewer, three to six sessions, and seven sessions or more), the counselling strategy used, and the characteristics of the participants, in particular their motivation to quit or stage of change at baseline.

\section{'Summary of findings' table}

Following standard Cochrane methodology, we created 'Summary of findings' tables for the two main subgroups of participants, i.e. callers to a quitline and those not calling a quitline. Both 'Summary of findings' tables include data for the same primary outcome of long-term smoking cessation. Also following standard Cochrane methodology, we used the five GRADE considerations (study limitations, consistency of effect, imprecision, indirectness and publication bias) to assess the certainty of the body of evidence for each outcome, and to draw conclusions about the certainty of evidence within the text of the review.

\section{RES U L T S}

\section{Description of studies}

One hundred and four studies met the criteria for inclusion in the review, with a total of 111,653 participants, and a median trial size of 735 . Only seven studies had fewer than 100 participants (Brown 1992; Cossette 2011; Duffy 2006; Ebbert 2007; McClure 2011; Osinubi 2003; Vander Weg 2016), whilst seven studies, all involving callers to quitlines, had more than 3000 (Hollis 2007; Joyce 2008; Rabius 2004; Rabius 2007; Sherman 2017; Zhu 1996; Zhu 2002).

The most recent search resulted in 511 studies to screen (Figure 1). After title, and abstract, and then full-text screening, we found 30 new studies to include in this update, plus 15 new ongoing studies. 
Figure 1. Study flow diagram for most recent update

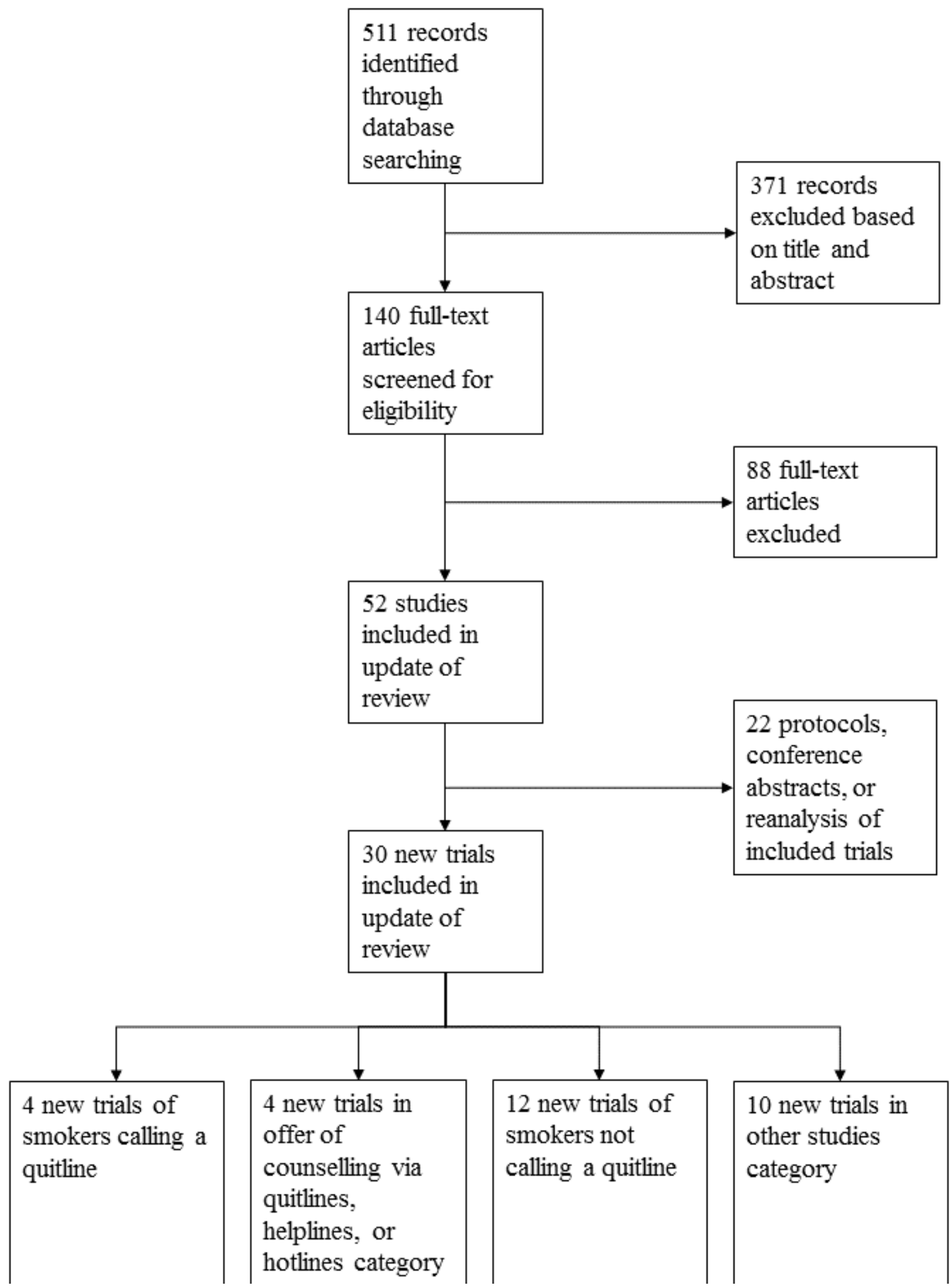


Figure 1. (Continued)

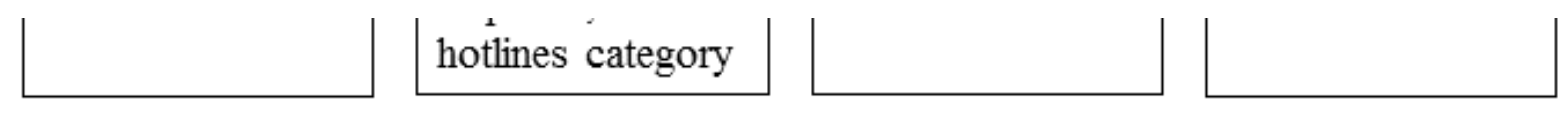

Most trials were conducted in North America (72). Nine were in Australia (Borland 2001; Borland 2003; Borland 2008; Brown 1992; Girgis 2011; MacLeod 2003; Tzelepis 2011a; Young 2008; Zwar 2015), six in Canada (Chouinard 2005; Cossette 2011; Reid 1999a; Reid 2007; Reid 2018; Smith 2004), three in Spain (Miguez 2002; Miguez 2008; Ramon 2013), three in the UK (Aveyard 2003; Gilbert 2006; Ferguson 2012), two in Hong Kong (Abdullah 2005; Chan 2015), two in Germany (Flöter 2009; Metz 2007), two in Sweden (Lindqvist 2013; Nohlert 2014), one in Norway (Hanssen 2009), one in Malaysia (Blebil 2014), one in the Netherlands (Schuck 2014), one in Denmark (Skov-Ettrup 2016), and one in China (Wu 2017). Participants were predominantly older adults with an average age typically in the 40s. One study recruited teenagers (Lipkus 2004), one high school students (Peterson 2016), one young people aged 18 to 24 (Sims 2013), and three recruited older people, aged over 50 (Rimer 1994), over 60 (Ossip-Klein 1997), or over 65 (Joyce 2008). Four recruited pregnant women (Cummins 2016b; McBride 1999b; McBride 2004; Stotts 2002) and a further five recruited only women (McBride 1999a; McClure 2005; Flöter 2009; Solomon 2000; Solomon 2005). Four predominantly recruited men (Abdullah 2005; An 2006; Osinubi 2003; Sorensen 2007a). One was culturally tailored for Chinese, Korean and Vietnamese smokers (Zhu 2012) and one recruited Arabic smokers in Australia (Girgis 2011).

Most of the studies were trials of proactive calls from a counsellor, or from an automated interactive voice response system (IVR) (Reid 2007 IVR with counsellor follow-up in case of need, Velicer 2006 IVR only). Only five assessed interventions that did not involve a counsellor contacting a participant (McFall 1993; Orleans 1998; Ossip-Klein 1991; Sood 2009; Thompson 1993). Sixteen studies recruited participants who had phoned a quitline, but evaluated the addition of further proactive contacts (Borland 2001; Borland 2003; Bricker 2014; Cummins 2016b; Ferguson 2012; Gilbert 2006; Hollis 2007; Lindqvist 2013; Nohlert 2014; Rabius 2004; Rabius 2007; Sims 2013; Smith 2004; Zhu 1996; Zhu 2002; Zhu 2012). One study recruited proactively to quitline counselling (Tzelepis 2011a). Sixteen studies recruited participants in healthcare settings and referred them to services provided by quitlines, involving proactive counselling for those following through referral (Bastian 2012; Blebil 2014; Borland 2008; Brunette 2017; Collins 2018; Cummins 2016a; Duffy 2006; Ebbert 2007; Piper 2016; Ramon 2013; Rogers 2016; Schlam 2016; Sherman 2017; Warner 2016; Wu 2017; Zwar 2015). Ellerbeck 2009 repeatedly mailed primary care patients an offer of free pharmacotherapy and tested two levels of disease management, including proactive calls or no contact. One study offered either a proactive or reactive service as covered benefit (Joyce 2008). Additional details are in the Characteristics of included studies tables.

The number, duration and content of the telephone calls was variable. The potential number of calls ranged from one to 12 and in some studies was flexible. The duration of the calls also varied; 10 to 20 minutes was common, although the initial call might be longer. The call schedule could be spaced over weeks or months. Amongst studies that did not recruit participants on the basis of their willingness to make a quit attempt, the content was typically individualised to enhance motivation in those undecided about quitting, or to support a quit attempt where appropriate. Counselling was most commonly provided by professional counsellors or trained healthcare professionals. One trial used trained postgraduate students (Aveyard 2003). Three trials used trained peer counsellors, in one case survivors of childhood cancer (Emmons 2005), and in the other two women exsmokers (Solomon 2000; Solomon 2005).

Many trials reported both short-term point prevalence abstinence (seven-day or 24-hour) and sustained abstinence, at one or more longer follow-ups. Long-term sustained abstinence was available for 53 of the 104 trials (51\%). For the remainder, the outcome was based on point prevalence abstinence at the longest follow-up. Length of longest follow-up ranged from six months from start of intervention ( 35 trials), to seven years (Peterson 2016).

We grouped trials into three broad categories: trials of interventions for smokers who contacted a helpline; trials assessing the effect of providing access to a helpline; and trials that offered support proactively in other settings. Finally there are 10 trials that do not fit into any of these categories, so are considered individually (Bastian 2012; Collins 2018; Halpin 2006; Klemperer 2017; Reid 2018; Smith 2013; Sumner 2016; Vander Weg 2016; Warner 2016; Wu 2017).

\section{Trials of interventions for people calling helplines}

Nineteen trials recruited people who had phoned helplines/ quitlines. We distinguished between trials where the intervention involved further proactive contact by the counsellor, and those that tested different interventions at the initial call. Fourteen studies tested proactive calls back to people who had initiated the contact with the quitline. The number of calls varied, with four studies comparing more than one schedule (Hollis 2007; Rabius 2007; Smith 2004; Zhu 1996). There were small differences in the support for the control group. In one trial, all participants had brief counselling during their initial call (Borland 2001); in three, some control group participants received some counselling (Borland 2003; Gilbert 2006; Zhu 2002). Ferguson 2012 was a factorial trial comparing proactive counselling to standard support, which included further contact by email, letter or text, and the offer of proactive calls. Participants were also randomised to an offer of nicotine replacement therapy (NRT). In the others the control group received self-help materials (Cummins 2016b; Hollis 2007; Nohlert 2014; Rabius 2004; Rabius 2007; Sims 2013; Smith 2004; Zhu 1996; Zhu 2012).

Five trials compared different interventions at the time a participant called the helpline. Sood 2009 compared counselling at the initial call to mailed self-help materials only. Orleans 1998 and Thompson 1993 compared different counselling interventions provided during the initial call; Orleans 1998 compared counselling and materials targeted at African-American smokers to standard advice and materials, and Thompson 1993 compared a counselling approach based on the 'stage of change' model to the provision 
of more general information. Two trials offered two different modalities of proactive telephone counselling. Bricker 2014 compared Acceptance and Commitment Therapy (ACT) counselling with Cognitive Behavioural Therapy (CBT), with both arms receiving a two-week supply of NRT. Lindqvist 2013 compared Motivational Interviewing (MI) telephone counselling with standard telephone counselling.

\section{Trials providing access to a helpline}

Three studies assessed the impact of offering reactive counselling by providing access to a helpline/quitline/hotline, compared to not being provided access to a telephone helpline/quitline/hotline. One randomised counties to hotline access or not, and followed up smokers who were planning to stop and had registered for a smokers' self-help project (Ossip-Klein 1991). One compared a referral to a quitline to the usual care of a GP practice (Zwar 2015). One combined newsletter mailings and hotline access compared to no follow-up support for smokers who had registered for a selfhelp televised cessation programme (McFall 1993). Three studies compared referral to a quitline to proactive telephone counselling (Rogers 2016; Sherman 2017; Skov-Ettrup 2016). Joyce 2008 compared four different levels of benefit for Medicare beneficiaries aged 65 or older. The most intensive intervention offered a choice of accessing either a reactive hotline or multisession proactive counselling, along with self-help materials and coverage of nicotine patch with a small co-payment. Other arms offered coverage of brief provider counselling with or without coverage of pharmacotherapy, and usual care.

\section{Trials of proactive counselling, not initiated by calls to quitlines}

There were 65 trials in this category that we judged to have sufficient features in common to consider pooling their results. There were some differences in the intensity of the telephone component, the amount of cessation support that was common to both the control and intervention groups, and the populations recruited.

\section{Studies with minimal intervention controls}

There were 33 studies in this subgroup. In 26 studies proactive telephone counselling calls were the only form of personal contact in the cessation intervention. The control groups generally received mailed self-help materials, but Graham 2011 provided access to a cessation website. In six studies in healthcare settings the telephone intervention was an adjunct to usual care that involved at most a brief smoking intervention (Duffy 2006; Hanssen 2009; Holmes-Rovner 2008; Rigotti 2006; Stotts 2002; Young 2008). In two further studies that recruited participants through healthcare systems, advice and support were part of usual care but not all participants had clinic visits; the telephone counselling was delivered independently of any clinic visit rather than being an adjunct to a specific episode of care (An 2006; Lipkus 1999). Pharmacotherapy was not systematically offered to all intervention participants in any of the above trials, but in two there was greater use of pharmacotherapy by intervention participants (An 2006; McClure 2005). An 2006 encouraged the use of NRT or bupropion for intervention group participants making a quit attempt and this increased their use, although pharmacotherapy was available to all participants as part of their usual care. In McClure 2005 all participants could enrol in the Free \& Clear phone-based support programme, which could also provide access to pharmacotherapy; this was used more by intervention than control groups.

\section{Studies with brief intervention/counselling controls}

Thirteen trials incorporated what we judged to be more substantial face-to-face advice for all participants, but without systematic use of pharmacotherapy (Borland 2008; Brown 1992; Brunette 2017; Chouinard 2005; Cossette 2011; Ebbert 2007; Flöter 2009; McBride 2004; Metz 2007; Ockene 1991; Osinubi 2003; Ramon 2013; Reid 2007). The support common to all participants included: a single information session and the provision of a self-help manual (Brown 1992); usual prenatal care including provider advice and self-help materials (McBride 2004); assessment, advice or brief counselling from a physician (relevant arms of Borland 2008; Ockene 1991; Ramon 2013) or hygienist/dentist (Ebbert 2007); advice from an occupational physician to consult a personal physician (Osinubi 2003); inpatient nurse counselling (Brunette 2017; Chouinard 2005; Cossette 2011; Reid 2007); or multisession group counselling (Flöter 2009; Metz 2007).

\section{Studies of counselling added to pharmacotherapy}

Eighteen trials provided telephone counselling as an adjunct to pharmacotherapy. In 15 trials there was a systematic offer or provision of NRT (Bastian 2013; Blebil 2014; Cummins 2016a; Fiore 2004; Fraser 2014; Hughes 2010; Lando 1997; MacLeod 2003; NCT00534404; Ockene 1991; Reid 1999a; Schlam 2016; Solomon 2000; Solomon 2005; Velicer 2006). Swan 2010 provided varenicline. Boyle 2007 recruited health maintenance organisation (HMO) members who were filling a prescription for any cessation medication, and Ellerbeck 2009 offered free medication four times over two years. The support common to all participants in other trials included: access to a website (Swan 2010); physician advice and an offer of free nicotine gum (relevant arms of Ockene 1991); provision of free nicotine patch after a primary care visit (Fiore 2004); three sessions of physician advice and free nicotine patch (Reid 1999a); a single 90-minute session, a free prescription for nicotine patch and access to a helpline (Lando 1997); or provision of free nicotine patches (two-week supply only) but no face-toface contact (Bastian 2013; Blebil 2014; Fraser 2014; MacLeod 2003; Solomon 2000; Solomon 2005; Velicer 2006). Cummins 2016 a provided up to six weeks of NRT with the number of weeks depending on how many cigarettes smoked per day , whereas NCT00534404 and Schlam 2016 provided up to eight weeks' free supply of NRT. Velicer 2006 provided nicotine patches to participants meeting criteria for readiness to make a quit attempt; $86 \%$ received some during the study.

\section{Studies of counselling added to incentives}

One study provided telephone counselling as an adjunct to incentives. Thomas 2016 compared the effect of adding telephone counselling as an adjunct to entry into a 'Quit and win' contest.

\section{Telephone counselling intensity}

The number of calls and the period over which they were delivered in this group of 65 studies was very varied. We provide a summary in the following table. 


\begin{tabular}{|c|c|c|c|c|}
\hline $\begin{array}{l}\text { Maximum no. of } \\
\text { calls }\end{array}$ & Within 4 weeks & Within 3 months & Within 6 months & $\begin{array}{l}\text { Over longer peri- } \\
\text { od/other }\end{array}$ \\
\hline Single call & $\begin{array}{l}\text { Fiore 2004; Miguez } \\
2008\end{array}$ & - & - & - \\
\hline 2 calls & $\begin{array}{l}\text { Ellerbeck } 2009 \\
\text { (moderate intensi- } \\
\text { ty arm, up to } 2 \text { after } \\
\text { each offer of phar- } \\
\text { macotherapy); Lan- } \\
\text { do 1992; Lichten- } \\
\text { stein 2000; Lichten- } \\
\text { stein 2008; Lipkus } \\
1999\end{array}$ & $\begin{array}{l}\text { Ossip-Klein 1997; Stotts } 2002 \text { (in late } \\
\text { pregnancy) }\end{array}$ & Rimer 1994 & - \\
\hline 3 calls & $\begin{array}{l}\text { Ebbert 2007; Flöter } \\
2009\end{array}$ & $\begin{array}{l}\text { Abdullah 2005; Curry 1995; Lipkus } \\
\text { 2004; McBride 1999a; Ockene 1991; } \\
\text { Reid 1999a }\end{array}$ & $\begin{array}{l}\text { Aveyard 2003; Prochaska } \\
2001\end{array}$ & $\begin{array}{l}\text { McBride 1999b } \\
\text { (part, during preg- } \\
\text { nancy) }\end{array}$ \\
\hline 4 calls & $\begin{array}{l}\text { Blebil 2014; Young } \\
2008\end{array}$ & $\begin{array}{l}\text { Lando 1997; Reid } 2007 \text { (average } 2 \text { au- } \\
\text { tomated and } 2 \text { counsellor) }\end{array}$ & $\begin{array}{l}\text { McClure 2005; Prochas- } \\
\text { ka 1993; Ramon 2013; } \\
\text { Tzelepis 2011a (if not set- } \\
\text { ting TQD) }\end{array}$ & $\begin{array}{l}\text { Chan 2015; Or- } \\
\text { leans } 1991\end{array}$ \\
\hline 5 calls & Fraser 2014 & $\begin{array}{l}\text { Graham 2011; Hughes 2010; MacLeod } \\
\text { 2003; Metz 2007; NCT00534404; Osin- } \\
\text { ubi 2003; Swan } 2010\end{array}$ & & $\begin{array}{l}\text { Rigotti } 2006 \text { ( } 4 \text { in } \\
\text { pregnancy and } 1 \\
\text { postpartum) }\end{array}$ \\
\hline 6 calls & $\begin{array}{l}\text { Brown 1992; } \\
\text { Tzelepis 2011a (if } \\
\text { setting TQD) }\end{array}$ & $\begin{array}{l}\text { Bastian 2013; Borland 2008; } \\
\text { Chouinard 2005; Cossette 2011; Eller- } \\
\text { beck } 2009 \text { (high intensity arm, up to } \\
6 \text { after each offer of pharmacothera- } \\
\text { py); Girgis 2011; Holmes-Rovner 2008; } \\
\text { Miguez 2002; Sorensen 2007a }\end{array}$ & Emmons 2005 & $\begin{array}{l}\text { McBride } 1999 \mathrm{~b} \\
\text { (part) and McBride } \\
2004 \text { ( } 3 \text { during } \\
\text { pregnancy and } 3 \\
\text { postpartum) }\end{array}$ \\
\hline 7 or more & Brunette 2017 & An 2006; Schuck 2014; Solomon 2000 & $\begin{array}{l}\text { Boyle } 2007 \text { (up to 9, aver- } \\
\text { age 5); Duffy } 2006 \text { ( } 9 \text { to } 11 \text { ); } \\
\text { (Hanssen } 2009 \text { (9); (Velicer } \\
2006 \text { (up to } 10 \text { automated } \\
\text { calls); (Solomon } 2005 \text { (up } \\
\text { to } 12 \text { ); McClure } 2011 \text { (up to } \\
\text { 12, also covering depres- } \\
\text { sion and physical activity); } \\
\text { Schlam } 2016 \text { (up to 8) }\end{array}$ & $\begin{array}{l}\text { Cummins 2016a } \\
\text { (up to 10); Peter- } \\
\text { son } 2016 \text { (up to } \\
\text { 10) }\end{array}$ \\
\hline
\end{tabular}

The average number of calls completed, where reported, was typically considerably smaller than the maximum available. For studies where the intervention involved a process of referral to proactive support from another source, the proportion of participants reaching and accepting counselling was small, but those accepting the intervention generally had multisession support.

\section{Recruitment and motivation of participants}

We tried to categorise this set of 65 trials according to whether or not they selected participants with an interest in stopping smoking, or whether they were non-selective or designed to reach a wider population of smokers. Of the 25 trials in the 'Selected' subgroup, 13 recruited from the general population using advertisements for smokers planning to quit or interested in quitting (Brown 1992; Fraser 2014; Graham 2011; MacLeod 2003; Miguez 2002; Miguez 2008; NCT00534404; Orleans 1991; Ossip-Klein 1997; Rimer 1994; Solomon 2000; Solomon 2005; Swan 2010). Seven recruited during healthcare visits (Blebil 2014; Brunette 2017; Cummins 2016a; Fiore 2004; Ramon 2013; Reid 1999a; Schlam 2016); Boyle 2007 and Lando 1997 recruited HMO members, and An 2006 mailed invitations to patients of Veterans Administration Medical Centres. Schuck 2014 recruited parents of children through their primary schools, and Thomas 2016 recruited higher education students. 
There were 38 trials in which motivation or interest in quitting was not an explicit entry criterion. Many recruited people in healthcare settings and the level of motivation to quit as assessed by stage of change at baseline, or other measures, was often high. Four recruited pregnant women (McBride 1999b; McBride 2004; Rigotti 2006; Stotts 2002); 15 recruited people during healthcare visits including in family practices, dental practices and hospitals (Bastian 2013; Borland 2008; Chouinard 2005; Cossette 2011; Duffy 2006; Ebbert 2007; Flöter 2009; Girgis 2011; Hanssen 2009; Holmes-Rovner 2008; Metz 2007; Ockene 1991; Osinubi 2003; Reid 2007; Young 2008); seven others recruited through healthcare system records (Aveyard 2003; Ellerbeck 2009; Lipkus 1999; McClure 2005; McClure 2011; Prochaska 2001; Velicer 2006). Of the other miscellaneous methods, Lichtenstein 2000 and Lichtenstein 2008 recruited smokers in households that were offered free radon testing kits, Lipkus 2004 recruited teens approached in shopping malls, Chan 2015 recruited adults approached in shopping malls, Peterson 2016 recruited students from high schools, Abdullah 2005 recruited smoking parents of children in a birth cohort study, Emmons 2005 recruited smokers from a cohort study of childhood cancer survivors, and Sorensen 2007a recruited union members. Prochaska 1993 advertised for community volunteers, irrespective of quitting interest. In three trials contact was initiated with smokers who had not been specifically recruited to a trial (Curry 1995; Lando 1992; McBride 1999a).

\section{Studies comparing intense versus minimal telephone counselling}

Three studies did not have a no-telephone support control and compared interventions with different numbers of calls (Miller 1997; Piper 2016; Swan 2003). Miller 1997 assessed the effect of increasing the amount of telephone follow-up after an inpatient counselling intervention. Piper 2016 compared three 15-minute phone sessions within a 10-day period versus a single 10-minute session on the quit date in a factorial design. Swan 2003 compared two intensities of behavioural support, both of which involved telephone contact without face-to-face support, for smokers also randomised to one of two doses of bupropion.

\section{Other studies}

We identified 10 other studies where we judged the nature of the main intervention or the conditions compared to be so distinctively different from any other included studies that we describe them separately rather than pooling them.

Bastian 2012 compared standard telephone counselling with family-supported telephone counselling, which included a support skills booklet and additional telephone counselling content focusing on social support skills that aimed to help increase positive interactions between the participant and their designated support person, to facilitate smoking cessation. Participants randomised to family support-based intervention also received an eight-page disease-specific family support booklet.

Collins 2018 compared an individual behavioural telephone counselling intervention that focused on reducing child secondhand smoke exposure and parent smoking cessation, to an individual telephone health education attention control intervention that focused on improving family nutrition on a budget.
Halpin 2006 compared different benefit designs for tobacco treatment. The control group was given coverage for pharmacotherapy only. One intervention group had coverage for telephone counselling and pharmacotherapy (bupropion or NRT, USD 15 co-payment) whilst the other had pharmacotherapy coverage only if enrolled for telephone counselling. Participants were not required to take up any treatment during the study period.

Klemperer 2017 compared three different arms of telephone counselling: smoking reduction telephone counselling, brief motivational telephone counselling, and a usual care five-minute call.

Reid 2018 included an automated telephone follow-up system that posed a series of questions to participants about their smoking status, confidence in staying smoke-free, use of smoking cessation aids (medication and behavioural support), and need for assistance. This flagged eligible participants for contact by a nursecounsellor, who provided additional assistance as appropriate. The effect of this intervention was compared to standard care.

Smith 2013 tested the addition of a medication adherence counselling component to standard four-session counselling in a factorial trial that also compared two durations of free NRT and a combination of patch and gum versus patch alone.

Sumner 2016 tested different approaches to telephone counselling, comparing nondirective with directive telephone coaching. In nondirective counselling, the quitline coach allowed the participant to set the agenda for each call, whereas in directive counselling the quitline coach followed a prespecified agenda for each call, and did not allow the participant to deviate from the agenda.

Vander Weg 2016 compared tailored telephone counselling, which combined counselling on tobacco use and related issues including depressive symptoms, risky alcohol use, and weight concern, with referral to a state tobacco quitline. Both arms received an offer of NRT, bupropion or varenicline.

Warner 2016 compared the effects of a brief (approximately fiveminute) quitline facilitation intervention with brief (approximately five-minute) cessation advice. Both arms received a free two-week supply of nicotine patches.

Wu 2017 compared smoking-reduction telephone counselling consisting of a minimal face-to-face individual smoking reduction intervention lasting for about one minute, and five follow-up interventions lasting for about one minute each, with brief faceto-face individual exercise and dietetic advice lasting for the same intervention time as the smoking reduction intervention, and five follow-up interventions lasting for about one minute each with different intervention contents.

\section{Risk of bias in included studies}

A summary of the evaluation of risks of bias for each study is shown in Figure 2. Overall, we judged 12 studies (11.5\%) to be at low risk of bias across all domains, $60(57.7 \%)$ to be at high risk of bias in at least one domain, and the remaining $32(30.8 \%)$ to be at unclear risk of bias. Full details for 'Risk of bias' judgements for all included studies can be found in the Characteristics of included studies table. 
Figure 2. Methodological quality summary: review authors' judgements about each methodological quality item for each included study.

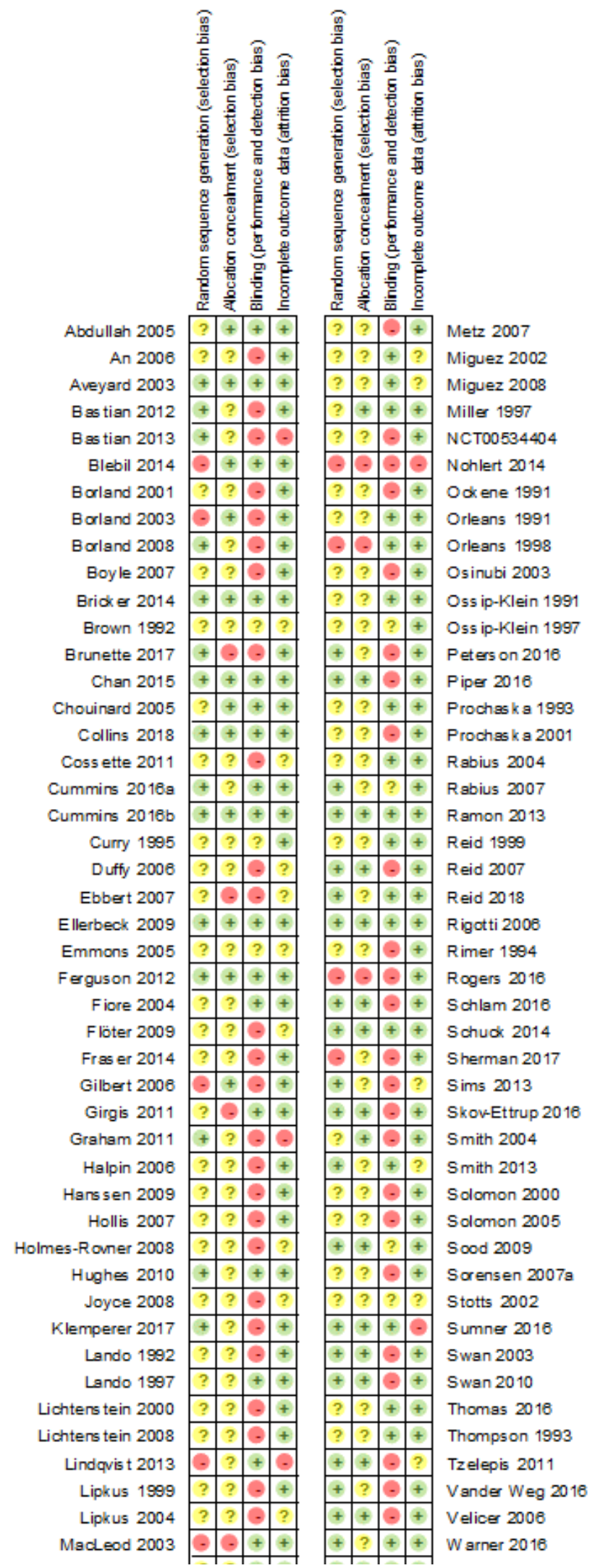


Figure 2. (Continued)

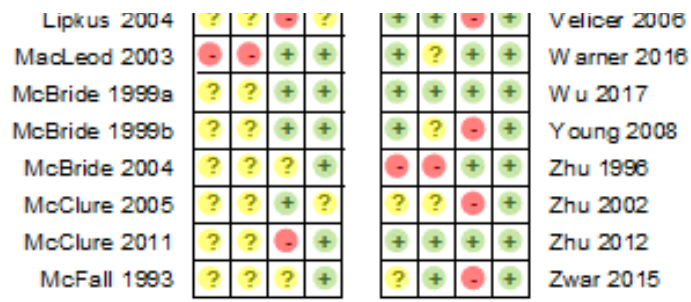

\section{Allocation}

We judged 13 studies to be at high risk of selection bias because of the way the sequence was generated or concealed; we rated 21 at low risk of selection bias, and the remainder to be at unclear risk.

All included studies described treatment allocation as 'random', but most did not give sufficient details about the method for generating the sequence. Thirty-eight (36\%) gave sufficient detail to be judged at low risk for sequence generation. We judged 10 $(10 \%)$ to be at high risk of bias for sequence generation (Borland 2003; Blebil 2014; Gilbert 2006; Lindqvist 2013; MacLeod 2003; Nohlert 2014; Orleans 1998; Rogers 2016; Sherman 2017; Zhu 1996). We judged the remaining studies to be at unclear risk of bias.

Twelve trials used cluster randomisation, nine of which contributed to a meta-analysis. In two of these, households were the unit of randomisation, and about $54 \%$ of households contained more than one smoker (Lichtenstein 2000; Lichtenstein 2008). The reported intraclass correlation was small. Borland 2008 randomised general practitioners. The reported odds ratio that adjusted for clustering and other factors was similar to that generated by the crude data. Lando 1997 randomised by the orientation session attended. Chouinard 2005 randomised clusters of two to six participants. Ebbert 2007 randomised by dental practice, and Zwar 2015 randomised by general practice. Peterson 2016 randomised by high school and Lindqvist 2013 by quitline counsellor. Excluding these studies did not have a major effect on any of the meta-analysis findings.

We did not pool the other three cluster-randomised trials with other studies in a meta-analysis. In one, participants were given access to a hotline according to county of residence, so that the availability of a hotline could be advertised in the intervention counties (Ossip-Klein 1991). Joyce 2008 randomised areas within states to different Medicare benefits. Sumner 2016 randomised families to either directive or nondirective telephone coaching.

Methods for concealing the allocation were also incompletely reported in most studies. Thirty $(29 \%)$ reported sufficient detail to be judged at low risk. We judged eight $(8 \%)$ to be at high risk of bias due to lack of concealment (Brunette 2017; Ebbert 2007; Girgis 2011; MacLeod 2003; Nohlert 2014; Orleans 1998; Rogers 2016; Zhu 1996). .

\section{Blinding of outcome measurement (detection bias)}

Overall, we judged most studies to be at high risk of detection bias (54 studies, $51.9 \%$ ), while 41 studies (39.4\%) were at low risk of detection bias. We rated the remaining nine studies $(8.7 \%)$ at unclear risk of detection bias.
As set out in the Methods, we assessed detection bias based on whether abstinence was biochemically validated. If abstinence was not validated, we considered whether the intervention group received substantially more contact than the control group, in which case we suspected that differential misreport was possible.

The studies in quitline callers typically did not attempt to use biochemical verification of self-reported quitting. Two tested a local convenience sample (Rabius 2004; Zhu 1996). Ferguson 2012 reported carbon monoxide- (CO) validated rates, although only $52 \%$ of self-reported quitters provided samples. Studies in other settings were more likely to require biochemical verification of all self-reported abstinence. Aveyard 2003, Collins 2018, Cummins 2016a, Cummins 2016b, Lando 1992 and Ossip-Klein 1991 measured cotinine levels. Blebil 2014, Fiore 2004, Hughes 2010, Lando 1997, Miguez 2002, Ramon 2013, Reid 2018, Rigotti 2006, and Wu 2017 measured CO levels. Brunette 2017, Chan 2015, Chouinard 2005, and Schuck 2014 used a mixture of CO and cotinine assessments. Ellerbeck 2009 and Miller 1997 tested for cotinine but allowed family-member verification of some selfreports. Warner 2016 measured urine anabasine levels. Thomas 2016 used NicCheck test strips. Some other studies attempted biochemical verification but did not report validated abstinence (Bastian 2012; Bastian 2013; Brown 1992; Curry 1995; Lipkus 2004; McBride 1999a; McBride 1999b; McBride 2004; McClure 2005; Orleans 1991; Reid 1999a; Solomon 2000; Sumner 2016; Thompson 1993). Stotts 2002 validated abstinence at an early follow-up but not at the follow-up used in this review.

One trial in teenagers reported particularly high misreport rates ( $45 \%$ to $55 \%$ ) in both groups; some admitted smoking in the seven days before returning the sample (Lipkus 2004).

\section{Incomplete outcome data}

All studies reported the numbers randomised to each group. We judged five studies (4.8\%) to be at high risk of attrition bias (Bastian 2013; Graham 2011; Lindqvist 2013; Nohlert 2014; Sumner 2016), due to the large proportion of participants lost to follow-up, while 16 were at unclear risk of attrition bias as the number followed up was not provided (Brown 1992; Cossette 2011; Duffy 2006; Ebbert 2007; Emmons 2005; Flöter 2009; Holmes-Rovner 2008; Joyce 2008; Lipkus 2004; McClure 2005; Miguez 2002; Miguez 2008; Sims 2013; Smith 2004; Stotts 2002; Tzelepis 2011a). We rated most studies (83 studies, $79.8 \%$ ) at low risk of attrition bias.

Most studies reported findings based on treating all dropouts as smokers, although some did not note the number lost to follow-up who were assumed to be continuing smokers. Many also reported complete-case analyses (excluding dropouts), or used methods 
for imputing missing data. In most cases this had little impact on the relative effect, because numbers lost were similar across conditions. We did not identify any studies where using complete cases or using adjusted estimates of quit rates would have changed the relative effect enough to alter the conclusions of a metaanalysis.

We detected no other biases.

\section{Effects of interventions}

See: Summary of findings for the main comparison Interventions for callers to quitlines - effect of additional proactive calls for smoking cessation; Summary of findings 2 Interventions for smokers not calling quitlines - effect of proactive telephone counselling

\section{Trials of interventions for people calling helplines}

\section{Effect of additional proactive support}

Fourteen studies ( $\mathrm{N}=32,484)$ that compared an intervention involving multisession proactive counselling with a control condition providing self-help materials or brief counselling at a single call showed evidence of a benefit from the additional support. With the addition of two new studies published since the last update (Cummins 2016b; Nohlert 2014), the pooled risk ratio (RR) was unchanged but the confidence interval is now wider, given the substantial heterogeneity in the effect size between studies and the random-effects model now being used: RR 1.38, 95\% confidence interval $(\mathrm{Cl}) 1.19$ to $1.61 ; \mathrm{I}^{2}=72 \%$; Figure 3, Analysis 1.1). Exclusion of eight studies that were at high risk of bias for any of the domains (Borland 2001; Borland 2003; Gilbert 2006; Hollis 2007; Nohlert 2014; Smith 2004; Zhu 1996; Zhu 2002) resulted in a slightly larger effect size, but the confidence intervals overlapped (RR 1.52, $95 \% \mathrm{Cl} 1.16$ to $1.98 ; 6$ trials, 16,293 participants; $\mathrm{I}^{2}=80 \%$ ).

Figure 3. Comparison 1. Interventions for callers to quitlines. Effect of additional proactive calls.

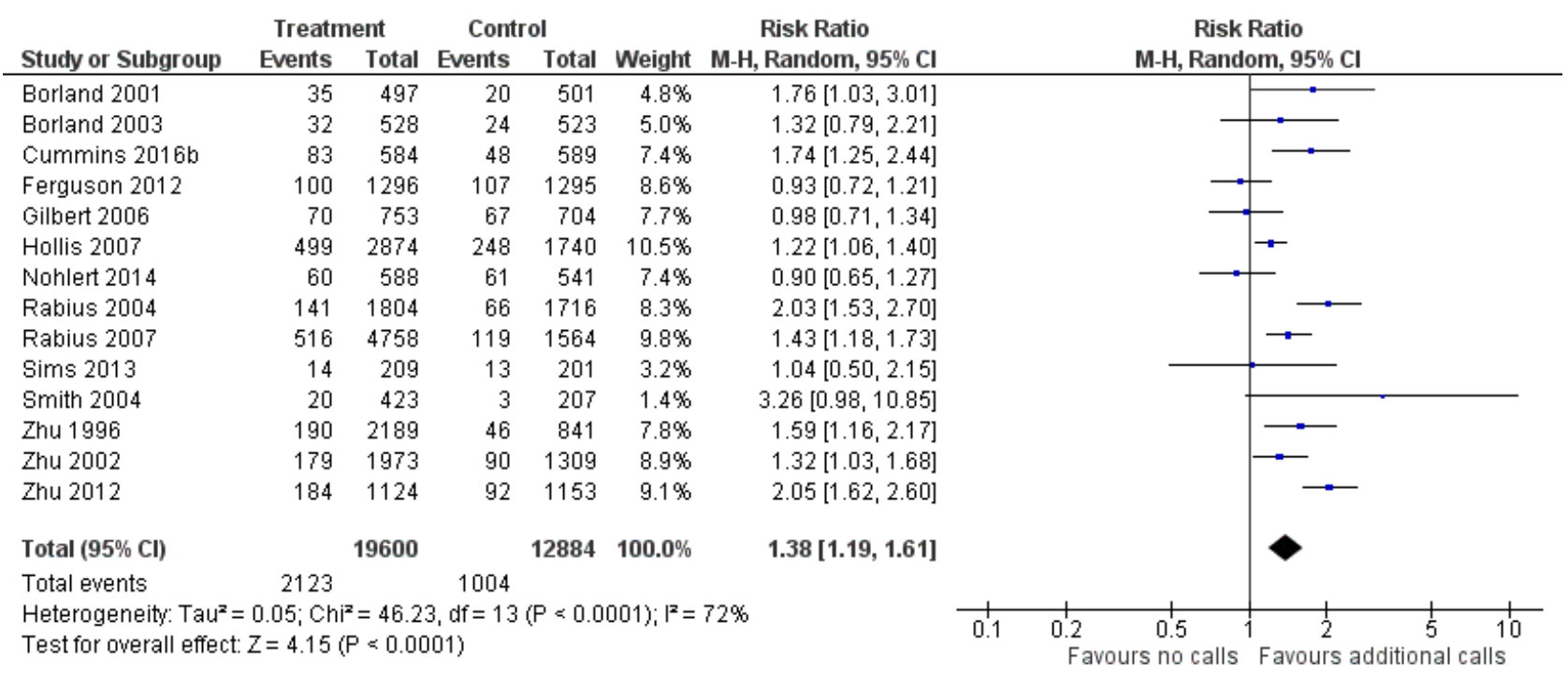

The two studies with the largest weights in the meta-analysis detected statistically significant effects, as did six other studies, suggesting that there is a benefit from these types of interventions in most settings but perhaps not in all. We examined the characteristics of the six studies in which the point estimates suggested no effect of counselling (Borland 2003; Ferguson 2012; Gilbert 2006; Nohlert 2014; Sims 2013; Smith 2004). These studies were conducted mainly in the USA $(n=8)$, but also in the UK ( $n$ $=2)$, Australia $(n=2)$, Sweden $(n=1)$, and Canada $(n=1)$. In the earliest UK trial (Gilbert 2006), the authors thought that the unstructured counselling might have explained the lack of effect, but in the second trial (Ferguson 2012) a more structured protocol was used. In both cases the control groups would have received some support at the original call, as well as mailed or emailed materials. The context of the UK healthcare system may contribute to the difference, since there has historically been a well-developed Stop Smoking Service with access to support and medication. Ferguson 2012 also failed to detect an effect of offering free nicotine replacement therapy (NRT), in a factorial design. The difference in the healthcare setting may also explain the lack of effect for the
Australian (Borland 2003), Swedish (Nohlert 2014) and Canadian (Smith 2004) studies. In addition, in the Australian study (Borland 2003), the group in the control arm received an intensive tailored self-help programme, the efficacy of which may be more similar to that of a proactive telephone counselling programme. In the Swedish study (Nohlert 2014), most of the bias domains were at high risk, which could have obscured an effect of the proactive telephone counselling. In the only American study with a point estimate suggesting no effect (Sims 2013), the participants were young adults, for whom there is limited evidence for any effective interventions (Fanshawe 2017). However, the confidence interval for this study was wide and encompassed the possibility of effects consistent with the other studies.

Using only the Hollis 2007 trial data for intervention and control arms that were not offered NRT as an adjunct slightly decreased the effect size (RR 1.36, 95\% Cl 1.14 to $1.62 ; 31,048$ participants), while using the data for the arms that had NRT as an adjunct therapy increased the effect size (RR $1.41,95 \% \mathrm{Cl} 1.21$ to 1.64; 31,046 participants). This is because the addition of NRT enhanced 
the effect of the combined telephone counselling arms, despite the study reporting no evidence of interaction.

\section{Counselling intensity}

In the main analysis we pooled more than one intensity of intervention into the treatment arms of four studies (Hollis 2007; Rabius 2007; Smith 2004; Zhu 1996). Using only the more intensive interventions in the two trials that reported outcomes for two different interventions (Hollis 2007; Zhu 1996) marginally increased the pooled effect size (RR $1.40,95 \% \mathrm{Cl} 1.20$ to $1.64 ; 29,908$ participants; $1^{2}=72 \%$; ). Smith 2004 did not detect a difference between groups receiving two or six follow-up calls after an initial 50-minute session, and we were unable to obtain separate results for different telephone counselling intensities. Rabius 2007 tested six different intervention formats, varying the number of calls, their duration and the use of two brief booster calls at four and eight weeks after counselling. There was no clear dose-response effect: five brief counselling calls plus boosters were no less effective than the standard American Cancer Society protocol of five longer calls and boosters.

Analysis 2.1 includes comparisons of different telephone counselling intensities across studies. In Rabius 2007, a higher number of calls was associated with higher cessation rates. Seven calls, including five brief or standard calls with two booster calls (RR $1.44,95 \% \mathrm{Cl} 1.09$ to $1.89 ; 1,908$ participants), and five calls, including brief or standard calls with or without booster calls (RR $1.28,95 \% \mathrm{Cl} 1.00$ to $1.64 ; 3669$ participants) were more effective in increasing cessation rates than the three standard calls without booster calls. However in the same study, seven calls were no more effective than five calls in increasing cessation rates (RR $1.12,95 \% \mathrm{Cl}$ 0.93 to 1.36 ; 3939 participants). In Hollis 2007, intensive counselling (five calls) was not more effective than moderate counselling (two calls) (RR 1.05, 95\% Cl 0.89 to 1.23; 2874 participants). Lastly, in Zhu 1996 multiple counselling (five calls) was more effective than a single counselling session (RR 1.32, 1.01 to 1.74; 2189 participants).

In a post hoc subgroup analysis by telephone counselling intensity (Analysis 3.1), there were no statistically significant subgroup differences $\left(\mathrm{Chi}^{2}=1.32, \mathrm{df}=2(\mathrm{P}=0.52), \mathrm{I}^{2}=0 \%\right)$. Subgroups of low and medium intensity detected a statistically significant benefit of the intervention (two sessions or fewer: RR $1.22,95 \% \mathrm{Cl} 1.02$ to 1.46 ; 2 trials, 3867 participants; $\left.\right|^{2}=0 \%$; three to six sessions: RR 1.38, 95\% $\mathrm{Cl} 1.17$ to $1.63 ; 11$ trials, 22,612 participants; $\mathrm{I}^{2}=67 \%$ ); the difference was not statistically significant for seven or more sessions, but the confidence interval was wide and narrowly missed one (RR 1.49 , $95 \% \mathrm{Cl} 0.98$ to $2.25 ; 4$ trials, 6005 participants; $1^{2}=77 \%$ ).

\section{Comparisons between different types of support at initial call}

Five studies compared different modalities of telephone counselling with varying support at initial call (Analysis 4.1).

One study (Sood 2009) compared reactive counselling to mailed self-help materials alone. All participants in the intervention group had counselling at the time of their call and had the option to get repeated support. We found no effect of the intervention (RR 0.96, $95 \% \mathrm{Cl} 0.71$ to 1.30 ; 990 participants).

Two studies compared different reactive support for helpline callers during a single session. They did not detect a significantly increased benefit from either counselling and materials designed for African-
Americans (Orleans 1998) (RR 1.10, 95\% Cl 0.80 to 1.52 ; 1422 participants), or stage-based counselling designed for blue-collar workers (Thompson 1993) (RR $1.10,95 \% \mathrm{Cl} 0.73$ to $1.67 ; 382$ participants) compared to standard support. Quit rates in these trials were from $15 \%$ to $20 \%$ for point prevalence rates at six months.

In this latest update we found two new trials that compared telephone counselling interventions using different behavioural change theories. Bricker 2014 compared acceptance and commitment therapy to cognitive behavioural therapy, but observed no difference between the two (RR $1.35,95 \% \mathrm{Cl} 0.74$ to $2.46 ; 121$ participants). Lindqvist 2013 found that motivational interviewing may be more effective than standard telephone counselling (RR $1.39,95 \% \mathrm{Cl} 1.01$ to $1.92 ; 772$ participants).

\section{Trials providing access to a helpline}

Two studies (Ossip-Klein 1991; Zwar 2015) compared the provision of a hotline versus a minimal intervention. When we combined them, we noted a substantial increase in quit rates (RR $1.62,95 \% \mathrm{Cl}$ 1.16 to $2.25 ; 3327$ participants; $\left.\right|^{2}=0 \%$; Analysis 5.1 ).

In McFall 1993 smokers who had enrolled to be sent materials for a self-help programme with a televised component were randomised to receive follow-up newsletters and access to a helpline for six months. The intervention combined a helpline and written materials, but quit rates were not lower in the intervention than in the control condition after 24 months (RR $0.86,95 \% \mathrm{Cl} 0.70$ to 1.06 ; 1311 participants).

In another four trials (Joyce 2008; Rogers 2016; Sherman 2017; Skov-Ettrup 2016), reactive or proactive calls were compared with provider counselling (quitline service), demonstrating a moderate increase in cessation rates for reactive or proactive counselling (RR $1.40,95 \% \mathrm{Cl} 1.07$ to $1.84 ; 7780$ participants; $\left.\right|^{2}=73 \%$ ) compared with provider counselling. The four trials were very heterogeneous in terms of target populations and interventions provided: in Joyce 2008 enrollees for a Medicare Stop Smoking Programme were randomised to a quitline that offered the choice of a reactive hotline with prerecorded messages and ad hoc counselling, or a proactive service, in addition to insurance coverage for the nicotine patch. The control group received pharmacotherapy coverage only. In Rogers 2016, people with mental health conditions were randomised to proactive telephone counselling for mental health patients or counselling provided by the state quitline. In Sherman 2017 smokers attending the Department of Vereran Affairs outpatient primary care clinics were recruited, and in Skov-Ettrup 2016 the participants were a nationally representative sample of the Danish population. In both studies the participants were randomised to either proactive or reactive telephone counselling, or to self-help. The cessation rates were much larger in the three trials in which the participants had been offered pharmacotherapy (Joyce 2008; Rogers 2016; Sherman 2017). Also in these three trials, point prevalence abstinence was reported, compared to SkovEttrup 2016 which reported prolonged abstinence at 12 months.

Two studies identified for this latest update (Sherman 2017; Skov-Ettrup 2016) provided data for comparisons of proactive and reactive telephone counselling versus each other, and versus self-help. Proactive counselling was not associated with an improvement in cessation rates compared with reactive counselling (RR 2.06, 95\% Cl: 0.58 to $7.31 ; 2908$ participants; $\left.\right|^{2}$ 
$=90 \%)$. However, neither proactive (RR 1.42, 95\% 0.76 to 2.63 2498 participants; $\mathrm{I}^{2}=74 \%$ ) nor reactive (RR $0.78,95 \% \mathrm{Cl} 0.44$ to $1.40 ; 2364$ participants; $\left.\right|^{2}=51 \%$ ) were significantly associated with increased cessation rates when compared with self-help.

\section{Trials of proactive counselling, not initiated by calls to quitlines}

\section{Overall effect of counselling}

There were 65 trials in this comparison (Ockene 1991 contributed different data to two subgroups, making a total of 66 estimates in the analysis). The pooled effect suggested a modest benefit of proactive telephone counselling: RR $1.25,95 \% \mathrm{Cl} 1.15$ to 1.35; 41,233 participants; $1^{2}=52 \%$ (Figure 4, Analysis 6.1). Our prespecified subgroup analyses based on the baseline support provided to both intervention and control, counselling intensity, or motivation did not fully explain the heterogeneity, nor was heterogeneity reduced by excluding the trials amongst teenagers or pregnant women. Exclusion of 38 trials that were at high risk of bias in at least one of the domains did not have a large influence on the pooled effect size, but widened the confidence interval (RR $1.23,1.05$ to $1.45 ; 26$ trials, 15,701 participants; $\left.\right|^{2}=62 \%$ ). 
Figure 4. Comparison 6. Interventions for smokers not calling quitlines - subgroups by baseline support.

\begin{tabular}{|c|c|c|c|c|c|c|c|}
\hline Study or Subgroup & Treatment & $\begin{array}{l}\text { ent } \\
\text { Total } \\
\end{array}$ & \multicolumn{2}{|c|}{ Control } & Weight & $\begin{array}{l}\text { Risk Ratio } \\
\text { M-H, Random, } 95 \% \mathrm{Cl} \\
\end{array}$ & $\begin{array}{c}\text { Risk Ratio } \\
\text { M-H, Random, } \mathbf{9 5} \% \mathrm{Cl}\end{array}$ \\
\hline \multicolumn{7}{|c|}{ 6.1.1 Adjunct to self-help or minimal intervention } & \\
\hline Abdullah 2005 & 47 & 444 & 21 & 459 & $1.5 \%$ & $2.31[1.41,3.81]$ & \\
\hline An 2006 & 53 & 407 & 17 & 414 & $1.4 \%$ & $3.17[1.87,5.38]$ & \\
\hline Aweyard 2003 & 14 & 685 & 15 & 683 & $0.9 \%$ & $0.93[0.45,1.91]$ & \\
\hline Brown 1992 & 7 & 23 & 2 & 22 & $0.3 \%$ & $3.35[0.78,14.40]$ & \\
\hline Chan 2015 & 16 & 338 & 17 & 330 & $1.1 \%$ & $0.92[0.47,1.79]$ & \\
\hline Curry 1995 & 8 & 150 & 10 & 329 & $0.7 \%$ & $1.75[0.71,4.36]$ & \\
\hline Duffy 2006 & 15 & 48 & 6 & 51 & $0.7 \%$ & $2.66[1.12,6.28]$ & \\
\hline Emmons 2005 & 60 & 398 & 35 & 386 & $2.0 \%$ & $1.66[1.12,2.46]$ & \\
\hline Girgis 2011 & 18 & 213 & 22 & 194 & $1.2 \%$ & $0.75[0.41,1.35]$ & 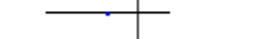 \\
\hline Graham 2011 & 52 & 675 & 29 & 651 & $1.8 \%$ & $1.73[1.11,2.69]$ & \\
\hline Hanssen 2009 & 30 & 77 & 23 & 61 & $1.8 \%$ & $1.03[0.67,1.58]$ & \\
\hline Holmes-Rovner 2008 & 40 & 76 & 25 & 60 & $2.1 \%$ & $1.26[0.87,1.82]$ & \\
\hline Lando 1992 & 20 & 716 & 10 & 683 & $0.9 \%$ & $1.91[0.90,4.05]$ & \\
\hline Lichtenstein 2000 & 25 & 355 & 15 & 349 & $1.2 \%$ & $1.64[0.88,3.05]$ & \\
\hline Lichtenstein 2008 & 46 & 905 & 42 & 916 & $1.9 \%$ & $1.11[0.74,1.67]$ & \\
\hline Lipkus 1999 & 10 & 52 & 18 & 55 & $1.0 \%$ & $0.59[0.30,1.15]$ & + \\
\hline Lipkus 2004 & 19 & 209 & 14 & 193 & $1.1 \%$ & $1.25[0.65,2.43]$ & \\
\hline McBride 1999a & 16 & 288 & 14 & 292 & $1.0 \%$ & $1.16[0.58,2.33]$ & \\
\hline McBride 1999b & 144 & 600 & 71 & 297 & $2.7 \%$ & $1.00[0.78,1.29]$ & $\leftarrow$ \\
\hline Mcclure 2005 & 15 & 138 & 14 & 137 & $1.0 \%$ & $1.06[0.53,2.12]$ & \\
\hline Mcclure 2011 & 3 & 27 & 5 & 25 & $0.3 \%$ & $0.56[0.15,2.09]$ & \\
\hline Miguez 2002 & 27 & 100 & 14 & 100 & $1.3 \%$ & $1.93[1.08,3.45]$ & \\
\hline Miguez 2008 & 25 & 118 & 10 & 110 & $1.0 \%$ & $2.33[1.17,4.63]$ & \\
\hline Orleans 1991 & 86 & 474 & 92 & 938 & $2.6 \%$ & $1.85[1.41,2.43]$ & \\
\hline Ossip-Klein 1997 & 18 & 92 & 17 & 85 & $1.2 \%$ & $0.98[0.54,1.77]$ & \\
\hline Peterson 2016 & 116 & 1058 & 117 & 1093 & $2.7 \%$ & $1.02[0.80,1.31]$ & - \\
\hline Prochaska 1993 & 17 & 187 & 23 & 191 & $1.2 \%$ & $0.75[0.42,1.37]$ & - \\
\hline Prochaska 2001 & 25 & 361 & 25 & 362 & $1.4 \%$ & $1.00[0.59,1.71]$ & \\
\hline Rigotti 2006 & 10 & 209 & 7 & 210 & $0.6 \%$ & $1.44[0.56,3.70]$ & \\
\hline Rimer 1994 & 88 & 463 & 93 & 463 & $2.6 \%$ & $0.95[0.73,1.23]$ & - \\
\hline Schuck 2014 & 60 & 256 & 15 & 256 & $1.4 \%$ & $4.00[2.33,6.85]$ & \\
\hline Sorensen $2007 a$ & 19 & 125 & 7 & 106 & $0.8 \%$ & $2.30[1.01,5.26]$ & \\
\hline Stotts 2002 & 10 & 134 & 14 & 135 & $0.8 \%$ & $0.72[0.33,1.56]$ & \\
\hline Tzelepis 2011a & 11 & 769 & 6 & 793 & $0.6 \%$ & $1.89[0.70,5.09]$ & \\
\hline Young 2008 & 13 & 169 & 9 & 149 & $0.8 \%$ & $1.27[0.56,2.89]$ & \\
\hline Subtotal $(95 \% \mathrm{Cl})$ & & 11339 & & 11578 & $45.6 \%$ & $1.35[1.16,1.57]$ & \\
\hline Total events & 1183 & & 874 & & & & \\
\hline \multicolumn{8}{|c|}{$\begin{array}{l}\text { Heterogeneity: } \operatorname{Tau}^{2}=0.11 ; \mathrm{Chi}^{2}=91.09, \mathrm{df}=34(\mathrm{P}<0.00001) ; \mathrm{I}^{2}=63 \% \\
\text { Test for overall effect: } Z=3.95(\mathrm{P}=0.0001)\end{array}$} \\
\hline \multicolumn{8}{|c|}{ 6.1.2 Adjunct to brief intervention or counselling } \\
\hline Borland 2008 & 32 & 728 & 5 & 311 & $0.6 \%$ & $2.73[1.08,6.95]$ & \\
\hline Brunette 2017 & 19 & 212 & 10 & 146 & $0.9 \%$ & $1.31[0.63,2.73]$ & \\
\hline Chouinard 2005 & 13 & 53 & 13 & 53 & $1.1 \%$ & $1.00[0.51,1.95]$ & \\
\hline Cossette 2011 & 5 & 20 & 6 & 20 & $0.5 \%$ & $0.83[0.30,2.29]$ & \\
\hline Ebbert 2007 & 15 & 60 & 6 & 22 & $0.8 \%$ & $0.92[0.41,2.06]$ & \\
\hline Flöter 2009 & 94 & 316 & 40 & 211 & $2.3 \%$ & $1.57[1.13,2.17]$ & \\
\hline McBride 2004 & 38 & 192 & 30 & 198 & $1.8 \%$ & $1.31[0.84,2.02]$ & \\
\hline Met 2007 & 31 & 99 & 33 & 191 & $1.8 \%$ & $1.81[1.18,2.77]$ & \\
\hline Ockene 1991 & 42 & 386 & 46 & 457 & $1.9 \%$ & $1.08[0.73,1.61]$ & \\
\hline Osinubi 2003 & 5 & 30 & 2 & 29 & $0.3 \%$ & $2.42[0.51,11.48]$ & \\
\hline Ramon 2013 & 58 & 200 & 56 & 201 & $2.4 \%$ & $1.04[0.76,1.42]$ & 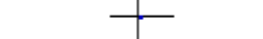 \\
\hline Reid 2007 & 23 & 50 & 17 & 49 & $1.6 \%$ & $1.33[0.81,2.16]$ & \\
\hline Subtotal $(95 \% \mathrm{Cl})$ & & 2346 & & 1888 & $15.9 \%$ & $1.30[1.12,1.50]$ & \\
\hline Total events & 375 & & 264 & & & & \\
\hline \multicolumn{8}{|c|}{$\begin{array}{l}\text { Heterogeneity: } \operatorname{Tau}^{2}=0.00 ; \mathrm{Ch}^{2}=11.56, \mathrm{df}=11(P=0.40) ;\left.\right|^{2}=5 \% \\
\text { Test for overall effect: } Z=3.42(P=0.0006)\end{array}$} \\
\hline \multicolumn{8}{|c|}{ 6.1.3 Adjunct to pharmacotherapy } \\
\hline Bastian 2013 & 30 & 245 & 35 & 251 & $1.7 \%$ & $0.88[0.56,1.38]$ & - \\
\hline Blebil 2014 & 86 & 120 & 54 & 111 & $2.9 \%$ & $1.47[1.18,1.84]$ & - \\
\hline Bovle 2007 & 87 & 663 & 82 & 666 & $2.5 \%$ & $1.07[0.80 .1 .41]$ & $千$ \\
\hline
\end{tabular}


Figure 4. (Continued)

$\begin{array}{lrrrrr}\text { Blebil 2014 } & 86 & 120 & 54 & 111 & 2.9 \% \\ \text { Boyle 2007 } & 87 & 663 & 82 & 666 & 2.5 \% \\ \text { Cummins 2016a } & 31 & 634 & 51 & 636 & 1.8 \% \\ \text { Ellerbeck 2009 } & 71 & 482 & 33 & 244 & 2.0 \% \\ \text { Fiore 2004 } & 21 & 313 & 25 & 330 & 1.3 \% \\ \text { Fraser 2014 } & 125 & 453 & 165 & 581 & 3.0 \% \\ \text { Hughes 2010 } & 21 & 299 & 8 & 150 & 0.8 \% \\ \text { Lando 1997 } & 21 & 162 & 46 & 347 & 1.6 \% \\ \text { MacLeod 2003 } & 110 & 412 & 82 & 442 & 2.7 \% \\ \text { NCT00534404 } & 252 & 827 & 194 & 830 & 3.2 \% \\ \text { Ockene 1991 } & 48 & 263 & 18 & 117 & 1.5 \% \\ \text { Reid 1999a } & 46 & 197 & 48 & 199 & 2.2 \% \\ \text { Schlam 2016 (1) } & 25 & 66 & 17 & 70 & 1.5 \% \\ \text { Solomon 2000 } & 21 & 106 & 16 & 108 & 1.2 \% \\ \text { Solomon 2005 } & 49 & 171 & 31 & 159 & 2.0 \% \\ \text { Swan 2010 } & 244 & 801 & 110 & 401 & 3.0 \% \\ \text { Velicer 2006 } & 42 & 500 & 41 & 509 & 1.9 \% \\ \text { Subtotal (95\% Cl) } & & 6714 & & 6151 & 36.7 \% \\ \text { Total events } & 1330 & & 1056 & & \\ \text { Heterogeneity Tau } & 0.02 \% & \end{array}$

Heterogeneity: $\operatorname{Tau}^{2}=0.02 ; \mathrm{Chi}^{2}=28.84, \mathrm{df}=17(\mathrm{P}=0.04) ; \mathrm{I}^{2}=41 \%$

Test for overall effect: $Z=2.50(P=0.01)$

6.1.4 Adjunct to incentives for smoking cessation

$\begin{array}{lcccccc}\text { Thomas } 2016 & 36 & 602 & 35 & 615 & 1.7 \% & 1.05[0.67,1.65] \\ \text { Subtotal }(\mathbf{9 5 \%} \mathrm{Cl}) & & \mathbf{6 0 2} & & \mathbf{6 1 5} & \mathbf{1 . 7 \%} & \mathbf{1 . 0 5}[\mathbf{0 . 6 7}, \mathbf{1 . 6 5}] \\ \text { Total events } & 36 & & 35 & & & \end{array}$

Heterogeneity: Not applicable

Test for overall effect: $Z=0.22$ ( $P=0.83$ )

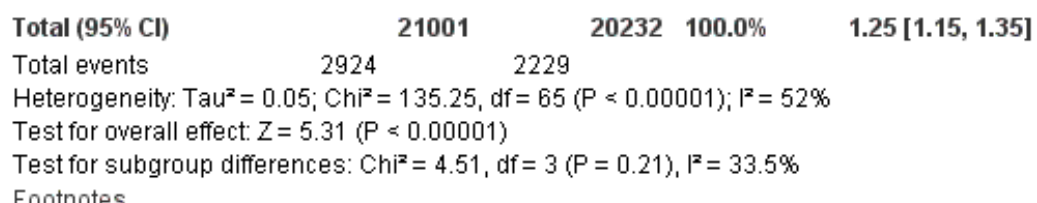

$1.47[1.18,1.84]$

$1.07[0.80,1.41]$

$0.61[0.40,0.94]$

$1.09[0.74,1.60]$

$0.89[0.51,1.55]$

$0.97[0.80,1.18]$

$1.32[0.60,2.90]$

$0.98[0.60,1.58]$

$1.44[1.12,1.85]$

$1.30[1.11,1.53]$

$1.19[0.72,1.95]$

$0.97[0.68,1.38]$

$1.56[0.93,2.61]$

$1.34[0.74,2.42]$

$1.47[0.99,2.18]$

$1.11[0.92,1.34]$

$1.04[0.69,1.57]$

$1.14[1.03,1.26]$

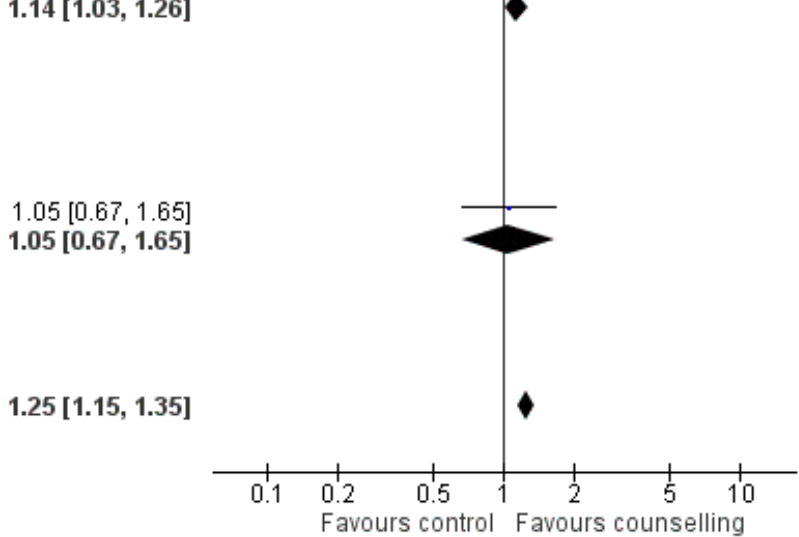

ootnotes

(1) Excludes those who received Medication Adherence Counseling (MAC) and Helping Hand $(\mathrm{HH})$ with Counseling interventions

\section{Baseline support offered}

Thirty-five trials tested the effect of telephone counselling as an adjunct to self-help or to a minimal intervention. In this subgroup the effect of telephone counselling was slightly stronger: RR 1.35, $95 \% \mathrm{Cl} 1.16$ to $1.57 ; 22,917$ participants, than that for all 65 trials, although the heterogeneity was more pronounced within this subgroup $(12=63 \%)$.

Twelve trials tested the effect of telephone counselling as an adjunct to face-to-face counselling or to a brief intervention. In this subgroup the effect of telephone counselling was also slightly stronger: $\mathrm{RR} 1.30,95 \% \mathrm{Cl} 1.12$ to $1.50 ; 4234$ participants, than that for all 65 trials but with less evidence of statistical heterogeneity ( 12 $=5 \%)$.

Eighteen trials tested the effect of telephone counselling as an adjunct to the systematic use or offer of NRT (patch or gum), bupropion, or varenicline. In this subgroup the effect of telephone counselling was slightly smaller: RR $1.14,95 \% \mathrm{Cl} 1.03$ to $1.26 ; 12,865$ participants, than that for all 65 trials, and the heterogeneity was slightly lower $\left(1^{2}=41 \%\right)$.

One additional trial tested the effect of telephone counselling as an adjunct to incentives. In this trial, telephone counselling had no effect on smoking cessation: RR $1.05,95 \% \mathrm{Cl} 0.67$ to $1.65 ; 1217$ participants.

\section{Counselling intensity}

Three trials directly compared moderate-intensity telephone counselling (three to five calls) to low-intensity telephone counselling (one call). The pooled effect suggests that moderateintensity telephone counselling is more effective than minimal telephone counselling: RR $1.27,95 \% \mathrm{Cl} 1.12$ to $1.44 ; 2602$ participants, with no evidence of heterogeneity $\left(I^{2}=0 \%\right)$ (Analysis 7.1).

A subgroup analysis of the 65 trials comparing telephone counselling to control explored the impact of the number of calls planned as part of the intervention, using three categories; two or fewer, three to six, and seven or more calls. We had no strong a priori rationale for the choice of cut points, although the one-to-two-call group predominantly captured trials with 'brief' interventions. We initially analysed these categories within the grouping by the control condition used above, but since the pattern of results was largely consistent we simplified the comparisons (Analysis 8.1). There was no evidence of statistically significant differences between subgroups $\left(\mathrm{Chi}^{2}=1.70, \mathrm{df}=2(\mathrm{P}=0.43), \mathrm{I}^{2}\right.$ $=0 \%)$. In two of the three subgroups in this analysis, we did not find a statistically significant effect, but confidence intervals were wide; these were the smaller subgroups. Nine trials provided lowintensity telephone counselling, i.e. two or fewer calls: RR 1.09, 95\% $\mathrm{Cl} 0.86$ to $1.40 ; 6274$ participants; $\mathrm{I}^{2}=45 \%$, and 13 provided high- 
intensity telephone counselling, i.e. seven or more calls: RR 1.22, $95 \% \mathrm{Cl} 0.98$ to $1.51 ; 8273$ participants; $\left.\right|^{2}=63 \%$.

The largest subgroup was the group of 44 trials providing mediumintensity telephone counselling, i.e. three to six calls. For studies in this subgroup telephone counselling had a statistically significant effect on smoking cessation rates: RR $1.29,95 \% \mathrm{Cl} 1.18$ to 1.42 ; 26,686 participants; $\left.\right|^{2}=48 \%$.

We also considered whether including the 14 trials of proactive counselling for quitline callers in their intensity subgroups would alter these conclusions. The overall effect of telephone counselling was slightly stronger: RR $1.28,95 \% \mathrm{Cl} 1.19$ to $1.37 ; 73,717$ participants; $12=56 \%$; analysis not shown, and the test for heterogeneity between subgroups was not statistically significant $(P=0.33)$.

To explain the higher heterogeneity among trials of high-intensity telephone counselling, we conducted another post hoc subgroup analysis by baseline support. High-intensity telephone counselling had no effect on cessation rates when provided as an adjunct to self-help: RR $1.45,95 \% \mathrm{Cl} 0.85$ to $2.46,3261$ participants, $1^{2}$ $=80 \%$, analysis not shown; to pharmacotherapy: RR $1.10,95 \%$ $\mathrm{Cl} 0.88$ to 1.38 ; 4654 participants; $\mathrm{I}^{2}=48 \%$; analysis not shown; or to a brief intervention or counselling: RR $1.31,95 \% \mathrm{Cl} 0.63$ to $2.73 ; 358$ participants; analysis not shown. A further source of methodological heterogeneity between high-intensity telephone counselling trials is that Velicer 2006 used an automated voice response system to provide tailored but prerecorded support. However, exclusion of this study did not have an effect on the pooled effect estimate or on statistical heterogeneity.

\section{Motivation}

A third subgroup analysis for the 65 trials explored the effect of motivation (Analysis 9.1). Twenty-six studies specifically recruited smokers who wanted to make a quit attempt, including most of the studies (14/18) where pharmacotherapy was common to both intervention and control. Thirty-nine studies did not state that participants were included on the basis of motivation, although a relatively high proportion may have been interested in quitting. The effect size was slightly larger for those 'selected' for motivation: RR $1.31,95 \% \mathrm{Cl} 1.15$ to $1.49 ; 17,877$ participants; $12=70 \%$, than for those 'unselected': RR 1.20, 95\% Cl 1.09 to 1.33; 23,356 participants; $\mathrm{I}^{2}=26 \%$, but the test for subgroup differences was non-significant $\left(\mathrm{Chi}^{2}=0.99, \mathrm{df}=1(\mathrm{P}=0.32), \mathrm{I}^{2}=0 \%\right)$.

\section{Results of a meta-regression}

In univariate meta-regression analyses none of the potential moderators tested was a significant predictor of the effect (RR) of telephone counselling on smoking cessation rates. When all potential moderators were fitted together in a multivariate metaregression analysis (Appendix 2), the relative difference in the RR compared to pharmacotherapy as an adjunctive treatment was $35 \%$ greater for self-help (RR change $1.35,95 \% \mathrm{Cl} 1.10$ to $1.67, \mathrm{P}$ $<0.01$ ), and $37 \%$ greater for a brief face-to-face intervention (RR change $1.37,95 \% \mathrm{Cl} 1.05$ to $1.79, \mathrm{P}=0.02$ ). In the same multivariate model, studies that selected participants for motivation were associated with a $26 \%$ greater RR (RR change $1.26,95 \% \mathrm{Cl} 1.04$ to $1.52, P=0.02)$, compared to studies that did not select participants for motivation. When telephone counselling intensity was fitted as a categorical variable, only medium intensity, compared to low intensity, was statistically significantly associated with a change in the RR (RR change $1.34,95 \% \mathrm{Cl} 1.03$ to $1.74, \mathrm{P}=0.02$; analysis not shown).

\section{Other studies}

We judged 10 other studies to be too dissimilar for pooling, but their results are shown in Analysis 10.1.

Seven studies compared counselling matched in contact time, but using different approaches or containing different content, or both.

Bastian 2012 compared family-supported telephone counselling with standard telephone counselling, and found no difference in self-reported seven-day point prevalent cessation at the 12-month follow-up: RR $1.02,95 \% \mathrm{Cl} 0.72$ to $1.45 ; 471$ participants.

Collins 2018 compared individual behavioural telephone counselling focusing on parental smoking cessation and reduction of child second-hand smoke exposure to individual telephone health education focusing on improving family nutrition on a budget. There was no statistically significant difference in cotinineverified seven-day point prevalence abstinence at 12 months: RR $2.01,95 \% \mathrm{Cl} 0.97$ to 4.17 ; 327 participants.

Klemperer 2017 tested the effects of three different interventions: smoking reduction telephone counselling, brief motivational telephone counselling, and standard telephone counselling. There was a significant difference in seven-day point prevalence abstinence at 12 months for the brief motivational versus standard telephone counselling: RR $2.63,95 \% \mathrm{Cl} 1.12$ to 6.14 ; 374 participants, but not for smoking reduction versus brief motivational telephone counselling: RR $0.88,95 \% \mathrm{Cl} 0.47$ to 1.68; 371 participants, or for smoking reduction versus standard telephone counselling: RR 2.32, 0.98 to 5.52, 375 participants.

Sumner 2016 compared nondirective telephone coaching with directive telephone coaching and found no difference in 12-month abstinence: RR $1.15,95 \% \mathrm{Cl} 0.82$ to $1.62 ; 518$ participants.

Vander Weg 2016 compared the offer of tailored telephone counselling with referral to a state tobacco quitline, but there was no significant difference in the quit rates at six months: RR 1.03, 95\% $\mathrm{Cl} 0.47$ to 2.25 ; 63 participants.

Warner 2016 compared a brief (approximately five-minute) quitline facilitation intervention with brief (approximately five-minute) cessation advice, and found no significant difference in quit rates at six months: RR $1.62,95 \% \mathrm{Cl} 0.96$ to $2.72 ; 600$ participants.

Wu 2017 tested different focuses of a telephone intervention, with one group focusing on smoking reduction and the other on exercise and diet advice. There was no significant difference in quit rates at 12 months: RR $2.86,95 \% \mathrm{Cl} 0.93$ to $8.81 ; 369$ participants.

Two studies evaluated additional features added to telephone counselling. Smith 2013 did not detect any additional benefit of a counselling component to increase adherence to the NRT that was provided to all participants who received counselling from the Wisconsin Tobacco Quit Line. There was no difference in 30day abstinence at six months: RR $0.98,95 \% \mathrm{Cl} 0.83$ to 1.15 ; 987 participants. Reid 2018 compared an automated telephone followup with standard care, and found no significant difference in 
continuous abstinence at 52 weeks: RR $1.22,95 \% \mathrm{Cl} 0.92$ to $1.60 ; 440$ participants.

Halpin 2006 compared benefit designs that included telephone counselling and pharmacotherapy. There was no significant difference between the group offered coverage for telephone counselling and pharmacotherapy compared with the group offered pharmacotherapy alone: RR $0.68,95 \% \mathrm{Cl} 0.38$ to $1.18 ; 266$ participants.

\section{DISCUSSION}

\section{Summary of main results}

This review considers telephone services for delivering behavioural counselling and support, both proactively and reactively. Interventions studied in trials range from brief contact with the potential to motivate a quit attempt, to intensive support for smokers already engaged in quitting.

\section{Interventions for callers to quitlines}

This update continues to provide moderate-certainty evidence of a benefit from providing proactive telephone counselling for smokers who initiate contact with quitlines (Summary of findings for the main comparison), limited by unexplained statistical heterogeneity. Compared to smokers who have only a single contact with the quitline, and are either sent self-help materials or receive brief counselling, or both, those who are randomised to one or more additional calls increase their chances of quitting by between $20 \%$ and $60 \%$. This estimate remains almost unchanged after the inclusion of two new trials contributing over 2300 participants to this update.

In this update we conducted new post hoc subgroup analyses by counselling intensity. Even though the risk ratios increased from low-, to medium-, to high-intensity telephone counselling, the confidence intervals overlapped. Single estimates from included trials comparing higher versus lower number of calls were also inconclusive. Although in some trials many telephone counselling sessions were planned, the mean number of calls completed was often smaller. In Rabius 2007, the authors proposed that fewer shorter calls could be as effective as more and longer ones. They observed that "[t]he finding that different protocols generally yielded similar outcomes may be because they all contained the same basic elements and because those with five or more sessions had similar completion rates". If only a minority of participants are willing to accept all sessions, differences between more and less intensive protocols will have little impact.

Five further trials including callers to quitlines evaluated different telephone counselling interventions in comparisons that were too heterogeneous to be pooled. None of these studies showed an effect on quit rates except for one (Lindqvist 2013), in which motivational interviewing appeared to be more effective than standard telephone counselling; however, we judged this trial to be at high risk of bias.

\section{Offer of counselling through quitlines/helplines/hotlines}

Different types of interventions have been offered through quitlines, but their results are inconsistent, and relatively few studies contribute to each analysis in this group, leading to uncertainty. Two trials combined (Ossip-Klein 1991; Zwar 2015) suggest that provision of a quitline may be more effective than a minimal intervention, but another trial showed that a hotline and self-help materials may not be more effective in increasing quit rates than self-help materials alone (McFall 1993). Similarly, proactive and reactive telephone counselling appeared to increase quit rates compared to healthcare provider counselling (Joyce 2008; Rogers 2016; Sherman 2017; Skov-Ettrup 2016), but proactive counselling was not more effective than reactive counselling (Sherman 2017; Skov-Ettrup 2016), and there was no statistically significant effect when these studies compared proactive and reactive counselling to self-help materials.

\section{Interventions for people not calling quitlines}

Proactive telephone counselling may also be offered to people who have not contacted quitlines, but are being offered cessation support in other settings. These people may or may not be motivated to make a quit attempt when recruited. There is moderate-certainty evidence of benefit from telephone counselling under these conditions (Summary of findings 2). Estimates from pooling studies suggest a $15 \%$ to $35 \%$ increase in quitting. Based on a control group quit rate of $11 \%$, this is equivalent to an absolute increase of 2 to 4 percentage points. The certainty of the evidence was again limited by statistical heterogeneity, which was only partially explained by the baseline support offered.

In the subgroups by intervention intensity, confidence intervals overlapped for all three subgroups, but the effect was strongest in the medium-intensity group. The effect was small and the confidence interval did not exclude no effect when the intervention consisted of only one or two calls (low-intensity telephone counselling). This is consistent with findings from three trials that directly compared medium-intensity to low-intensity counselling, and found medium-intensity counselling to be more effective. No studies directly compared high intensity to medium or low intensity.

In univariate and multivariate meta-regression models there was no evidence of a linear trend between the total number of calls offered and the effectiveness of telephone counselling on quit rates. However, there was evidence that the baseline support offered to both intervention and control groups, and whether participants were selected for motivation to quit at the time of recruitment, may have had some influence on the effect size.

\section{Overall completeness and applicability of evidence}

A substantial number of randomised controlled trials have now tested the effect of offering telephone counselling to smokers not calling quitlines. However, rigorous evaluation of reactive services (quitlines, hotlines or helplines) has been difficult because of a reluctance to undertake randomised trials that would require callers who sought help to be refused support. This review restricted formal inclusion to randomised or quasi-randomised trials. Two trials provide evidence that hotlines are beneficial (Ossip-Klein 1991; Zwar 2015). In Ossip-Klein 1991 use of the hotline was relatively high: $36 \%$ of the intervention participants called the hotline for recorded messages of support, and $8.7 \%$ spoke to counsellors.

There is much more evidence about the benefit of proactive counselling once smokers have called a telephone-based service. One study was able to evaluate the impact of the counselling element of a helpline by capitalising on the constraints on capacity 
at certain times (Zhu 2002). In Sood 2009 the authors allocated callers to immediate reactive counselling, or self-help only. This study did not detect an effect of the counselling; the evidence of a relationship between the number of calls and the effect suggests that it may be important to engage callers into a multisession protocol as used by most quitlines, at least in North America (Cummins 2007).

A further issue with this evidence base is that the vast majority of studies were conducted in high-income countries. Only four out of the 104 studies were conducted in low- and middle-income countries, three of which we identified for this update. None of the studies was conducted in Latin America or Africa. Smoking rates and, accordingly, the burden of tobacco-related diseases are highest (and increasing) in lower- and middle-income countries.

A final consideration is that quitlines may exert an impact beyond that which can be measured by quit rates amongst callers. They may have a symbolic role, emphasising the importance of smoking cessation (Wakefield 2000), and may increase the number of smokers making a quit attempt each year because of awareness generated by the campaigns to promote them (Ossip-Klein 2003). Their availability may alter provider behaviour and encourage referral (Boldemann 2006). This is not something we could evaluate in this review.

\section{Certainty of evidence}

For the two main analyses presented in this review (studies of additional proactive calls offered to callers of quitlines, and studies of telephone counselling for people not calling quitlines) we judged results to be of moderate certainty (Summary of findings for the main comparison; Summary of findings 2), meaning that further research is likely to have an important impact on our confidence in the estimate of effect, and may change the estimate. Although both analyses contained a substantial number of randomised controlled trials, we downgraded our certainty in the effect estimate due to substantial unexplained statistical heterogeneity. It could be that the content of the calls contributed to the statistical heterogeneity but as we did not set out to evaluate programme content we are unable to investigate this here. This would be a useful topic for further research. An additional limitation of the evidence base is that we rated most of the included studies at unclear or high risk of bias; however, we did not downgrade on this basis, as results were not significantly different when we conducted sensitivity analyses removing those studies at high risk of bias.

\section{Potential biases in the review process}

As in standard Cochrane Tobacco Addiction Group methodology, estimates are based on treating all people lost to follow-up as continuing smokers. In this group of studies, loss to follow-up was relatively high. However, in a post hoc sensitivity analysis in the group of trials providing additional proactive telephone calls to people calling quitlines, excluding losses to follow-up from all conditions reduced the total numbers by about 35\% and increased the estimate of absolute effect, but only by a percentage point.

Another potential source of bias in this process is access to grey literature. Although we searched clinical trials registries, it is still possible that we did not identify some relevant unpublished data. Our concerns here are somewhat alleviated by the fact that funnel plots showed no evidence of asymmetry (Figure 5; Figure 6). 
Figure 5. Funnel plot of studies in Comparison 1: Interventions for callers to quitlines - effect of additional proactive calls.

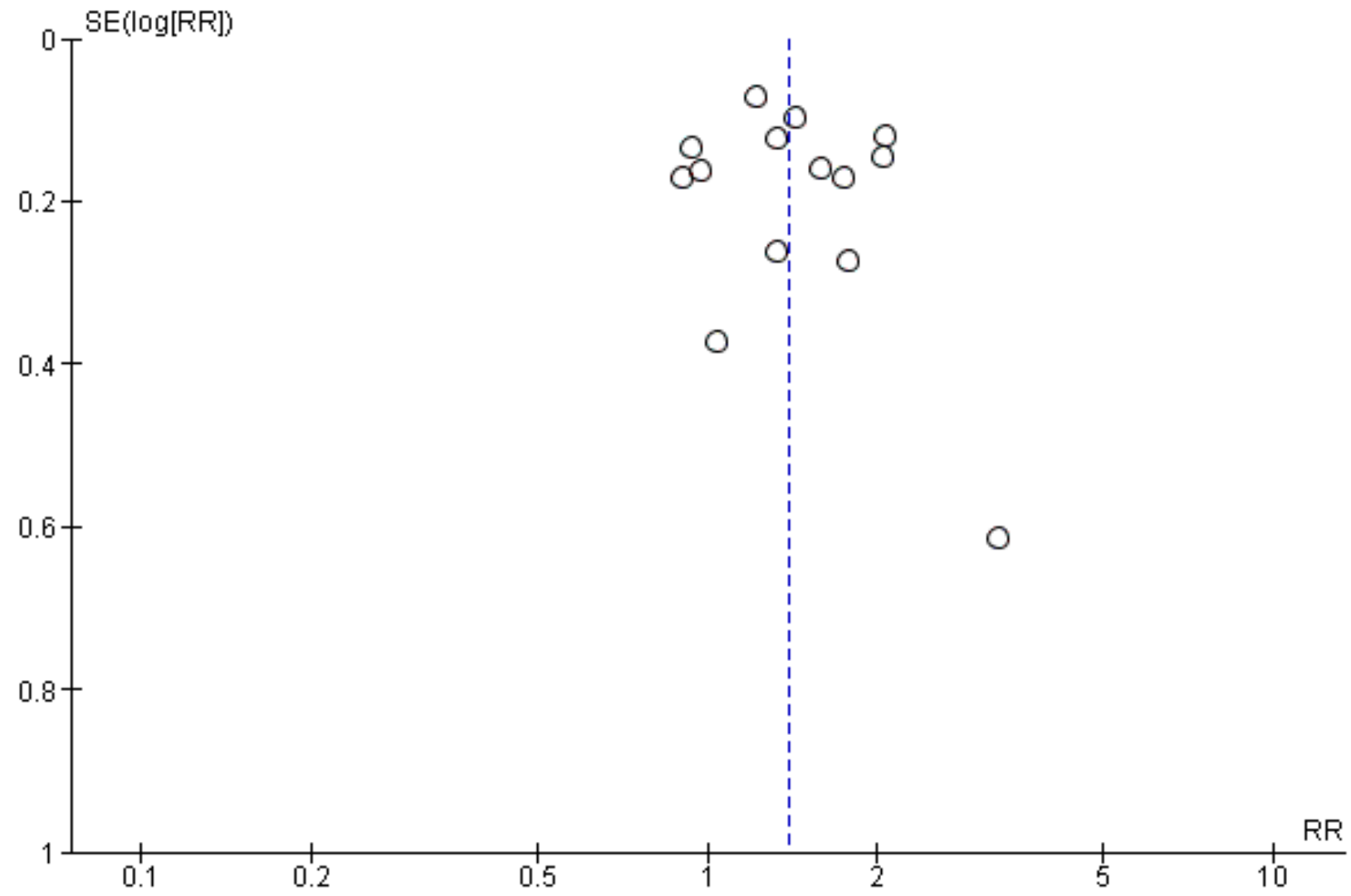


Figure 6. Funnel plot of studies in Comparison 6: Interventions for smokers not calling quitlines - subgroups by baseline support.

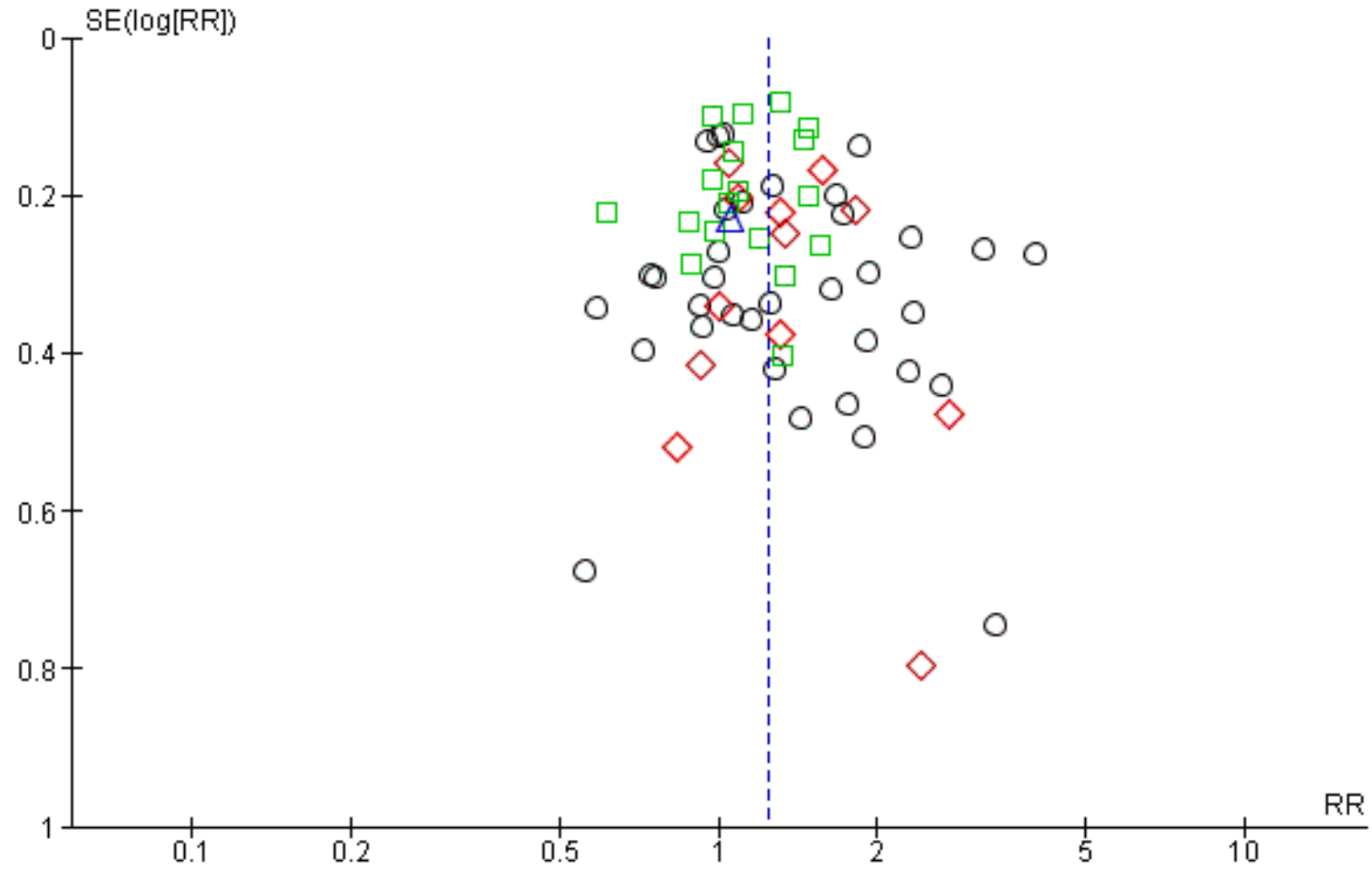

Subgroups

\section{Agreements and disagreements with other studies or reviews}

Our updated results suggest a more modest effect estimate for proactive telephone counselling than that estimated in the 2008 update of the US Clinical Practice Guideline Treating Tobacco Use and Dependence (Fiore 2008) (odds ratio (OR) 1.6, $95 \% \mathrm{Cl} 1.4$ to 1.8; table 6.16). This is probably due to the fact that our review covers a longer period and thus includes more trials with tighter confidence intervals. The guideline also identified a benefit of adding quitline counselling to pharmacotherapy (OR 1.3, 95\% Cl 1.1 to 1.6; table 6.17). Our subgroup analysis in Analysis 6.1.3 also suggests a smaller estimate.

A 2011 meta-analysis of proactive telephone counselling (Tzelepis 2011b) distinguished between trials that proactively recruited participants and those with reactive recruitment, showing benefits in each subgroup. The seven trials they classified as active recruitment (Aveyard 2003; Abdullah 2005; Curry 1995; Lichtenstein 2000; Lichtenstein 2008; McBride 1999a; Prochaska 2001) were all in our subgroup of studies that did not select participants on the basis of motivation to quit. We also found a benefit of intervention in this group. A recent systematic review (Schwindt 2018) evaluated tobacco quitlines for smoking cessation in people with mental illness, and also found promising results within these populations.
In North America a third of quitlines distribute free NRT (Cummins 2007). Evaluations suggest that this increases call volume, and pre-post comparisons also suggest that quit rates are increased (e.g. An 2006a; Bush 2008; Campbell 2008; Cummings 2006b; Davis 2013; Fellows 2007; Miller 2009; Tinkelman 2007; Zawertailo 2013). In our group of studies evaluating telephone counselling as an adjunct to pharmacotherapy, we found a small and statistically significant benefit of the intervention. These findings are consistent with the results of a separate Cochrane Review of behavioural interventions as adjuncts to pharmacotherapy (Stead 2015), which also found a relatively small although clinically important benefit from increasing the amount of behavioural support. Studies that offered pharmacotherapy, with or without behavioural support, to all participants and evaluated the additional effect of telephone counselling were eligible for inclusion in both reviews. That review found that in a post hoc subgroup of trials in which all contact was by telephone, there was a clearer benefit of the telephone counselling over and above the pharmacotherapy. In our review some trials provided both pharmacotherapy and face-toface support to all participants, and in these the addition of the telephone component did not show as strong an effect.

Telephone counselling may also have a role in increasing the appropriate use of pharmacotherapy. In a trial with one of the largest effects, the authors comment that the large effect observed 
may in part be attributable to the greater use of pharmacotherapy amongst those receiving counselling, even though NRT and bupropion were also available in the usual-care condition (An 2006). Increased use of pharmacotherapy was also noted in the intervention groups in Emmons 2005. A study of callers to the California Smokers' Helpline provides useful information about the acceptability of a telephone referral service as an adjunct to pharmacotherapy (Zhu 2000). Participants in this follow-up study all planned to use NRT and had a pre-quit counselling session. Those who chose to receive further counselling were more likely to attempt to quit, and to remain non-smokers for up to a year. Seventy-nine per cent of participants continued with counselling, and $26 \%$ of these stayed quit for a year. Of the $21 \%$ who had only a single session of counselling, $16 \%$ quit. More than half the smokers had called the helpline as a requirement for obtaining free NRT, and the high uptake of further behavioural support suggests that it was popular as an adjunct to pharmacotherapy. However a UK trial did not show a benefit of additional calls or of offering free NRT (Ferguson 2012).

Telephone-based support systems are increasingly well established as part of comprehensive tobacco treatment initiatives (Borland 2006; Lichtenstein 2007; McAfee 2007). The US Department of Health \& Human Services has introduced a single national quitline number, allowing access to the National Network of Tobacco Cessation Quitlines (Anon 2005). The North American Quitline Consortium promotes and supports evidence-based quitline services in the USA, Canada and Mexico. The European Network of Quitlines had 30 member quitlines in 2010. There is also a Global Quitline Network. The evaluation of systems that encourage and facilitate healthcare providers to refer people to specialist quitline services for extended support is an important area of research (Perry 2005; Sherman 2008; Winickoff 2006; Wolfenden 2008). Possible future developments include the use of direct mail or 'cold calling' to initiate contact with smokers (O'Connor 2008; Tzelepis 2011b; Van Deusen 2007; Vidrine 2011).

\section{AUTHORS' CONCLUSIONS}

\section{Implications for practice}

Proactive telephone counselling aids smokers who seek help from quitlines and smokers in other settings. The benefits of telephone counselling appear most pronounced when provided as an adjunct to print-based self-help materials, or brief face-toface advice, and less pronounced when provided as an adjunct to pharmacotherapy. There is not enough evidence to suggest that a higher number of calls would result in a larger effect, although limited evidence suggests interventions offering three to six calls may be more effective than those offering one call only. Evidence was inconclusive on the effect of reactive telephone counselling, due to a limited number studies, which reflects the difficulty of studying this intervention.

\section{Implications for research}

Further research directly comparing the provision of different numbers of telephone counselling calls would be useful, particularly as there is some evidence that suggests that higher numbers of calls may be more effective than a single call. Research on reactive helpline services that compare different counselling protocols and different schedules of call-back sessions may also lead to improved outcomes.

\section{ACK N OWLEDGEMENTS}

Elaine Harkness assisted with data extraction in the first version of this review. Hitomi Kobayashi translated a paper from Japanese. We would like to acknowledge the helpful suggestions of Ed Lichtenstein and Corinne Husten on both the original version of the review and the update in 2006. Additional data were provided by Vance Rabius and Jennifer McClure, and other authors confirmed or clarified data. Data from Flöter 2009 were extracted by Carole Clair.

We would like to thank Lindsay Stead and Tim Lancaster, who originally developed the protocol and were authors on previous versions of the review.

We would like to thank Rafael Perera who substantially contributed to previous versions of the review.

We would like to thank Jonathan Livingstone-Banks for conducting the literature search for this update and making revisions to the review text.

We would like to thank Thomas R. Fanshawe for checking the titles and abstracts to ensure we were not excluding any relevant studies at this stage.

We would like to thank Lee Bromhead and Sandra Wilcox for reviewing and providing feedback on the Plain Language Summary.

The work of JMOM was partly supported by the NIHR Biomedical Research Centre, Oxford and NIHR Community Healthcare Medtech and In Vitro Diagnostics Cooperative (MIC).

The work of WM was part of the University of Oxford Bachelor of Medicine Final Honours School (FHS) project supervised by JMOM.

This update was supported by the National Institute for Health Research (NIHR), via Cochrane Infrastructure and Cochrane Programme Grant funding to the Cochrane Tobacco Addiction Group. JHB is also part-funded by the NIHR Oxford Biomedical Research Centre (BRC). The views and opinions expressed therein are those of the authors and do not necessarily reflect those of the Systematic Reviews Programme, NIHR, NHS or the Department of Health and Social Care. 


\section{R E F E R E N C E S}

\section{References to studies included in this review}

Abdullah 2005 \{published data only\}

Abdullah AS, Lam TH, Mak YW, Loke AY. A randomized control trial of a smoking cessation intervention on parents of young children- a preliminary report (POS2-011). Society for Research on Nicotine and Tobacco 10th Annual Meeting 2004 February 18-21, Phoenix, Arizona. 2004

* Abdullah AS, Mak YW, Loke AY, Lam TH. Smoking cessation intervention in parents of young children: a randomised controlled trial. Addiction 2005;100(11):1731-40.

Mak YW, Loke AY, Lam TH, Abdullah AS. Predictors of the participation of smoking parents in a proactive telephonebased smoking cessation program. Addictive Behaviors 2006;31(10):1731-43.

\section{An 2006 \{published data only\}}

An LC, Partin M, Zhu SH, Arikian NJ, Nelson DB, Nugent SM, et al. Delivery of bupropion SR as part of a telephone counseling intervention for veteran smokers (POS1-040). Society for Research on Nicotine and Tobacco 10th Annual Meeting 2005 February 18-21, Phoenix, Arizona. 2004

* An LC, Zhu S-H, Nelson DB, Arikian NJ, Nugent S, Partin MR, et al. Benefits of telephone care over primary care for smoking cessation. Archives of Internal Medicine 2006;166(5):536-42.

An LC, Zhu SH, Arikian NJ, Nelson DB, Nugent SM, Partin M, et al. Telestop: a randomized trial of increased access to behavioral and pharmacological therapy for smoking cessation (abstract). Nicotine \& Tobacco Research 2005;7(4):689.

Smith M, Fu S, Nugent S, Nelson D, Joseph A, An L. A costeffective telehealth intervention for smoking cessation. Journal of General Internal Medicine 2010;25(Suppl 3):S208.

Smith MW, An LC, Fu SS, Nelson DB, Joseph AM. Costeffectiveness of an intensive telephone-based intervention for smoking cessation. Journal of Telemedicine and Telecare. England, 2011; Vol. 17, issue 8:437-40. [; 4]

\section{Aveyard 2003 \{published data only\}}

Aveyard P, Griffin C, Lawrence T, Cheng KK. A controlled trial of an expert system and self-help manual intervention based on the stages of change versus standard self-help materials in smoking cessation. Addiction 2003;98(3):345-54.

\section{Bastian 2012 \{published data only\}}

Bastian LA, Fish LJ, Gierisch JM, Rohrer L, Stechuchak KM, Grambow SC. Comparative effectiveness trial of familysupported smoking cessation intervention versus standard telephone counseling for chronically ill veterans using proactive recruitment. Comparative Effectiveness Research 2012;2:45-46.

\section{Bastian 2013 \{published data only\}}

Bastian LA, Fish LJ, Peterson BL, Biddle AK, Garst J, Lyna P, et al. Assessment of the impact of adjunctive proactive telephone counseling to promote smoking cessation among lung cancer patients' social networks. American Journal of Health Promotion 2013;27(3):181-90.

\section{Blebil 2014 \{published data only\}}

Blebil AQ, Sulaiman SA, Hassali MA, Dujaili JA, Zin AM. Impact of additional counselling sessions through phone calls on smoking cessation outcomes among smokers in Penang State, Malaysia. BMC Public Health 2014;14:460.

\section{Borland 2001 \{published data only\}}

Borland R, Segan CJ, Livingston PM, Owen N. The effectiveness of callback counselling for smoking cessation: a randomized trial. Addiction 2001;96(6):881-9.

\section{Borland 2003 \{published data only\}}

Balmford J, Borland R, Burney S. The role of prior quitting experience in the prediction of smoking cessation. Psychology \& Health 2010;25(8):911-24.

* Borland R, Balmford J, Segan C, Livingston P, Owen N. The effectiveness of personalized smoking cessation strategies for callers to a Quitline service. Addiction 2003;98(6):837-46.

\section{Borland 2008 \{published data only\}}

* Borland R, Balmford J, Bishop N, Segan C, Piterman L, McKayBrown $L$, et al. In-practice management versus quitline referral for enhancing smoking cessation in general practice: A cluster randomized trial. Family Practice 2008;25(5):382-9.

McKay-Brown L, Borland R, Balmford J, Segan CJ, Andrews C, Tasker $C$, et al. The challenges of recruiting and retaining GPs in research: Findings from a smoking cessation project. Australian Journal of Primary Health 2007;13(1):61-7.

Boyle 2007 \{published data only\}

Boyle RG, Solberg LI, Asche SE, Boucher JL, Pronk NP, Jensen CJ. Offering telephone counseling to smokers using pharmacotherapy. Nicotine \& Tobacco Research 2005;7 Suppl 1:S19-27.

* Boyle RG, Solberg LI, Asche SE, Maciosek MV, Boucher JL, Pronk NP. Proactive recruitment of health plan smokers into telephone counseling. Nicotine \& Tobacco Research 2007;9(5):581-9.

Bricker 2014 \{published data only\}

* Bricker JB, Bush T, Zbikowski SM, Mercer LD, Heffner JL. Randomized trial of telephone-delivered acceptance and commitment therapy versus cognitive behavioral therapy for smoking cessation: a pilot study.. Nicotine \& Tobacco Research 2014;16(11):1446-54.

Heffner JL, Mull K, Mercer L, Vilardaga R, Bricker J. Effects of two telephone-delivered smoking cessation interventions on hazardous drinking rates: ACT vs. CBT. Alcoholism, Clinical and Experimental Research 2014;38(Suppl. S1):137A.

Vilardaga R, Heffner JL, Mercer LD, Bricker JB. Do counselor techniques predict quitting during smoking cessation treatment? A component analysis of telephone-delivered 
Acceptance and Commitment Therapy. Behaviour Research and Therapy 2014;61:89-95.

\section{Brown 1992 \{published data only\}}

Brown S, Hunt G, Owen N. The effect of adding telephone contact to self-instructional smoking-cessation materials. Behavior Change 1992;9:216-22.

\section{Brunette 2017 \{published data only\}}

Brunette MF, Pratt SI, Bartels SJ, Scherer EA, Sigmon SC, Ferron JC, et al. Randomized trial of interventions for smoking cessation among medicaid beneficiaries with mental illness. Psychiatric Services (Washington, D.C.) 2017;69(3):appips201700245.

\section{Chan 2015 \{published data only\}}

Chan SS, Wong DC, Cheung YT, Leung DY, Lau L, Lai V, et al. A block randomized controlled trial of a brief smoking cessation counselling and advice through short message service on participants who joined the Quit to Win Contest in Hong Kong. Health Education Research 2015;30(4):609-21.

\section{Chouinard 2005 \{published data only\}}

Chouinard MC, Robichaud-Ekstrand S. The effectiveness of a nursing inpatient smoking cessation program in individuals with cardiovascular disease. Nursing Research 2005;54(4):243-54.

\section{Collins 2018 \{published data only\}}

Collins BN, Lepore SJ, Winickoff JP, Nair US, Moughan B, BryantStephens T, et al. An office-initiated multilevel intervention for tobacco smoke exposure: a randomized trial. Pediatrics 2018;141(Suppl 1):S75-S86.

Lepore SJ, Winickoff JP, Moughan B, Bryant-Stephens TC, Taylor DR, Fleece D, et al. Kids Safe and Smokefree (KiSS): a randomized controlled trial of a multilevel intervention to reduce secondhand tobacco smoke exposure in children. BMC Public Health 2013;13:792.

\section{Cossette 2011 \{published data only\}}

Cossette S, Frasure-Smith N, Robert M, Chouinard MC, Juneau M, Guertin MC, et al. A pre-assessment for nursing intervention to support tobacco cessation in patients hospitalized for cardiac problems: a pilot study (So-Live) [Évaluation préliminaire d'une intervention infirmière de soutien à la cessation tabagique chez des patients hospitalisés pour un problème cardiaque : étude pilote (So-Live)]. Recherche En Soins Infirmiers 2011;June(105):60-75.

\section{Cummins 2016a \{published data only\}}

Cummins S, Zhu SH, Gamst A, Kirby C, Brandstein K, KlonoffCohen $\mathrm{H}$, et al. Nicotine patches and quitline counseling to help hospitalized smokers stay quit: study protocol for a randomized controlled trial. Trials 2012;13:128.

* Cummins SE, Gamst AC, Brandstein K, Seymann GB, KlonoffCohen $\mathrm{H}$, Kirby $\mathrm{CA}$, et al. Helping hospitalized smokers: a factorial RCT of nicotine patches and counseling. American Journal of Preventive Medicine 2016;51(4):578-86.
Cummins 2016b \{published data only\}

* Cummins SE, Tedeschi GJ, Anderson CM, Zhu SH. Telephone intervention for pregnant smokers: a randomized controlled trial. American Journal of Preventive Medicine 2016;51(3):318-26.

Zhu SH, Cummins S, Anderson C, Tedeschi G, Rosbrook B, Gutierrez-Terrell E. Telephone intervention for pregnant smokers: a randomized trial (abstract). Nicotine \& Tobacco Research 2004;6(4):740-1.

Curry 1995 \{published data only\}

Britt J, Curry SJ, McBride C, Grothaus LC, Louie D. Implementation and acceptance of outreach telephone counseling for smoking cessation with nonvolunteer smokers. Health Education Quarterly 1994;21(1):55-68.

* Curry SJ, McBride C, Grothaus LC, Louie D, Wagner EH. A randomized trial of self-help materials, personalized feedback, and telephone counselling with nonvolunteer smokers. Journal of Consulting and Clinical Psychology 1995;63(6):1005-14.

\section{Duffy 2006 \{published data only\}}

Duffy SA, Ronis DL, Valenstein M, Lambert MT, Fowler KE, Gregory L, et al. A tailored smoking, alcohol, and depression intervention for head and neck cancer patients. Cancer Epidemiology, Biomarkers \& Prevention 2006;15(11):2203-8.

\section{Ebbert 2007 \{published data only\}}

Ebbert JO, Carr AB, Patten CA, Morris RA, Schroeder DR. Tobacco use quitline enrollment through dental practices: a pilot study. Journal of the American Dental Association 2007;138(5):595-601.

\section{Ellerbeck 2009 \{published data only\}}

Cox LS, Cupertino AP, Mussulman LM, Nazir N, Greiner KA, Mahnken JD, et al. Design and baseline characteristics from the KAN-QUIT disease management intervention for rural smokers in primary care. Preventive Medicine 2008;47(2):200-5.

Cupertino AP, Mahnken JD, Richter K, Cox LS, Casey G, Resnicow $\mathrm{K}$, et al. Long-term engagement in smoking cessation counseling among rural smokers. Journal of Health Care for the Poor and Underserved 2007;18(4 Suppl):39-51.

* Ellerbeck EF, Mahnken JD, Cupertino AP, Cox LS, Greiner KA, Mussulman LM, et al. Effect of varying levels of disease management on smoking cessation: a randomized trial.[see comment]. Annals of Internal Medicine 2009;150(7):437-46.

Emmons 2005 \{published data only\}

Emmons KM, Puleo E, Mertens A, Gritz ER, Diller L, Li FP. Longterm smoking cessation outcomes among childhood cancer survivors in the Partnership for Health study. Journal of Clinical Oncology 2009;27(1):52-60.

* Emmons KM, Puleo E, Park E, Gritz ER, Butterfield RM, Weeks JC, et al. Peer-delivered smoking counseling for childhood cancer survivors increases rate of cessation: The Partnership for Health Study. Journal of Clinical Oncology 2005;23(27):6516-23. 
Park ER, Puleo E, Butterfield RM, Zorn M, Mertens AC, Gritz ER, et al. A process evaluation of a telephone-based peer-delivered smoking cessation intervention for adult survivors of childhood cancer: The Partnership for Health study. Preventive Medicine 2006;42(6):435-42.

\section{Ferguson 2012 \{published data only\}}

Coleman T, McEwen A, Bauld L, Ferguson J, Lorgelly P, Lewis S. Protocol for the Proactive Or Reactive Telephone Smoking CeSsation Support (PORTSSS) trial. Trials [Electronic Resource] 2009;10:26.

* Ferguson J, Docherty G, Bauld L, Lewis S, Lorgelly P, Boyd KA, et al. Effect of offering different levels of support and free nicotine replacement therapy via an English national telephone quitline: randomised controlled trial. BMJ March 2012;344:e1696. [DOI: 10.1136/bmj.e1696]

Taggar JS, Lewis S, Docherty G, Bauld L, McEwen A, Coleman T. Do cravings predict smoking cessation in smokers calling a national quit line: secondary analyses from a randomised trial for the utility of 'urges to smoke' measures. Substance Abuse Treatment, Prevention, and Policy 2015;10:15.

\section{Fiore 2004 \{published data only\}}

Fiore MC, McCarthy DE, Jackson TC, Zehner ME, Jorenby DE, Mielke $\mathrm{M}$, et al. Integrating smoking cessation treatment into primary care: An effectiveness study. Preventive Medicine 2004;38(4):412-20.

\section{Flöter 2009 \{published data only\}}

Flöter S, Kröger C. Effectiveness of telephone aftercare following a smoking cessation program for women on inpatient rehabilitation. Deutsche Medizinische Wochenschrift 2009;134(47):2382-7.

\section{Fraser 2014 \{published data only\}}

Fraser D, Kobinsky K, Smith SS, Kramer J, Theobald WE, Baker TB. Five population-based interventions for smoking cessation: a MOST trial. Translational Behavioral Medicine 2014;4(4):382-90.

\section{Gilbert 2006 \{published data only\}}

Gilbert H, Sutton S. Does adding tailored feedback to telephone counselling improve quit rates? (POS1-033). Society for Research on Nicotine and Tobacco 10th Annual Meeting 2004 February 18-21, Phoenix, Arizona. 2004.

* Gilbert H, Sutton S. Evaluating the effectiveness of proactive telephone counselling for smoking cessation in a randomized controlled trial. Addiction 2006;101(4):590-8.

\section{Girgis 2011 \{published data only\}}

Girgis S, Adily A, Velasco MJ, Zwar NA, Jalaludin BB, Ward JE. Feasibility, acceptability and impact of a telephone support service initiated in primary medical care to help Arabic smokers quit. Australian Journal of Primary Health 2011;17(3):274-81.

\section{Graham 2011 \{published data only\}}

Cobb CO, Niaura RS, Donaldson EA, Graham AL. Quit now? Quit soon? Quit when you're ready? Insights about target quit dates for smoking cessation from an online quit date tool. Journal of Medical Internet Research 2014;16(2):e55.

Cobb CO, Graham AL. Use of non-assigned interventions in a randomized trial of internet and telephone treatment for smoking cessation. Nicotine \& Tobacco Research 2014;16(10):1289-97.

Graham AL. A randomized trial of internet and telephone treatment for smoking cessation. Archives of Internal Medicine 2011;171(5):395.

Graham AL, Chang Y, Fang Y, Cobb NK, Tinkelman DS, Niaura RS, et al. Cost-effectiveness of internet and telephone treatment for smoking cessation: an economic evaluation of The iQUITT Study. Tobacco Control 2013;22(6):e11.

* Graham AL, Cobb NK, Papandonatos GD, Moreno JL, Kang $\mathrm{H}$, Tinkelman DG, et al. A randomized trial of internet and telephone treatment for smoking cessation. [Erratum in Arch Intern Med. 2011 Mar 14;171(5):395]. Archives of Internal Medicine 2011;171(1):46-53.

Graham AL, Papandonatos GD. Reliability of internet- versus telephone-administered questionnaires in a diverse sample of smokers. Journal of Medical Internet Research 2008; Vol. 10, issue 1:e8. []

Graham AL, Papandonatos GD, Cobb CO, Cobb NK, Niaura RS, Abrams DB, et al. Internet and telephone treatment for smoking cessation: mediators and moderators of short-term abstinence. Nicotine \& Tobacco Research 2015;17(3):299-308.

Graham AL, Papandonatos GD, Kang H, Moreno JL, Abrams DB. Development and validation of the online social support for smokers scale. Journal of Medical Internet Research 2011;13(3):427-39.

Graham AL, Stanton CA, Papandonatos GD, Erar B. Use of an online smoking cessation community promotes abstinence: results of propensity score weighting. Health Psychology 2015;34S:1286-95.

Papandonatos GD, Erar B, Stanton CA, Graham AL. Online community use predicts abstinence in combined internet/ phone intervention for smoking cessation. Journal of Consulting and Clinical Psychology 2016;84(7):633-44.

Rigotti NA. Integrating comprehensive tobacco treatment into the evolving US health care system: it's time to act: comment on "A randomized trial of Internet and telephone treatment for smoking cessation". Archives of Internal Medicine 2011; Vol. 171, issue 1:53-5. []

\section{Halpin 2006 \{published data only\}}

Halpin HA, McMenamin S, Rideout J, Boyce-Smith G. The effectiveness and costs of different benefit designs for treating tobacco dependence. Results from a randomized trial. Nicotine \& Tobacco Research 2005;7(4):681-2.

* Halpin HA, McMenamin SB, Rideout J, Boyce-Smith G. The costs and effectiveness of different benefit designs for treating tobacco dependence: results from a randomized trial. Inquiry 2006;43(1):54-65. 


\section{Hanssen 2009 \{published data only\}}

* Hanssen TA, Nordrehaug JE, Eide GE, Hanestad BR. Does a telephone follow-up intervention for patients discharged with acute myocardial infarction have long-term effects on healthrelated quality of life? A randomised controlled trial. Journal of Clinical Nursing 2009;18(9):1334-45.

Hanssen TA, Nordrehaug JE, Eide GE, Hanestad BR. Improving outcomes after myocardial infarction: a randomized controlled trial evaluating effects of a telephone follow-up intervention. European Journal of Cardiovascular Prevention \& Rehabilitation 2007;14(3):429-37.

\section{Hollis 2007 \{published and unpublished data\}}

Hollis J, Fellows J, Aickin M, Riedlinger K, McAfee T, Zbikowski S, et al. Efficacy of six state-level tobacco quitline interventions (POS1-023). Society for Research on Nicotine and Tobacco 10th Annual Meeting 2004 February 18-21, Phoenix, Arizona. 2004.

Hollis J, McAfee T, Stark M, Fellows J, Zbikowski S, Riedlinger K. One-year outcomes for six Oregon tobacco Quitline interventions. Annals of Behavioral Medicine 2005;29 Suppl:S056.

* Hollis JF, McAfee TA, Fellows JL, Zbikowski SM, Stark M, Riedlinger $\mathrm{K}$. The effectiveness and cost effectiveness of telephone counselling and the nicotine patch in a state tobacco quitline. Tobacco Control 2007;16 Suppl 1:i53-9.

\section{Holmes-Rovner 2008 \{published data only\}}

* Holmes-Rovner M, Stommel M, Corser WD, Olomu A, Holtrop JS, Siddiqi A, et al. Does outpatient telephone coaching add to hospital quality improvement following hospitalization for acute coronary syndrome?. Journal of General Internal Medicine 2008;23(9):1464-70.

Holtrop JS, Stommel M, Corser WD, Holmes-Rovner M. Predictors of smoking cessation and relapse after hospitalization for acute coronary syndrome. Journal of Hospital Medicine 2009;4(3):e3-9.

\section{Hughes 2010 \{published data only\}}

Hughes JR, Solomon LJ, Livingston AE, Callas PW, Peters EN. A randomized, controlled trial of NRT-aided gradual vs. abrupt cessation in smokers actively trying to quit. Drug and Alcohol Dependence 2010;111(1-2):105-13..

\section{Joyce 2008 \{published data only\}}

* Joyce GF, Niaura R, Maglione M, Mongoven J, Larson-Rotter C, Coan J, et al. The effectiveness of covering smoking cessation services for medicare beneficiaries. Health Services Research 2008;43(6):2106-23

Niaura R, Joyce G, Maglione M, Morton S, Coan J, Lapin P, et al. Helping older smokers quit: The Medicare Stop Smoking Program (PA11-6). Society for Research on Nicotine and Tobacco 12th Annual Meeting 2006 February 15-18, Orlando, Florida. 2006.

\section{Klemperer 2017 \{published data only\}}

Klemperer EM, Hughes J. Does perception of treatment predict outcome in interventions for smokers who are not ready to quit?. Drug and Alcohol Dependence 2015;156:e114.

Klemperer EM, Hughes J. Reduction in cigarettes per day prospectively predicts quit attempts and cessation in smokers who are not ready to quit.. Drug and Alcohol Dependence. Conference: 2016 Annual Meeting of the College on Problems of Drug Dependence, CPDD 2016. United States CNO CN-01423239. 2017; Vol. 171:e107.

Klemperer EM, Hughes JR, Callas PW, Solomon LJ. A mediation analysis of motivational, reduction, and usual care interventions for smokers who are not ready to quit. Nicotine \& Tobacco Research 2017;19(8):916-21.

Klemperer EM, Hughes JR, Callas PW, Solomon LJ. Working alliance and empathy as mediators of brief telephone counseling for cigarette smokers who are not ready to quit. Psychology of Addictive Behaviors 2017;31(1):130-5.

* Klemperer EM, Hughes JR, Solomon LJ, Callas PW, Fingar JR. Motivational, reduction and usual care interventions for smokers who are not ready to quit: a randomized controlled trial. Addiction (Abingdon, England) 2017;112(1):146-55.

\section{Lando 1992 \{published data only\}}

Lando HA, Hellerstedt WL, Pirie PL, McGovern PG. Brief supportive telephone outreach as a recruitment and intervention strategy for smoking cessation. American Journal of Public Health 1992;82(1):41-6.

\section{Lando 1997 \{published data only\}}

* Lando HA, Rolnick S, Klevan D, Roski J, Cherney L, Lauger G. Telephone support as an adjunct to transdermal nicotine in smoking cessation. American Journal of Public Health 1997;87(10):1670-4.

Rolnick SJ, Klevan D, Cherney L, Lando HA. Nicotine replacement therapy in a group model HMO. HMO Practice 1997;11(1):34-7.

\section{Lichtenstein 2000 \{published data only\}}

Lee ME, Lichtenstein E, Andrews JA, Glasgow RE, Hampson SE. Radon-smoking synergy: A population-based behavioral risk reduction approach. Preventive Medicine 1999;29(3):222-7.

* Lichtenstein E, Andrews JA, Lee ME, Glasgow RE, Hampson SE. Using radon risk to motivate smoking reduction: evaluation of written materials and brief telephone counselling. Tobacco Control 2000;9(3):320-6.

\section{Lichtenstein 2008 \{published data only\}}

Hampson SE, Andrews JA, Barckley M, Lichtenstein E, Lee ME. Personality traits, perceived risk, and risk-reduction behaviors: A further study of smoking and radon. Health Psychology 2006;25(4):530-6.

* Lichtenstein E, Boles SM, Lee ME, Hampson SE, Glasgow RE, Fellows J. Using radon risk to motivate smoking reduction II: randomized evaluation of brief telephone counseling and a targeted video. Health Education Research 2008;23(2):191-201. 
Lindqvist 2013 \{published data only\}

Lindqvist H, Forsberg LG, Forsberg L, Rosendahl I, Enebrink P, Helgason AR. Motivational interviewing in an ordinary clinical setting: a controlled clinical trial at the Swedish National Tobacco Quitline. Addictive Behaviors 2013;38(7):2321-4.

\section{Lipkus 1999 \{published data only\}}

Lipkus IM, Lyna PR, Rimer BK. Using tailored interventions to enhance smoking cessation among African-Americans at a community health center. Nicotine \& Tobacco Research 1999;1(1):77-85.

\section{Lipkus 2004 \{published data only\}}

Lipkus IM, McBride CM, Pollak KI, Schwartz-Bloom RD, Tilson E, Bloom PN. A randomized trial comparing the effects of self-help materials and proactive telephone counseling on teen smoking cessation. Health Psychology 2004;23(4):397-406.

\section{MacLeod 2003 \{published data only\}}

Macleod ZR, Charles MA, Arnaldi VC, Adams IM. Telephone counselling as an adjunct to nicotine patches in smoking cessation: a randomised controlled trial. Medical Journal of Australia 2003;179(7):349-52.

\section{McBride 1999a \{published data only\}}

McBride CM, Scholes D, Grothaus LC, Curry SJ, Ludman E, Albright J. Evaluation of a minimal self-help smoking cessation intervention following cervical cancer screening. Preventive Medicine 1999;29(2):133-8.

\section{McBride 1999b \{published data only\}}

Lando HA, Valanis BG, Lichtenstein E, Curry SJ, McBride CM, Pirie PL, et al. Promoting smoking abstinence in pregnant and postpartum patients: a comparison of 2 approaches. American Journal of Managed Care 2001;7(7):685-93.

* McBride CM, Curry SJ, Lando HA, Pirie PL, Grothaus LC, Nelson JC. Prevention of relapse in women who quit smoking during pregnancy. American Journal of Public Health 1999;89(5):706-11.

\section{McBride 2004 \{published data only\}}

McBride CM, Baucom DH, Peterson BL, Pollak KI, Palmer C, Westman E, et al. Prenatal and postpartum smoking abstinence - A partner-assisted approach. American Journal of Preventive Medicine 2004;27(3):232-8.

\section{McClure 2005 \{published data only\}}

McClure J, Wetter D, Curry SJ. Acceptability of proactive contact and counseling among female smokers. Nicotine \& Tobacco Research 2004;6(4):722.

* McClure JB, Westbrook E, Curry SJ, Wetter DW. Proactive, motivationally enhanced smoking cessation counseling among women with elevated cervical cancer risk. Nicotine \& Tobacco Research 2005;7(6):881-9.

\section{McClure 2011 \{published data only\}}

McClure JB, Catz SL, Ludman EJ, Richards J, Riggs K, Grothaus L. Feasibility and acceptability of a multiple risk factor intervention: the Step Up randomized pilot trial. BMC Public Health 2011;11:167.

McFall 1993 \{published data only\}

McFall SL, Michener A, Rubin D, Flay BR, Mermelstein RJ, Burton $D$, et al. The effects and use of maintenance newsletters in a smoking cessation intervention. Addictive Behaviors 1993;18(2):151-8.

Metz 2007 \{published data only\}

Flöter S, Metz K, Kroeger C, Donath C, Piontek D, Gradi S. Evaluation of telephone booster sessions after intensive inpatient treatment - a randomized treatment control trial (POS1-78). Society for Research on Nicotine and Tobacco 12th Annual Meeting 2006 February 15-18, Orlando, Florida. 2006.

* Metz K, Flöter S, Kroger C, Donath C, Piontek D, Gradl S. Telephone booster sessions for optimizing smoking cessation for patients in rehabilitation centers. Nicotine \& Tobacco Research 2007;9(8):853-63.

Metz K, Kroeger C, Schuetz C, Flöter S, Donath C. Which smoking cessation intervention works for smokers with an alcohol addiction?. 68th Annual Scientific Meeting of the College on Problems of Drug Dependence. 2006.

Miguez 2002 \{published data only\}

Miguez MC, Becoña E. Abstinence from smoking ten years after participation in a randomized controlled trial of a self-help program. Addictive Behaviors 2008;33(10):1369-74.

* Miguez MC, Vázquez FL, Becoña E. Effectiveness of telephone contact as an adjunct to a self-help program for smoking cessation: a randomized controlled trial in Spanish smokers. Addictive Behaviors 2002;27(1):139-44.

Miguez 2008 \{published data only\}

Miguez MC, Becoña E. Evaluating the effectiveness of a single telephone contact as an adjunct to a self-help intervention for smoking cessation in a randomized controlled trial. Nicotine \& Tobacco Research 2008;10(1):129-35.

Miller 1997 \{published data only\}

Miller NH, Smith PM, DeBusk RF, Sobel DS, Taylor CB. Smoking cessation in hospitalized patients - Results of a randomized trial. Archives of Internal Medicine 1997;157(4):409-15.

\section{NCT00534404 \{published data only\}}

NCT00534404. iQuit Smoking: a randomized trial of internet access to nicotine patches. clinicaltrials.gov/show/ NCT00534404 (first received 24 September 2007).

Nohlert 2014 \{published data only\}

* Nohlert E, Öhrvik J, Helgason ÁR. Effectiveness of proactive and reactive services at the Swedish National Tobacco Quitline in a randomized trial. Tobacco Induced Diseases 2014;12(1):9.

Nohlert E, Öhrvik J, Helgason ÁR. Non-responders in a quitline evaluation are more likely to be smokers - a drop-out and longterm follow-up study of the Swedish National Tobacco Quitline. Tobacco Induced Diseases 2016;14:5. 


\section{Ockene 1991 \{published data only\}}

* Ockene JK, Kristeller J, Goldberg R, Amick TL, Pekow PS, Hosmer D, et al. Increasing the efficacy of physician-delivered smoking interventions: a randomized clinical trial. Journal of General Internal Medicine 1991;6(1):1-8.

Ockene JK, Kristeller J, Pbert L, Hebert JR, Luippold R, Goldberg RJ, et al. The physician-delivered smoking intervention project: can short-term interventions produce long-term effects for a general outpatient population?. Health Psychology 1994;13(3):278-81.

\section{Orleans 1991 \{published data only\}}

* Orleans CT, Schoenbach VJ, Wagner EH, Quade D, Salmon MA, Pearson DC, et al. Self-help quit smoking interventions: effects of self-help materials, social support instructions, and telephone counseling. Journal of Consulting and Clinical Psychology 1991;59(3):439-48.

Schoenbach VJ, Orleans CT, Wagner EH, Quade D, Salmon MAP, Porter CQ. Characteristics of smokers who enroll and quit in self-help programs. Health Education Research 1992;7:369-80.

\section{Orleans 1998 \{published data only\}}

Orleans CT, Boyd NR, Bingler R, Sutton C, Fairclough D, Heller D, et al. A self-help intervention for African American smokers: tailoring cancer information service counseling for a special population. Preventive Medicine 1998;27(5):S61-S70.

\section{Osinubi 2003 \{published data only\}}

Osinubi OY, Moline J, Rovner E, Sinha S, Perez-Lugo M, Demissie K, et al. A pilot study of telephone-based smoking cessation intervention in asbestos workers. Journal of Occupational and Environmental Medicine 2003;45(5):569-74.

Ossip-Klein 1991 \{published data only\}

Ossip Klein DJ, Giovino GA, Megahed N, Black PM, Emont SL, Stiggins J, et al. Effects of a smoker's hotline: results of a 10-county self-help trial. Journal of Consulting and Clinical Psychology 1991;59(2):325-32.

\section{Ossip-Klein 1997 \{published data only\}}

Ossip Klein DJ, Carosella AM, Krusch DA. Self-help interventions for older smokers. Tobacco Control 1997;6(3):188-93.

\section{Peterson 2016 \{published data only\}}

Heffner JL, Kealey KA, Marek PM, Bricker JB, Ludman EJ, Peterson AV Jr. Proactive telephone counseling for adolescent smokers: comparing regular smokers with infrequent and occasional smokers on treatment receptivity, engagement, and outcomes. Drug and Alcohol Dependence 2016;165:229-235.

Liu J, Peterson AV, Kealey KA, Mann SL, Bricker JB, Marek PM. Addressing challenges in adolescent smoking cessation: design and baseline characteristics of the HS group-randomized trial. Preventive Medicine 2007;45(2-3):215-25.

* Peterson AV Jr, Marek PM, Kealey KA, Bricker JB, Ludman EJ, Heffner JL. Does effectiveness of adolescent smokingcessation intervention endure into young adulthood? 7-year follow-up results from a group-randomized trial. PloS One 2016;11(2):e0146459.

\section{Piper 2016 \{published data only\}}

Baker TB, Collins LM, Mermelstein R, Piper ME, Schlam TR, Cook JW, et al. Enhancing the effectiveness of smoking treatment research: conceptual bases and progress. Addiction 2016;111(1):107-16.

Piper ME, Cook JW, Schlam TR, Smith SS, Bolt DM, Collins LM, et al. Toward precision smoking cessation treatment II: proximal effects of smoking cessation intervention components on putative mechanisms of action. Drug and Alcohol Dependence 2017;171:50-8.

* Piper ME, Fiore MC, Smith SS, Fraser D, Bolt DM, Collins LM, et al. Identifying effective intervention components for smoking cessation: a factorial screening experiment. Addiction 2016;111(1):129-41.

Piper ME, Schlam TR, Cook JW, Smith SS, Bolt DM, Loh WY, et al. Toward precision smoking cessation treatment l: moderator results from a factorial experiment. Drug and Alcohol Dependence 2017;171:59-65.

Schlam TR, Fiore MC, Smith SS, Fraser D, Bolt DM, Collins LM, et al. Comparative effectiveness of intervention components for producing long-term abstinence from smoking: a factorial screening experiment. Addiction 2016;111(1):142-55.

Prochaska 1993 \{published and unpublished data\} Prochaska JO, Di Clemente CC, Velicer WF, Rossi JS. Standardized, individualized, interactive, and personalized self-help programs for smoking cessation. Health Psychology 1993;12(5):399-405.

\section{Prochaska 2001 \{published data only\}}

Prochaska JO, Velicer WF, Fava JL, Ruggiero L, Laforge RG, Rossi JS, et al. Counselor and stimulus control enhancements of a stage-matched expert system intervention for smokers in a managed care setting. Preventive Medicine 2001;32(1):23-32.

\section{Rabius 2004 \{published data only\}}

McAlister AL, Rabius V, Geiger A, Glynn TJ, Huang P, Todd R. Telephone assistance for smoking cessation: one year cost effectiveness estimations. Tobacco Control 2004;13(1):85-6.

* Rabius V, McAlister AL, Geiger A, Huang P, Todd R. Telephone counseling increases cessation rates among young adult smokers. Health Psychology 2004;23(5):539-41.

\section{Rabius 2007 \{published data only\}}

Rabius V, Pike J, Geiger AT, McAlister AL. Telephone counseling for smoking cessation; effects of number and duration of counseling sessions and NRT use (PA2-3). Society for Research on Nicotine and Tobacco 10th Annual Meeting 2004 February 18-21, Phoenix, Arizona. 2004.

Rabius V, Pike J, Hunter J, Wiatrek D, McAlister A. Optimizing telephone counseling for smoking cessation: Six-month effects of varying the number and duration of counseling sessions. American Association for Cancer Research. Frontiers in Cancer Prevention Research. 2006 November 12-15, Boston, MA. 2006. 
* Rabius V, Pike KJ, Hunter J, Wiatrek D, McAlister AL. Effects of frequency and duration in telephone counselling for smoking cessation. Tobacco Control 2007;16 Suppl 1:i71-4.

Rabius V, Villars P, Pike J, Geiger AT, Hunter J, McAlister AL. Depression and other factors in cost-effective tailoring of telephone counseling. National Conference on Tobacco or Health 2005 May 4-6, Chicago, Ill. 2005.

\section{Ramon 2013 \{published data only\}}

Ramon JM, Nerin I, Comino A, Pinet C, Abella F, Carreras JM, et al. A multicentre randomized trial of combined individual and telephone counselling for smoking cessation. Preventive Medicine 2013;57(3):183-8.

\section{Reid 1999a \{published data only\}}

D'Angelo ME, Reid RD, Brown KS, Pipe AL. Gender differences in predictors for long-term smoking cessation following physician advice and nicotine replacement therapy. Canadian Journal of Public Health 2001;92(6):418-22.

* Reid RD, Pipe A, Dafoe WA. Is telephone counselling a useful addition to physician advice and nicotine replacement therapy in helping patients to stop smoking? A randomized controlled trial. Canadian Medical Association Journal 1999;160(11):1577-81.

\section{Reid 2007 \{published data only\}}

Reid RD, Pipe AL, Quinlan B, Oda J. Interactive voice response telephony to promote smoking cessation in patients with heart disease: A pilot study. Patient Education and Counseling 2007;66(3):319-26.

\section{Reid 2018 \{published data only\}}

Reid RD, Aitken DA, McDonnell L, Armstrong A, MullenKA, Jones $L$, et al. Randomized trial of an automated telephone follow-up system for smoking cessation insmokers with CHD. Canadian Journal of Cardiology 2011;27(5 Suppl 1):S67.

* Reid RD, Aitken DA, Mullen KA, McDonnell L, Armstrong A, Leblanc AG, et al. Automated telephone follow-up for smoking cessation in smokers with coronary heart disease: a randomized controlled trial. Nicotine \& Tobacco Research May 252018 [Epub ahead of print].

\section{Rigotti 2006 \{published data only\}}

Park ER, Quinn VP, Chang Y, Regan S, Loudin B, Cummins S, et al. Recruiting pregnant smokers into a clinical trial: using a network-model managed care organization versus communitybased practices. Preventive Medicine 2007;44(3):223-9.

Rigotti NA, Park ER, Chang Y, Regan S. Smoking cessation medication use among pregnant and postpartum smokers. Obstetrics and Gynecology 2008;111(2 Pt 1):348-55.

Rigotti NA, Park ER, Chang Y, Regan S, Perry K. Actual practice when evidence is unclear: how often do pregnant smokers use cessation medications and how often do obstetric providers recommend them? (PA6-2). Society for Research on Nicotine and Tobacco 13th Annual Meeting; 2007 February 21-24, Austin, Texas 2007:25. []
* Rigotti NA, Park ER, Regan S, Chang Y, Perry K, Loudin B, et al. Efficacy of telephone counseling for pregnant smokers: a randomized controlled trial. Obstetrics and Gynecology 2006;108(1):83-92.

\section{Rimer 1994 \{published data only\}}

Rimer BK, Orleans CT, Fleisher L, Cristinzio S. Does tailoring matter? The impact of a tailored guide on ratings and shortterm smoking-related outcomes for older smokers. Health Education Research 1994;9(1):69-84.

\section{Rogers 2016 \{published data only\}}

Axtmayer A, Rogers E, Sherman S. Telephone-based smoking cessation treatment for mental health patients. Journal of General Internal Medicine 2011;26:S353.

Parker L, Rogers E, Wang B, Sherman S. Smoking cessation in the elderly: Is it too late?. Journal of the American Geriatrics Society 2014;62:S153.

Rogers E, Fernandez S, Gillespie C, Smelson D, Hagedorn HJ, Elbel B, et al. Telephone care coordination for smokers in VA mental health clinics: protocol for a hybrid type-2 effectivenessimplementation trial. Addiction Science \& Clinical Practice 2013;8:7.

Rogers E, Fernandez S, Smelson D, Axtmayer A, Sherman SE. Proactive telephone smoking cessation treatment in a VA mental health population: Preliminary treatment engagement and cessation outcomes. Journal of General Internal Medicine 2011;26:S343.

Rogers ES, Gillespie C, Zabar S, Sherman SE. Using standardized patients to train telephone counselors for a clinical trial. BMC Research Notes 2014;7:341.

* Rogers ES, Smelson DA, Gillespie CC, Elbel B, Poole S, Hagedorn HJ, et al. Telephone smoking-cessation counseling for smokers in mental health clinics: a patient-randomized controlled trial. American Journal of Preventive Medicine 2016;50(4):518-27.

\section{Schlam 2016 \{published data only\}}

Baker TB, Collins LM, Mermelstein R, Piper ME, Schlam TR, Cook JW, et al. Enhancing the effectiveness of smoking treatment research: conceptual bases and progress. Addiction 2016;111(1):107-16.

Piper ME, Fiore MC, Smith SS, Fraser D, Bolt DM, Collins LM, et al. Identifying effective intervention components for smoking cessation: a factorial screening experiment. Addiction 2016;111(1):129-41.

* Schlam TR, Fiore MC, Smith SS, Fraser D, Bolt DM, Collins LM, et al. Comparative effectiveness of intervention components for producing long-term abstinence from smoking: a factorial screening experiment. Addiction 2016;111(1):142-55.

\section{Schuck 2014 \{published data only\}}

* Schuck K, Bricker JB, Otten R, Kleinjan M, Brandon TH, Engels RC. Effectiveness of proactive quitline counselling for smoking parents recruited through primary schools: results of a randomized controlled trial. Addiction 2014;109(5):830-41. 
Schuck K, Otten R, Kleinjan M, Bricker JB, Engels RC. Effectiveness of proactive telephone counselling for smoking cessation in parents: study protocol of a randomized controlled trial. BMC Public Health 2011;11:732.

\section{Sherman 2017 \{published data only\}}

Sherman SE, Cummins S, Finney J, Kalra P, Kuschner W, York L, et al. Preliminary results from a study of telephone care coordination for smoking cessation. Journal of General Internal Medicine 2008;23((Suppl 2)):376-7.

* Sherman SE, Krebs P, York LS, Cummins SE, Kuschner W, Guvenc-Tuncturk S, et al. Telephone care co-ordination for tobacco cessation: randomised trials testing proactive versus reactive models. Tobacco Control 2017;27(1):78-82.

\section{Sims 2013 \{published data only\}}

Sims T, Smith SS, McAfee T, Baker TB, Fiore M, Sheffer M. Randomized clinical trial to evaluate quitline cessation counseling for 18 to 24 year-old smokers [PA2-1]. Society for Research on Nicotine and Tobacco 17th Annual Meeting, 2011 February 16-19, Toronto. 2011:17.

* Sims TH, McAfee T, Fraser DL, Baker TB, Fiore MC, Smith SS. Quitline cessation counseling for young adult smokers: a randomized clinical trial. Nicotine \& Tobacco Research 2013;15(5):932-41.

\section{Skov-Ettrup 2016 \{published data only\}}

* Skov-Ettrup LS, Dalum P, Bech M, Tolstrup JS. The effectiveness of telephone counselling and internet- and textmessage-based support for smoking cessation: results from a randomized controlled trial. Addiction 2016;111(7):1257-66.

Skov-Ettrup LS, Dalum P, Ekholm O, Tolstrup JS. Reach and uptake of Internet- and phone-based smoking cessation interventions: results from a randomized controlled trial. Preventive Medicine 2014;62:38-43.

Skov-Ettrup LS, Dalum P, Tolstrup JS. Internet-based intervention and telephone counselling for smoking cessation: Results from a 4-arm randomised controlled trial. European Journal of Epidemiology 2013;28(1 Suppl 1):S48-S49.

Smith 2004 \{published data only\}

* Smith PM, Cameron R, McDonald PW, Kawash B, Madill C, Brown KS. Telephone counseling for population-based smoking cessation. American Journal of Health Behavior 2004;28(3):231-41.

Smith PM, Cameron R, Payne B, Madill C, McDonald P, Brown S. Randomised controlled trial of a telephone smoking cessation program: effect of 3 vs 7 calls. 11th World Conference on Tobacco or Health; 2000 August 6-11, Chicago, Illinois. 2000; Vol. 1.

\section{Smith 2013 \{published data only\}}

Smith SS, Keller PA, Kobinsky KH, Baker TB, Fraser DL, Bush T, et al. Enhancing tobacco quitline effectiveness: Identifying a superior pharmacotherapy adjuvant. Nicotine \& Tobacco Research 2013; Vol. 15, issue 3:718-28. []

\section{Solomon 2000 \{published data only\}}

Solomon LJ, Scharoun GM, Flynn BS, Secker-Walker RH, Sepinwall D. Free nicotine patches plus proactive telephone peer support to help low-income women stop smoking. Preventive Medicine 2000;31(1):68-74.

\section{Solomon 2005 \{published data only\}}

Solomon LJ, Marcy TW, Howe KD, Skelly JM, Reinier K, Flynn BS. Does extended proactive telephone support increase smoking cessation among low-income women using nicotine patches? Preventive Medicine 2005;40(3):306-13.

\section{Sood 2009 \{published data only\}}

Coleman T. Adding live, reactive telephone counselling to selfhelp literature does not increase smoking cessation. EvidenceBased Medicine 2010;15(2):53-4.

Gilbert H. Adding live, reactive telephone counselling to selfhelp literature does not increase smoking cessation. EvidenceBased Nursing 2010;13(2):42.

Pbert L. Enhancing the effect of telephone quitline counseling through proactive call-back counseling. Chest 2009;136(5):1199-200.

* Sood A, Andoh J, Verhulst S, Ganesh M, Edson B, HopkinsPrice P. "Real-world" effectiveness of reactive telephone counseling for smoking cessation: a randomized controlled trial. Chest 2009;136(5):1229-36.

\section{Sorensen 2007a \{published and unpublished data\}}

Hunt MK, Harley AE, Stoddard AM, Lederman RI, MacArthur MJ, Sorensen $\mathrm{G}$. Elements of external validity of tools for health: an intervention for construction laborers. American Journal of Health Promotion 2010;24(5):e11-20.

* Sorensen G, Barbeau EM, Stoddard AM, Hunt MK, Goldman R, Smith A, et al. Tools for health: the efficacy of a tailored intervention targeted for construction laborers. Cancer Causes \& Control 2007;18(1):51-9.

\section{Stotts 2002 \{published data only\}}

Stotts AL, Diclemente CC, Dolan-Mullen P. One-to-one - A motivational intervention for resistant pregnant smokers. Addictive Behaviors 2002;27(2):275-92.

\section{Sumner 2016 \{published data only\}}

Sumner W, Walker MS, Highstein GR, Fischer I, Yan Y, McQueen A, et al. A randomized controlled trial of directive and nondirective smoking cessation coaching through an employee quitline. BMC Public Health 2016;16:550.

\section{Swan 2003 \{published data only\}}

Jack LM, Swan GE, Thompson E, Curry SJ, McAfee T, Dacey S, et al. Bupropion SR and smoking cessation in actual practice: methods for recruitment, screening, and exclusion for a field trial in a managed-care setting. Preventive Medicine 2003;36(5):585-93

Javitz HS, Swan GE, Zbikowski SM, Curry SJ, McAfee TA, Decker DL, et al. Cost-effectiveness of different combinations of bupropion SR dose and behavioral treatment for smoking 
cessation: a societal perspective. American Journal of Managed Care 2004;10(3):217-26.

McAfee T, Zbikowski SM, Bush T, McClure J, Swan G, Jack LM, et al. The effectiveness of bupropion SR and phone counseling for light and heavy smokers [abstract]. Nicotine \& Tobacco Research 2004;6:721.

Swan GE, Jack LM, Curry S, Chorost M, Javitz H, McAfee T, et al. Bupropion SR and counseling for smoking cessation in actual practice: Predictors of outcome. Nicotine \& Tobacco Research 2003;5(6):911-21.

Swan GE, Jack LM, Javitz HS, McAfee T, McClure JB. Predictors of 12-month outcome in smokers who received bupropion sustained-release for smoking cessation. Central Nervous System Drugs 2008;22(3):239-56.

Swan GE, Javitz HS, Jack LM, Curry SJ, McAfee T. Heterogeneity in 12-month outcome among female and male smokers. Addiction 2004;99(2):237-50.

* Swan GE, McAfee T, Curry SJ, Jack LM, Javitz H, Dacey S, et al. Effectiveness of bupropion sustained release for smoking cessation in a health care setting: a randomized trial. Archives of Internal Medicine 2003;163(19):2337-44.

\section{Swan 2010 \{published data only\}}

Halperin AC, McAfee TA, Jack LM, Catz SL, McClure JB, Deprey TM, et al. Impact of symptoms experienced by varenicline users on tobacco treatment in a real world setting. Journal of Substance Abuse Treatment 2009;36(4):428-34.

Javitz HS, Zbikowski SM, Deprey M, McAfee TA, McClure JB, Richards J, et al. Cost-effectiveness of varenicline and three different behavioral treatment formats for smoking cessation. Translational Behavioral Medicine 2011; Vol. 1, issue 1:182-90. []

* Swan GE, McClure JB, Jack LM, Zbikowski SM, Javitz HS, Catz SL, et al. Behavioral counseling and varenicline treatment for smoking cessation. American Journal of Preventive Medicine 2010;38(5):482-90.

Zbikowski SM, Jack LM, McClure JB, Deprey M, Javitz HS, Mcafee TA, et al. Utilization of services in a randomized trial testing phone- and web-based interventions for smoking cessation. Nicotine \& Tobacco Research 2011;13(5):319-27.

\section{Thomas 2016 \{published data only\}}

Thomas JL, Luo X, Bengtson J, Wang Q, Ghidei W, Nyman J, et al. Enhancing Quit \& Win contests to improve cessation among college smokers: a randomized clinical trial. Addiction 2016;111(2):331-9.

\section{Thompson 1993 \{published data only\}}

Kinne S, Thompson B, Wooldridge JA. Response to a telephone smoking information line. American Journal of Health Promotion 1991;5(6):410-3.

* Thompson B, Kinne S, Lewis FM, Wooldridge JA. Randomized telephone smoking-intervention trial initially directed at blue-collar workers. Journal of the National Cancer Institute. Monographs 1993;1993(14):105-12.

\section{Tzelepis 2011a \{published data only\}}

Carpenter MJ. Proactive recruitment in clinical trials: an idea whose time has come. Tobacco Control 2011;20(4):317.

Tzelepis F, Paul CL, Walsh RA, Knight J, Wiggers J. Who enrolled in a randomized controlled trial of quitline support? Comparison of participants versus nonparticipants. Nicotine \& Tobacco Research 2013;15(12):2107-13.

Tzelepis F, Paul CL, Walsh RA, Wiggers J, Duncan SL, Knight J. Active telephone recruitment to quitline services: are nonvolunteer smokers receptive to cessation support?. Nicotine \& Tobacco Research 2009;11(10):1205-15.

Tzelepis F, Paul CL, Walsh RA, Wiggers J, Duncan SL, Knight J. Predictors of abstinence among smokers recruited actively to quitline support. Addiction 2013; Vol. 108, issue 1:181-5. []

Tzelepis F, Paul CL, Walsh RA, Wiggers J, Knight J, Lecathelinais $C$, et al. Telephone recruitment into a randomized controlled trial of quitline support. American Journal of Preventive Medicine 2009;37(4):324-9.

* Tzelepis F, Paul CL, Wiggers J, Walsh RA, Knight J, Duncan SL, et al. A randomised controlled trial of proactive telephone counselling on cold-called smokers' cessation rates. Tobacco Control 2011;20(1):40-6.

\section{Vander Weg 2016 \{published data only\}}

Vander Weg MW, Cozad AJ, Howren MB, Cretzmeyer M, Scherubel M, Turvey C, et al. An individually-tailored smoking cessation intervention for rural Veterans: a pilot randomized trial. BMC Public Health 2016;16(1):811.

\section{Velicer 2006 \{published data only\}}

Velicer WF, Friedman RH, Fava JL, Gulliver SB, Keller S, Sun X, et al. Evaluating nicotine replacement therapy and stage-based therapies in a population-based effectiveness trial. Journal of Consulting and Clinical Psychology 2006;74(6):1162-72.

\section{Warner 2016 \{published data only\}}

Warner DO, Nolan MB, Kadimpati S, Burke MV, Hanson AC, Schroeder DR. Quitline tobacco interventions in hospitalized patients: a randomized trial. American Journal of Preventive Medicine 2016;51(4):473-84.

\section{Wu 2017 \{published data only\}}

Wu L, He Y, Jiang B, Zhang D, Tian H, Zuo F, et al. Very brief physician advice and supplemental proactive telephone calls to promote smoking reduction and cessation in Chinese male smokers with no intention to quit: a randomized trial. Addiction 2017;112(11):2032-40.

\section{Young 2008 \{published data only\}}

Young JM, Girgis S, Bruce TA, Hobbs M, Ward JE. Acceptability and effectiveness of opportunistic referral of smokers to telephone cessation advice from a nurse: a randomised trial in Australian general practice. BMC Family Practice 2008;9:16.

\section{Zhu 1996 \{published data only\}}

Zhu SH, Stretch V, Balabanis M, Rosbrook BP, Sadler G, Pierce JP. Telephone counseling for smoking cessation - effects 
of single-session and multiple-session interventions. Journal of Consulting and Clinical Psychology 1996;64(1):202-11.

Zhu 2002 \{published data only\}

Zhu SH, Anderson CM, Tedeschi GJ, Rosbrook B, Johnson CE, Byrd $M$, et al. Evidence of real-world effectiveness of a telephone quitline for smokers. New England Journal of Medicine 2002;347(14):1087-93.

\section{Zhu 2012 \{published data only\}}

Tedeschi GJ, Zhu S-H, Cummins SE, Shin H, Nguyen MH. Counselling Asian smokers: key considerations for a telephone intervention. Journal of Smoking Cessation 2013;8(1):2-10.

* Zhu SH, Cummins SE, Wong S, Gamst AC, Tedeschi GJ, ReyesNocon J. The effects of a multilingual telephone quitline for Asian smokers: a randomized controlled trial. Journal of the National Cancer Institute 2012;104(4):299-310.

\section{Zwar 2015 \{published data only\}}

Halcomb EJ, Furler JS, Hermiz OS, Blackberry ID, Smith JP, Richmond RL, et al. Process evaluation of a practice nurse-led smoking cessation trial in Australian general practice: Views of general practitioners and practice nurses. Family Practice 2015;32(4):468-73

Zwar N, Richmond R, Halcomb E, Furler J, Smith J, Hermiz O, et al. Supporting smoking cessation in primary care: Results of the quit in general practice study. Respirology 2014;19(Suppl 2):23.

Zwar N, Richmond RL, Halcomb E, Furler J, Smith J, Hermiz O, et al. Supporting smoking cessation in Australian primary care: Results of the quit in general practice study. Global Heart 2014;9(1 Suppl):e232.

* Zwar NA, Richmond RL, Halcomb EJ, Furler JS, Smith JP, Hermize $\mathrm{O}$, et al. Quit in general practice: A cluster randomized trial of enhanced in-practice support for smoking cessation. Family Practice 2015;32(2):173-80.

\section{References to studies excluded from this review}

\section{Abroms 2014 \{published data only\}}

* Abroms LC, Boal AL, Simmens SJ, Mendel JA, Windsor RA. A randomized trial of Text2Quit: a text messaging program for smoking cessation. American Journal of Preventive Medicine 2014;47(3):242-50

Heminger CL, Boal AL, Zumer M, Abroms LC. Text2Quit: an analysis of participant engagement in the mobile smoking cessation program. American Journal of Drug and Alcohol Abuse 2016;42(4):450-8.

Hoeppner BB, Hoeppner SS, Abroms LC. How do text-messaging smoking cessation interventions confer benefit? A multiple mediation analysis of Text2Quit. Addiction 2017;112(4):673-82.

\section{Ahijevych 1995 \{published data only\}}

Ahijevych K, Wewers ME. Low-intensity smoking cessation intervention among African- American women cigarette smokers - a pilot study. American Journal of Health Promotion 1995;9(5):337-9.

\section{Alonso-Perez 2007 \{published data only\}}

Alonso-Perez F, Secades-Villa R, Duarte CG. Are psychological treatments effective to stop smoking?. Trastornos Adictivos 2007;9(1):21-30.

\section{Amos 1995 \{published data only\}}

Amos A, White DA, Elton RA. Is a telephone helpline of value to the workplace smoker?. Occupational Medicine 1995;45(5):234-8.

\section{An 2008 \{published data only\}}

An LC, Bluhm JH, Foldes SS, Alesci NL, Klatt CM, Center BA, et al. $A$ randomized trial of a pay-for-performance program targeting clinician referral to a state tobacco quitline. Archives of Internal Medicine 2008;168(18):1993-9.

Asfar 2010 \{published data only\}

* Asfar T, Klesges RC, Sanford SD, Sherrill-Mittleman D, Robison LL, Hudson MM, et al. Trial design: The St. Jude Children's Research Hospital Cancer Survivors Tobacco Quit Line study. Contemporary Clinical Trials 2010; Vol. 31, issue $1: 82-91$. []

Berger VW. Randomization, permuted blocks, masking, allocation concealment, and selection bias in the Tobacco Quit Line Study. Contemporary Clinical Trials 2010;31(3):201.

Klesges RC, Krukowski RA, Klosky JL, Liu W, Srivastava DK, Boyett JM, et al. Efficacy of a tobacco quitline among adult cancer survivors. Preventive Medicine 2015;73:22-7.

Klesges RC, Krukowski RA, Klosky JL, Liu W, Srivastava DK, Boyett JM, et al. Efficacy of a tobacco quitline among adult survivors of childhood cancer. Nicotine \& Tobacco Research 2015;17(6):710-8.

Augustine 2015 \{published data only\}

Augustine MR, Strauss H, Levine DM, Chugh P, Wang B, Grossman E, et al. Predictors of adherence to telephone counseling for smoking cessation amongst veterans presenting to VA mental health clinics. Journal of General Internal Medicine 2015;30:S232-S233.

\section{Baker 2015 \{published data only\}}

Baker A, Richmond R, Kay-Lambkin F, Castle D, Filia S, Williams J, et al. Smoking and other cardiovascular disease risk behaviours among people with severe mental disorders. Schizophrenia Research 2012;136:S175.

Baker A, Richmond R, Kay-Lambkin F, Filia S, Castle D, Williams J, et al. A smoking intervention among people with psychotic disorders-preliminary results from a randomized controlled trial. Asia-Pacific Journal of Clinical Oncology 2012;8:339.

* Baker AL, Richmond R, Kay-Lambkin FJ, Filia SL, Castle D, Williams JM, et al. Randomized controlled trial of a healthy lifestyle intervention among smokers With psychotic disorders. Nicotine \& Tobacco Research 2015;17(8):946-54. 
Balanda 1999 \{published data only\}

Balanda KP, Lowe JB, O'Connor-Fleming ML. Comparison of two self-help smoking cessation booklets. Tobacco Control 1999;8(1):57-61.

\section{Berndt 2014 \{published data only\}}

* Berndt N, Bolman C, Froelicher ES, Mudde A, Candel M, De Vries $\mathrm{H}$, et al. Effectiveness of a telephone delivered and a face-to-face delivered counseling intervention for smoking cessation in patients with coronary heart disease: a 6-month follow-up. Journal of Behavioral Medicine 2014;37(4):709-24.

Berndt N, Bolman C, Lechner L, Max W, Mudde A, De Vries H, et al. Economic evaluation of a telephone- and face-to-facedelivered counseling intervention for smoking cessation in patients with coronary heart disease. European Journal of Health Economics 2016;17(3):269-85.

Berndt N, Bolman C, Lechner L, Mudde A, Verheugt FW, De Vries H. Effectiveness of two intensive treatment methods for smoking cessation and relapse prevention in patients with coronary heart disease: study protocol and baseline description. BMC Cardiovascular Disorders 2012;12:33.

Berndt N, De Vries H, Lechner L, Van Acker F, Froelicher ES, Verheugt $F$, et al. High intensity smoking cessation interventions: cardiac patients of low socioeconomic status and low intention to quit profit most. Netherlands Heart Journal 2017;25(1):24-32.

Berndt N, Lechner L, De Vries H, Van Acker F, Mudde A, Froelicher $\mathrm{E}$, et al. Effectiveness of two intensive smoking cessation interventions for the secondary prevention of coronary heart disease: Benefits for patients with low socioeconomic status and low quit motivations. European Heart Journal 2013;34:475.

Berndt N, Lechner L, Mudde A, De Vries H, Bolman C. Feasibility and acceptability of a telephone- and face-to-face-delivered counseling intervention for smoking cessation in Dutch patients with coronary heart disease. Research in Nursing \& Health 2017;40(5):444-58.

\section{Bernstein 2018 \{published data only\}}

Bernstein SL, Dziura J, Weiss J, Miller T, Vickerman KA, Grau LE, et al. Tobacco dependence treatment in the emergency department: a randomized trial using the Multiphase Optimization Strategy. Contemporary Clinical Trials 2018;66:1-8.

\section{Best 1977 \{published data only\}}

Best JA, Bass F, Owen LE. Mode of service delivery in a smoking cessation program for public health. Canadian Journal of Public Health 1977;68(6):469-73.

\section{Bliksrud 2002 \{published data only\}}

Bliksrud T, Nygaard E. Telephone Quitline and changed smoking behavior [Royketelefonen og endret roykeatferd]. Tidsskrift for Den Norske Laegeforening 2002; Vol. 122, issue 27:2616-8. []

\section{Bock 2008 \{published data only\}}

Bock BC, Becker BM, Niaura RS, Partridge R, Fava JL, Trask P.

Smoking cessation among patients in an emergency chest pain observation unit: outcomes of the Chest Pain Smoking Study (CPSS). Nicotine \& Tobacco Research 2008;10(10):1523-31.

Borland 1989 \{published data only\}

Borland R. Three-month follow-up on callers to a telephone counselling service in 1987. Quit Evaluation Studies: Volume 3 Chapter 6 www.quit.org.au 1989 (accessed 18 July 2000).

\section{Borland 2004 \{published data only\}}

Borland R, Balmford J, Hunt D. The effectiveness of personally tailored computer-generated advice letters for smoking cessation. Addiction 2004;99(3):369-77.

Boyle 2004 \{published data only\}

Boyle RG, Pronk NP, Enstad CJ. A randomized trial of telephone counseling with adult moist snuff users. American Journal of Health Behavior 2004;28(4):347-51.

Boyle 2008 \{published data only\}

Boyle RG, Enstad C, Asche SE, Thoele MJ, Sherwood NE, Severson $\mathrm{HH}$, et al. A randomized controlled trial of telephone counseling with smokeless tobacco users: the ChewFree Minnesota study. Nicotine \& Tobacco Research 2008;10(9):1433-40.

\section{Brandon 2000 \{published data only\}}

Brandon TH, Collins BN, Juliano LM, Lazev AB. Preventing relapse among former smokers: A comparison of minimal interventions through telephone and mail. Journal of Consulting and Clinical Psychology 2000;68(1):103-13.

\section{Bronshtein 2016 \{published and unpublished data\}}

Bronshtein E, Ondersma SJ, Sokol RJ. Optimizing ehealth for smoking in pregnancy: a pilot factorial evaluation of providing single vs multiple options. Reproductive Sciences (Thousand Oaks, Calif.) 2016;Conference: 63rd Annual Scientific Meeting of the Society for Gynecologic Investigation, SGI 2016 Montreal, QC Canada(Suppl 1):195A.

\section{Brunner-Frandsen 2010 \{published data only\}}

Brunner-Frandsen NS, Bak S. Smoking cessation intervention after stroke or transient ischemic attack. A randomised controlled trial. Cerebrovascular Diseases 2010;29:323.

\section{Buchanan 2004 \{published data only\}}

Buchanan LM, El Banna M, White A, Moses S, Siedlik C, Wood M. An exploratory study of multicomponent treatment intervention for tobacco dependency. Journal of Nursing Scholarship 2004;36(4):324-30.

\section{Buller 2012 \{published data only\}}

Buller D, Borland R, Severson H, Bettinghaus E, Halperin A, Tinkelman D, et al. Results of a randomized trial comparing an online smoking cessation program to a self-help booklet and telephone quit line among young adults (POS2-17). Society for Research on Nicotine and Tobacco 18th Annual Meeting; 2012 March 13-16, Houston, Texas. 2012:66. [] 
Burns 2010 \{published data only\}

Burns EK, Tong S, Levinson AH. Reduced NRT supplies through a quitline: smoking cessation differences. Nicotine \& Tobacco Research 2010;12(8):845-9.

\section{Bush 2012 \{published data only\}}

Bush T, Levine MD, Beebe LA, Cerutti B, Deprey M, McAfee T, et al. Addressing weight gain in smoking cessation treatment: A randomized controlled trial. American Journal of Health Promotion 2012;27(2):94-102. []

\section{Bush 2016 \{published data only\}}

Bush T, Lovejoy J, Javitz H, Magnusson B, Torres AJ, Mahuna S, et al. Comparative effectiveness of adding weight control simultaneously or sequentially to smoking cessation quitlines: study protocol of a randomized controlled trial. BMC Public Health 2016;16:615.

\section{Carlini 2008 \{published data only\}}

Carlini BH, Zbikowski SM, Javitz HS, Deprey TM, Cummins SE, Zhu SH. Telephone-based tobacco-cessation treatment: re-enrollment among diverse groups. American Journal of Preventive Medicine 2008;35(1):73-6.

\section{Carlini 2012 \{published data only\}}

Carlini BH, McDaniel A, Weaver M, Kauffman R, Cerutti B, Stratton RM, et al. No smokers left behind: using interactive voice response technology to recycle low income smokers back to quitline treatment - a randomized control trial (POS2-21). Society for Research on Nicotine and Tobacco 18th Annual Meeting; 2012 March 13-16, Houston, Texas. 2012:67. []

* Carlini BH, McDaniel AM, Weaver MT, Kauffman RM, Cerutti B, Stratton RM, et al. Reaching out, inviting back: using Interactive voice response (IVR) technology to recycle relapsed smokers back to Quitline treatment--a randomized controlled trial. BMC Public Health 2012;12(1):507. []

\section{Carlin-Menter 2011 \{published data only\}}

Carlin-Menter S, Cummings KM, Celestino P, Hyland A, Mahoney MC, Willett J, et al. Does offering more support calls to smokers influence quit success?. Journal of Public Health Management \& Practice 2011;17(3):E9-15

\section{Carreras 2007 \{published data only\}}

Carreras Castellet JM, Fletes DI, Quesada LM, Sanchez TB, Sanchez AL. Design and early results of a proactive telephonebased smoking cessation treatment compared with face-to-face group sessions. Medicina Clinica 2007;128(7):247-50.

\section{Cheung 2013 \{published data only\}}

Cheung K, Wong I, Brubacher J, Abu-Laban R, Schulzer M. Emergency department tobacco cessation counseling: implementation and evaluation of a community-based program: a pilot study (conference abstract). Canadian Journal of Emergency Medicine 2013;15(S79):S3.

\section{Cheung 2017 \{published data only\}}

Cheung KW, Wong IW, Fingrut W, Tsai APY, Ke SR, Shojaie S, et al. Randomized controlled trial of emergency department initiated smoking cessation counselling and referral to a community counselling service. Canadian Journal of Emergency Medicine 2018;20(4):556-64

Choi 2014 \{published data only\}

* Choi SH, Waltje AH, Ronis DL, Noonan D, Hong O, Richardson CR, et al. Web-enhanced tobacco tactics with telephone support versus 1-800-QUIT-NOW telephone line intervention for operating engineers: randomized controlled trial. Journal Medical Internet Research 2014;16(11):e255.

Duffy SA, Ronis DL, Richardson C, Waltje AH, Ewing LA, Noonan $\mathrm{D}$, et al. Protocol of a randomized controlled trial of the Tobacco Tactics website for operating engineers. BMC Public Health 2012;12:335. []

\section{Conway 2004 \{published data only\}}

Conway TL, Woodruff SI, Edwards CC, Elder JP, Hurtado SL, Hervig LK. Operation Stay Quit: evaluation of two smoking relapse prevention strategies for women after involuntary cessation during US Navy recruit training. Military Medicine 2004;169(3):236-42.

Cooper 2004 \{published data only (unpublished sought but not used)\}

Cooper TV, Debon MW, Stockton M, Klesges RC, Steenbergh TA, Sherrill-Mittleman D, et al. Correlates of adherence with transdermal nicotine. Addictive Behaviors 2004;29(8):1565-78.

\section{Cummings 1988 \{published data only\}}

* Cummings KM, Emont SL, Jaen C, Sciandra R. Format and quitting instructions as factors influencing the impact of a selfadministered quit smoking program. Health Education Quarterly 1988;15(2):199-216.

Jaen CR, Cummings KM, Zielezny M, O'Shea R. Patterns and predictors of smoking cessation among users of a telephone hotline. Public Health Reports 1993;108(6):772-8.

\section{Cummings 1989 \{published data only\}}

Cummings KM, Sciandra R, Davis S, Rimer B. Response to antismoking campaign aimed at mothers with young children. Health Education Research 1989;4:429-37.

\section{Cummings 2006a \{published data only\}}

* Cummings KM, Hyland A, Fix B, Bauer U, Celestino P, CarlinMenter $\mathrm{S}$, et al. Free nicotine patch giveaway program 12month follow-up of participants. American Journal of Preventive Medicine 2006;31(2):181-4.

Miller N, Frieden TR, Liu SY, Matte TD, Mostashari F, Deitcher DR, et al. Effectiveness of a large-scale distribution programme of free nicotine patches: a prospective evaluation. Lancet 2005;365(9474):1849-54.

\section{Cummings 2010 \{published data only\}}

Cummings KM, Fix BV, Celestino P, Hyland A, Mahoney M, Ossip DJ, et al. Does the number of free nicotine patches given to smokers calling a quitline influence quit rates: results from a quasi-experimental study. BMC Public Health 2010;10:181. [] 
Cummings 2011 \{published data only\}

Cummings KM, Hyland A, Carlin-Menter S, Mahoney MC, Willett J, Juster HR. Costs of giving out free nicotine patches through a telephone quit line. Journal of Public Health Management \& Practice 2011;17(3):E16-23.

\section{Curry 2003 \{published data only\}}

Curry SJ, Ludman EJ, Graham E, Stout J, Grothaus L, Lozano P. Pediatric-based smoking cessation intervention for lowincome women: a randomized trial. Archives of Pediatrics and Adolescent Medicine 2003;157(3):295-302.

Danaher 2011 \{published data only\}

Danaher BG, Severson HH, Zhu S-H, Lichtenstein E, Andrews JA, Yearick $\mathrm{C}$. Evaluating the relative efficacy of web-based intervention and helpline in smokeless tobacco cessation: the CHEWFREE II RCT [SM 12C]. Society for Research on Nicotine and Tobacco Conference; 2011 February 16-19, Toronto. 2011:15.

\section{Danaher 2015 \{published data only\}}

Danaher BG, Severson HH, Zhu S-H, Andrews JA, Cummins SE, Lichtenstein E, Tedeschi GJ, Hudkins C, Widdop C, Crowley R, Seeley JR. Randomized controlled trial of the combined effects of Web and Quitline interventions for smokeless tobacco cessation. Internet Interventions 2015;2(2):143-151.

\section{Davis 1992 \{published data only\}}

Davis SW, Cummings KM, Rimer BK, Sciandra R. The impact of tailored self-help smoking cessation guides on young mothers. Health Education Quarterly 1992;19(4):495-504.

\section{De Azevedo 2010 \{published data only\}}

De Azevedo RC, Mauro ML, Lima DD, Gaspar KC, Da Silva VF, Botega NJ. General hospital admission as an opportunity for smoking-cessation strategies: A clinical trial in Brazil. General Hospital Psychiatry 2010;32(6):599-606.

\section{DeBusk 1994 \{published data only\}}

DeBusk RF, Miller NH, Superko HR, Dennis CA, Thomas RJ, Lew HT, et al. A case-management system for coronary risk factor modification after acute myocardial infarction. Annals of Internal Medicine 1994;120(9):721-9.

\section{Decker 1989 \{published data only\}}

Decker BD, Evans RG. Efficacy of a minimal contact version of a multimodal smoking cessation program. Addictive Behaviors 1989;14(5):487-91.

\section{Dent 2009 \{published data only\}}

Dent LA, Harris KJ, Noonan CW. Randomized trial assessing the effectiveness of a pharmacist-delivered program for smoking cessation. Annals of Pharmacotherapy 2009;43(2):194-201.

\section{Dubren 1977 \{published data only\}}

Dubren R. Self-reinforcement by recorded telephone messages to maintain non-smoking behavior. Journal of Consulting and Clinical Psychology 1977;45(3):358-60.

\section{Edelman 2014 \{published data only\}}

* Edelman D, Coffman CJ, Dolor R, Lindquist JH, Pereira KC, Granger BB, et al. Randomized trial of telephone nurse case co-management of diabetes and hypertension in community practice. Journal of General Internal Medicine 2014;29(1 Supplement):S193.

Edelman D, Dolor RJ, Coffman CJ, Pereira KC, Granger BB, Lindquist $\mathrm{JH}$, et al. Nurse-led behavioral management of diabetes and hypertension in community practices: a randomized trial. Journal of General Internal Medicine 2015;30(5):626-33.

\section{Fellows 2016 \{published data only\}}

Fellows JL, Mularski R, Waiwaiole L, Funkhouser K, Mitchell J, Arnold $\mathrm{K}$, et al. Health and economic effects from linking bedside and outpatient tobacco cessation services for hospitalized smokers in two large hospitals: study protocol for a randomized controlled trial. Trials 2012;13:129.

* Fellows JL, Mularski RA, Leo MC, Bentz CJ, Waiwaiole LA, Francisco MC, et al. Referring hospitalized smokers to outpatient quit services: a randomized trial. American Journal of Preventive Medicine 2016;51(4):609-19.

Fu 2016 \{published data only\}

Fu SS, Van Ryn M, Burgess DJ, Nelson D, Clothier B, Thomas JL, et al. Proactive tobacco treatment for low income smokers: study protocol of a randomized controlled trial. BMC Public Health 2014;14:337.

* Fu SS, Van Ryn M, Nelson D, Burgess DJ, Thomas JL, Saul J, et al. Proactive tobacco treatment offering free nicotine replacement therapy and telephone counselling for socioeconomically disadvantaged smokers: a randomised clinical trial. Thorax 2016;71(5):446-53.

\section{Garvey 2012 \{published data only\}}

Garvey AJ, Kalman D, Hoskinson RA, Kinnunen T, Armour CD, Copp S, et al. Effects of extended-duration counseling vs. shorter-duration counseling after 1.5 years of follow-up (POS4-49). Society for Research on Nicotine and Tobacco 18th Annual Meeting; 2012 March 13-16, Houston, Texas. 2012:139.

Gianos 2015 \{published data only\}

Gianos E, Schoenthaler A, Mushailov M, Fisher EA, Berger JS. Rationale and design of the Investigation of Motivational Interviewing and Prevention Consults to Achieve Cardiovascular Targets (IMPACT) trial. American Heart Journal 2015;170(3):430-7.e9.

Gies 2008 \{published data only\}

Gies CE, Buchman D, Robinson J, Smolen D. Effect of an inpatient nurse-directed smoking cessation program. Western Journal of Nursing Research 2008;30(1):6-19.

\section{Glasgow 2009 \{published data only\}}

Glasgow RE, Estabrooks PA, Marcus AC, Smith TL, Gaglio B, Levinson $\mathrm{AH}$, et al. Evaluating initial reach and robustness of a practical randomized trial of smoking reduction. Health Psychology 2008;27(6):780-8. 
* Glasgow RE, Gaglio B, Estabrooks PA, Marcus AC, Ritzwoller DP, Smith TL, et al. Long-term results of a smoking reduction program. Medical Care 2009;47:115-20.

Levinson AH, Glasgow RE, Gaglio B, Smith TL, Cahoon J, Marcus AC. Tailored behavioral support for smoking reduction: development and pilot results of an innovative intervention. Health Education Research 2008;23(2):335-46.

\section{Gong 2016 \{published data only\}}

Gong J, Baker CL, Zou KH, Bruno M, Jumadilova Z, Lawrence D, et al. A pragmatic randomized trial comparing telephone-based enhanced pharmacy care and usual care to support smoking cessation. Journal of Managed Care and Specialty Pharmacy 2016;22(12):1417-25.

\section{Gordon 2010 \{published data only\}}

Gordon JS, Andrews JA, Crews KM, Payne TJ, Severson HH. The $5 A$ 's vs $3 A^{\prime}$ 's plus proactive quitline referral in private practice dental offices: preliminary results. Tobacco Control 2007;16(4):285-8.

* Gordon JS, Andrews JA, Crews KM, Payne TJ, Severson HH, Lichtenstein $\mathrm{E}$. Do faxed quitline referrals add value to dental office-based tobacco-use cessation interventions?. Journal of the American Dental Association 2010;141(8):1000-7.

\section{Gritz 2012 \{published data only\}}

Gritz ER, Vidrine DJ, Marks RM, Danysh MH, Arduino RC. A cell phone-delivered intervention for HIV-positive smokers: Project Reach Out [POS3-113]. Society for Research on Nicotine and Tobacco 18th Annual Meeting; 2012 March 13-16, Houston, Tx. 2012:123. []

\section{Haas 2015 \{published data only\}}

Haas JS, Linder JA, Park ER, Gonzalez I, Rigotti NA, Klinger EV, et al. Proactive tobacco cessation outreach to smokers of low socioeconomic status: a randomized clinical trial. JAMA Internal Medicine 2015;175(2):218-26.

\section{Hackbarth 2006 \{published data only\}}

Hackbarth D, Cohen RA, Preckwinkel L, Younker L, Mckee C, Solinski J, et al. Spirometry screening and an invitation to quit from a state tobacco quit line as motivators for smoking cessation among community dwelling adults. Chest 2006;130(4):145S.

\section{Hammett 2018 \{published data only\}}

Hammett P, Fu SS, Nelson D, Clothier B, Saul JE, Widome R, et al. A proactive smoking cessation intervention for socioeconomically disadvantaged smokers: the role of smoking-related stigma. Nicotine \& Tobacco Research 2018;20(3):286-94

\section{Han 2010 \{published data only\}}

Han HR, Kim J, Kim KB, Jeong S, Levine D, Li C, et al. Implementation and success of nurse telephone counseling in linguistically isolated Korean American patients with high blood pressure. Patient Education and Counseling 2010;80(1):130-4.

\section{Harris 2015 \{published data only\}}

Harris M, Reynolds B. A pilot study of home-based smoking cessation programs for rural, Appalachian, pregnant smokers. Journal of Obstetric, Gynecologic, and Neonatal Nursing 2015;44(2):236-45.

\section{Hasuo 2004 \{published data only\}}

Hasuo S, Tanaka H, Oshima A. Efficacy of a smoking relapse prevention program by postdischarge telephone contacts: a randomized trial. Nippon Koshu Eisei Zasshi [Japanese Journal of Public Health] 2004;51(6):403-12.

\section{Hawkes 2013 \{published data only\}}

Hawkes AL, Chambers SK, Pakenham KI, Patrao TA, Baade PD, Lynch BM, et al. Effects of a telephone-delivered multiple health behavior change intervention (CanChange) on health and behavioral outcomes in survivors of colorectal cancer: a randomized controlled trial. Journal of Clinical Oncology 2013;31(18):2313-21.

\section{Hebert 2011 \{published data only\}}

Hebert Kiandra K. Effects of proactive telephone counseling on cessation rates of smokers with major depression. Dissertation Abstracts International: Section B: The Sciences and Engineering 2011;71(9-B):5791.

\section{Hennrikus 2002 \{published data only\}}

Hennrikus DJ, Jeffery RW, Lando HA, Murray DM, Brelje K, Davidann B, et al. The SUCCESS Project: The effect of program format and incentives on participation and cessation in worksite smoking cessation programs. American Journal of Public Health 2002;92(2):274-9.

\section{Hokanson 2006 \{published data only\}}

Hokanson JM, Anderson RL, Hennrikus DJ, Lando HA, Kendall DM. Integrated tobacco cessation counseling in a diabetes self-management training program: a randomized trial of diabetes and reduction of tobacco. Diabetes Educator 2006;32(4):562-70.

\section{Holtrop 2005 \{published data only\}}

Holtrop JS, Wadland WC, Vansen S, Weismantel D, Fadel H. Recruiting health plan members receiving pharmacotherapy into smoking cessation counseling. American Journal of Managed Care 2005;11(8):501-7.

\section{Johnson 1999 \{published data only\}}

Johnson JL, Budz B, Mackay M, Miller C. Evaluation of a nursedelivered smoking cessation intervention for hospitalized patients with cardiac disease. Heart \& Lung 1999;28(1):55-64.

\section{Joseph 2011 \{published data only\}}

Joseph AM, Fu SS, Lindgren B, Rothman AJ, Kodl M, Lando H, et al. Chronic disease management for tobacco dependence: a randomized, controlled trial. Archives of Internal Medicine 2011; Vol. 171, issue 21:1894-900. [; 9400123000011861$]$

\section{Katz 2004 \{published data only\}}

Katz DA, Muehlenbruch DR, Brown RL, Fiore MC, Baker TB. Effectiveness of implementing the Agency for Healthcare Research and Quality smoking cessation clinical practice 
guideline: a randomized, controlled trial. Journal of the National Cancer Institute 2004;96(8):594-603.

Keten 2013 \{published data only\}

Keten E, Golbasi Z. The effect of three different smoking cessation intervention for smoker pregnant women. TAF Preventive Medicine Bulletin 2013;12(5):553-62.

Killen 2008 \{published data only\}

Killen JD, Fortmann SP, Schatzberg AF, Arredondo C, Murphy G, Hayward C, et al. Extended cognitive behavior therapy for cigarette smoking cessation. Addiction 2008;103(8):1381-90.

\section{Kim 2013 \{published data only\}}

$\mathrm{Kim} \mathrm{H}$, Kim O. The lifestyle modification coaching program for secondary stroke prevention. Journal of Korean Academy of Nursing 2013;43(3):331-40.

\section{Kim 2016 \{published data only\}}

Kim SS, Sitthisongkram S, Bernstein K, Fang $\mathrm{H}$, Choi WS, Ziedonis D. A randomized controlled trial of a videoconferencing smoking cessation intervention for Korean American women: preliminary findings. International Journal of Women's Health 2016;8:453-62.

\section{Kim 2017 \{published data only\}}

Kim SS, Darwish S, Lee SA, Demarco RF. A pilot study of a smoking cessation intervention for women living with HIV: study protocol. Open Access Journal of Clinical Trials 2017;9:11-20.

\section{Klesges 2015 \{published data only\}}

* Klesges RC, Ebbert JO, Talcott GW, Thomas F, Richey PA, Womack $\mathrm{C}$, et al. Efficacy of a tobacco quitline in active duty military and TRICARE beneficiaries: a randomized trial. Military Medicine 2015;180(8):917-25.

Richey PA, Klesges RC, Talcott GW, Debon M, Womack C, Thomas F, et al. Efficacy of a smoking quit line in the military: baseline design and analysis. Contemporary Clinical Trials 2012;33(5):959-68.

\section{Koffman 1998 \{published data only\}}

Koffman DM, Lee JW, Hopp JW, Emont SL. The impact of including incentives and competition in a workplace smoking cessation program on quit rates. American Journal of Health Promotion 1998;13:105-11.

\section{Lando 1996 \{published data only\}}

Lando HA, Pirie PL, Roski J, McGovern PG, Schmid LA. Promoting abstinence among relapsed chronic smokers: The effect of telephone support. American Journal of Public Health 1996;86(12):1786-90.

\section{Leed-Kelly 1996 \{published data only\}}

Bobo JK, Mcllvain HE, Lando HA, Walker RD, Leed-Kelly A. Effect of smoking cessation counseling on recovery from alcoholism: findings from a randomized community intervention trial. Addiction 1998;93(6):877-87.

* Leed-Kelly A, Russell KS, Bobo JK, Mcllvain H. Feasibility of smoking cessation counseling by phone with alcohol treatment center graduates. Journal of Substance Abuse Treatment 1996;13(3):203-10

\section{Lichtenstein 2002b \{published data only\}}

Lichtenstein E, Lee ME, Boles SM, Foster L, Hampson SE. Using radon risk to motivate smoking reduction: replication and extension (PO3 21). Society for Research on Nicotine and Tobacco 8th Annual Meeting; 2002 February 20-23, Savannah, Georgia. 2002.

\section{Linder 2014 \{published data only\}}

Linder JA, Haas J, Rigotti NA, Park ER, Kontos E, Gonzalez I, et al. Proactive outreach of tobacco cessation treatment to disadvantaged smokers after a primary care visit: A randomized controlled trial. Journal of General Internal Medicine 2014;29(1 Supplement):S184.

\section{Lindinger 2012 \{published data only\}}

Lindinger P, Strunk M, Nubling M, Lang P. Protocol and effectiveness of telephone counselling for smoking cessation [Arbeitsweise und Wirksamkeit einer Telefonberatung fur Tabakentwohnung]. Sucht: Zeitschrift Fur Wissenschaft Und Praxis 2012; Vol. 58, issue 1:33-43. []

\section{Little 2009 \{published data only\}}

Little SJ, Hollis JF, Fellows JL, Snyder JJ, Dickerson JF. Implementing a tobacco assisted referral program in dental practices. Journal of Public Health Dentistry 2009; Vol. 69, issue 3:149-55. []

\section{Mahabee-Gittens 2008 \{published data only\}}

Mahabee-Gittens EM, Gordon J, Krugh M, Henry B, Leonard AC. A smoking cessation intervention plus proactive quitline referral in the pediatric emergency department: A pilot study. Nicotine \& Tobacco Research 2008;10(12):1745-51.

\section{Manfredi 1999 \{published data only\}}

Manfredi C, Crittenden KS, Warnecke R, Engler J, Cho YI, Shaligram C. Evaluation of a motivational smoking cessation intervention for women in public health clinics. Preventive Medicine 1999;28(1):51-60.

Manfredi 2011 \{published data only\}

Manfredi C, Cho YI, Warnecke R, Saunders S, Sullivan M. Dissemination strategies to improve implementation of the PHS smoking cessation guideline in $\mathrm{MCH}$ public health clinics: experimental evaluation results and contextual factors. Health Education Research 2011;26(2):348-60.

Mayer 2010 \{published data only\}

Mayer C, Vandecasteele H, Bodo M, Primo C, Slachmuylder J$\mathrm{L}$, Kaufman L, et al. Smoking relapse prevention programs and factors that predict abstinence: A controlled study comparing the efficacy of workplace group counselling and proactive phone counseling. Journal of Smoking Cessation 2010;5(1):83-94.

\section{McAfee 2008 \{published data only\}}

McAfee TA, Bush T, Deprey TM, Mahoney LD, Zbikowski SM, Fellows JL, et al. Nicotine patches and uninsured Quitline 
callers. A randomized trial of two versus eight weeks. American Journal of Preventive Medicine 2008;35(2):103-10.

\section{McBride 2002 \{published data only\}}

McBride CM, Bepler G, Lipkus IM, Lyna P, Samsa G, Albright J, et al. Incorporating genetic susceptibility feedback into a smoking cessation program for African-American smokers with low income. Cancer Epidemiology, Biomarkers \& Prevention 2002;11(6):521-8.

\section{McClure 2018 \{published data only\}}

McClure JB, Blasi PR, Cook A, Bush T, Fishman P, Nelson J, et al. Oral health 4 life: design and methods of a semi-pragmatic randomized trial to promote oral health care and smoking abstinence among tobacco quitline callers. Contemporary Clinical Trials 2017;57:90-7.

* McClure JB, Bush T, Anderson ML, Blasi P, Thompson E, Nelson J, et al. Oral health promotion and smoking cessation program delivered via tobacco quitlines: the Oral Health 4 Life Trial. American Journal of Public Health 2018;108(5):689-95.

\section{McDaniel 2015 \{published data only\}}

McDaniel AM, Vickerman KA, Stump TE, Monahan PO, Fellows JL, Weaver MT, et al. A randomised controlled trial to prevent smoking relapse among recently quit smokers enrolled in employer and health plan sponsored quitlines. BMJ Open 2015;5(6):e007260.

\section{McGrath 2014 \{published data only\}}

McGrath CA, Zak CL, Baldwin K, Lutfiyya MN. Smoking cessation in primary care: implementation of a proactive telephone intervention. Journal of the American Association of Nurse Practitioners 2014;26(5):248-54.

\section{Mermelstein 2003 \{published data only\}}

Mermelstein R, Hedeker D, Wong SC. Extended telephone counseling for smoking cessation: does content matter?. Journal of Consulting and Clinical Psychology 2003;71(3):565-74.

\section{Miller 2009 \{published data only\}}

Miller CL, Sedivy V. Using a quitline plus low-cost nicotine replacement therapy to help disadvantaged smokers to quit. Tobacco Control 2009;18(2):144-9.

\section{Morris 2011 \{published data only\}}

Morris CD, Waxmonsky JA, May MG, Tinkelman DG, Dickinson M, Giese AA. Smoking reduction for persons with mental illnesses: 6-month results from community-based interventions. Community Mental Health Journal. United States, 2011; Vol. 47, issue 6:694-702. []

\section{Mullen 2016 \{published data only\}}

Mullen PD, Savas LS, Bundy LT, Haardorfer R, Hovell M, Fernandez ME, et al. Minimal intervention delivered by 2-1-1 information and referral specialists promotes smoke-free homes among 2-1-1 callers: a Texas generalisation trial. Tobacco Control 2016;25(Supplement 1):i10-i18.
Nair 2017 \{published data only\}

Nair US, Patterson F, Rodriguez D, Collins BN. A telephonebased intervention to promote physical activity during smoking cessation: a randomized controlled proof-of-concept study. Translational Behavioral Medicine 2017;7(2):138-47.

Ockene 1992 \{published data only\}

Ockene J, Kristeller J, Goldberg R, Ockene IS, Merriam P, Barrett S, et al. Smoking cessation and severity of disease: The coronary artery smoking intervention study. Health Psychology 1992;11(2):119-26.

Oddone 2017 \{published data only\}

Oddone EZ, Damschroder LJ, Gierisch J, Olsen M, Fagerlin A, Sanders $\mathrm{L}$, et al. A Coaching by Telephone Intervention for Veterans and Care Team Engagement (ACTIVATE): a study protocol for a hybrid type I effectiveness-implementation randomized controlled trial. Contemporary Clinical Trials 2017;55:1-9.

Owen 2000 \{published data only\}

Owen L. Impact of a telephone helpline for smokers who called during a mass media campaign. Tobacco Control 2000;9(2):148-54.

Papadakis 2013 \{published data only\} Papadakis S, McDonald PW, Pipe AL, Letherdale ST, Reid RD, Brown KS. Effectiveness of telephone-based follow-up support delivered in combination with a multi-component smoking cessation intervention in family practice: a cluster-randomized trial. Preventive Medicine 2013;56(6):390-7.

Parker 2007 \{published data only\}

Parker DR, Windsor RA, Roberts MB, Hecht J, Hardy NV, Strolla LO, et al. Feasibility, cost, and cost-effectiveness of a telephone-based motivational intervention for underserved pregnant smokers. Nicotine \& Tobacco Research 2007;9(10):1043-51.

Partin 2006 \{published data only\}

Partin MR, An LC, Nelson DB, Nugent S, Snyder A, Fu SS, et al. Randomized trial of an intervention to facilitate recycling for relapsed smokers. American Journal of Preventive Medicine 2006;31(4):293-9.

Patten 2009 \{published data only\}

* Patten CA, Petersen LR, Hughes CA, Ebbert JO, Morgenthaler Bonnema S, Brockman TA, et al. Feasibility of a telephonebased intervention for support persons to help smokers quit: a pilot study. Nicotine \& Tobacco Research 2009;11(4):427-32.

Patten CA, Smith CM, Brockman TA, Decker PA, Anderson KJ, Hughes $C A$, et al. Support person intervention to promote smoker utilization of the QUITPLAN Helpline. American Journal of Preventive Medicine 2008;35(6 Suppl):S479-85.

Patten 2011 \{published data only\}

Patten CA, Smith CM, Brockman TA, Decker PA, Hughes CA, Nadeau AM, et al. Support-person promotion of a smoking quitline: a randomized controlled trial. American Journal of Preventive Medicine 2011;41(1):117-23. [3141328] 


\section{Peng 2011 \{published data only\}}

Peng W-D. Evaluation of a web-phone intervention system on preventing smoking relapse. Dissertation Abstracts International 2011; Vol. 72, issue 3-A:1083. []

\section{Peterson 2009 \{published data only\}}

Bricker JB, Liu J, Comstock BA, Peterson AV, Kealey KA, Marek PM. Social cognitive mediators of adolescent smoking cessation: results from a large randomized intervention trial. Psychology of Addictive Behaviors 2010;24(3):436-45.

Liu J, Peterson AV Jr, Kealey KA, Mann SL, Bricker JB, Marek PM. Addressing challenges in adolescent smoking cessation: design and baseline characteristics of the HS Group-Randomized trial. Preventive Medicine 2007;45(2-3):215-25.

* Peterson AV, Kealey KA, Mann SL, Marek PM, Ludman EJ, Liu J, et al. Group-randomized trial of a proactive, personalized telephone counseling intervention for adolescent smoking cessation. Journal of the National Cancer Institute 2009;101(20):1378-92.

\section{Peterson 2015 \{published data only\}}

Peterson J, Prochazka AV, Battaglia C. Smoking cessation and care management for veterans with posttraumatic stress disorder: a study protocol for a randomized controlled trial. BMC Health Services Research 2015;15:46.

\section{Platt 1997 \{published data only\}}

Platt S, Tannahill A, Watson J, Fraser E. Effectiveness of antismoking telephone helpline: Follow up survey. BMJ 1997;314(7091):1371-5.

\section{Prue 1983 \{published data only\}}

Prue DM, Davis CJ, Martin JE, Moss RA. An investigation of a minimal contact brand fading program for smoking treatment. Addictive Behaviors 1983;8(3):307-10.

\section{Racelis 1998 \{published data only\}}

Racelis MC, Lombardo K, Verdin J. Impact of telephone reinforcement of risk reduction education on patient compliance. Journal of Vascular Nursing 1998;16(1):16-20.

\section{Ratner 2004 \{published data only\}}

Bottorff JL, Johnson JL, Moffat B, Fofonoff D, Budz B, Groening M. Synchronizing clinician engagement and client motivation in telephone counseling. Qualitative Health Research 2004;14(4):462-77.

* Ratner PA, Johnson JL, Richardson CG, Bottorff JL, Moffat B, Mackay M, et al. Efficacy of a smoking-cessation intervention for elective-surgical patients. Research in Nursing and Health 2004;27(3):148-61.

\section{Reid 1999b \{published data only\}}

Reid RD, Pipe AL. A telephone-based support program for overthe-counter nicotine patch users. Canadian Journal of Public Health 1999;90(6):397-8.

\section{Richter 2015 \{published data only\}}

Lambart L, Casey G, Nazir N, Richter K. Satisfaction with video versus phone couseling in a rural smoking cessation trial.
Society for Research on Nicotine and Tobacco 18th Annual Meeting; 2012 March 13-16,Houston, Texas. 2012:105.

Leon-Salas A, Hunt JJ, Richter KP, Nazir N, Ellerbeck EF, Shireman TI. Pharmaceutical assistance programs to support smoking cessation medication access. Journal of the American Pharmacists Association 2017;57(1):67-71.

Mussulman L, Ellerbeck EF, Cupertino AP, Preacher KJ, Spaulding R, Catley D, et al. Design and participant characteristics of a randomized-controlled trial of telemedicine for smoking cessation among rural smokers. Contemporary Clinical Trials 2014;38(2):173-81.

* Richter KP, Shireman TI, Ellerbeck EF, Cupertino AP, Catley D, Cox LS, et al. Comparative and cost effectiveness of telemedicine versus telephone counseling for smoking cessation. [Erratum appears in J Med Internet Res. 2015;17(6): e124]. Journal of Medical Internet Research 2015;17(5):e113.

\section{Rigotti 2014 \{published data only\}}

Japuntich SJ, Regan S, Viana J, Tymoszczuk J, Reyen M, Levy DE, et al. Comparative effectiveness of post-discharge interventions for hospitalized smokers: study protocol for a randomized controlled trial. Trials 2012;13:124.

Regan S, Reid ZZ, Kelley JH, Reyen M, Korotkin M, Japuntich SJ, et al. Smoking status confirmation by proxy: validation in a smoking cessation trial. Nicotine \& Tobacco Research 2016;18(1):34-40.

Rigotti NA, Japuntich S, Regan S, Kelley JH, Chang Y, Reyen M, et al. Promoting smoking cessation after hospital discharge: The helping hand randomized controlled comparative effectiveness trial. Journal of General Internal Medicine 2013;28(1 Suppl):S160.

* Rigotti NA, Regan S, Levy DE, Japuntich S, Chang Y, Park ER, et al. Sustained care intervention and postdischarge smoking cessation among hospitalized adults: a randomized clinical trial. JAMA 2014;312(7):719-28.

Rigotti 2016 \{published data only\}

Rigotti NA, Tindle H, Regan S, Levy D, Chang Y, Carpenter KM, et al. Adapting a post-discharge intervention for hospitalized smokers to enhance scalability: the helping hand 2 randomized controlled trial. Journal of General Internal Medicine 2016;31(2 Suppl. 1):S112-S113.

* Rigotti NA, Tindle HA, Regan S, Levy DE, Chang Y, Carpenter KM, et al. A post-discharge smoking-cessation intervention for hospital patients: Helping Hand 2 randomized clinical trial. American Journal of Preventive Medicine 2016;51(4):597-608.

\section{Rigotti 2017 \{published data only\}}

Rigotti NA, Chang Y, Rosenfeld LC, Japuntich SJ, Park ER, Tindle HA, et al. Interactive voice response calls to promote smoking cessation after hospital discharge: pooled analysis of two randomized clinical trials. Journal of General Internal Medicine 2017;32(9):1-9. 
Ringen 2002 \{published data only\}

Ringen K, Anderson N, McAfee T, Zbikowski SM, Fales D. Smoking cessation in a blue-collar population: results from an evidence-based pilot program. American Journal of Industrial Medicine 2002;42(5):367-77.

\section{Rodgers 2005 \{published data only\}}

Bramley D, Riddell T, Whittaker R, Corbett T, Lin RB, Wills M, et al. Smoking cessation using mobile phone text messaging is as effective in Maori as non-Maori. New Zealand Medical Journal 2005;118(1216):U1494.

* Rodgers A, Corbett T, Bramley D, Riddell T, Wills M, Lin RB, et al. Do u smoke after txt? Results of a randomised trial of smoking cessation using mobile phone text messaging. Tobacco Control 2005;14(4):255-61.

\section{Rogers 2018 \{published data only\}}

* Rogers ES, Fu SS, Krebs P, Noorbaloochi S, Nugent SM, Gravely A, et al. Proactive tobacco treatment for smokers using Veterans Administration mental health clinics. American Journal of Preventive Medicine 2018;54(5):620-9.

Rogers ES, Fu SS, Krebs P, Noorbaloochi S, Nugent SM, Rao R, et al. Proactive outreach for smokers using VHA mental health clinics: protocol for a patient-randomized clinical trial. $B M C$ Public Health 2014;14:1294.

\section{Roski 2003 \{published data only\}}

Roski J, Jeddeloh R, An L, Lando H, Hannan P, Hall C, et al. The impact of financial incentives and a patient registry on preventive care quality: increasing provider adherence to evidence-based smoking cessation practice guidelines. Preventive Medicine 2003;36(3):291-9.

\section{Rothemich 2010 \{published data only\}}

Rothemich SF, Woolf SH, Johnson RE, Devers KJ, Flores SK, Villars $\mathrm{P}$, et al. Promoting primary care smoking-cessation support with quitlines: the QuitLink randomized controlled trial. American Journal of Preventive Medicine 2010; Vol. 38, issue 4:367-74. []

\section{Schiebel 2007 \{published data only\}}

Schiebel NE, Ebbert JO. Quitline referral vs. self-help manual for tobacco use cessation in the Emergency Department: A feasibility study. BMC Emergency Medicine 2007;7:15.

\section{Schneider 1995 \{published data only\}}

Schneider SJ, Schwartz MD, Fast J. Computerized, telephonebased health promotion.1: Smoking cessation program. Computers and Human Behavior 1995;11:135-48.

\section{Segan 2011 \{published data only\}}

Segan CJ, Borland R. Does extended telephone callback counselling prevent smoking relapse?. Health Education Research 2011;26(2):336-47.

\section{Sharifirad 2012 \{published data only\}}

Sharifirad GR, Eslami AA, Charkazi A, Mostafavi F, Shahnazi H. The effect of individual counseling, line follow-up, and free nicotine replacement therapy on smoking cessation in the samples of Iranian smokers: Examination of transtheoretical model. Journal of Research in Medical Sciences 2012;17(12):1128-36.

\section{Sherman 2008 \{published data only\}}

Sherman SE, Takahashi N, Kalra P, Gifford E, Finney JW, Canfield J, et al. Care coordination to increase referrals to smoking cessation telephone counseling: a demonstration project. American Journal of Managed Care 2008;14(3):141-8.

Sherman 2016 \{published data only\}

Grossman E, Shelley D, Braithwaite RS, Lobach I, Goffin A, Rogers $E$, et al. Effectiveness of smoking-cessation interventions for urban hospital patients: study protocol for a randomized controlled trial. Trials 2012;13(13):126.

Rogers ES, Friedes R, Jakes A, Grossman E, Link A, Sherman SE. Long-term abstinence and predictors of tobacco treatment uptake among hospitalized smokers with serious mental illness enrolled in a smoking cessation trial. Journal of Behavioral Medicine 2017;40(5):750-9.

Sherman S, Link AR, Rogers E, Krebs P, Ladapo JA, Shelley D, et al. Smoking cessation interventions for urban hospital patients: A randomized comparative effectiveness trial. Journal of General Internal Medicine 2015;30(2 Suppl):S253.

* Sherman SE, Link AR, Rogers ES, Krebs P, Ladapo JA, Shelley DR, et al. Smoking-cessation interventions for urban hospital patients: a randomized comparative effectiveness trial. American Journal of Preventive Medicine 2016;51(4):566-77.

\section{Shiffman 2000 \{published data only\}}

Shiffman S, Paty JA, Rohay JM, Di Marino ME, Gitchell J. The efficacy of computer-tailored smoking cessation material as a supplement to nicotine polacrilex gum therapy. Archives of Internal Medicine 2000;160(11):1675-81.

\section{Sidhu 2015 \{published data only}

Sidhu MS, Daley A, Jordan R, Coventry PA, Heneghan C, Jowett $S$, et al. Patient self-management in primary care patients with mild COPD - protocol of a randomised controlled trial of telephone health coaching. BMC Pulmonary Medicine 2015;15(1):16.

\section{Simon 1997 \{published data only\}}

Simon JA, Solkowitz SN, Carmody TP, Browner WS. Smoking cessation after surgery - A randomized trial. Archives of Internal Medicine 1997;157(12):1371-6.

Simon 2003 \{published data only\}

Simon JA, Carmody TP, Hudes ES, Snyder E, Murray J. Intensive smoking cessation counseling versus minimal counseling among hospitalized smokers treated with transdermal nicotine replacement: a randomized trial. American Journal of Medicine 2003;114(7):555-62.

\section{Sivarajan 2004 \{published data only\}}

Sivarajan Froelicher ES, Miller NH, Christopherson DJ, Martin K, Parker KM, Amonetti M, et al. High rates of sustained smoking cessation in women hospitalized with cardiovascular disease: 
the Women's Initiative for Nonsmoking (WINS). Circulation 2004;109(5):587-93.

\section{Sorensen 2007b \{published data only\}}

Sorensen LT, Hemmingsen U, Jorgensen T. Strategies of smoking cessation intervention before hernia surgery - Effect on perioperative smoking behavior. Hernia 2007;11(4):327-33.

\section{Stevens 1993 \{published data only\}}

Stevens VJ, Glasgow RE, Hollis JF, Lichtenstein E, Vogt TM. A smoking-cessation intervention for hospital patients. Medical Care 1993;31(1):65-72.

\section{Stoltzfus 2011 \{published data only\}}

Stoltzfus K, Ellerbeck EF, Hunt S, Rabius V, Carlini B, Ayers C, et al. A pilot trial of proactive versus reactive referral to tobacco quitlines. Journal of Smoking Cessation 2011; Vol. 6, issue 2:133-7. []

\section{Strong 2012 \{published data only\}}

Strong DR, Taylor AN, Abrantes A, Kahler CW, Miller V, Brown RA, et al. Mood management phone counseling for smokers with recurrent depression (POS3-22). Society for Research on Nicotine and Tobacco 18th Annual Meeting; 2012 March 13-16, 2012, Houston, Texas 2012:98. []

\section{Sutton 2007 \{published data only\}}

Gilbert H, Sutton S. Does adding tailored feedback to telephone counselling improve quit rates? (POS1-033). Society for Research on Nicotine and Tobacco 10th Annual Meeting; 2004 February 18-21, Phoenix, Arizona. 2004.

* Sutton S, Gilbert H. Effectiveness of individually tailored smoking cessation advice letters as an adjunct to telephone counselling and generic self-help materials: Randomized controlled trial. Addiction 2007;102(6):994-1000.

\section{Szklo 2010 \{published data only\}}

Szklo AS, Coutinho ES. The influence of smokers' degree of dependence on the effectiveness of message framing for capturing smokers for a Quitline. Addictive Behaviors 2010; Vol. 35 , issue 6:620-4. [; 214]

\section{Taylor 1990 \{published data only\}}

Taylor CB, Houston-Miller N, Killen JD, DeBusk RF. Smoking cessation after acute myocardial infarction: effects of a nurse-managed intervention. Annals of Internal Medicine 1990;113(2):118-23.

\section{Terazawa 2001 \{published data only\}}

Terazawa T, Mamiya T, Masui S, Nakamura M. The effect of smoking cessation counseling at health checkup. Sangyo Eiseigaku Zasshi [Journal of Occupational Health] 2001; Vol. 43, issue 6:207-13. []

\section{Terry 2011 \{published data only\}}

Terry PE, Seaverson EL, Staufacker MJ, Tanaka A. The effectiveness of a telephone-based tobacco cessation program offered as part of a worksite health promotion program. Population Health Management 2011;14(3):117-25.

\section{Toll 2010 \{published data only\}}

Croyle RT. Increasing the effectiveness of tobacco quitlines. Journal of the National Cancer Institute 2010;102(2):72-3.

Fucito LM, Latimer AE, Carlin-Menter S, Salovey P, Cummings KM, Makuch RW, et al. Nicotine dependence as a moderator of a quitline-based message framing intervention. Drug and Alcohol Dependence 2011;114(2-3):229-32.

Latimer-Cheung AE, Fucito LM, Carlin-Menter S, Rodriguez J, Raymond L, Salovey P, et al. How do perceptions about cessation outcomes moderate the effectiveness of a gainframed smoking cessation telephone counseling intervention?. Journal of Health Communication 2012;17(9):1081-98. []

* Toll BA, Martino S, Latimer A, Salovey P, O'Malley S, CarlinMenter S, et al. Randomized trial: Quitline specialist training in gain-framed vs standard-care messages for smoking cessation. Journal of the National Cancer Institute 2010;102(2):96-106.

\section{Tseng 20162015 \{published data only\}}

Tseng TY, Krebs P, Schoenthaler A, Wong S, Sherman S, Gonzalez M, et al. Combining text messaging and telephone counseling to increase varenicline adherence and smoking abstinence among cigarette smokers living with HIV: a randomized controlled study. AIDS and Behavior 2016;21(7):1964-74.

\section{Urso 2003 \{published data only\}}

Urso PP. Augmenting tobacco cessation treatment outcomes with telephone-delivered interventions. Dissertation Abstracts International: Section B: The Sciences and Engineering 2003;64(5-B):2133.

\section{Van der Meer 2010 \{published data only\}}

Schippers G, Van der Meer R, Willemsen M, Smit PH, Cuypers P. Preliminary results from a RCT of a smoking cessation intervention for smokers with a history of major depression. European Neuropsychopharmacology 2006;16:S201.

* Van der Meer RM, Willemsen MC, Smit F, Cuijpers P, Schippers GM. Effectiveness of a mood management component as an adjunct to a telephone counselling smoking cessation intervention for smokers with a past major depression: a pragmatic randomized controlled trial. Addiction 2010;105(11):1991-9.

\section{Vidrine 2006 \{published data only\}}

Vidrine DJ, Arduino RC, Gritz ER. Impact of a cell phone intervention on mediating mechanisms of smoking cessation in individuals living with HIV/AIDS. Nicotine \& Tobacco Research 2006;8 Suppl 1:S103-8.

* Vidrine DJ, Arduino RC, Lazev AB, Gritz ER. A randomized trial of a proactive cellular telephone intervention for smokers living with HIV/AIDS. AIDS 2006;20(2):253-60.

\section{Wadland 1999 \{published data only\}}

Wadland WC, Stoffelmayr B, Berger E, Crombach A, Ives K. Enhancing smoking cessation rates in primary care. Journal of Family Practice 1999;48(9):711-8. 
Wadland 2001 \{published data only\}

Wadland WC, Stoffelmayr B, Ives K. Enhancing smoking cessation of low-income smokers in managed care. Journal of Family Practice 2001;50(2):138-44.

\section{Wadland 2007 \{published data only\}}

Holtrop JS, Malouin R, Weismantel D, Wadland WC. Clinician perceptions of factors influencing referrals to a smoking cessation program. BMC Family Practice 2008;9:18.

* Wadland WC, Holtrop JS, Weismantel D, Pathak PK, Fadel H, Powell J. Practice-based referrals to a tobacco cessation quit line: assessing the impact of comparative feedback vs general reminders. Annals of Family Medicine 2007;5(2):135-42.

\section{Walker 2011a \{published data only\}}

Walker N, Howe C, Bullen C, Grigg M, Glover M, McRobbie H, et al. Does improved access and greater choice of nicotine replacement therapy affect smoking cessation success? Findings from a randomized controlled trial. Addiction 2011;106(6):1176-85.

\section{Walker 2011b \{published data only\}}

Walker NK, Howe C, Bullen C, Grigg M, Glover M, McRobbie H, et al. Study protocol for a randomised trial of nicotine-free cigarettes as an adjunct to usual NRT-based cessation practice, in people who wish to stop smoking. BMC Public Health 2011;11(1):37.

\section{Wang 2017 \{published data only\}}

Wang MP, Suen YN, Li WH-C, Lam CO-B, Wu SY-D, Kwong AC-S, et al. Intervention with brief cessation advice plus active referral for proactively recruited community smokers: a pragmatic cluster randomized clinical trial. JAMA Internal Medicine 2017;177(12):1790-7.

\section{Warner 2011 \{published data only\}}

Warner DO, Klesges RC, Dale LC, Offord KP, Schroeder DR Shi Y, et al. Clinician-delivered intervention to facilitate tobacco quitline use by surgical patients. Anesthesiology 2011;114(4):847-55.

\section{Weaver 2015 \{published data only\}}

Weaver K, Kaplan S, Urbanic J, Case D, Zbikowski S, Dakhil CS, et al. Incorporating evidence-based smoking cessation into community oncology practices: Feasibility and preliminary efficacy of an enhanced quitline-based smoking cessation intervention for cancer survivors. Psycho-Oncology 2015;24(Suppl. 2):32.

Weaver KE, Kaplan S, Griffin L, Urbanic J, Zbikowski S, Danhauer SC. Satisfaction with a quitline-based smoking cessation intervention among cancer survivors. Cancer Epidemiology, Biomarkers \& Prevention. 39th Annual Conference of the American Society of Preventive Oncology, ASPO 2015. United States 2015;24(4):759.

* Weaver KE, Urbanic JJ, Case D, Kaplan SG, Lesser GJ, Zbikowski S, et al. Preliminary efficacy of an enhanced quitline smoking cessation intervention for cancer patients. Journal of Clinical Oncology 2015;33(15 Suppl. 1):e20671.
Westman 1993 \{published data only\}

Westman EC, Levin ED, Rose JE. The nicotine patch in smoking cessation. A randomized trial with telephone counseling. Archives of Internal Medicine 1993;153(16):1917-23.

\section{Wetter 2007 \{published data only\}}

Daza P, Nguyen L, Mazas C, Mejia C, Wetter D. Smoking cessation among hispanic smoker: jadios al fumar! (POS3-065). Society for Research on Nicotine and Tobacco 11th Annual Meeting; 2005 March 20-23, Prague. Czech Republic. 2005

Mazas C, Li Y, Cofta-Woerpel L, Wetter DW, Daza P, Nguyen L, et al. Disparities and smoking cessation among Latinos (SYM 2B). Society for Research on Nicotine and Tobacco 13th Annual Meeting; 2007 February 21-24, Austin, Texas. 2007.

Reitzel LR, Costello TJ, Mazas CA, Vidrine JI, Businelle MS, Kendzor DE, et al. Low-level smoking among Spanish-speaking Latino smokers: relationships with demographics, tobacco dependence, withdrawal, and cessation. Nicotine \& Tobacco Research 2009;11(2):178-84.

* Wetter DW, Mazas C, Daza P, Nguyen L, Fouladi RT, Li Y, et al. Reaching and treating Spanish-speaking smokers through the National Cancer Institute's Cancer Information Service. A randomized controlled trial. Cancer 2007;109(2 Suppl):406-13.

\section{Wewers 2017 \{published data only\}}

Nemeth JM, Cooper S, Wermert A, Shoben A, Wewers ME. The relationship between type of telephone service and smoking cessation among rural smokers enrolled in quitline tobacco dependence treatment. Preventive Medicine Reports 2017;8:226-231.

* Wewers ME, Shoben A, Conroy S, Curry E, Ferketich AK, Murray DM, et al. Effectiveness of two community health worker models of tobacco dependence treatment among community residents of Ohio Appalachia. Nicotine \& Tobacco Research 2017;19(12):1499-507.

Willemsen 2008 \{published data only\}

Willemsen MC, Van der Meer RM, Bot S. Description, effectiveness, and client satisfaction of 9 European Quitlines:Results of the European Smoking Cessation Helplines Evaluation Project (ESCHER). https:// www.alliantienederlandrookvrij.nl/wp-content/uploads/2012/ docs/rapporten/stoppenmetroken/ESCHER\%20Final \%20Report.pdf (accessed 25/06/2013). Stivoro, 2008.

\section{Wolfenden 2008a \{published data only\}}

Wolfenden L, Wiggers J, Campbell E, Knight J. Pilot of a preoperative smoking cessation intervention incorporating post-discharge support from a Quitline. Health Promotion Journal of Australia 2008;19(2):158-60.

\section{Zanis 2011 \{published data only\}}

Zanis DA, Hollm RE, Derr D, Ibrahim JK, Collins BN, Coviello D, et al. Comparing intervention strategies among rural, low SES, young adult tobacco users. American Journal of Health Behavior 2011;35(2):240-7. 
Zawertailo 2013 \{published data only\}

Zawertailo L, Dragonetti R, Bondy SJ, Victor JC, Selby P. Reach and effectiveness of mailed nicotine replacement therapy for smokers: 6-month outcomes in a naturalistic exploratory study. Tobacco Control 2013;22(3):e4.

\section{Zhu 2000 \{published and unpublished data\}}

Zhu SH, Rosbrook B, Anderson C, Tedeschi GJ, Gutierrez E, Johnson C, et al. Use of nicotine patch and its effects for smokers calling a statewide telephone counseling helpline. Nicotine \& Tobacco Research 1999;1(1):113.

* Zhu SH, Tedeschi GJ, Anderson CM, Rosbrook B, Byrd M, Johnson $\mathrm{CE}$, et al. Telephone counseling as adjuvant treatment for nicotine replacement therapy in a "Real-World" setting. Preventive Medicine 2000;31(4):357-63.

\section{References to ongoing studies}

Argyropoulou 2005 \{published data only\}

Argyropoulou P, Pataka A, Pitsiou G, Zisi P, Manolakoglou N, Kontakiotis T. Smoking cessation: data for two years from two different interventions. European Respiratory Journal 2005;26(Suppl 49):388s.

\section{Humfleet 2012 \{published data only\}}

Humfleet G, Hall SM. Using telephone-based and internet-based smoking treatments with LGBT smokers: preliminary findings (PA7-3). Society for Research on Nicotine and Tobacco 18th Annual Meeting; 2012 March 13-16, Houston Texas 2012:26. []

\section{Mak 2015 \{published data only\}}

Mak YW, Lee PH, Loke AY. Predictors of participation in a telephone-based Acceptance and Commitment Therapy for smoking cessation study. BMC Public Health 2015;23(15):1288.

* Mak YW, Loke AY. The acceptance and commitment therapy for smoking cessation in the primary health care setting: a study protocol. BMC Public Health 2015;15:105.

\section{NCT00311948 \{published data only\}}

NCT00311948. Telephone and web-based teen tobacco cessation in HMOs. clinicaltrials.gov/ct2/show/NCT00311948 (First received 6 April 2006).

\section{NCT00851357 \{published data only\}}

NCT00851357. Telephone counseling and the distribution of nicotine patches to smokers. clinicaltrials.gov/ct2/show/ NCT00851357 (First received 25 February 2009).

\section{NCT01892813 \{published data only\}}

NCT01892813. Dissemination of a tailored tobacco quitline for rural veteran smokers. clinicaltrials.gov/ct2/show/NCT01892813 (First received 4 July 2013).

\section{NCT01893502 \{published data only\}}

NCT01893502. Duration of follow-up counselling on smoking cessation outcomes. clinicaltrials.gov/ct2/show/NCT01893502 (First received 9 July 2013).
NCT02157610 \{published data only\}

NCT02157610. Smoking cessation for cervical cancer survivors. clinicaltrials.gov/ct2/show/NCT02157610 (First received 4 June 2014.

\section{NCT02397369 \{published data only\}}

NCT02397369. Evaluation of efficacy of different methods of tobacco cessation interventions among BEST employees in Mumbai. clinicaltrials.gov/ct2/show/NCT02397639 (First received 24 March 2015).

\section{NCT02421991 \{published data only\}}

NCT02421991. Telephone-delivered interventions for smoking cessation (TALK). clinicaltrials.gov/ct2/show/NCT02421991 (First received 21 April 2015).

\section{NCT03002883 \{published data only\}}

NCT03002883. STAND community college tobacco cessation trial. clinicaltrials.gov/ct2/show/NCT03002883 (First received 26 December 2016).

\section{NCT03194958 \{published data only\}}

NCT03194958. Helping poor smokers quit. clinicaltrials.gov/ct2/ show/NCT03194958 (First received 21 June 2017).

NCT03236025 \{published data only\}

NCT03236025. A video-led smoking cessation intervention in helping male smokers who is planning to have a baby to quit. clinicaltrials.gov/ct2/show/NCT03236025 (First received 1 August 2017).

NCT03538938 \{published data only\}

NCT03538938. Improving quitline support study (IQS). clinicaltrials.gov/ct2/show/NCT03538938 (First received 28 May 2018).

\section{NTR6092 \{published data only\}}

NTR6092. Recruitment strategies for an effective smoking cessation programme for parents (De implementatie van een effectieve interventie om te stoppen met roken voor ouders). www.trialregister.nl/trialreg/admin/rctview.asp?TC=6092 (First received 15 September 2016).

Salgado Garcia 2018 \{published data only\} Salgado Garcia FI, Derefinko KJ, Bursac Z, Hand S, Klesges RC. Planning a Change Easily (PACE): a randomized controlled trial for smokers who are not ready to quit. Contemporary Clinical Trials 2018;68:14-22.

\section{Sienkiewicz-Jarosz 2015 \{published data only\}}

Sienkiewicz-Jarosz H, Glebicka A, Restel M, KurkowskaJastrzebska I, Bozek M, Ryglewicz D, et al. Antismoking interventions in stroke patients-polish perspective. Journal of the Neurological Sciences 2015;357:e410-e411.

\section{Additional references \\ An 2006a}

An LC, Schillo BA, Kavanaugh AM, Lachter RB, Luxenberg MG, Wendling $A H$, et al. Increased reach and effectiveness of 
a statewide tobacco quitline after the addition of access to free nicotine replacement therapy. Tobacco Control 2006;15(4):286-93

\section{Anderson 2007}

Anderson CM, Zhu SH. Tobacco quitlines: looking back and looking ahead. Tobacco Control 2007;16 Suppl 1:i81-86.

\section{Anon 2005}

Anon. HHS 'Quitline' helps Americans stop smoking. FDA Consumer 2005;39:4-5.

\section{Boldemann 2006}

Boldemann C, Gilljam H, Lund KE, Helgason AR. Smoking cessation in general practice: the effects of a quitline. Nicotine \& Tobacco Research 2006;8(6):785-90.

\section{Borland 2006}

Borland R, Segan CJ. The potential of quitlines to increase smoking cessation. Drug and Alcohol Review 2006;25(1):73-8.

\section{Bush 2008}

Bush TM, McAfee T, Deprey M, Mahoney L, Fellows JL, McClure, $J$, et al. The impact of a free nicotine patch starter kit on quit rates in a state quit line. Nicotine \& Tobacco Research 2008;10(9):1511-6.

\section{Campbell 2008}

Campbell SL, Lee L, Haugland C, Helgerson SD, Harwell TS. Tobacco quitline use: enhancing benefit and increasing abstinence. American Journal of Preventive Medicine 2008;35(4):386-8.

\section{Chamberlain 2017}

Chamberlain C, O'Mara-Eves A, Porter J, Coleman T, Perlen SM, Thomas J, et al. Psychosocial interventions for supporting women to stop smoking in pregnancy. Cochrane Database of Systematic Reviews 2017, Issue 2. [DOI: 10.1002/14651858.CD001055.pub5]

\section{Chan 2008}

Chan SS, Wong DC, Fong DY, Leung AY, Lam DO, Mak YW, et al. The establishment and promotion of the first Youth Quitline in Hong Kong: challenges and opportunities. Evaluation \& the Health Professions 2008;31(3):258-71.

\section{Cummings 2006b}

Cummings KM, Fix B, Celestino P, Carlin-Menter S, O'Connor R, Hyland A. Reach, efficacy, and cost-effectiveness of free nicotine medication giveaway programs. Journal of Public Health Management and Practice 2006;12(1):37-43.

\section{Cummins 2007}

Cummins SE, Bailey L, Campbell S, Koon-Kirby C, Zhu SH. Tobacco cessation quitlines in North America: a descriptive study. Tobacco Control 2007;16 Suppl 1:i9-15.

\section{Davis 2013}

Davis KA, Coady MH, Mbamalu IG, Sacks R, Kilgore EA. Lessons learned from the implementation of a time-limited, large-scale nicotine replacement therapy giveaway program in New York City. Health Promotion Practice 2013; Vol. 14, issue 5:767-76.

\section{Doll 2004}

Doll R, Peto R, Boreham J, Sutherland I. Mortality in relation to smoking: 50 years' observations on male British doctors. $B M J$ 2004;328(7455):1519.

\section{Fanshawe 2017}

Fanshawe TR, Halliwell W, Lindson N, Aveyard P, LivingstoneBanks J, Hartmann-Boyce J. Tobacco cessation interventions for young people. Cochrane Database of Systematic Reviews 2017, Issue 11. [DOI: 10.1002/14651858.CD003289.pub6]

\section{Farley 2012}

Farley AC, Hajek P, Lycett D, Aveyard P. Interventions for preventing weight gain after smoking cessation. Cochrane Database of Systematic Reviews 2012, Issue 1. [DOI: 10.1002/14651858.CD006219.pub3]

\section{Fellows 2007}

Fellows JL, Bush T, McAfee T, Dickerson J. Cost effectiveness of the Oregon quitline "free patch initiative". Tobacco Control 2007;16 Suppl 1:i47-52.

\section{Fiore 2008}

Fiore MC, Jaén CR, Baker TB, Bailey WC, Benowitz NL, Curry SJ, et al. Treating Tobacco Use and Dependence: 2008 Update. Clinical Practice Guideline. Rockville, MD: U.S. Department of Health and Human Services. Public Health Service, May 2008.

\section{Gilbert 2005}

Gilbert H, Sutton S, Sutherland G. Who calls QUIT? The characteristics of smokers seeking advice via a telephone helpline compared with smokers attending a clinic and those in the general population. Public Health 2005;119(10):933-9.

\section{Glasgow 1991}

Glasgow RE, Hollis JF, McRae SG, Lando HA, LaChance P. Providing an integrated program of low intensity tobacco cessation services in a health maintenance organization. Health Education Research 1991;6(1):87-9.

\section{Hall 2001}

Hall SM, Delucchi KL, Velicer WF, Kahler CW, Ranger-Moore J, Hedeker D, et al. Statistical analysis of randomized trials in tobacco treatment: longitudinal designs with dichotomous outcome. Nicotine \& Tobacco Research 2001;3(3):193-202.

\section{Higgins 2003}

Higgins JP, Thompson SG, Deeks JJ, Altman DG. Measuring inconsistency in meta-analyses. BMJ 2003;327(7414):557-60.

\section{La Porta 2007}

La Porta M, Hagood H, Kornfeld J, Treiman K. Evaluating the $\mathrm{NCl}$ 's Cancer Information Service Contact Centers: meeting and exceeding the expectations of the public. Journal of Cancer Education 2007;22(1 Suppl):S18-25. 


\section{Lancaster 2017}

Lancaster T, Stead LF. Individual behavioural counselling for smoking cessation. Cochrane Database of Systematic Reviews 2017, Issue 3. [DOI: 10.1002/14651858.CD001292.pub3]

\section{Lichtenstein 1996}

Lichtenstein E, Glasgow RE, Lando HA, Ossip Klein DJ, Boles SM. Telephone counseling for smoking cessation - rationales and metaanalytic review of evidence. Health Education Research 1996;11(2):243-57.

\section{Lichtenstein 2002a}

Lichtenstein $\mathrm{E}$. The effectiveness of telephone counseling for smoking cessation. Society for Research on Nicotine and Tobacco 4th European Conference; 2002 October 3-5, Santander, Spain. 2002.

\section{Lichtenstein 2007}

Lichtenstein E. Quitlines. Tobacco Control 2007;16 Suppl 1:i1-12.

\section{Livingstone-Banks 2019a}

Livingstone-Banks J, Ordóñez-Mena JM, Hartmann-Boyce J. Print-based self-help interventions for smoking cessation. Cochrane Database of Systematic Reviews 2019, Issue 1. [DOI: 10.1002/14651858.CD001118.pub4]

\section{Livingstone-Banks 2019b}

Livingstone-Banks J, Norris E, Hartmann-Boyce J, West R, Jarvis M, Hajek P. Relapse prevention interventions for smoking cessation. Cochrane Database of Systematic Reviews 2019, Issue 2. [DOI: 10.1002/14651858.CD003999.pub5]

\section{McAfee 2007}

McAfee TA. Quitlines a tool for research and dissemination of evidence-based cessation practices. American Journal of Preventive Medicine 2007;33(6 Suppl):S357-67.

\section{Mons 2015}

Mons U, Müezzinler A, Gellert C, Schöttker B, Abnet CC, Bobak M, et al. Impact of smoking and smoking cessation on cardiovascular events and mortality among older adults: metaanalysis of individual participant data from prospective cohort studies of the CHANCES consortium. BMJ 2015;350:h1551.

\section{Müezzinler 2015}

Müezzinler A, Mons U, Gellert C, Schöttker B, Jansen E, Kee F, et al. Smoking and all-cause mortality in older adults: results from the CHANCES consortium. American Journal of Preventive Medicine 2015;49(5):e53-63.

\section{O'Connor 2008}

O'Connor RJ, Carlin-Menter SM, Celestino PB, Bax P, Brown A, Cummings $\mathrm{KM}$, et al. Using direct mail to prompt smokers to call a quitline. Health Promotion Practice 2008;9(3):262-70.

\section{Ordóñez-Mena 2016}

Ordóñez-Mena JM, Schöttker B, Mons U, Jenab M, Freisling H, Bueno-de-Mesquita B, et al. Quantification of the smokingassociated cancer risk with rate advancement periods: metaanalysis of individual participant data from cohorts of the CHANCES consortium. BMC Medicine 2016;14(1):62.

\section{Ossip-Klein 2003}

Ossip-Klein DJ, McIntosh S. Quitlines in North America: Evidence base and applications. American Journal of the Medical Sciences 2003;326(4):201-5.

\section{Perry 2005}

Perry RJ, Keller PA, Fraser D, Fiore MC. Fax to quit: a model for delivery of tobacco cessation services to Wisconsin residents. Wisconsin Medical Journal 2005;104(4):37-40.

\section{Pirie 2013}

Pirie K, Peto R, Reeves GK, Green J, Beral V, Million Women Study Collaborators. The 21st century hazards of smoking and benefits of stopping: a prospective study of one million women in the UK. Lancet 2013;12(381):9861.

\section{R 2018 [Computer program]}

R Foundation for Statistical Computing. R: A language and environment for statistical computing. Version 3.5.0. Vienna, Austria: R Foundation for Statistical Computing, 2018.

\section{Schwarzer 2007}

Schwarzer G. meta: An R package for meta-analysis. $R$ News 2007;7(3):40-45.

\section{Schwindt 2018}

Schwindt R, Hudmon KS, Knisely M, Davis L, Pike C. Impact of tobacco quitlines on smoking cessation in persons with mental illness: a systematic review. Journal of Drug Education 2018;47(1-2):68-81.

\section{Stead 2015}

Stead LF, Koilpillai P, Lancaster T. Additional behavioural support as an adjunct to pharmacotherapy for smoking cessation. Cochrane Database of Systematic Reviews 2015, Issue 10. [DOI: 10.1002/14651858.CD009670.pub3]

\section{Stead 2017}

Stead LF, Carroll AJ, Lancaster T. Group behaviour therapy programmes for smoking cessation. Cochrane Database of Systematic Reviews 2017, Issue 3. [DOI: 10.1002/14651858.CD001007.pub3]

\section{Tinkelman 2007}

Tinkelman D, Wilson SM, Willett J, Sweeney CT. Offering free NRT through a tobacco quitline: impact on utilisation and quit rates. Tobacco Control 2007;16 Suppl 1:i42-6.

\section{Tzelepis 2011b}

Tzelepis F, Paul CL, Walsh RA, McElduff P, Knight J. Proactive telephone counseling for smoking cessation: meta-analyses by recruitment channel and methodological quality. Journal of the National Cancer Institute 2011;103(12):922-41.

\section{Tzelepis 2017}

Tzelepis F, Paul CL, Williams CM, Gilligan C, Regan T, Daly J, et al. Real-time video counselling for smoking cessation. Cochrane Database of Systematic Reviews 2017, Issue 5. [DOI: 10.1002/14651858.CD012659] 


\section{USDHHS 2014}

U.S. Department of Health and Human Services. The Health Consequences of Smoking-50 Years of Progress: A Report of the Surgeon General. Atlanta, GA: U.S. Department of Health and Human Services, Centers for Disease Control and Prevention, National Center for Chronic Disease Prevention and Health Promotion, Office on Smoking and Health, 2014.

\section{Van Deusen 2007}

Van Deusen AM, Hyland A, Abrams SM, Celestino P, Mahoney MC, Cummings KM. Smokers' acceptance of "cold calls" offering quitline services. Tobacco Control 2007;16(Suppl 1):i30-32.

\section{Vidrine 2011}

Vidrine DJ, Vidrine Jl. Active vs passive recruitment to quitline studies: public health implications. Journal of the National Cancer Institute 2011;103(12):909-10.

\section{Viechtbauer 2010}

Viechtbauer W. Conducting meta-analyses in R with the metafor package. Journal of Statistical Software 2010;36(3):1-48.

\section{Wakefield 2000}

Wakefield M, Borland R. Saved by the bell: the role of telephone helpline services in the context of mass-media anti-smoking campaigns. Tobacco Control 2000;9(2):117-9.

\section{Whittaker 2016}

Whittaker R, McRobbie H, Bullen C, Rodgers A, Gu Y. Mobile phone-based interventions for smoking cessation. Cochrane Database of Systematic Reviews 2016, Issue 4. [DOI: 10.1002/14651858.CD006611.pub4]

\section{WHO 2018}

World Health Organization. Tobacco: Key Facts. World Health Organization Fact Sheets 9 March 2019:www.who.int/newsroom/fact-sheets/detail/tobacco.

\section{Winickoff 2006}

Winickoff JP, Tanski SE, McMillen RC, Hipple BJ, Friebely J, Healey EA. A national survey of the acceptability of quitlines to help parents quit smoking. Pediatrics 2006;117(4):e695-700.

\section{Wolfenden 2008}

Wolfenden L, Wiggers J, Campbell E, Knight J, Kerridge R, Moore K, et al. Feasibility, acceptability, and cost of referring surgical patients for postdischarge cessation support from a quitline. Nicotine \& Tobacco Research 2008;10(6):1105-8.

\section{Zhu 2000a}

Zhu SH, Anderson CM, Johnson CE, Tedeschi G, Roeseler A. A centralised telephone service for tobacco cessation: the California experience. Tobacco Control 2000;9 (Suppl 2):ii48ii55.

\section{Zhu 2006}

Zhu SH, Nguyen QB, Cummins S, Wong S, Wightman V. Nonsmokers seeking help for smokers: a preliminary study. Tobacco Control 2006;15(2):107-13.

\section{References to other published versions of this review Stead 2000}

Stead LF, Lancaster T. Telephone counselling for smoking cessation. Cochrane Database of Systematic Reviews 2000, Issue 4.

\section{Stead 2001}

Stead LF, Lancaster T. Telephone counselling for smoking cessation. Cochrane Database of Systematic Reviews 2001, Issue 2. [DOI: 10.1002/14651858.CD002850]

\section{Stead 2003}

Stead LF, Lancaster T. Telephone counselling for smoking cessation. Cochrane Database of Systematic Reviews 2003, Issue 1. [DOI: 10.1002/14651858.CD002850]

\section{Stead 2006}

Stead LF, Perera R, Lancaster T. Telephone counselling for smoking cessation. Cochrane Database of Systematic Reviews 2006, Issue 3. [DOI: 10.1002/14651858.CD002850.pub2]

\section{Stead 2007}

Stead LF, Perera R, Lancaster T. A systematic review of interventions for smokers who contact quitlines. Tobacco Control 2007;16 Suppl 1:i3-8.

\section{Stead 2009}

Stead LF, Perera R, Lancaster T. Telephone counselling for smoking cessation. Cochrane Database of Systematic Reviews 2009, Issue 3. [DOI: 10.1002/14651858.CD002850.pub2]

\section{Stead 2013}

Stead LF, Hartmann-Boyce J, Perera R, Lancaster T. Telephone counselling for smoking cessation. Cochrane Database of Systematic Reviews 2013, Issue 8. [DOI: 10.1002/14651858.CD002850.pub3]

* Indicates the major publication for the study

\section{CHARACTERISTICS OF STUDIES}

\section{Characteristics of included studies [author-defined order]}

Abdullah 2005

Methods Setting: Parents of children in a birth cohort study, Hong Kong Recruitment: Active; by mail, current smokers, not selected for motivation 
Abdullah 2005 (Continued)

Participants $\quad 903$ current smokers with young children (49 recent quitters not included here); $84 \% \mathrm{M},>50 \%$ aged 36 to $45,91 \%$ smoked $\leq 20 /$ day

Interventions

1. Single mailing of stage-matched $\mathrm{S}-\mathrm{H}$ (either preparation/action or contemplation/precontemplation)

2. As 1 , plus 20 to 30 mins of TC at time of enrolment by trained nurse counsellor. Hotline number, fur-

ther counselling at 1 month and 3 months. Average duration of counselling 38 mins over 3 contacts

$\begin{array}{ll}\text { Outcomes } & \text { Validated abstinence at } 6 \mathrm{~m}(7 \text {-day PP). } \\ & \text { Validation: } \mathrm{CO}<9 \mathrm{ppm} \text { or urine cotinine }<100 \mathrm{mmol} / \mathrm{mol}\end{array}$

Notes

\section{Risk of bias}

\begin{tabular}{lll}
\hline Bias & Authors' judgement & Support for judgement \\
\hline $\begin{array}{l}\text { Random sequence genera- } \\
\text { tion (selection bias) }\end{array}$ & Unclear risk & Randomised, method not described \\
\hline $\begin{array}{l}\text { Allocation concealment } \\
\text { (selection bias) }\end{array}$ & Low risk & Numbered sealed opaque envelopes \\
\hline $\begin{array}{l}\text { Blinding of outcome as- } \\
\text { sessment (detection bias) }\end{array}$ & Low risk & $\begin{array}{l}\text { Quote: "Independent interviewer...was unaware of subjects' group alloca- } \\
\text { tion... All respondents who reported they were not smoking during the preced- } \\
\text { ing 7 days were invited to attend the research centre for biochemical valida- } \\
\text { tion." }\end{array}$ \\
\hline $\begin{array}{l}\text { Incomplete outcome data } \\
\begin{array}{l}\text { (attrition bias) } \\
\text { All outcomes }\end{array}\end{array}$ & Low risk & $\begin{array}{l}\text { Losses to follow-up 11\% intervention/ 4\% control. Included as continuing } \\
\text { smokers }\end{array}$ \\
\hline
\end{tabular}

An 2006

$\begin{array}{ll}\text { Methods } & \text { Setting: } 5 \text { Veterans Administration medical centres, USA } \\ \text { Recruitment: By mail, planning to quit in next } 30 \text { days }\end{array}$

Participants

821 smokers interested in quitting (excludes 16 deaths, 1 withdrawal); $91 \% \mathrm{M}$, av. age 57, av. cigs/day 26. $26 \%$ had $>7$-day abstinence in previous year, $44 \%$ ever use of bupropion, $82 \%$ ever use NRT

Interventions

1. Mailed S-H and standard care; opportunity for intervention during routine health care and referral to individual or group cessation programmes. NRT and bupropion avail on formulary

2. As 1, plus proactive TC, modified California helpline protocol, 7 calls over $2 \mathrm{~m}$, relapse-sensitive schedule. NRT and bupropion available, could be mailed directly after screening and primary provider approval for bupropion

$\begin{array}{ll}\text { Outcomes } & \begin{array}{l}\text { Abstinence at } 12 \mathrm{~m} \text { (sustained }>6 \mathrm{~m}, 7 \text {-day PP also reported) } \\ \text { Validation: none }\end{array}\end{array}$

Notes

\section{Risk of bias}

Bias Authors' judgement Support for judgement


An 2006 (Continued)

Random sequence genera- Unclear risk $\quad$ Randomised, method not described
tion (selection bias)

$\begin{array}{ll}\text { Allocation concealment } & \text { Unclear risk }\end{array}$

\begin{tabular}{lll}
\hline $\begin{array}{l}\text { Blinding of outcome as- } \\
\text { sessment (detection bias) } \\
\text { All outcomes }\end{array}$ & High risk & $\begin{array}{l}\text { Self-reported outcomes from participants not blinded to treatment condition. } \\
\text { Level of personal contact differed between arms }\end{array}$ \\
\hline $\begin{array}{l}\text { Incomplete outcome data } \\
\text { (attrition bias) } \\
\text { All outcomes }\end{array}$ & Low risk to follow-up included as smokers, 16 deaths excluded \\
\hline
\end{tabular}

\section{Aveyard 2003}

\begin{tabular}{|c|c|}
\hline Methods & $\begin{array}{l}\text { Setting: } 65 \text { general practices, UK } \\
\text { Recruitment: Active; volunteers from random selection of smoking patients, not selected for motiva- } \\
\text { tion } \\
\text { Randomisation: Centralised, minimisation to balance SoC, addiction and SES }\end{array}$ \\
\hline Participants & $\begin{array}{l}2471 \text { smokers ( } 2058 \text { in relevant arms); > } 80 \% \text { in precontemplation or contemplation, } 10 \% \text { to } 14 \% \text { in } \\
\text { preparation, } 46 \% \mathrm{M} \text {, av. age } 41 \text {, av. cigs/day } 20\end{array}$ \\
\hline Interventions & $\begin{array}{l}\text { 1. Standard S-H materials, single mailing } \\
\text { 2. S-H manual based on Transtheoretical model, expert-system letter tailored on baseline question- } \\
\text { naire. Further questionnaires at } 3 \text { and } 6 \mathrm{~m} \text { for additional letters (approx } 50 \% \text { received } 3 \text { letters) } \\
\text { 3. As 2, plus proactive TC after receipt of each questionnaire (max } 3 \text { calls). Designed as reminders, } \\
\text { scripted, delivered by trained postgraduate students }\end{array}$ \\
\hline Outcomes & $\begin{array}{l}\text { Abstinence at } 12 \mathrm{~m} \text { (sustained for } 6 \mathrm{~m} \text { ) } \\
\text { Validation: saliva cotinine }<14.2 \mathrm{ng} / \mathrm{ml}\end{array}$ \\
\hline Notes & $\begin{array}{l}\text { We included arms } 3 \text { vs } 2 \text { in the analyses. Sensitivity analysis comparing arms } 3 \text { vs } 2+1.66 \% \text { received } 1 \text { st } \\
\text { phone call, } 36 \% 2 \text { nd, } 31 \% 3 \text { rd }\end{array}$ \\
\hline
\end{tabular}

\section{Risk of bias}

\begin{tabular}{lll}
\hline Bias & Authors' judgement & Support for judgement \\
\hline $\begin{array}{l}\text { Random sequence genera- } \\
\text { tion (selection bias) }\end{array}$ & Low risk & $\begin{array}{l}\text { Centralised randomisation procedure, with minimisation to balance SoC, ad- } \\
\text { diction and SES }\end{array}$ \\
\hline $\begin{array}{l}\text { Allocation concealment } \\
\text { (selection bias) }\end{array}$ & Low risk & Centralised \\
\hline $\begin{array}{l}\text { Blinding of outcome as- } \\
\text { sessment (detection bias) } \\
\text { All outcomes }\end{array}$ & Low risk & 12 m PP "was confirmed with salivary cotinine, so that we had unconfirmed \\
\hline $\begin{array}{l}\text { Incomplete outcome data } \\
\text { (attrition bias) } \\
\text { All outcomes }\end{array}$ & Low risk & $\begin{array}{l}\text { Loss to follow-up 24\% in group 1, 31\% in 2 and 3. All included as smokers. Sen- } \\
\text { sitivity analysis allowing for differential dropout did not change findings }\end{array}$ \\
\hline
\end{tabular}


Bastian 2012

Setting: North Carolina, USA; Medical Center
Recruitmenet: Mailed smokers an introductory letter from the Chief of Cardiology, Chief of Oncology, or
a primary care physician (the Principal Investigator (PI)) informing them of the study and encouraging
smoking cessation

Participants

471 smokers enrolled in Durham Veterans Affairs Medical Center, receiving treatment for chronic illnesses (i.e. cancer, cardiovascular disease, HTN, diabetes, COPD) and wanting to quit in the next 30 days; $91.5 \% \mathrm{M}$, av. age 59.2, av. cigs/day not reported

Interventions

1. Standard telephone counselling, a letter from a VA physician encouraging smoking cessation, NRT, if not contra-indicated, a S-H cessation kit, and up to 5 TC calls (every 3 - 4 weeks, av. duration 20 minutes)

2. "Family-supported telephone counseling, included all components of the standard TC arm plus an enhanced family-supported intervention that included a support skills booklet and additional telephone counseling content focusing on social support skills [...] The main distinction between the two arms of this comparative effectiveness study was the family-supported intervention that aimed to help increase positive interactions between the participant and their designated support person, to facilitate smoking cessation [...] Participants randomized to family support-based intervention also received an 8-page disease-specific family support booklet."

Outcomes Abstinence at $12 \mathrm{~m}$ (7-day PP)

Validation: available for only $50.5 \%$ of the participants

Notes New for 2018 update

Funding: "This material is based upon work supported by the Department of Veterans Affairs, Veterans Health Administration, Office of Research and Development, and Health Services Research and Development. IIR-05-202."

Declarations of interest: "SCG serves as a consultant to Gilead Sciences and Watermark Research Partners. Although these relationships are not perceived to represent a conflict with the present work, it is included in the spirit of full disclosure. Presented in part at the Society of General Internal Medicine Annual Meeting, Phoenix AZ May 2011."

\section{Risk of bias}

\begin{tabular}{lll}
\hline Bias & Authors' judgement & Support for judgement \\
\hline $\begin{array}{l}\text { Random sequence genera- } \\
\text { tion (selection bias) }\end{array}$ & Low risk & Quote: "blocked randomization, stratified by sex and disease type" \\
\hline $\begin{array}{l}\text { Allocation concealment } \\
\text { (selection bias) }\end{array}$ & Unclear risk & Not described \\
\hline $\begin{array}{l}\text { Blinding of outcome as- } \\
\text { sessment (detection bias) } \\
\text { All outcomes }\end{array}$ & High risk & $\begin{array}{l}\text { The investigators mailed participants saliva-sampling kits to measure cotinine, } \\
\text { but the return rates for saliva samples were low at all follow-ups. Level of per- } \\
\text { sonal contact differed between arms }\end{array}$ \\
\hline $\begin{array}{l}\text { Incomplete outcome data } \\
\text { (attrition bias) } \\
\text { All outcomes }\end{array}$ & Low risk & $\begin{array}{l}\text { Quote: "Follow-up rates were 86\% and 81.1\% at 5 months and } 12 \text { months, re- } \\
\text { spectively. Loss to follow-up was similar in both arms." }\end{array}$ \\
\hline
\end{tabular}


Bastian 2013

Setting: North Carolina, USA; Academic setting
Recruitment: Investigators asked lung cancer patients' permission to contact members of their social
networks who smoked and were aged 18 and older; these received a letter describing the study and
providing them a toll-free number to call to decline participation

Participants $\begin{aligned} & 496 \text { relatives of lung cancer patients, } 41.5 \% \mathrm{M} \text {, av. age } 46.9 \text {, av. cigs/day } 19.5 \text {. More than half the partici- } \\ & \text { pants have made more than } 3 \text { quit attempts before inclusion in the study }\end{aligned}$

Interventions
$\begin{aligned} & \text { 2. Asilored self-directed materials and nicotine patches } \\ & \text { with an av. duration of each session of } 30 \text { mins. The mean number of sessions completed was } 2.4 .81 \\ & \text { participants in this group (33\%) did not complete at least } 1 \text { session }\end{aligned}$

\begin{tabular}{ll}
\hline Outcomes & Abstinence at $12 \mathrm{~m}$ (7-day PP) \\
& Validation: saliva cotinine, not possible due to low return rates \\
\hline Notes & New for 2018 update. \\
& $\begin{array}{l}\text { Funding: "This work was supported by National Cancer Institute grant 5U01-CA-92622. This research } \\
\text { was also supported in part by the Intramural Program of the National Human Genome Research Insti- } \\
\text { tute, National Institutes of Health." } \\
\text { Declarations of interest: not reported }\end{array}$
\end{tabular}

\section{Risk of bias}

\begin{tabular}{lll}
\hline Bias & Authors' judgement & Support for judgement \\
\hline $\begin{array}{l}\text { Random sequence genera- } \\
\text { tion (selection bias) }\end{array}$ & Low risk & $\begin{array}{l}\text { Quote: "Randomization was blocked by patient, with entire social network } \\
\text { units stratified by site and size of social network enrolled (one vs. two or more) } \\
\text { assigned to the same condition." }\end{array}$ \\
\hline $\begin{array}{l}\text { Allocation concealment } \\
\text { (selection bias) }\end{array}$ & Unclear risk & Not described \\
\hline
\end{tabular}

\begin{tabular}{lll}
\hline $\begin{array}{l}\text { Blinding of outcome as- } \\
\text { sessment (detection bias) } \\
\text { All outcomes }\end{array}$ & High risk & Self-reported. Level of personal contact differed between arms \\
\hline $\begin{array}{l}\text { Incomplete outcome data } \\
\text { (attrition bias) }\end{array}$ & High risk & $\begin{array}{l}\text { Large withdrawal of participants after } 12 \text { months of follow-up (>50\%), al- } \\
\text { though similar across arms }\end{array}$ \\
\hline
\end{tabular}

\section{Blebil 2014}

\begin{tabular}{|c|c|}
\hline Methods & $\begin{array}{l}\text { Setting: Malaysia; Outpatient Quit Smoking Clinic based at } 2 \text { hospitals } \\
\text { Recruitment: Quote: "All individuals who attended the clinics during the period under review were in- } \\
\text { vited to participate in the research." }\end{array}$ \\
\hline Participants & 231 outpatient smokers, $96.1 \%$ M, av. age 48.3, av. cigs/day 13.8 \\
\hline Interventions & $\begin{array}{l}\text { 1. Usual care, which included a combination of nicotine gum and CBT ( } 4 \text { counselling sessions during } \\
\text { the } 1 \text { st month, } 2 \text { counselling sessions during the } 2 \text { nd month }+2 \text { phone calls (av. duration } 20-30 \text { mins), } \\
\text { and } 1 \text { counselling session during the } 3 \text { rd month plus } 2 \text { phone calls (av. duration } 20-30 \text { mins)) }\end{array}$ \\
\hline
\end{tabular}


Blebil 2014 (Continued)

2. As above, +1 extra weekly proactive call (av. duration 10 - 15 mins) during the first month of the quit attempt

\begin{tabular}{ll}
\hline Outcomes & Abstinence at 6 months (4-week PP) \\
& Validation: exhaled CO level $<7 \mathrm{ppm}$ \\
\hline Notes & New for 2018 update \\
& Funding: not reported \\
& Declarations of interest: none declared
\end{tabular}

\section{Risk of bias}

\begin{tabular}{lll}
\hline Bias & Authors' judgement & Support for judgement \\
\hline $\begin{array}{l}\text { Random sequence genera- } \\
\text { tion (selection bias) }\end{array}$ & High risk & $\begin{array}{l}\text { Even though "urn design was used to achieve balanced groups", participants } \\
\text { walking in the study and being referred from outpatient clinics at the hospitals } \\
\text { were more likely to be assigned to the intervention than those coming from } \\
\text { other hospitals }\end{array}$ \\
\hline $\begin{array}{l}\text { Allocation concealment } \\
\text { (selection bias) }\end{array}$ & Low risk & $\begin{array}{l}\text { Quote: "the assignments of treatment within a sequence created by the urn } \\
\text { design are not as predictable as those of other types of restricted randomisa- } \\
\text { tion processed" }\end{array}$ \\
\hline $\begin{array}{l}\text { Blinding of outcome as- } \\
\text { sessment (detection bias) } \\
\text { All outcomes }\end{array}$ & Low risk & $\begin{array}{l}\text { Biochemical validation of self-reported outcome. The data were collected by } \\
\text { another research member not connected with counselling and the data analy- } \\
\text { sis }\end{array}$ \\
\hline $\begin{array}{l}\text { Incomplete outcome data } \\
\begin{array}{l}\text { (attrition bias) } \\
\text { All outcomes }\end{array}\end{array}$ & Low risk & $\begin{array}{l}\text { Percentage lost to follow-up was overall low (8\%), although larger in the usu- } \\
\text { al-care (12\%) than in the intervention group (4\%). }\end{array}$ \\
\hline
\end{tabular}

\section{Borland 2001}

\begin{tabular}{ll}
\hline Methods & $\begin{array}{l}\text { Setting: Community, Australia } \\
\text { Recruitment: Callers to a quitline }\end{array}$ \\
\hline Participants & 998 smokers interested in quitting; $48 \% \mathrm{M}, 37 \%$ aged $15-29,26 \%$ aged $30-39$, av. cigs/day 23 \\
\hline Interventions & $\begin{array}{l}\text { 1. Proactive call-back TC following initial call to quitline: Multiple calls, first pre-quit, quit, then accord- } \\
\text { ing to need. Up to } 6 \text { m. Mailed materials } \\
\text { 2. Control: Mailed materials } \\
\text { Both groups also received the standard motivational counselling in response to their first call }\end{array}$ \\
\hline Outcomes & $\begin{array}{l}\text { Self-reported abstinence at } 12 \mathrm{~m} \text { (sustained for } 9 \text { m) } \\
\text { Validation: none }\end{array}$ \\
\hline Notes & $\begin{array}{l}\text { Average number of calls } 2.8,67 \% \text { received } 1 \text { or more. } 20 \% \text { refused call-back or wanted to initiate the } \\
\text { calls, further } 7 \% \text { did not receive any }\end{array}$ \\
\hline Risk of bias & Authors' judgement Support for judgement \\
\hline Bias & \\
\hline
\end{tabular}


Borland 2001 (Continued)
Random sequence genera-
Unclear risk
Randomised, method not described tion (selection bias)

\begin{tabular}{lll}
\hline $\begin{array}{l}\text { Allocation concealment } \\
\text { (selection bias) }\end{array}$ & Unclear risk & No details given
\end{tabular}

\begin{tabular}{lll}
\hline $\begin{array}{l}\text { Blinding of outcome as- } \\
\text { sessment (detection bias) } \\
\text { All outcomes }\end{array}$ & High risk & $\begin{array}{l}\text { Self-reported outcomes from participants not blinded to treatment condition. } \\
\text { Level of personal contact differed between arms }\end{array}$ \\
\hline $\begin{array}{l}\text { Incomplete outcome data } \\
\begin{array}{l}\text { (attrition bias) } \\
\text { All outcomes }\end{array}\end{array}$ & Low risk & $\begin{array}{l}\text { Loss to follow-up 37\% intervention, 30\% control. All participants included as } \\
\text { smokers in the meta-analysis }\end{array}$ \\
\hline
\end{tabular}

\section{Borland 2003}

\begin{tabular}{ll}
\hline Methods & Setting: Community, Australia \\
& Recruitment: Callers to a quitline
\end{tabular}

\begin{tabular}{ll}
\hline Participants & 1578 smokers; $46 \% \mathrm{M}$, modal age $30-49$, av. cigs/day 23 \\
\hline Interventions & 1. Standard S-H quit pack based around SoC \\
2. Additional tailored letters at baseline, and at 3 and $6 \mathrm{~m}$ based on mailed assessments \\
3. As 2, plus proactive cognitive behavioural stage-base TC, calls at negotiated times, $\sim 10-15$ mins. \\
Usually over $2-3$ weeks, could extend further. \\
Some participants in all groups received brief reactive counselling before enrolment
\end{tabular}

\begin{tabular}{ll}
\hline Outcomes & Self-reported abstinence at $12 \mathrm{~m}$ (sustained for $9 \mathrm{~m}$ ) \\
& Validation: none \\
\hline Notes & 3 vs 2 , sensitivity analysis 3 vs $2+1$ \\
& $68 \%$ received calls, av. 4.8 for those receiving any, $23 \%$ received $\geq 7$ \\
\end{tabular}

\section{Risk of bias}

\begin{tabular}{lll}
\hline Bias & Authors' judgement & Support for judgement \\
\hline $\begin{array}{l}\text { Random sequence genera- } \\
\text { tion (selection bias) }\end{array}$ & High risk & Allocation by shuffling questionnaires \\
\hline $\begin{array}{l}\text { Allocation concealment } \\
\text { (selection bias) }\end{array}$ & Low risk & $\begin{array}{l}\text { Author states "no opportunity for interviewers to influence choice"; baseline } \\
\text { characteristics balanced, likelihood of bias judged low }\end{array}$ \\
\hline $\begin{array}{l}\text { Blinding of outcome as- } \\
\text { sessment (detection bias) } \\
\text { All outcomes }\end{array}$ & High risk & $\begin{array}{l}\text { Self-reported outcomes from participants not blinded to treatment condition. } \\
\text { Level of personal contact differed between arms }\end{array}$ \\
\hline $\begin{array}{l}\text { Incomplete outcome data } \\
\text { (attrition bias) }\end{array}$ & Low risk & $\begin{array}{l}\text { Loss to follow-up 21\% in 1, 23\% in 2, 26\% in 3. All participants included as } \\
\text { smokers in the MA }\end{array}$ \\
\hline
\end{tabular}


Borland 2008

\begin{tabular}{ll}
\hline Methods & $\begin{array}{l}\text { Setting: General practice, Australia } \\
\text { Recruitment: } 45 \text { participating GPs recruiting patients who smoked }\end{array}$ \\
\hline Participants & $\begin{array}{l}\text { 1039 smokers, not selected for motivation but } ~ \\
\text { cigs/day } 17\end{array}$ \\
\hline Interventions & $\begin{array}{l}\text { 1. Referral: Smokers with any interest in quitting referred by fax to Victorian Quitline. Proactive contact } \\
\text { attempted with up to } 2 \text { pre-quit and } 4 \text { post-quit sessions typically using relapse-sensitive schedule. In- } \\
\text { ternet support available as an alternative (4.4\% reported use) }\end{array}$ \\
$\begin{array}{l}\text { 2. In-practice support, could include external referral if this was clinical preference } \\
\text { All participants given guideline-based assessment of readiness to quit and offer of pharmacotherapy if } \\
\text { appropriate }\end{array}$ \\
\hline Outcomes & $\begin{array}{l}\text { Self-reported abstinence at } 12 \text { m (sustained } \geq 10 \mathrm{~m} \text { ) } \\
\text { Validation: none }\end{array}$ \\
\hline Notes & TC as adjunct to face-to-face intervention.
\end{tabular}

\section{Risk of bias}

\begin{tabular}{lll}
\hline Bias & Authors' judgement & Support for judgement \\
\hline $\begin{array}{l}\text { Random sequence genera- } \\
\text { tion (selection bias) }\end{array}$ & Low risk & $\begin{array}{l}\text { Cluster-randomised by GP (1:2 ratio). Computer allocation before GPs attend- } \\
\text { ed education session for their assigned intervention }\end{array}$ \\
\hline $\begin{array}{l}\text { Allocation concealment } \\
\text { (selection bias) }\end{array}$ & Unclear risk & $\begin{array}{l}\text { Initially concealed but } 13 \text { referral (30\%) and } 11(42 \%) \text { control GPs failed to re- } \\
\text { cruit participants. Allocation not blind at time of recruitment of individual par- } \\
\text { ticipants, so further selection bias possible. Measured characteristics at base- } \\
\text { line were similar }\end{array}$
\end{tabular}

\begin{tabular}{lll}
\hline Blinding of outcome as- & High risk & Quote: "Three- and 12-month questionnaires were administered...by trained \\
sessment (detection bias) & interviewers who were blind to treatment condition until after the outcome \\
All outcomes & data were collected." However, reliant on self-reported outcomes from partic- \\
& ipants not blinded to treatment condition. Level of personal contact differed \\
between arms
\end{tabular}

$\begin{array}{ll}\begin{array}{l}\text { Incomplete outcome data } \\ \text { (attrition bias) }\end{array} & \text { Low risk } \\ \text { All outcomes } & \begin{array}{l}33 \% \text { lost in referral condition, 39\% in control, all included as smokers in MA. } \\ \text { Excluding losses does not affect MA }\end{array}\end{array}$

\section{Boyle 2007}

\begin{tabular}{|c|c|}
\hline Methods & $\begin{array}{l}\text { Setting: Health Maintenance Organisation, USA } \\
\text { Recruitment: Proactive recruitment of members filling a prescription for cessation medications (moti- } \\
\text { vated) }\end{array}$ \\
\hline Participants & 1329 HMO members; $42 \%$ M, av. age $47,66 \%$ smoked > pack/day \\
\hline Interventions & $\begin{array}{l}\text { All participants had filled a prescription. Almost } 95 \% \text { used; } ~ 51 \% \text { only bupropion, } 26 \% \text { only NRT, re- } \\
\text { mainder both } \\
\text { 1. No further intervention } \\
\text { 2. Proactive call to offer counselling, up to } 9 \text { calls, given choice of structured course or unstructured } \\
\text { format }\end{array}$ \\
\hline
\end{tabular}


Boyle 2007 (Continued)

Validation: none

Notes $49 \%$ of intervention group reached, $36 \%$ of those declined, $31 \%$ of total accepted counselling. Average no of calls 5 .

\section{Risk of bias}

\begin{tabular}{lll}
\hline Bias & Authors' judgement & Support for judgement \\
\hline $\begin{array}{l}\text { Random sequence genera- } \\
\text { tion (selection bias) }\end{array}$ & Unclear risk & Randomised, stratified by presence of chronic disease. Method not described \\
\hline $\begin{array}{l}\text { Allocation concealment } \\
\text { (selection bias) }\end{array}$ & Unclear risk & No details given \\
\hline $\begin{array}{l}\text { Blinding of outcome as- } \\
\text { sessment (detection bias) } \\
\text { All outcomes }\end{array}$ & High risk & $\begin{array}{l}\text { Quote: "The follow-up survey was conducted by the Data Collection Center } \\
\text { within the Health Partners Research Foundation, using staff not involved in } \\
\text { the intervention." However, reliant on self-reported outcomes from partici- } \\
\text { pants not blinded to treatment condition. Level of personal contact differed } \\
\text { between arms }\end{array}$ \\
\hline $\begin{array}{l}\text { Incomplete outcome data } \\
\text { (attrition bias) } \\
\text { All outcomes }\end{array}$ & Low risk & 33\% lost to follow-up, balanced across groups, included in MA as smokers \\
\hline
\end{tabular}

\section{Bricker 2014}

$\begin{array}{ll}\text { Methods } & \text { Setting: South Carolina, USA } \\ & \text { Recruitment: Staff advertised the study to the quitline callers }\end{array}$

Participants

Interventions

121 uninsured callers to the South Carolina State Quitline who wanted to quit in the following 30 days

1. Telephone counselling (CBT) + NRT

2. Telephone counselling (ACT) + NRT

5 weekly calls, 30-min first session and 15-min subsequently, were offered. All participants received standard 2-week NRT (patch or gum) of choice

Outcomes Self-reported abstinence at $6 \mathrm{~m}$ (30-day PP)

Validation: none

Notes New for 2018 update

Funding: "This study was supported by the National Institutes of Health (T32MH082709 to RV, K23DA026517 to JLH, R21DA030646 to JB) and the Fred Hutchinson Cancer Research Center."

Declarations of interest: not reported

\section{Risk of bias}

\begin{tabular}{lll}
\hline Bias & Authors' judgement & Support for judgement \\
\hline $\begin{array}{l}\text { Random sequence genera- } \\
\text { tion (selection bias) }\end{array}$ & Low risk & Quote: "Randomized study arm assignments were computer generated" \\
\hline
\end{tabular}


Bricker 2014 (Continued)

$\begin{aligned} & \text { Allocation concealment } \\ & \text { (selection bias) }\end{aligned} \quad$ Low risk $\quad$ Quote: "Randomized study arm assignments were [...] concealed"

\begin{tabular}{lll}
\hline $\begin{array}{l}\text { Blinding of outcome as- } \\
\text { sessment (detection bias) } \\
\text { All outcomes }\end{array}$ & Low risk & $\begin{array}{l}\text { Abstinence not biochemically validated, but same level of personal contact in } \\
\text { different study arms }\end{array}$ \\
\hline $\begin{array}{l}\text { Incomplete outcome data } \\
\text { (attrition bias) } \\
\text { All outcomes }\end{array}$ & Low risk & $\begin{array}{l}\text { Proportion of individuals lost to follow-up was greater in CBT than in ACT arm } \\
\text { (39\% and } 27 \%, \text { respectively) but less than 50\% overall }\end{array}$ \\
\hline
\end{tabular}

Brown 1992

\begin{tabular}{ll}
\hline Methods & $\begin{array}{l}\text { Setting: Community, Australia } \\
\text { Recruitment: Advertising for smokers interested in cessation }\end{array}$ \\
\hline Participants & 45 smokers attending an information evening on smoking cessation; 38\% M, av. age 40, av. cigs/day 23 \\
\hline Interventions & $\begin{array}{l}\text { 1. S-H manual } \\
\text { 2. S-H manual and proactive TC; } 6 \text { calls at } 1,2,4,6,8,10 \text { weeks which asked about use of manual, and } \\
\text { gave additional information about any techniques or skills proving difficult }\end{array}$ \\
\hline Outcomes & $\begin{array}{l}\text { Abstinence at } 12 \text { m (7-day PP) } \\
\text { Validation: Saliva samples collected but not apparently tested - 1 participant refusing to provide a } \\
\text { sample was classified as smoking }\end{array}$ \\
\hline Notes & Effect of TC compared to S-H and single information session alone
\end{tabular}

\section{Risk of bias}

\begin{tabular}{lll}
\hline Bias & Authors' judgement & Support for judgement \\
\hline $\begin{array}{l}\text { Random sequence genera- } \\
\text { tion (selection bias) }\end{array}$ & Unclear risk & Randomised, method not described \\
\hline $\begin{array}{l}\text { Allocation concealment } \\
\text { (selection bias) }\end{array}$ & Unclear risk & No details given \\
\hline $\begin{array}{l}\text { Blinding of outcome as- } \\
\text { sessment (detection bias) } \\
\text { All outcomes }\end{array}$ & Unclear risk & Saliva samples collected but not apparently tested \\
\hline $\begin{array}{l}\text { Incomplete outcome data } \\
\text { (attrition bias) } \\
\text { All outcomes }\end{array}$ & Unclear risk & No details given \\
\hline
\end{tabular}

Brunette 2017

\begin{tabular}{ll}
\hline Methods & $\begin{array}{l}\text { Setting: New Hampshire, USA; community mental health centres } \\
\text { Recruitment: Through flyers, clinician referral, and direct mail }\end{array}$ \\
\hline Participants & $\begin{array}{l}661 \text { medicaid beneficiaries with mental illness and low income (< USD } 1317 \text { a month) willing to initiate } \\
\text { cessation treatment within } 30 \text { days, } 36 \% \text { M, av. age } 45, \text { av. cigs/day } 17.3\end{array}$
\end{tabular}


Brunette 2017 (Continued)

Interventions

1. Usual care, a prescriber visit for smoking cessation (NRT or cessation medications, i.e. bupropion/varenicline)

2. As in 1, plus referral to New Hampshire Tobacco Helpline which provides an average of 3 manualised

TC sessions

3. As in 1, plus TC (av. 9 sessions) CBT initiated by a CBT therapist

$\begin{array}{ll}\text { Outcomes } & \text { Abstinence at } 12 \mathrm{~m}(7 \text {-day PP) } \\ \text { Validation: breath } \mathrm{CO} \leq 4 \mathrm{ppm} \text { and urine cotinine }<100 \mathrm{ng} / \mathrm{ml} \text { (or solely breath CO if using NRT) }\end{array}$

Notes New for 2018 update.

Funding: "This research received financial support from the Centers for Medicare and Medicaid Services (Medicaid Incentives for the Prevention of Chronic Diseases grant 1B1CMS330880) and from the New Hampshire Department of Health and Human Services (NHDHHS)."

Declarations of interest: "Dr. Brunette reports receipt of research funding from Alkermes. The other authors report no financial relationships with commercial interests."

\section{Risk of bias}

\begin{tabular}{lll}
\hline Bias & Authors' judgement & Support for judgement \\
\hline $\begin{array}{l}\text { Random sequence genera- } \\
\text { tion (selection bias) }\end{array}$ & Low risk & $\begin{array}{l}\text { Quote: "Computer-generated tables for each strata within each site were used } \\
\text { for random assignment." }\end{array}$ \\
\hline $\begin{array}{l}\text { Allocation concealment } \\
\text { (selection bias) }\end{array}$ & High risk & $\begin{array}{l}\text { Quote: "We used equipoise randomization [...] that allowed participants to opt } \\
\text { out of one of the cessation treatment conditions or allowed randomization to } \\
\text { any of the three options. [...] Randomization strata were defined by conditions } \\
\text { to which the participant was willing to be randomly assigned. Within the stra- } \\
\text { tum, a participant was then randomly assigned with equal probability to the } \\
\text { selected treatment condition options." Not a true randomisation method; par- } \\
\text { ticipants can choose what intervention they do not want to be allocated to and } \\
\text { this can lead to selection bias. This led to different numbers between arms, } \\
\text { and significant baseline age differences }\end{array}$ \\
\hline
\end{tabular}

Blinding of outcome as- High risk sessment (detection bias) All outcomes
Biochemical validation for only half of the participants in the trial (those receiving an incentive), and there are significant differences between those receiving and not receiving an incentive. Level of personal contact differed between arms

Incomplete outcome data Low risk Proportion of participants lost to follow-up was lower than 50\% overall
(attrition bias)

All outcomes

Chan 2015

Methods Setting: Hong-Kong, China; community-based

Recruitment: Participants were approached by investigators at shopping malls or public areas in 16 out of the 18 districts in Hong Kong. Participants who expressed an interest in joining the contest were screened for eligibility and tested on their exhaled $\mathrm{CO}$ to ascertain their smoking status 
Chan 2015 (Continued)

Participants

1003 Hong Kong residents aged 18 or older, who smoked 1 or more cig/day in the past 6 months, $82 \%$ M; 38\% 18 - 39 years, $49 \% 40$ - 59 years, 13\% 60+ years, $42 \% 1-10$ cigs/day, $43 \% 11-20$ cigs/day, 15\% $>20$ cigs/day
1. S-H booklet and the contact information of the smoking cessation services at the enrolment

2. As 1 , plus 8 mobile phone text messages corresponding to the 8 pages of the $\mathrm{S}$-H booklet (not used in review)

3. As 1 , plus 4 sessions (within 1 week, after 2, 6 and $12 \mathrm{~m}$ ) of 5-min smoking cessation telephone counselling provided by a trained nurse, using the AWARD Protocol

\section{Risk of bias}

\begin{tabular}{lll}
\hline Bias & Authors' judgement & Support for judgement \\
\hline $\begin{array}{l}\text { Random sequence genera- } \\
\text { tion (selection bias) }\end{array}$ & Low risk & Block randomisation was used to ensure similar group sizes. \\
\hline $\begin{array}{l}\text { Allocation concealment } \\
\text { (selection bias) }\end{array}$ & Low risk & $\begin{array}{l}\text { Quote: "The randomization and allocation were conducted by the author who } \\
\text { did not participate in subject recruitment to ensure allocation concealment" }\end{array}$ \\
\hline $\begin{array}{l}\text { Blinding of outcome as- } \\
\text { sessment (detection bias) } \\
\text { All outcomes }\end{array}$ & Low risk & Abstinence biochemically validated \\
\hline $\begin{array}{l}\text { Incomplete outcome data } \\
\text { (attrition bias) } \\
\begin{array}{l}\text { All outcomes } \\
\text { L }\end{array}\end{array}$ & Low risk & $\begin{array}{l}\text { Efforts were made to minimise loss to follow-up: } \\
\text { Quote: "at least seven call attempts at different times were made before par- } \\
\text { ticipants were considered as loss to follow-up." In the end follow-up was com- } \\
\text { parable across arms. Reasons for losses to follow-up are provided }\end{array}$ \\
\hline
\end{tabular}

\section{Chouinard 2005}

\begin{tabular}{ll}
\hline Methods & $\begin{array}{l}\text { Setting: Canada } \\
\text { Recruitment setting: Inpatients with cardiovascular disease (myocardial infarction, angina, congestive } \\
\text { heart failure) or peripheral vascular disease, unselected by motivation }\end{array}$ \\
\hline Participants & 168 past-month smokers; $27 \% \mathrm{M}$, av. age $56,60 \%$ in preparation or action SoC \\
\hline Interventions & $\begin{array}{l}\text { 1. Counselling by research nurse }(1 \times 10 \text { - } 60 \text { mins, av. } 40 \text { mins, based on Transtheoretical Model, includ- } \\
\text { ed component to enhance social support from a significant family member) } \\
\text { 2. As } 1 \text {, plus telephone follow-up, } 6 \text { calls over } 2 \text { m post-discharge } \\
\text { 3. Usual care cessation advice (not used in review) }\end{array}$ \\
\hline
\end{tabular}


Chouinard 2005 (Continued)

Outcomes Abstinence at $6 \mathrm{~m}$ (sustained at 2 and $6 \mathrm{~m}$ )

Validation: Urine cotinine or CO

Notes TC as adjunct to face-to-face counselling. $75 \%$ received 6 calls

\section{Risk of bias}

Bias Authors' judgement Support for judgement

Random sequence genera- Unclear risk Cluster-randomised in groups of 3 - 6 "to prevent contamination between tion (selection bias) groups", method not described

Allocation concealment Low risk Quote: "Individuals not familiar with the study were in charge of the random(selection bias) ization procedure which included inserting the information into envelopes that were sealed and would be opened by the investigator only at the time of recruitment."

Blinding of outcome as- Low risk Biochemical validation used

sessment (detection bias)

All outcomes

Incomplete outcome data Low risk

(attrition bias)

4 deaths ( 3 in Grp 1, 1 in Grp 2) and 3 not meeting follow-up criteria excluded

All outcomes from MA denominators. Other losses to follow-up included

Collins 2018

\begin{tabular}{ll}
\hline Methods & Setting: North and West Philadelphia, PA, US; 4 paediatric clinics \\
& Recruitment: Clinic providers referred smoking parents of children exposed to SHS to the cessation re- \\
& sources, including the current study
\end{tabular}

Participants 327 smoking parents from predominantly low-income, racial- and ethnic-minority families of children under the age of $11,16.5 \% \mathrm{M}$, av. age 33 , av. cigs/day 11.5

Interventions $\quad$ 1. Individual TC health education attention control (AC) intervention that focuses on improving family nutrition on a budget

2. Individual behavioural TC intervention that focuses on reducing child SHS exposure and parent smoking cessation

The TC dosage ( 5 sessions over 12 weeks) was similar between arms

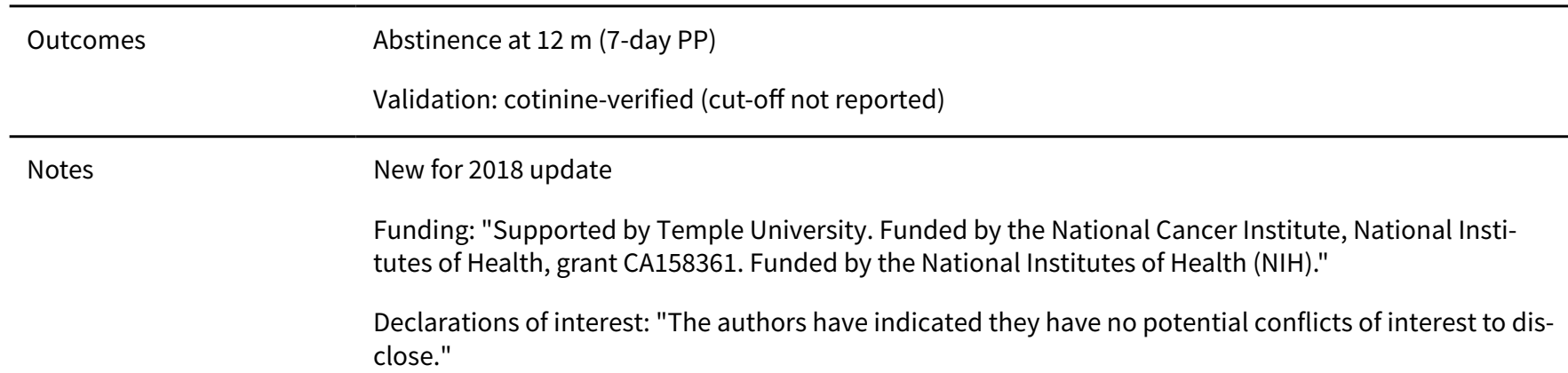

\section{Risk of bias}


Collins 2018 (Continued)

\begin{tabular}{|c|c|c|}
\hline Bias & Authors' judgement & Support for judgement \\
\hline $\begin{array}{l}\text { Random sequence genera- } \\
\text { tion (selection bias) }\end{array}$ & Low risk & Quote: "Randomization was seeded using values obtained from random.org." \\
\hline $\begin{array}{l}\text { Allocation concealment } \\
\text { (selection bias) }\end{array}$ & Low risk & $\begin{array}{l}\text { Quote: "The project biostatistician provided the allocations to the data collec- } \\
\text { tion team in opaque sealed security envelopes." }\end{array}$ \\
\hline $\begin{array}{l}\text { Blinding of outcome as- } \\
\text { sessment (detection bias) } \\
\text { All outcomes }\end{array}$ & Low risk & Cotinine-verified smoking cessation \\
\hline $\begin{array}{l}\text { Incomplete outcome data } \\
\text { (attrition bias) } \\
\text { All outcomes }\end{array}$ & Low risk & $\begin{array}{l}\text { The percentage of participants lost to follow-up is minimal (12\%), although } \\
\text { slightly different between intervention (17\%) and control ( } 8 \%) \text { arms. }\end{array}$ \\
\hline
\end{tabular}

Cossette 2011

\begin{tabular}{|c|c|}
\hline Methods & $\begin{array}{l}\text { Setting: Specialised cardiac hospital, Canada } \\
\text { Recruitment: All smokers who were hospitalised were asked to participate by the study nurse (not se- } \\
\text { lected by motivation) }\end{array}$ \\
\hline Participants & $\begin{array}{l}40 \text { current daily smokers with cardiovascular disease, } 60 \% \mathrm{M} \text {, av. age } 57 . \text { Most in preparation stage } \\
\text { Therapists: nurse specialised in smoking cessation }\end{array}$ \\
\hline Interventions & $\begin{array}{l}\text { All participants had } 1 \text { or more sessions with the study nurse during hospitalisation. Conditions differed } \\
\text { after discharge } \\
\text { 1. Intervention: } 6 \text { phone calls by study nurse at weeks } 1,2,3,4,8,12 \text {. If needed additional phone calls } \\
\text { could be arranged between } 3 \text { and } 6 \text { m post-discharge. At week } 3 \text { appointment with the study nurse if re- } \\
\text { quested by participant } \\
\text { 2. Control: referral to a national quitline or a community centre for smoking cessation } \\
\text { Pharmacotherapy: NRT, bupropion or varenicline were suggested during hospitalisation and follow-up }\end{array}$ \\
\hline Outcomes & $\begin{array}{l}\text { Self-reported abstinence at } 6 \mathrm{~m} \text { (7-day PP) } \\
\text { Validation: only for } 1 \text { participant }\end{array}$ \\
\hline
\end{tabular}

Notes

\section{Risk of bias}

\begin{tabular}{lll}
\hline Bias & Authors' judgement & Support for judgement \\
\hline $\begin{array}{l}\text { Random sequence genera- } \\
\text { tion (selection bias) }\end{array}$ & Unclear risk & Not specified, but generated by a centre for randomised controlled trials \\
\hline $\begin{array}{l}\text { Allocation concealment } \\
\text { (selection bias) }\end{array}$ & Unclear risk & Opaque sealed envelopes \\
\hline $\begin{array}{l}\text { Blinding of outcome as- } \\
\text { sessment (detection bias) } \\
\text { All outcomes }\end{array}$ & High risk & $\begin{array}{l}\text { Self-reported outcomes from participants not blinded to treatment condition. } \\
\text { Level of personal contact differed between arms }\end{array}$ \\
\hline
\end{tabular}




\section{Cossette 2011 (Continued)}

Incomplete outcome data (attrition bias)

Unclear risk

All outcomes
High loss to follow-up, but missing data similar in both groups and analyses are ITT, participants lost to follow-up considered smokers

\section{Cummins 2016a}

Setting: California, USA; hospital-based
Recruitment: Quote: "Recruitment procedures differed between healthcare systems based on the per-
sonnel involved and the hospital's reliance on electronic medical records (EMRs)". In 1 study site re-
cruitment was part of the therapists' workflow, while in another academic site, research staff were in-
volved instead

\begin{tabular}{|c|c|}
\hline Participants & $\begin{array}{l}1270 \text { hospitalised adult smokers who smoked } 6 \text { or more cigs/day, were interested in quitting, spoke } \\
\text { English or Spanish, and were not pregnant, } 56.7 \% \mathrm{M} \text {, av. age } 49.9 \text {, av. cigs/day } 14.6\end{array}$ \\
\hline \multirow[t]{3}{*}{ Interventions } & Factorial $2 \times 2$ design comparing TC vs no TC, and NRT vs no NRT \\
\hline & $\begin{array}{l}\text { 1. No TC (usual care) } \pm \text { NRT patches. In general usual care consisted of providing smokers with the quit- } \\
\text { line number, but some hospitals may have also provided counselling or prescribed quitting aids }\end{array}$ \\
\hline & $\begin{array}{l}\text { 2. TCg } \pm \text { NRT patches, with } 10 \text { calls scheduled, but on av. } 3.6 \text { completed. The av. number of calls in the } \\
\text { usual care arm was } 1.7\end{array}$ \\
\hline \multirow[t]{2}{*}{ Outcomes } & Abstinence at 6 m (7-day PP) \\
\hline & Validation: saliva cotinine $<10 \mathrm{ng} / \mathrm{mL}$ \\
\hline \multirow[t]{3}{*}{ Notes } & New for 2018 update. Previously listed under ongoing studies as Cummins 2012 \\
\hline & Funding: "This research was supported by a grant from the National Cancer Institute (CA159533)." \\
\hline & Declarations of interest: none reported \\
\hline
\end{tabular}

\section{Risk of bias}

\begin{tabular}{lll}
\hline Bias & Authors' judgement & Support for judgement \\
\hline $\begin{array}{l}\text { Random sequence genera- } \\
\text { tion (selection bias) }\end{array}$ & Low risk & Quote: "randomly assigned by computer" \\
\hline $\begin{array}{l}\text { Allocation concealment } \\
\text { (selection bias) }\end{array}$ & Unclear risk & Not described \\
\hline $\begin{array}{l}\text { Blinding of outcome as- } \\
\text { sessment (detection bias) } \\
\text { All outcomes }\end{array}$ & Low risk & Biochemically-confirmed abstinence \\
\hline $\begin{array}{l}\text { Incomplete outcome data } \\
\text { (attrition bias) } \\
\begin{array}{l}\text { All outcomes } \\
\hline\end{array}\end{array}$ & Low risk & Similar loss to follow-up across arms ( $33 \%)$ \\
\hline
\end{tabular}

Cummins 2016b

Methods Setting: California USA; pregnant women


Cummins 2016b (Continued)

Recruitment: Callers to University of California San Diego California Smokers' Helpline

\begin{tabular}{ll}
\hline Participants & $\begin{array}{l}1173 \text { pregnant (<27 weeks) women, willing to quit within } 1 \text { month or recent quitters, av. age 26.3, av. } \\
\text { cigs/day } 11.2\end{array}$ \\
\hline Interventions & $\begin{array}{l}\text { 1. Self-help American Cancer Society's Make Yours a Fresh Start Family fact sheets, and additional tips } \\
\text { for quitting while pregnant } \\
\text { 2. As } 1, \text { plus proactive TC specifically developed for pregnant smokers, including } 9 \times 30-45-m i n \text { ses- } \\
\text { sions on days } 0,1,3,7,14 \text {, and } 30 \text { after quit date, at } 32 \text { weeks of gestation, and } 2 \text { and } 4 \text { weeks after de- } \\
\text { livery }\end{array}$ \\
\hline Outcomes & $\begin{array}{l}\text { Abstinence at } 6 \text { m post-partum (180-day abstinence) } \\
\text { Notes }\end{array}$ \\
New for 2018 update. Previously listed under studies awaiting assignment as Zhu 2004 \\
Funding: "This research was supported by the Tobacco-Related Disease Research Program (Grant \\
8RT-0103) and First 5 California (Contract CCFC-6810) and by funds received from the California Depart- \\
ment of Health Services Tobacco Control Section (Contract 00-90605)." \\
Declarations of interest: none declared
\end{tabular}

\section{Risk of bias}

\begin{tabular}{lll}
\hline Bias & Authors' judgement & Support for judgement \\
\hline $\begin{array}{l}\text { Random sequence genera- } \\
\text { tion (selection bias) }\end{array}$ & Low risk & $\begin{array}{l}\text { Quote: "Random allocation to condition was done by computer using blocks of } \\
20 "\end{array}$ \\
\hline $\begin{array}{l}\text { Allocation concealment } \\
\text { (selection bias) }\end{array}$ & Low risk & $\begin{array}{l}\text { Quote: "staff were blind to group assignment until the end of the intake, when } \\
\text { the appropriate script was presented" }\end{array}$ \\
\hline $\begin{array}{l}\text { Blinding of outcome as- } \\
\text { sessment (detection bias) } \\
\text { All outcomes }\end{array}$ & Low risk & Abstinence biochemically validated \\
\hline $\begin{array}{l}\text { Incomplete outcome data } \\
\text { (attrition bias) } \\
\begin{array}{l}\text { All outcomes } \\
\hline\end{array}\end{array}$ & Low risk & Higher \% lost to follow-up in intervention arm \\
\hline
\end{tabular}

Curry 1995

\begin{tabular}{ll} 
Methods & $\begin{array}{l}\text { Setting: Health Maintenance Organisation, USA } \\
\text { Recruitment: Active; smokers identified through a telephone survey of health behaviour in a random } \\
\text { sample of HMO members, not selected for motivation }\end{array}$ \\
\hline Participants & $\begin{array}{l}1137 \text { smokers, } 479 \text { in relevant arms, not selected by motivation to quit; } 48 \% \text { M, av. age 41, av. cigs/day } \\
17\end{array}$ \\
\hline Interventions & $\begin{array}{l}\text { 1. Control - no materials or counselling } \\
\text { 2. S-H booklet (Breaking Away) } \\
\text { 3. As 2, plus feedback based on computer analysis of initial survey } \\
\text { 4. As 3, plus proactive TC; up to } 3 \text { calls at 2, 6, } 10 \text { weeks }\end{array}$
\end{tabular}

Outcomes

Abstinence at $12 \mathrm{~m}$ (sustained from $3 \mathrm{~m}-12 \mathrm{~m}$ ) 
Curry 1995 (Continued)

Validation: saliva cotinine requested but not obtained for all self-reported quitters. Disconfirmation rates (cut off $>20 \mathrm{ng} / \mathrm{ml}$ ) not significantly different between groups

Notes 4 vs 3 , effect of TC compared to S-H and feedback alone.

\section{Risk of bias}

\begin{tabular}{lll}
\hline Bias & Authors' judgement & Support for judgement \\
\hline $\begin{array}{l}\text { Random sequence genera- } \\
\text { tion (selection bias) }\end{array}$ & Unclear risk & Randomised, method not described \\
\hline $\begin{array}{l}\text { Allocation concealment } \\
\text { (selection bias) }\end{array}$ & Unclear risk & No details given \\
\hline $\begin{array}{l}\text { Blinding of outcome as- } \\
\text { sessment (detection bias) } \\
\text { All outcomes }\end{array}$ & Unclear risk & $\begin{array}{l}\text { Quote: "Collecting saliva cotinine...was challenging because participants had } \\
\text { neither explicitly volunteered for a study of smoking behavior nor requested } \\
\text { treatment for smoking cessation... nearly one fourth of those contacted re- } \\
\text { fused to provide a sample." Higher disconfirmation in control group but differ- } \\
\text { ence was not significant }\end{array}$ \\
\hline
\end{tabular}

Incomplete outcome data Low risk (attrition bias)

All outcomes
$88 \%$ provided data at all 3 and $12 \mathrm{~m}$. No difference in response rates across groups. Missing counted as smoking in MA

\section{Duffy 2006}

\begin{tabular}{ll}
\hline Methods & Setting: ENT clinics at 4 hospitals, USA \\
& Recruitment: Patients with head and neck cancer who screened positive for smoking, alcohol problem \\
& or depression, not selected for motivation
\end{tabular}

\begin{tabular}{ll}
\hline Participants & 89 current smokers used in MA, out of 184 trial participants who also included 26 quit within last month \\
and 21 within last $6 \mathrm{~m}$. Demographics are for all participants; $84 \%$ M, av. age 57
\end{tabular}

Interventions
Smokers with problem drinking or depression received counselling for these too
2. Enhanced usual care with assessment and referral

\begin{tabular}{ll}
\hline Outcomes & $\begin{array}{l}\text { Abstinence at } 6 \mathrm{~m} \text { (sustained) } \\
\text { Validation: none }\end{array}$ \\
\hline
\end{tabular}

\begin{tabular}{lll}
\hline Notes & \\
\hline Risk of bias & \\
\hline Bias & Authors' judgement & Support for judgement \\
\hline $\begin{array}{l}\text { Random sequence genera- } \\
\text { tion (selection bias) }\end{array}$ & Unclear risk & Randomised, method not described \\
\hline $\begin{array}{l}\text { Allocation concealment } \\
\text { (selection bias) }\end{array}$ & Unclear risk & $\begin{array}{l}\text { No details given. Smokers were a higher proportion of the intervention than } \\
\text { control groups, and a higher proportion of those randomised than those who } \\
\text { refused, raising possibility of selection bias }\end{array}$ \\
\hline $\begin{array}{l}\text { Blinding of outcome as- } \\
\text { sessment (detection bias) }\end{array}$ & High risk & $\begin{array}{l}\text { Self-reported outcomes from participants not blinded to treatment condition. } \\
\text { Level of personal contact differed between arms. }\end{array}$ \\
\hline
\end{tabular}


Duffy 2006 (Continued)

All outcomes

\begin{tabular}{|c|c|c|}
\hline $\begin{array}{l}\text { Incomplete outcome data } \\
\text { (attrition bias) }\end{array}$ & Unclear risk & $\begin{array}{l}22 \text { in total (including non-smokers) lost to follow-up, evenly distributed. Loss- } \\
\text { es appear to have been included as smokers }\end{array}$ \\
\hline
\end{tabular}

All outcomes

22 in total (including non-smokers) lost to follow-up, evenly distributed. Loss-

Alloutcomes

\section{Ebbert 2007}

$\begin{array}{ll}\text { Methods } & \text { Setting: } 8 \text { dental practices, USA } \\ & \text { Recruitment: Patients screened by questionnaire at routine hygiene appointments, not selected for } \\ & \text { motivation }\end{array}$
motivation

\begin{tabular}{|c|c|c|}
\hline Participants & \multicolumn{2}{|c|}{82 smokers (60 intervention, 22 control). No baseline data for controls } \\
\hline Interventions & \multicolumn{2}{|c|}{$\begin{array}{l}\text { 1. Control: Brief counselling ( } 10 \text { mins) from hygienist, reinforced by dentist } \\
\text { 2. As } 1 \text { plus faxed referral to quitline, proactive counselling, } 45 \text { mins baseline, } 20 \text { mins at } 1 \text { week and } 2 \\
\text { weeks, further calls if requested }\end{array}$} \\
\hline Outcomes & \multicolumn{2}{|c|}{$\begin{array}{l}\text { Abstinence at } 6 \mathrm{~m} \text { (7-day PP) } \\
\text { Validation: none }\end{array}$} \\
\hline \multicolumn{3}{|l|}{ Notes } \\
\hline \multicolumn{3}{|l|}{ Risk of bias } \\
\hline Bias & Authors' judgement & Support for judgement \\
\hline $\begin{array}{l}\text { Random sequence genera- } \\
\text { tion (selection bias) }\end{array}$ & Unclear risk & Cluster-randomised by practice, method not described \\
\hline $\begin{array}{l}\text { Allocation concealment } \\
\text { (selection bias) }\end{array}$ & High risk & $\begin{array}{l}\text { Hygienists who recruited participants after screening not blind, large differ- } \\
\text { ence in numbers recruited, not possible to establish baseline similarity }\end{array}$ \\
\hline $\begin{array}{l}\text { Blinding of outcome as- } \\
\text { sessment (detection bias) } \\
\text { All outcomes }\end{array}$ & High risk & $\begin{array}{l}\text { Self-reported outcomes from participants not blinded to treatment condition. } \\
\text { Level of personal contact differed between arms }\end{array}$ \\
\hline $\begin{array}{l}\text { Incomplete outcome data } \\
\text { (attrition bias) } \\
\text { All outcomes }\end{array}$ & Unclear risk & No description of number lost at follow-up \\
\hline
\end{tabular}

\section{Ellerbeck 2009}

\begin{tabular}{ll}
\hline Methods & Settng: Primary care patients, 50 rural practices, Kansas, USA \\
Recruitment: Smokers not selected for motivation, but $67 \%$ of those eligible enrolled, only $8.7 \%$ in pre- \\
contemplation stage of change
\end{tabular}

\section{Participants} 750 smokers of $>10$ cigs/day, $41 \%$ M, av. age 47 , av. cigs/day $24,61 \%$ contemplation, $30 \%$ preparation

Interventions

All participants mailed an offer of free pharmacotherapy every $6 \mathrm{~m}, 4$ times in total. Nicotine patch 21 $\mathrm{mg}$ for 6 weeks or bupropion SR (150 mg twice daily) for 7 weeks

1. Control. No other contact. 
2. Moderate-intensity disease management: up to 2 calls from counsellor in each cycle encouraging uptake of pharmacotherapy, newsletter mailings and periodic progress reports with counselling suggestions faxed to physician

3. High-intensity disease management, up to 6 calls at approx 1, 3, 6, 9, 12 weeks from start of each cycle

$\begin{array}{ll}\text { Outcomes } & \text { Abstinence at } 24 \mathrm{~m}(\mathrm{PP}) \text {. Study also reported analysis based on combination of effects at all follow-up } \\ \text { points. Sustained abstinence not a suitable outcome since no quit date and repeated intervention } \\ \text { Validation: attempted saliva cotinine }(<15 \mathrm{ng} / \mathrm{ml}) \text { by mail at } 12 \text { and } 24 \mathrm{~m} \text {. Proxy report used at } 24 \mathrm{~m} \text { for } \\ \text { non-returners. Rate of validation similar across groups }\end{array}$

Notes

For analysis on counselling intensity, classified on basis of average calls; moderate in 3 - 6 sessions, high in $7+$ subgroups

\begin{tabular}{|c|c|c|}
\hline \multicolumn{3}{|l|}{ Risk of bias } \\
\hline Bias & Authors' judgement & Support for judgement \\
\hline $\begin{array}{l}\text { Random sequence genera- } \\
\text { tion (selection bias) }\end{array}$ & Low risk & Quote: "computer generated random-number table" in blocks of 24 \\
\hline $\begin{array}{l}\text { Allocation concealment } \\
\text { (selection bias) }\end{array}$ & Low risk & $\begin{array}{l}\text { Quote: "To conceal allocation, we placed these cards in sequentially num- } \\
\text { bered, opaque, sealed envelopes." }\end{array}$ \\
\hline $\begin{array}{l}\text { Blinding of outcome as- } \\
\text { sessment (detection bias) } \\
\text { All outcomes }\end{array}$ & Low risk & Biochemical validation used \\
\hline $\begin{array}{l}\text { Incomplete outcome data } \\
\text { (attrition bias) } \\
\text { All outcomes }\end{array}$ & Low risk & $\begin{array}{l}\text { Differential rates of loss to follow-up (1: } 22.0 \% ; 2: 31.3 \% ; 3: 31.1 \%) \text {. Partici- } \\
\text { pants lost to follow-up counted as smokers but sensitivity analysis shows no } \\
\text { significant difference in analysis outcome if excluding those lost to follow-up }\end{array}$ \\
\hline
\end{tabular}

Emmons 2005

$\begin{array}{ll}\text { Methods } & \text { Setting: Childhood Cancer Survivors Study cohort, USA } \\ \text { Recruitment: Smokers contacted by telephone to assess eligibility and enrol, not selected for motiva- } \\ \text { tion }\end{array}$

\begin{tabular}{ll}
\hline Participants & 794 smokers (excludes 2 deaths in control); $53 \%$ M, av. age 31, av. cigs/day 12 \\
\hline Interventions & $\begin{array}{l}\text { 1. S-H control. Mailed manual (Clearing the Air) and letter from study physician } \\
\text { 2. Peer counselling. Up to } 6 \text { calls in 7-m period, by trained cancer survivor. Motivational, tailored to } \\
\text { SoC. Free NRT available. Individually-tailored materials before } 1 \text { st call and other materials during inter- } \\
\text { vention }\end{array}$
\end{tabular}

\begin{tabular}{ll}
\hline Outcomes & Abstinence at $12 \mathrm{~m}$ (7-day PP) \\
Validation: none (warning that samples might be requested)
\end{tabular}

Notes No data on average number of calls. Longer-term follow-up, assessed at 2 - 4 years, reported in Emmons 2009. Not used in MA - sustained rates not reported.

\section{Risk of bias}

Bias Authors' judgement Support for judgement


Emmons 2005 (Continued)

Random sequence genera- Unclear risk $\quad$ Randomised, method not described
tion (selection bias)

\begin{tabular}{lll}
\hline $\begin{array}{l}\text { Allocation concealment } \\
\text { (selection bias) }\end{array}$ & Unclear risk & No details given \\
\hline $\begin{array}{l}\text { Blinding of outcome as- } \\
\text { sessment (detection bias) } \\
\text { All outcomes }\end{array}$ & Unclear risk & Bogus pipeline procedure used, no further details provided \\
\hline $\begin{array}{l}\text { Incomplete outcome data } \\
\text { (attrition bias) }\end{array}$ & Unclear risk & $\begin{array}{l}19 \% \text { lost in intervention vs } 24 \% \text { in control at } 12 \mathrm{~m} \text {. All included as smokers in } \\
\text { All outcomes }\end{array}$
\end{tabular}

\section{Ferguson 2012}

\begin{tabular}{ll} 
Methods & Setting: English Quitline \\
& Recruitment: Callers to the NHS Smoking Helpline from any location in England \\
\hline Participants & $\begin{array}{l}2591 \text { smokers aged } 16 \text { or older, motivated to quit in } 4 \text { days - } 4 \text { weeks. } 45 \% \text { M; av. age 38; } 47 \% \text { smoking } \\
11 \text { - } 20 \text { cigs/day }\end{array}$ \\
\hline Interventions & $\begin{array}{l}\text { 1. Standard telephone support (after call, further support by email, letter or text message, offer of } \\
\text { proactive contact) }\end{array}$ \\
$\begin{array}{l}\text { 2. As } 1 \text { plus additional proactive telephone support (up to } 2 \text { calls pre-quit date, } 1 \text { call on quit date, then } \\
\text { calls at 3, } 7,14 \text { and } 21 \text { days post-quit date). Structured call content using MI template (except for } 7-\text { and } \\
\text { 14-day calls) } \\
\text { 3. As 1, plus offer of free NRT } \\
\text { 4. As 2, plus offer of free NRT }\end{array}$ \\
\hline
\end{tabular}

$\begin{array}{ll}\text { Outcomes } & \text { Prolonged abstinence at } 6 \mathrm{~m} \text { (allowing grace period of up to } 5 \text { cigs smoked). 7-day PP also recorded } \\ & \text { Validation: exhaled } \mathrm{CO}<10 \mathrm{ppm}\end{array}$

Notes

Arms 1 and 3 combined and compared with arms 2 and 4 combined. No difference in cessation outcomes between participants offered NRT and those not offered NRT

\section{Risk of bias}

\begin{tabular}{|c|c|c|}
\hline Bias & Authors' judgement & Support for judgement \\
\hline $\begin{array}{l}\text { Random sequence genera- } \\
\text { tion (selection bias) }\end{array}$ & Low risk & Quote: "computer generated random number sequence" \\
\hline $\begin{array}{l}\text { Allocation concealment } \\
\text { (selection bias) }\end{array}$ & Low risk & Subjects allocated by central computerised system \\
\hline $\begin{array}{l}\text { Blinding of outcome as- } \\
\text { sessment (detection bias) } \\
\text { All outcomes }\end{array}$ & Low risk & Biochemical validation rates used \\
\hline $\begin{array}{l}\text { Incomplete outcome data } \\
\text { (attrition bias) }\end{array}$ & Low risk & $\begin{array}{l}\text { High rates of dropout but similar across groups (standard } 43 \% \text {, proactive } \\
45 \%) \text {. Dropouts counted as smokers }\end{array}$ \\
\hline
\end{tabular}


Ferguson 2012 (Continued)

All outcomes
Quote: "this conservative supposition could possibly mask variation....and we explored this possibility by trying alternative associations between missingness and smoking status. This analysis did not change our findings."

Fiore 2004

\begin{tabular}{ll} 
Methods & $\begin{array}{l}\text { Setting: Primary care patients, } 16 \text { clinics, USA } \\
\text { Recruitment: Clinic attenders willing to accept treatment }\end{array}$ \\
\hline Participants & $\begin{array}{l}961 \text { smokers of } \geqq 10 \text { cigs/day. (643 in relevant arms, a further } 908 \text { were allowed to select treatment. De- } \\
\text { mographic details based on } 1869) ; 42 \% \text { M, av. age } 40 \text {, av. cigs/day } 22\end{array}$
\end{tabular}

(Self-selected group of factorial trial not included in MA)
Interventions
2. As 1, plus Committed Quitters (CQ) programme, single TC session and tailored S-H
3. As 2, plus individual counselling, 4 × 15 - 25-min sessions, pre-quit, TQD, next 2 weeks (not used in
this review)

\begin{tabular}{ll}
\hline Outcomes & $\begin{array}{l}\text { Continuous abstinence at } 1 \text { year (no relapse lasting } 7 \text { days, also 7-day PP) } \\
\text { Validation: CO, cut-off not specified. } 2 \text { discordant }\end{array}$
\end{tabular}

Notes Arms 2 vs 1, TC as adjunct to pharmacotherapy

$69 \%$ of those randomised to group 2 enrolled in CQ programme

\section{Risk of bias}

\begin{tabular}{lll}
\hline Bias & Authors' judgement & Support for judgement \\
\hline $\begin{array}{l}\text { Random sequence genera- } \\
\text { tion (selection bias) }\end{array}$ & Unclear risk & Randomised, method not described \\
\hline $\begin{array}{l}\text { Allocation concealment } \\
\text { (selection bias) }\end{array}$ & Unclear risk & No details given \\
\hline $\begin{array}{l}\text { Blinding of outcome as- } \\
\text { sessment (detection bias) } \\
\text { All outcomes }\end{array}$ & Low risk & Biochemically-validated cessation \\
\hline $\begin{array}{l}\text { Incomplete outcome data } \\
\text { (attrition bias) } \\
\text { All outcomes }\end{array}$ & Low risk & 19\% lost at 1 year, no difference by condition \\
\hline
\end{tabular}

\section{Flöter 2009}

\begin{tabular}{ll}
\hline Methods & Setting: Germany \\
& Recruitment: 21 prevention or rehabilitation clinics \\
\hline Participants & $\begin{array}{l}527 \text { hospitalised female smokers } \geq 1 \text { cig during the } 30 \text { days preceding hospitalisation. Av. age } 35.9, \text { mo- } \\
\text { tivation to quit not required }\end{array}$ \\
\hline Interventions & 2. 3 face-to-face courses ( 60 mins each) in groups during clinic hospitalisation featuring CBT and MI \\
& 2. As 1 plus 3 proactive phone calls (10 mins duration) post-discharge in a structured and directive \\
\hline
\end{tabular}


Flöter 2009 (Continued)

3. As 2, but calls delivered in non-directive style

\begin{tabular}{lll}
\hline Outcomes & Self-reported abstinence at 6 m (30-day PP) \\
& Validation: none \\
\hline Notes & Intervention arms combined \\
\hline Risk of bias & & \\
\hline Bias & Authors' judgement & Support for judgement \\
\hline $\begin{array}{l}\text { Random sequence genera- } \\
\text { tion (selection bias) }\end{array}$ & Unclear risk & Method not described \\
\hline $\begin{array}{l}\text { Allocation concealment } \\
\text { (selection bias) }\end{array}$ & Unclear risk & Method not described \\
\hline $\begin{array}{l}\text { Blinding of outcome as- } \\
\text { sessment (detection bias) } \\
\text { All outcomes }\end{array}$ & High risk & $\begin{array}{l}\text { Self-reported outcome with participants not blinded to treatment condition. } \\
\text { Level of personal contact differed between arms }\end{array}$ \\
\hline $\begin{array}{l}\text { Incomplete outcome data } \\
\text { (attrition bias) } \\
\text { All outcomes }\end{array}$ & Unclear risk & Number lost to follow-up unclear (conflicting data available) \\
\hline
\end{tabular}

Fraser 2014

\begin{tabular}{ll} 
Methods & $\begin{array}{l}\text { Setting: USA; population-based } \\
\text { Recruitment: 5-step process: (1) clicked link to study; (2) completed eligibility screening questions; (3) } \\
\text { reviewed consent and confirm willingness to participate; (4) completed baseline questionnaire; (5) call } \\
\text { to an automated answering machine to confirm their participation }\end{array}$ \\
\hline Participants & $\begin{array}{l}1034 \text { smokers of } \geq 5 \text { cigs/day, aged } 17 \text { or older, interest in quitting smoking within the next } 30 \text { days, } \\
32 \% \text { M, av. age } 39.3 \text {, av. cigs/day } 19.3\end{array}$ \\
\hline Interventions & $\begin{array}{l}\text { Factorial design of the following } 5 \text { conditions: website (active/lite), S-H brochure (full/lite), text messag- } \\
\text { ing, NRT, and proactive TC - } 5 \text { sessions of a duration of } 30 \text { mins upon enrolment, and } 15 \text { mins on quit } \\
\text { day or day after, and weekly for } 3 \text { weeks }\end{array}$ \\
\hline Outcomes & $\begin{array}{l}\text { Self-reported abstinence at } 7 \text { m (7-day PP) } \\
\text { Validation: none }\end{array}$ \\
\hline Notes & $\begin{array}{l}\text { New for } 2018 \text { update } \\
\text { funding: "The project was funded through a contract to our university from Matthews Media Group, un- } \\
\text { National Cancer Institute (5K05CA139871)." } \\
\text { Declarations of interest: none declared }\end{array}$ \\
\hline
\end{tabular}

\section{Risk of bias}

Bias Authors' judgement Support for judgement

Random sequence genera- Unclear risk No detail on exactly how the participants were randomised: tion (selection bias) 
Quote: "Randomization occurred immediately after the confirmation call, and participants completing this step were sent an automated email welcoming them to the study and outlining services they would receive (based on their randomization)."

\begin{tabular}{lll}
\hline $\begin{array}{l}\text { Allocation concealment } \\
\text { (selection bias) }\end{array}$ & Unclear risk & As above \\
\hline $\begin{array}{l}\text { Blinding of outcome as- } \\
\begin{array}{l}\text { sessment (detection bias) } \\
\text { All outcomes }\end{array}\end{array}$ & High risk & $\begin{array}{l}\text { Abstinence not biochemically validated. Level of personal contact differed be- } \\
\text { tween arms }\end{array}$ \\
\hline $\begin{array}{l}\text { Incomplete outcome data } \\
\text { (attrition bias) } \\
\text { All outcomes }\end{array}$ & Low risk & Small percentage of lost to follow-up in each arm \\
\hline
\end{tabular}

\section{Gilbert 2006}

\begin{tabular}{|c|c|c|}
\hline Methods & \multicolumn{2}{|c|}{$\begin{array}{l}\text { Setting: Quitline, UK } \\
\text { Recruitment: Quitline callers who engaged in counselling }\end{array}$} \\
\hline Participants & \multicolumn{2}{|c|}{1457 smokers planning quit attempt within 2 weeks; $34 \%$ M, av. age 39, av. cigs/day NS } \\
\hline Interventions & \multicolumn{2}{|c|}{$\begin{array}{l}\text { 1. Standard QUIT information pack and counselling at initial contact. } \\
\text { 2. As } 1 \text {, plus offered } 5 \text { proactive calls, starting TQD if possible, } 2 \text { in week } 1,1 \text { in weeks } 2 \text { and } 4 \text {. Client- } \\
\text { centred }\end{array}$} \\
\hline Outcomes & \multicolumn{2}{|c|}{$\begin{array}{l}\text { Self-reported abstinence at } 12 \mathrm{~m} \text { (sustained for } 6 \mathrm{~m} \text {, also 7-day PP) } \\
\text { Validation: none }\end{array}$} \\
\hline Notes & \multicolumn{2}{|c|}{$26 \%$ received no additional calls, $42 \%$ had $4+$ calls, $31 \%$ had $1-3$ calls } \\
\hline \multicolumn{3}{|l|}{ Risk of bias } \\
\hline Bias & Authors' judgement & Support for judgement \\
\hline $\begin{array}{l}\text { Random sequence genera- } \\
\text { tion (selection bias) }\end{array}$ & High risk & Pseudo-random by day of week \\
\hline $\begin{array}{l}\text { Allocation concealment } \\
\text { (selection bias) }\end{array}$ & Low risk & Recruiters blind so concealment judged adequate \\
\hline $\begin{array}{l}\text { Blinding of outcome as- } \\
\text { sessment (detection bias) } \\
\text { All outcomes }\end{array}$ & High risk & $\begin{array}{l}\text { Self-reported outcomes from participants not blinded to treatment condition. } \\
\text { Level of personal contact differed between arms }\end{array}$ \\
\hline $\begin{array}{l}\text { Incomplete outcome data } \\
\text { (attrition bias) } \\
\text { All outcomes }\end{array}$ & Low risk & $37 \%$ lost to follow-up in both groups. Missing counted as smoking in MA \\
\hline
\end{tabular}

Girgis 2011

Methods Setting: Australia


Girgis 2011 (Continued)

Recruitment: Arabic-speaking GPs in 29 practices in southwest Sydney

\begin{tabular}{|c|c|}
\hline Participants & $\begin{array}{l}407 \text { Arabic smokers, aged } 18-65 \\
48 \% \text { M, av. age } 29 \text {, av. cigs/day } 19\end{array}$ \\
\hline Interventions & $\begin{array}{l}\text { 1. Offer of free referral by GP to proactive TC provided by bilingual psychologist. If accepted offer, par- } \\
\text { ticipants called by counsellor for } 20 \text {-min initial session. If prepared to quit, called again on quit date, } 1 \text {, } \\
3,6 \text { weeks and } 3 \mathrm{~m} \text { after specified quit date. If not ready to set quit date, assigned "less intensive sched- } \\
\text { ule." Mailed quit kit and materials in Arabic and English } \\
\text { 2. Usual care }\end{array}$ \\
\hline Outcomes & $\begin{array}{l}\text { Self-reported abstinence at } 6 \text { and } 12 \text { m (1-day PP) } \\
\text { Validation: none }\end{array}$ \\
\hline Notes & $\begin{array}{l}\text { Low uptake: } 101 \text { of } 213 \text { participants agree to receive call, } 46 \text { receive at least } 1 \text { call, } 8 \text { completed all calls. } \\
\text { Described narratively in 'Other studies' section }\end{array}$ \\
\hline
\end{tabular}

\section{Risk of bias}

\begin{tabular}{lll}
\hline Bias & Authors' judgement & Support for judgement \\
\hline $\begin{array}{l}\text { Random sequence genera- } \\
\text { tion (selection bias) }\end{array}$ & Unclear risk & Not specified \\
\hline $\begin{array}{l}\text { Allocation concealment } \\
\text { (selection bias) }\end{array}$ & High risk & $\begin{array}{l}\text { Quote: "From each participating GP, we recruited a consecutive sample of pa- } \\
\text { tients of Arabic background aged 18-65 years during a specified 4-week peri- } \\
\text { od, irrespective of their smoking status" using an "unobtrusive mark visible to } \\
\text { only the GP to convey group randomization" on the baseline questionnaire. } \\
\text { Suggests allocation not concealed }\end{array}$ \\
\hline
\end{tabular}

Blinding of outcome as- Low risk sessment (detection bias) All outcomes
No biochemical validation, but research assistants conducting follow-up blind to assignment, low uptake of actual contact suggests risk of differential misreport low

Incomplete outcome data Low risk

(attrition bias)

Significantly more participants in intervention group lost to follow-up at $12 \mathrm{~m}$

All outcomes than control ( $45 \%$ vs $34 \%$ ), all dropouts counted as smokers in ITT analysis

\section{Graham 2011}

\begin{tabular}{ll}
\hline Methods & $\begin{array}{l}\text { Setting: USA } \\
\text { Recruitment: US residents searching for stop-smoking advice on a major internet search engine who } \\
\text { clicked on a link to www.quitnet.com, assumed to be motivated }\end{array}$ \\
\hline Participants & $\begin{array}{l}2005 \text { adult smokers of } 5 \text { or more cigs/day. 48.9\%, av. age 35.9, av. cigs/day 20, av. FTND 5.0. 1326 con- } \\
\text { tribute to this review }\end{array}$ \\
\hline Interventions & $\begin{array}{l}\text { 1. Free } 6 \text { m access to www.quitnet.com (interactive commercial cessation website) } \\
\text { 2. As } 1,+ \text { up to } 5 \text { sessions of proactive TC for } 3 \text { m; counsellors had access to www.quitnet.com info and } \\
\text { encouraged participants' use of it; counsellors sent individual emails after counselling sessions to rein- } \\
\text { force key points }\end{array}$
\end{tabular}


Graham 2011 (Continued)

3. Control: access to static, info-only (non-interactive) version of the content on QuitNet (not used in this review)

\begin{tabular}{ll}
\hline Outcomes & Multiple 30-day PP (at 3, 6, 12 and $18 \mathrm{~m})$. \\
& Validation: none \\
\hline Notes & Arm 2 versus 1
\end{tabular}

\section{Risk of bias}

\begin{tabular}{lll}
\hline Bias & Authors' judgement & Support for judgement \\
\hline $\begin{array}{l}\text { Random sequence genera- } \\
\text { tion (selection bias) }\end{array}$ & Low risk & $\begin{array}{l}\text { Quote: "random numbers table...stratified by sex and baseline motivation to } \\
\text { quit" }\end{array}$ \\
\hline $\begin{array}{l}\text { Allocation concealment } \\
\text { (selection bias) }\end{array}$ & Unclear risk & Method not specified \\
\hline $\begin{array}{l}\text { Blinding of outcome as- } \\
\text { sessment (detection bias) }\end{array}$ & High risk & $\begin{array}{l}\text { Self-reported outcome measure from participants not blinded to treatment } \\
\text { condition. Level of personal contact differed between arms }\end{array}$ \\
\hline $\begin{array}{l}\text { Incomplete outcome data } \\
\text { (attrition bias) }\end{array}$ & High risk & $\begin{array}{l}\text { Participants missing data counted as smokers. Sustained PP data not avail- } \\
\text { able for } 46 \% \text { El, 49\% El+P 49\% and 43\% Bl. Difference due to differential rate of } \\
\text { follow-up at 3 m. }\end{array}$ \\
& $\begin{array}{l}\text { Quote: "The lower follow-up assessment rate among El+P participants at 3 } \\
\text { months may have been owing to 'telephone fatigue'...Telephone counselling } \\
\text { was providing within the first 3 months of the study, which was the only as- } \\
\text { sessment period for which higher loss to follow-up was observed. If present, } \\
\text { this bias could have attenuated the effectiveness of the combined interven- } \\
\text { tion." }\end{array}$ \\
\hline
\end{tabular}

\section{Halpin 2006}

\begin{tabular}{ll}
\hline Methods & Setting: Health Maintenance Organisation, USA \\
& Recruitment: Health plan members without current smoking cessation benefit, recruited for a study \\
& giving access to coverage
\end{tabular}

\begin{tabular}{ll}
\hline Participants & 388 smokers; $34 \%$ M, 67\% age $40+, 84 \%$ smoked < a pack/day \\
\hline Interventions & $\begin{array}{l}\text { 1. Coverage for TC and pharmacotherapy (bupropion or NRT, USD 15 co-pay) } \\
\text { 2. Coverage for TC; coverage for pharmacotherapy (bupropion or NRT, USD 15 co-pay) only if enrolled } \\
\text { in TC } \\
\text { 3. Coverage for pharmacotherapy only (control) }\end{array}$ \\
\hline
\end{tabular}

$\begin{array}{ll}\text { Outcomes } & \begin{array}{l}\text { Abstinence at } 6 \mathrm{~m} \text { (7-day PP) } \\ \text { Validation: none }\end{array}\end{array}$

Notes

Not included in MA, results discussed separately, alongside trials for TC as adjunct to pharmacotherapy

\section{Risk of bias}

Bias Authors' judgement Support for judgement


Halpin 2006 (Continued)
Random sequence genera- Unclear risk
Randomised, method not described tion (selection bias)

\begin{tabular}{ll}
\hline $\begin{array}{l}\text { Allocation concealment } \\
\text { (selection bias) }\end{array}$ & Unclear risk details given
\end{tabular}

\begin{tabular}{|c|c|c|}
\hline $\begin{array}{l}\text { Blinding of outcome as- } \\
\text { sessment (detection bias) } \\
\text { All outcomes }\end{array}$ & High risk & $\begin{array}{l}\text { Self-reported outcomes from participants not blinded to treatment condition. } \\
\text { Level of personal contact differed between arms }\end{array}$ \\
\hline
\end{tabular}

Incomplete outcome data Low risk Number lost to follow-up not described, all participants included in analyses
(attrition bias)
All outcomes

Hanssen 2009

\begin{tabular}{ll}
\hline Methods & $\begin{array}{l}\text { Setting: Hospital/community, Norway } \\
\text { Recruitment: Inpatients with diagnosis of myocardial infarction, not selected for motivation }\end{array}$ \\
\hline Participants & 133 daily smokers amongst 288 participants. Demographics not given for smoking subgroup \\
\hline Interventions & $\begin{array}{l}\text { 1. Usual care; outpatient visit at } 6 \text { - } 8 \text { weeks and primary care follow-up } \\
\text { 2. Structured but individualised proactive TC addressing lifestyle issues including smoking, diet and } \\
\text { exercise. Nurse-initiated calls at } 1,2,3,4,6,8,12,24 \text { weeks post-discharge. Smoking not explicitly ad- } \\
\text { dressed at each call. Reactive phone support line available } 6 \text { hours/week }\end{array}$ \\
\hline Outcomes & $\begin{array}{l}\text { Abstinence at } 6,12 \text { and } 18 \text { m (assumed PP, not defined). Primary trial outcome was health-related qual- } \\
\text { ity of life } \\
\text { Validation: none }\end{array}$ \\
\hline Notes & $\begin{array}{l}\text { 18-m follow-up data added in 2013. Smoking was addressed as part of a multicomponent intervention. } \\
\text { TC as adjunct to brief/minimal intervention }\end{array}$
\end{tabular}

\section{Risk of bias}

\begin{tabular}{|c|c|c|}
\hline Bias & Authors' judgement & Support for judgement \\
\hline $\begin{array}{l}\text { Random sequence genera- } \\
\text { tion (selection bias) }\end{array}$ & Unclear risk & Randomised by computer-generated list \\
\hline $\begin{array}{l}\text { Allocation concealment } \\
\text { (selection bias) }\end{array}$ & Unclear risk & $\begin{array}{l}\text { Sequence in sealed opaque envelopes but not stated to be numbered. Fewer } \\
\text { control group participants raises possibility of selection bias, so not classified } \\
\text { as low risk }\end{array}$ \\
\hline $\begin{array}{l}\text { Blinding of outcome as- } \\
\text { sessment (detection bias) } \\
\text { All outcomes }\end{array}$ & High risk & $\begin{array}{l}\text { Self-reported outcomes from participants not blinded to treatment condition. } \\
\text { Level of personal contact differed between arms }\end{array}$ \\
\hline $\begin{array}{l}\text { Incomplete outcome data } \\
\text { (attrition bias) } \\
\text { All outcomes }\end{array}$ & Low risk & $\begin{array}{l}\text { At } 18 \mathrm{~m} \text {, losses amongst baseline smokers } 29 \% \text { in } 1,30 \% \text { in } 2 \text {. Losses reinclud- } \\
\text { ed as smokers in this MA }\end{array}$ \\
\hline
\end{tabular}


Hollis 2007

\begin{tabular}{ll}
\hline Methods & $\begin{array}{l}\text { Setting: Quitline, Oregon, USA } \\
\text { Recruitment: Callers to quitline }\end{array}$ \\
\hline Participants & 4500 smokers willing to make a quit attempt; $40 \%$ M, av. age 41, av. cigs/day 22 \\
\hline Interventions & $\begin{array}{l}\text { Factorial design; } 3 \text { levels of counselling, } \pm \text { offer of nicotine patch (5-week supply, } 80 \% \text { accepted, option } \\
\text { for } 3 \text { weeks more, } 25-28 \% \text { requested) } \\
\text { 1. Brief counselling (usual care), } 15 \text { mins + referral information and tailored S-H } \\
\text { 2. Moderate TC: } 30 \text { - } 40 \text { mins MI, brief call to encourage use of community services, tailored S-H } \\
\text { 3. Intensive; as } 2, \text { plus offer of up to } 4 \text { further calls (Free \& Clear) }\end{array}$
\end{tabular}

\begin{tabular}{ll}
\hline Outcomes & $\begin{array}{l}\text { Abstinence }>30 \text { days at } 12 \mathrm{~m} \\
\text { Validation: none }\end{array}$ \\
\hline Notes & First included as Hollis 2005, based on unpublished abstract.
\end{tabular}

\section{Risk of bias}

\begin{tabular}{lll}
\hline Bias & Authors' judgement & Support for judgement \\
\hline $\begin{array}{l}\text { Random sequence genera- } \\
\text { tion (selection bias) }\end{array}$ & Unclear risk & Randomised, method not described \\
\hline $\begin{array}{l}\text { Allocation concealment } \\
\text { (selection bias) }\end{array}$ & Unclear risk & No details given \\
\hline $\begin{array}{l}\text { Blinding of outcome as- } \\
\text { sessment (detection bias) } \\
\text { All outcomes }\end{array}$ & High risk & $\begin{array}{l}\text { Self-reported outcomes from participants not blinded to treatment condition. } \\
\text { Level of personal contact differed between arms }\end{array}$ \\
\hline $\begin{array}{l}\text { Incomplete outcome data } \\
\text { (attrition bias) } \\
\text { All outcomes }\end{array}$ & Low risk & $\begin{array}{l}\text { 69\% reached at } 12 \text { m. Losses assumed smoking in main analysis, sensitivity } \\
\text { analyses reported }\end{array}$ \\
\hline
\end{tabular}

Holmes-Rovner 2008

\begin{tabular}{ll}
\hline Methods & $\begin{array}{l}\text { Setting: } 5 \text { hospitals, Michigan, USA } \\
\text { Recruitment: Inpatients with acute coronary syndrome, not selected for motivation }\end{array}$ \\
\hline Participants & $\begin{array}{l}525 \text { participants, including } 136 \text { who smoked at admission and could be followed up. Smoker demo- } \\
\text { graphics not given }\end{array}$ \\
\hline Interventions & $\begin{array}{l}\text { 1. In-hospital care according to American College of Cardiology Guideline Applied to Practice quality } \\
\text { improvement (QI) programme, including written discharge contract } \\
\text { 2. Heart After-Hospital Recovery Planner (HARP), } 6 \text { session telephone coaching, } 15 \text { - 30-min weekly ses- } \\
\text { sions initiated } 0 \text { - } 4 \text { weeks post-discharge. Pharmacotherapy encouraged for cessation. Intervention } \\
\text { could address multiple behaviours }\end{array}$ \\
\hline Outcomes & $\begin{array}{l}\text { Abstinence at } 8 \text { m ("remained quit for the period") } \\
\text { Validation: none }\end{array}$ \\
\hline Notes & Data on smoking outcomes provided by authors from in-press paper by Holtrop et al \\
\hline
\end{tabular}

\section{Risk of bias}


Holmes-Rovner 2008 (Continued)

\begin{tabular}{lll} 
Bias & Authors' judgement & Support for judgement \\
\hline $\begin{array}{l}\text { Random sequence genera- } \\
\text { tion (selection bias) }\end{array}$ & Unclear risk & Blocked randomisation, method not described \\
\hline $\begin{array}{l}\text { Allocation concealment } \\
\text { (selection bias) }\end{array}$ & Unclear risk & $\begin{array}{l}\text { Change in methodology from randomisation at recruitment/consent to ran- } \\
\text { domisation after baseline interview due to initial imbalance in numbers. Data } \\
\text { collectors were blind to group }\end{array}$ \\
\hline
\end{tabular}

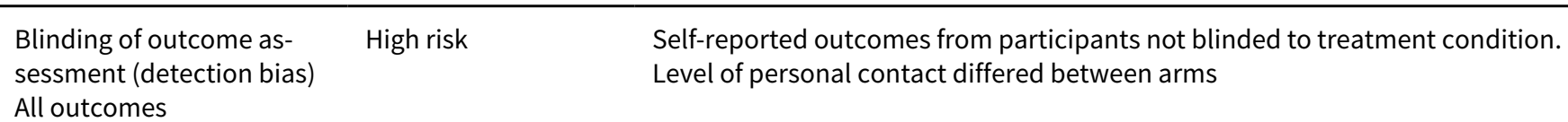

All outcomes

Incomplete outcome data Unclear risk (attrition bias)

All outcomes
15 people whose smoking status not confirmed and 15 losses to follow-up excluded because group not stated. ITT analysis said not to alter results

Hughes 2010

\begin{tabular}{ll}
\hline Methods & Setting: Columbia, SC, Albuquerque, NM and Florence, SC; \\
& Recruitment: Through newspaper and radio ads \\
\hline Participants & $\begin{array}{l}746 \text { adult smokers of } \geq 15 \text { cigs/day, interested in quitting gradually in the next } 30 \text { days, } 46 \% \text { M, av. age } \\
46, \text { av. cigs/day } 23\end{array}$
\end{tabular}

Interventions
$\begin{aligned} & \text { 1. Brief advice TC ( } 2 \text { sessions - } 5 \text { mins before, and } 10 \text { mins after quit day) } \\ & \text { 2. Abrupt cessation TC ( } 5 \text { sessions - } 30 \text { mins between } 7 \text { and } 21 \text { days before quit day, } 10 \text { mins subse- } \\ & \text { quently } 2 \text { days before, } 2,7 \text { and } 14 \text { days after quit day) } \\ & \text { 3. Gradual cessation TC (not used in this review due NRT being administered before and after quit day) } \\ & \text { In arms } 1 \text { and 2, participants were sent the US National Cancer Institute's Clearing the Air booklet, as } \\ & \text { well as nicotine lozenges after quit day }\end{aligned}$

$\begin{array}{ll}\text { Outcomes } & \text { Abstinence at } 6 \mathrm{~m} \text { (prolonged } 2 \text { weeks post-quit day to } 6 \text { m abstinence) } \\ \text { Validation: co level (cut-off not reported) }\end{array}$

Validation: CO level (cut-off not reported)

Notes New for 2018 update

Funding: "The conduct of this study and preparation of the manuscript was funded by grant DA-017825 (JH), Senior Scientist Award DA-00490 (JH) and Institutional Training Grant DA-07242 (EP) from the US National Institute on Drug Abuse."

Declarations of interest: "Since 1/1/2007, Dr Hughes has received research grants from the National Institute on Health and Pfizer. Pfizer develops and sells smoking cessation medications. During this time, he has accepted honoraria or consulting fees from several non-profit and for-profit organizations and companies that develop, sell or promote smoking cessation products or services or educate/advocate about smoking cessation: Abbot Pharmaceuticals; Acrux; Aradigm; American Academy of Addiction Psychiatry; American Psychiatric Association; Begbies Traynor; Cambridge Hospital, Cline, Davis and Mann; Constella Group; Consultants in Behavior Change; Dean Foundation, DLA Piper, EPI-Q, European Respiratory Society, Evotec; Exchange Limited; Fagerstrom Consulting; Free and Clear Glaxo-Smith Kline; Golin Harris; Healthwise; Insyght; Informed, Invivodata; Johns Hopkins University; JL Reckner; Maine Medical Center; McNeil Pharmaceuticals; Novartis Pharmaceuticals; Oglivy Health PR, Ottawa Heart Institute, Pfizer Pharmaceuticals; Pinney Associates; Propagate Pharmaceuticals. Reuters; Scientia, Selecta; Temple University of Health Sciences; University of Arkansas; University of California-San 
Hughes 2010 (Continued)

Francisco; University of Cantabria; University of Kentucky, US National Institutes on Health; Wolters Publishing, and Xenova."

\section{Risk of bias}

\begin{tabular}{|c|c|c|}
\hline Bias & Authors' judgement & Support for judgement \\
\hline $\begin{array}{l}\text { Random sequence genera- } \\
\text { tion (selection bias) }\end{array}$ & Low risk & $\begin{array}{l}\text { Quote: "statistician generated a concealed allocation sequence and random- } \\
\text { ized participants to the gradual, abrupt, or minimal treatment conditions in } \\
\text { a 2:2:1 ratio using blocked randomization (stratified by city and counselor) } \\
\text { based on the SAS procedure PLAN" }\end{array}$ \\
\hline $\begin{array}{l}\text { Allocation concealment } \\
\text { (selection bias) }\end{array}$ & Unclear risk & Not described \\
\hline $\begin{array}{l}\text { Blinding of outcome as- } \\
\text { sessment (detection bias) } \\
\text { All outcomes }\end{array}$ & Low risk & Biochemical verification \\
\hline $\begin{array}{l}\text { Incomplete outcome data } \\
\text { (attrition bias) } \\
\text { All outcomes }\end{array}$ & Low risk & Similar low percentage ( $21 \%$ ) lost to follow-up between groups \\
\hline
\end{tabular}

Joyce 2008

$\begin{array}{ll}\text { Methods } & \text { Setting: } 7 \text { states, USA } \\ \text { Recruitment: Smokers responding to mailings and media coverage of new service for Medicare benefi- } \\ \text { ciaries }\end{array}$
ciaries

\begin{tabular}{ll}
\hline Participants & $\begin{array}{l}7354 \text { smoking Medicare beneficiaries aged } 65+(4295 \text { contribute to review), } 40 \% \text { M, } 69 \% \text { contempla- } \\
\text { tion, 30\% preparation }\end{array}$ \\
\hline Interventions & Trial of 4 levels of Medicare benefit. All participants mailed a S-H kit \\
1. Usual care (not used in MA) \\
2. Provider counselling benefit; up to 4 sessions of 3 - 10 mins of stage-based counselling (not used in \\
MA) \\
3. As 2, plus pharmacotherapy benefit; nicotine patch or bupropion for USD 5 co-pay, up to $2 \times 12$-week \\
courses \\
4. Quitline benefit; choice of a reactive hotline with prerecorded messages/ad hoc counselling, or a \\
proactive helpline of up to 5 calls per 12 -week cycle, up to 2 cycles in the year. Also S-H manual and \\
coverage for nicotine patch for USD 5 co-pay
\end{tabular}

\begin{tabular}{ll}
\hline Outcomes & $\begin{array}{l}\text { Abstinence at } 12 \mathrm{~m} \text { (7-day PP) } \\
\text { Validation: none }\end{array}$ \\
\hline Notes & $\begin{array}{l}\text { Main comparison } 4 \mathrm{vs} \mathrm{3,} \mathrm{which} \mathrm{had} \mathrm{similar} \mathrm{levels} \mathrm{of} \mathrm{self-reported} \mathrm{use} \mathrm{of} \mathrm{any} \mathrm{pharmacotherapy} \mathrm{(60 \%} \mathrm{vs} \\
63.4 \%) . \text { Participants were not called unless they enrolled, so treated as trial of quitline availability }\end{array}$
\end{tabular}

\section{Risk of bias}

\begin{tabular}{lll}
\hline Bias & Authors' judgement & Support for judgement \\
\hline $\begin{array}{l}\text { Random sequence genera- } \\
\text { tion (selection bias) }\end{array}$ & Unclear risk & $\begin{array}{l}\text { Cluster-randomised, states divided into quarters balancing smoking preva- } \\
\text { lence and aged, restricted randomisation to different conditions }\end{array}$ \\
\hline
\end{tabular}


Joyce 2008 (Continued)

Allocation concealment Unclear risk Participants unaware of programme differences when enrolling and allocation (selection bias) determined by address. Low enrolment in 1 condition does not seem to have been due to bias

Blinding of outcome as sessment (detection bias) All outcomes
High risk

Self-reported outcomes from participants not blinded to treatment condition. Level of personal contact differed between arms

\section{Incomplete outcome data Unclear risk} (attrition bias)

$25 \%$ lost to follow-up at $12 \mathrm{~m}$, absolute differences between groups small. All outcomes

Klemperer 2017

$\begin{array}{ll}\text { Methods } & \text { Setting: USA, population-based } \\ & \text { Recruitment: Through email invitations to a nationally representative consumer panel }\end{array}$

Participants 560 adult smokers of $\geq 10$ cigs/day with a desire to quit some day, but not in the next 30 days, $33 \% \mathrm{M}$, av. age 51, av. cigs/day 20

\begin{tabular}{|c|c|}
\hline \multirow[t]{3}{*}{ Interventions } & $\begin{array}{l}\text { 1. Usual care } 5 \text {-min TC } \\
\text { 2. Brief motivational TC }\end{array}$ \\
\hline & 3. Smoking reduction TC \\
\hline & $\begin{array}{l}\text { Groups } 2 \text { and } 3 \text { were dosage-matched with } 1 \times 15 \text {-min call (week } 0 \text { ), followed by } 2 \times 10-15 \text {-min calls } \\
\text { (weeks } 2 \text { and } 4 \text { ) }\end{array}$ \\
\hline Outcomes & $\begin{array}{l}\text { Abstinence at } 12 \mathrm{~m} \text { (7-day PP) } \\
\text { Validation: none }\end{array}$ \\
\hline \multirow[t]{3}{*}{ Notes } & New for 2018 update \\
\hline & $\begin{array}{l}\text { Funding: "This work was supported by research grant NCI CA163176 from the National Cancer Institute } \\
\text { (J.R.H.) and training grant T32 DA 7242-23 from the National Institute on Drug Abuse (E.M.K.)." }\end{array}$ \\
\hline & $\begin{array}{l}\text { Declarations of interest: "One of the authors received consulting and speaking fees from several com- } \\
\text { panies that develop or market pharmacological and behavioral treatments for smoking cessation or } \\
\text { harm reduction and from several non-profit organizations that promote tobacco control. He also con- } \\
\text { sults (without payment) for Swedish Match." }\end{array}$ \\
\hline
\end{tabular}

\section{Risk of bias}

\begin{tabular}{lll}
\hline Bias & Authors' judgement & Support for judgement \\
\hline $\begin{array}{l}\text { Random sequence genera- } \\
\text { tion (selection bias) }\end{array}$ & Low risk & $\begin{array}{l}\text { One of the investigators designed a computer-generated block randomisation } \\
\text { schedule stratified by counsellor to assign participants to receive either inter- } \\
\text { vention }\end{array}$ \\
\hline $\begin{array}{l}\text { Allocation concealment } \\
\text { (selection bias) }\end{array}$ & Unclear risk & Not described \\
\hline $\begin{array}{l}\text { Blinding of outcome as- } \\
\text { sessment (detection bias) } \\
\text { All outcomes }\end{array}$ & High risk & Self-reported abstinence. Level of personal contact differed between arms \\
\hline
\end{tabular}


Klemperer 2017 (Continued)

Incomplete outcome data (attrition bias)

All outcomes
Low risk

Large percentage (> 50\%) of participants lost to follow-up but according to authors:

Quote: "The amount of missing data for all outcomes did not differ among conditions, nor were baseline characteristics associated with missing data". Sensitivity analyses were used to confirm robustness of their findings

Lando 1992

$\begin{array}{ll}\text { Methods } & \text { Setting: Community, Minnesota, USA } \\ & \text { Recruitment: From } 4 \text { groups of previously identified smokers }\end{array}$

Participants 1827 smokers, not selected by motivation to quit; $50 \%$ M, av. age 47 , av. cigs/day 22

\begin{tabular}{ll}
\hline Interventions & 1. Proactive TC, 2 calls over 3 weeks. Offered S-H materials \\
2. No intervention, contacted at follow-up only
\end{tabular}

\begin{tabular}{ll}
\hline Outcomes & $\begin{array}{l}\text { Abstinence at } 18 \mathrm{~m} \text { (no puff, }>3 \mathrm{~m} \text { and validated abstinent at } 6 \mathrm{~m} \text { ) } \\
\text { Validation: Saliva cotinine }<10 \mathrm{ng} / \mathrm{ml} \text { at } 6 \mathrm{~m}\end{array}$
\end{tabular}

Validation: Saliva cotinine $<10 \mathrm{ng} / \mathrm{ml}$ at $6 \mathrm{~m}$

Notes High level of cotinine disconfirmation. $70 \%$ agreed to second call

\section{Risk of bias}

\begin{tabular}{lll}
\hline Bias & Authors' judgement & Support for judgement \\
\hline $\begin{array}{l}\text { Random sequence genera- } \\
\text { tion (selection bias) }\end{array}$ & Unclear risk & Randomised, method not described \\
\hline $\begin{array}{l}\text { Allocation concealment } \\
\text { (selection bias) }\end{array}$ & Unclear risk & $\begin{array}{l}\text { Minimal contact intervention, likelihood of bias small but since control group } \\
\text { participants were not contacted at baseline and a large number of interven- } \\
\text { tion group participants could not be reached, impossible to compare baseline } \\
\text { characteristics }\end{array}$ \\
\hline $\begin{array}{l}\text { Blinding of outcome as- } \\
\text { sessment (detection bias) }\end{array}$ & High risk & $\begin{array}{l}\text { No biochemical validation at } 18 \mathrm{~m} \text {. At } 6 \text { m, validated abstinence rates "consid- } \\
\text { erably lower" than self-report }\end{array}$ \\
\hline $\begin{array}{l}\text { Incomplete outcome data } \\
\text { (attrition bias) } \\
\text { All outcomes }\end{array}$ & Low risk & $\begin{array}{l}\text { Only a sample of intervention and control participants were selected for fol- } \\
\text { low-up. Of this sample, } 91 \% \text { reached at } 18 \mathrm{~m} \text { in both groups. Numbers fol- } \\
\text { lowed up used as denominator in MA }\end{array}$ \\
\hline
\end{tabular}

Lando 1997

\begin{tabular}{ll}
\hline Methods & $\begin{array}{l}\text { Setting: Health Maintenance Organisation, USA } \\
\text { Recruitment: Physician referral and HMO clinic newsletters }\end{array}$ \\
\hline Participants & 509 smokers of > 20 cigs/day, motivated to quit; 44\% M, av. age 42, av. cigs/day 28 \\
\hline Interventions & $\begin{array}{l}\text { All participants received prescriptions for free nicotine patch (Prostep), } 22 \text { mg for a maximum of } 6 \\
\text { weeks plus } 2 \text { weeks } 11 \mathrm{mg} . \text { Proactive vs Reactive } \\
\text { Attended } 90 \text {-min group orientation session describing study, use of patch, behavioural information, set } \\
\text { quit date. Standard written materials with patch included description of a toll-free telephone help line } \\
\text { 1. No further support }\end{array}$ \\
\hline
\end{tabular}


Lando 1997 (Continued)

2. Orientation session included encouragement to call toll-free number and a registration card

3. Additional proactive TC, 410 - 15-min calls (approx 1, 4, 7 - 9, 12 weeks from quit date). Reinforced success or negotiated a new quit date

\begin{tabular}{ll}
\hline Outcomes & $\begin{array}{l}\text { Abstinence at } 12 \mathrm{~m} \text { (from quit date) } \\
\text { Validation: } \mathrm{CO} \text { at } 6 \mathrm{~m} .96 \% \text { of quitters were confirmed }\end{array}$ \\
\hline Notes & $\begin{array}{l}\text { Arms } 3 \text { vs } 1+2, \text { effect of proactive TC compared to contact and quitline alone. (1 \& } 2 \text { combined since } \\
\text { fewer than } 1 \% \text { called quitline and no difference between quit rates). Participants who did not return }\end{array}$ \\
& questionnaires at $2,5,8,12$ weeks were called by telephone. \\
& Average number of calls completed 3.76
\end{tabular}

\section{Risk of bias}

\begin{tabular}{lll}
\hline Bias & Authors' judgement & Support for judgement \\
\hline $\begin{array}{l}\text { Random sequence genera- } \\
\text { tion (selection bias) }\end{array}$ & Unclear risk & Cluster-randomised, method not described \\
\hline $\begin{array}{l}\text { Allocation concealment } \\
\text { (selection bias) }\end{array}$ & Unclear risk & $\begin{array}{l}\text { Allocation by orientation session attended; participants did not know condi- } \\
\text { tion in advance, so risk of selection bias probably low }\end{array}$ \\
\hline $\begin{array}{l}\text { Blinding of outcome as- } \\
\text { sessment (detection bias) } \\
\text { All outcomes }\end{array}$ & Low risk & Biochemically-validated quit rates \\
\hline $\begin{array}{l}\text { Incomplete outcome data } \\
\text { (attrition bias) }\end{array}$ & Low risk & $\begin{array}{l}82 \% \text { response rate at } 12 \text { m, no difference between groups, missing treated as } \\
\text { All outcomes }\end{array}$ \\
\hline
\end{tabular}

Lichtenstein 2000

$\begin{array}{ll}\text { Methods } & \text { Setting: Community, USA } \\ & \text { Recruitment: Active; by electric utility mailing to identify households with smokers and low radon con- } \\ & \text { centrations }\end{array}$

\begin{tabular}{ll}
\hline Participants & 1006 smokers in 714 households (651 in relevant arms); av. cigs/day 20 \\
\hline Interventions & $\begin{array}{l}\text { 1. Standard Environmental Protection Agency leaflet on risks of radon (this arm not used in review) } \\
\text { 2. Pamphlet highlighting risk of smoking in low concentrations of radon, with tips for quitting, or not } \\
\text { smoking indoors } \\
\text { 3. Pamphlet as 2, plus up to } 2 \text { brief (mean about } 6 \text { mins) proactive TC sessions }\end{array}$ \\
\hline
\end{tabular}

\begin{tabular}{ll}
\hline Outcomes & Self-reported abstinence at $12 \mathrm{~m}$ (sustained at 3 and $12 \mathrm{~m}$ ) \\
& Validation: none \\
\hline Notes & $\begin{array}{l}\text { Arms } 3 \mathrm{vs} 2, \text { effect of TC versus S-H alone } \\
\text { Cluster-randomisation, } 54 \% \text { of smokers lived with another smoker. Intraclass correlation coefficient } \\
\text { for sustained abstinence was .010. Analyses did not correct for this. }\end{array}$
\end{tabular}

\section{Risk of bias}

\begin{tabular}{lll}
\hline Bias & Authors' judgement & Support for judgement \\
\hline $\begin{array}{l}\text { Random sequence genera- } \\
\text { tion (selection bias) }\end{array}$ & Unclear risk & Randomised by household, method not described \\
\hline \hline
\end{tabular}


Lichtenstein 2000 (Continued)

\begin{tabular}{lll}
$\begin{array}{l}\text { Allocation concealment } \\
\text { (selection bias) }\end{array}$ & Unclear risk & No details given \\
\hline $\begin{array}{l}\text { Blinding of outcome as- } \\
\text { sessment (detection bias) } \\
\text { All outcomes }\end{array}$ & High risk & $\begin{array}{l}\text { Self-reported outcomes from participants not blinded to treatment condition. } \\
\text { Level of personal contact differed between arms }\end{array}$ \\
\hline
\end{tabular}

\begin{tabular}{ll}
\hline $\begin{array}{l}\text { Incomplete outcome data } \\
\text { (attrition bias) } \\
\text { All outcomes }\end{array}$ & $\begin{array}{l}80 \% \text { of households reached at } 3 \text { and } 12 \mathrm{~m} \text {, no difference across conditions. } \\
\text { Missing treated as smoking }\end{array}$ \\
\hline
\end{tabular}

\section{Lichtenstein 2008}

\begin{tabular}{ll}
\hline Methods & Setting: Community, USA \\
& $\begin{array}{l}\text { Recruitment: Active; by electric utility mailing with offer of radon test kit to identify households with } \\
\text { smokers }\end{array}$
\end{tabular}

\begin{tabular}{|c|c|}
\hline Participants & 1364 households with 1821 smokers, $~ 18$ cigs/day \\
\hline Interventions & $\begin{array}{l}\text { Factorial design crossing } \pm \text { brief phone counselling with } 15 \text {-min video } \mathrm{S}-\mathrm{H} \text { materials. All households giv- } \\
\text { en } A \text { Citizens Guide to Radon and letter tailored to results of radon level test } \\
1.1 \text { - } 2 \text { calls after receipt of radon test results. Clarified risk and encouraged quitting or no smoking in } \\
\text { house. Second call scheduled if interested } \\
\text { 2. No calls }\end{array}$ \\
\hline
\end{tabular}

\begin{tabular}{ll}
\hline Outcomes & $\begin{array}{l}\text { Self-reported abstinence at } 12 \mathrm{~m} \text { (sustained at } 3 \text { and } 12 \mathrm{~m} \text { ) } \\
\text { Validation: none }\end{array}$
\end{tabular}

\begin{tabular}{ll}
\hline Notes & $\begin{array}{l}\text { Results of analyses accounting for clustering of multiple smokers in households reported to yield re- } \\
\text { sults generally consistent with simple analyses }\end{array}$ \\
\hline
\end{tabular}

\section{Risk of bias}

\begin{tabular}{lll}
\hline Bias & Authors' judgement & Support for judgement \\
\hline $\begin{array}{l}\text { Random sequence genera- } \\
\text { tion (selection bias) }\end{array}$ & Unclear risk & $\begin{array}{l}\text { Responding households sequentially randomised to 4 conditions subject to } \\
\text { stratification on radon test status }\end{array}$ \\
\hline $\begin{array}{l}\text { Allocation concealment } \\
\text { (selection bias) }\end{array}$ & Unclear risk & No details given \\
\hline $\begin{array}{l}\text { Blinding of outcome as- } \\
\text { sessment (detection bias) } \\
\text { All outcomes }\end{array}$ & High risk & $\begin{array}{l}\text { Self-reported outcomes from participants not blinded to treatment condition. } \\
\text { Level of personal contact differed between arms }\end{array}$ \\
\hline $\begin{array}{l}\text { Incomplete outcome data } \\
\text { (attrition bias) } \\
\text { All outcomes }\end{array}$ & Low risk & $\begin{array}{l}83 \% \text { of households completed } 12 \mathrm{~m} \text { assessment, } 76 \% \text { completed both 3 and } \\
12 \mathrm{~m}\end{array}$ \\
\hline
\end{tabular}

Lindqvist 2013

Methods Setting: Sweden; clinic-based


Lindqvist 2013 (Continued)

Recruitment: Callers to Swedish National Tobacco Quitline were invited to participate in the study, if consented to participate, they were sent a postal baseline registration questionnaire

\begin{tabular}{|c|c|}
\hline Participants & $\begin{array}{l}772 \text { smokers distributed among } 9 \text { and } 8 \text { counsellors, missing baseline patients' characteristics, only } \\
\text { characteristics of completers at } 12 \text { m are provided, } 20 \% \mathrm{M} \text {, av. age } 48,>80 \% \text { used NRT or other medica- } \\
\text { tions }\end{array}$ \\
\hline \multirow[t]{3}{*}{ Interventions } & 1. Standard TC \\
\hline & 2. Motivational interviewing TC \\
\hline & Total contact was similar between arms, with a duration 50 ', and av. number of sessions 3 \\
\hline \multirow[t]{2}{*}{ Outcomes } & Self-reported abstinence at $12 \mathrm{~m}$ (continuous) \\
\hline & Validation: none \\
\hline \multirow[t]{5}{*}{ Notes } & New for 2018 update \\
\hline & Funding: "The research was funded by the Swedish Cancer Society, Stockholm County Council, the \\
\hline & Swedish Heart and Lung Association, the Swedish Research Council, the Swedish Council for Working \\
\hline & Life and Social Research and the Swedish National Institute of Public Health." \\
\hline & Declarations of interest: none reported \\
\hline
\end{tabular}

\section{Risk of bias}

Bias Authors' judgement Support for judgement

Random sequence genera- High risk tion (selection bias)

Allocation of counsellors was semi-randomised (with a flip of a coin)

Quote: "The allocation of the counsellors resulted in an uneven distribution of total working hours between the groups. In order to achieve a more equal distribution between the two arms, the groups were readjusted (again by coin flip)"

\begin{tabular}{lll}
\hline $\begin{array}{l}\text { Allocation concealment } \\
\text { (selection bias) }\end{array}$ & Unclear risk & Not described \\
\hline $\begin{array}{l}\text { Blinding of outcome as- } \\
\text { sessment (detection bias) } \\
\text { All outcomes }\end{array}$ & Low risk & $\begin{array}{l}\text { Self-reported abstinence, but same level of personal contact in different study } \\
\text { arms }\end{array}$ \\
\hline $\begin{array}{l}\text { Incomplete outcome data } \\
\text { (attrition bias) } \\
\text { All outcomes }\end{array}$ & High risk & $\begin{array}{l}\text { Quote: "In total, } 9 \text { counsellors were allocated to ST and } 8 \text { counsellors to MI. } \\
\text { During the study period, } 2 \text { (out of } 8 \text { - 25\%) of the MI counsellors left SNTQ. Con- } \\
\text { sequently, the Ml arm eventually came to consist of six counsellors." }\end{array}$
\end{tabular}

Lipkus 1999

\begin{tabular}{ll}
\hline Methods & $\begin{array}{l}\text { Setting: Health centre, USA } \\
\text { Recruitment: From telephone survey of patients }\end{array}$ \\
\hline Participants & $\begin{array}{l}\text { Low-income African-American smokers, } 266 \text { randomised, } 160 \text { followed up, } 107 \text { in relevant arms. Unse- } \\
\text { lected by motivation; } 48 \% \mathrm{M}, 49 \% \text { aged }>50\end{array}$ \\
\hline Interventions & $\begin{array}{l}\text { 1. Physician prompts attached to chart (included other screening tests). Providers trained to use 4As } \\
\text { (Ask/ Advise/ Assist/ Arrange follow-up) model. Only received if participants visited doctor } \\
\text { 2. As 1, plus } 1 \text { mailing of tailored print communication around birthday }\end{array}$
\end{tabular}


Lipkus 1999 (Continued)

3. As 2, plus proactive TC; 1 or 2 (for women also due other screening), stage-based, barriers and reasons for quitting, approx 6 mins

\begin{tabular}{ll}
\hline Outcomes & $\begin{array}{l}\text { Self-reported abstinence } 16 \mathrm{~m} \text { after last intervention (30-day PP) } \\
\text { Validation: none }\end{array}$ \\
\hline Notes & $\begin{array}{l}\text { Arms } 3 \text { vs 2, TC without face-to-face contact; physician advice was not an integral part of the interven- } \\
\text { tion - participants not required to have visited the doctor or received advice during the intervention pe- } \\
\text { riod }\end{array}$
\end{tabular}

\section{Risk of bias}

\begin{tabular}{lll}
\hline Bias & Authors' judgement & Support for judgement \\
\hline $\begin{array}{l}\text { Random sequence genera- } \\
\text { tion (selection bias) }\end{array}$ & Unclear risk & Randomised, method not described \\
\hline $\begin{array}{l}\text { Allocation concealment } \\
\text { (selection bias) }\end{array}$ & Unclear risk & No details given \\
\hline $\begin{array}{l}\text { Blinding of outcome as- } \\
\text { sessment (detection bias) } \\
\text { All outcomes }\end{array}$ & High risk & $\begin{array}{l}\text { Self-reported outcomes from participants not blinded to treatment condition. } \\
\text { Level of personal contact differed between arms }\end{array}$ \\
\hline $\begin{array}{l}\text { Incomplete outcome data } \\
\text { (attrition bias) } \\
\text { All outcomes }\end{array}$ & Low risk & $\begin{array}{l}\text { 38\% loss to follow-up primarily due to disconnected phone numbers. Report- } \\
\text { ed rates based on numbers followed up. Authors report that an analysis with } \\
\text { missing treated as smoking did not alter findings }\end{array}$ \\
\hline
\end{tabular}

\section{Lipkus 2004}

\begin{tabular}{|c|c|c|}
\hline Methods & \multicolumn{2}{|c|}{$\begin{array}{l}\text { Setting: Community, USA } \\
\text { Recruitment: Proactive in shopping malls }\end{array}$} \\
\hline Participants & \multicolumn{2}{|c|}{$\begin{array}{l}412 \text { teenage smokers (aged } 15-18 \text {, smoked in past } 7 \text { days); } 49 \% \mathrm{M}, 56 \% \text { aged } \geq 17 \text {, av cigs/day } 10,21 \% \\
\text { contemplation }\end{array}$} \\
\hline Interventions & \multicolumn{2}{|c|}{$\begin{array}{l}\text { 1. S-H, } 2 \text { booklets for teen smokers and video } \\
\text { 2. as } 1 \text {, plus proactive TC, } 3 \text { calls ( } 12 \text { - } 15 \text { mins) using } \mathrm{MI} \text { and problem-solving }\end{array}$} \\
\hline Outcomes & \multicolumn{2}{|c|}{$\begin{array}{l}\text { Abstinence at } 8 \mathrm{~m} \text { ( } 7 \text {-day PP) } \\
\text { Validation method: Saliva cotinine } \leq 10 \mathrm{ng} / \mathrm{mL} \text { at } 4 \mathrm{~m} \text { only. Low response, high failure to confirm. Absti- } \\
\text { nence based on self report only }\end{array}$} \\
\hline Notes & \multicolumn{2}{|c|}{ TC as adjunct to targeted $\mathrm{S}-\mathrm{H}$. } \\
\hline \multicolumn{3}{|l|}{ Risk of bias } \\
\hline Bias & Authors' judgement & Support for judgement \\
\hline $\begin{array}{l}\text { Random sequence genera- } \\
\text { tion (selection bias) }\end{array}$ & Unclear risk & Randomised, method not described, stratified by SoC \\
\hline $\begin{array}{l}\text { Allocation concealment } \\
\text { (selection bias) }\end{array}$ & Unclear risk & No details given \\
\hline
\end{tabular}


Lipkus 2004 (Continued)

Blinding of outcome as- High risk Biochemical validation done but final outcome figures based on self-report sessment (detection bias) only. High failure to confirm and low response rate. Level of personal contact All outcomes differed between arms

Incomplete outcome data Unclear risk (attrition bias)

$46 \%$ Intervention and $51 \%$ Control reached at both follow-ups. Losses includ-

All outcomes ed as smokers

\section{MacLeod 2003}

\begin{tabular}{|c|c|c|}
\hline Methods & \multicolumn{2}{|c|}{$\begin{array}{l}\text { Setting: Community, Australia } \\
\text { Recruitment: Community volunteers }\end{array}$} \\
\hline Participants & \multicolumn{2}{|c|}{854 smokers interested in quitting; 49\% M, av. age 42, av. cigs/day 24} \\
\hline Interventions & \multicolumn{2}{|c|}{$\begin{array}{l}\text { 1. Free } 2 \text {-week supply of nicotine patch by mail, instructed to purchase further supply. } 14 \text { or } 21 \mathrm{mg} \text { de- } \\
\text { pending on body weight } \\
\text { 2. As } 1,+5 \text { proactive TC sessions at } 1,2,3,6 \text { and } 10 \text { weeks. } 20 \text {-min session } 1,10 \text { mins others. Toll-free } \\
\text { hotline, S-H materials }\end{array}$} \\
\hline Outcomes & \multicolumn{2}{|c|}{$\begin{array}{l}\text { Self-reported abstinence at } 6 \mathrm{~m} \text { (90-day continuous) } \\
\text { Validation: none, warning of CO test only }\end{array}$} \\
\hline Notes & \multicolumn{2}{|c|}{$\begin{array}{l}\text { TC as adjunct to NRT } \\
\text { Average number of calls } 4.7 .9 \% \text { of participants called hotline }\end{array}$} \\
\hline \multicolumn{3}{|l|}{ Risk of bias } \\
\hline Bias & Authors' judgement & Support for judgement \\
\hline $\begin{array}{l}\text { Random sequence genera- } \\
\text { tion (selection bias) }\end{array}$ & High risk & $\begin{array}{l}\text { "randomized" by shuffling folders each day after participants to be included } \\
\text { were listed }\end{array}$ \\
\hline $\begin{array}{l}\text { Allocation concealment } \\
\text { (selection bias) }\end{array}$ & High risk & $\begin{array}{l}\text { Potential for bias, since allocation sequence not fixed in advance. Baseline } \\
\text { characteristics similar across groups }\end{array}$ \\
\hline $\begin{array}{l}\text { Blinding of outcome as- } \\
\text { sessment (detection bias) } \\
\text { All outcomes }\end{array}$ & Low risk & $\begin{array}{l}\text { Quote: "To minimise misleading reports of abstinence, a bogus pipeline tech- } \\
\text { nique was used, with the possibility of carbon monoxide breath testing men- } \\
\text { tioned in the consent form and at the } 3 \text { - and 6-month monitoring calls." }\end{array}$ \\
\hline $\begin{array}{l}\text { Incomplete outcome data } \\
\text { (attrition bias) } \\
\text { All outcomes }\end{array}$ & Low risk & $17 \%$ lost in NRT only, $15 \%$ in + counselling. Missing treated as smoking in MA \\
\hline
\end{tabular}

\section{McBride 1999a}

$\begin{array}{ll}\text { Methods } & \text { Setting: Health Maintenance Organisation, USA } \\ & \text { Recruitment: Active; health survey of women following a cervical smear (pap) test }\end{array}$

\section{Participants}

Interventions
580 current women smokers, not selected for motivation to quit; av. age 36, av. cigs/day 13

1. Usual care; no smoking cessation intervention 
McBride 1999a (Continued)

2. Mailed cessation kit, letter personalised to SoC and quit motivation, proactive TC, 3 counselling calls

(13 - $15 \mathrm{~min}$ ) 2 weeks after mailing, then monthly. Motivational- and stage-based

\begin{tabular}{ll}
\hline Outcomes & Abstinence at $15 \mathrm{~m}(7$-day PPA) obtained by telephone interview \\
& Validation: saliva cotinine $<20 \mathrm{ng} / \mathrm{ml}$, quit rates not corrected, low level of misreport \\
\hline Notes & $\begin{array}{l}\text { Effect of TC and S-H materials compared to no intervention } \\
\text { Counsellor discussed smoking and cervical cancer but not individual's pap results. }>80 \% \text { received at } \\
\text { least } 1 \text { call, } 60 \% \text { all } 3\end{array}$
\end{tabular}

\section{Risk of bias}

\begin{tabular}{lll}
\hline Bias & Authors' judgement & Support for judgement \\
\hline $\begin{array}{l}\text { Random sequence genera- } \\
\text { tion (selection bias) }\end{array}$ & Unclear risk & Randomised, method not stated, stratified on test result \\
\hline $\begin{array}{l}\text { Allocation concealment } \\
\text { (selection bias) }\end{array}$ & Unclear risk & No details given \\
\hline $\begin{array}{l}\text { Blinding of outcome as- } \\
\text { sessment (detection bias) } \\
\text { All outcomes }\end{array}$ & Low risk & $\begin{array}{l}\text { Biochemical validation, quit rates not corrected but low level of misreport and } \\
\text { Quote: "no differences between the two groups in the proportion of women } \\
\text { who returned samples, the proportion confirmed/disconfirmed, or the confir- } \\
\text { mation rate." }\end{array}$ \\
\hline $\begin{array}{l}\text { Incomplete outcome data } \\
\text { (attrition bias) } \\
\begin{array}{l}\text { All outcomes } \\
\text { Low risk }\end{array}\end{array}$ & $\begin{array}{l}\text { Loss to follow-up at 15 m 20\% in Intervention, 18\% in Control. Losses included } \\
\text { as smokers }\end{array}$ \\
\hline
\end{tabular}

\section{McBride 1999b}

\begin{tabular}{ll}
\hline Methods & $\begin{array}{l}\text { Setting: } 2 \text { Health Maintenance Organisations, USA } \\
\text { Recruitment: Pregnant women who had booked a prenatal appointment, by mail }\end{array}$ \\
\hline Participants & $\begin{array}{l}897 \text { pregnant smokers and recent quitters (44\% already quit) not selected for motivation to quit; av. } \\
\text { age } 28, \text { av. cigs/day } 15 \text { before pregnancy, } 5 \text { if still smoking }\end{array}$ \\
\hline Interventions & $\begin{array}{l}\text { 1. S-H booklet only } \\
\text { 2. Prepartum intervention: } 3 \text { proactive TC calls av } 81 / 2 \text { mins, approx } 2 \text { weeks after S-H mailing, and } 1 \mathrm{~m} \\
\text { and } 2 \text { m later. Tailored letter, S-H book. After } 28 \text {-week follow-up sent relapse prevention kit } \\
\text { 3. Pre- and postpartum intervention: as } 2 \text {, plus } 3 \text { calls within first } 4 \text { m postpartum, av } 7.7 \text { mins. } 3\end{array}$ \\
\hline nutcomes & $\begin{array}{l}\text { Abstinence at } 12 \text { m postpartum (7-day PP) } \\
\text { Validation: Saliva cotinine requested by mail, }<20 \mathrm{ng} / \mathrm{mL} \text {. Self-reported rates used in analyses, no dif- } \\
\text { ference in confirmation rates between groups }\end{array}$ \\
\hline Notes & Arms $3+2$ vs 1 , effect of TC versus S-H only \\
\hline
\end{tabular}

\section{Risk of bias}

\begin{tabular}{lll}
\hline Bias & Authors' judgement & Support for judgement \\
\hline $\begin{array}{l}\text { Random sequence genera- } \\
\text { tion (selection bias) }\end{array}$ & Unclear risk & Randomised, method not described \\
\hline
\end{tabular}


McBride 1999b (Continued)

Allocation concealment $\quad$ Unclear risk
(selection bias)

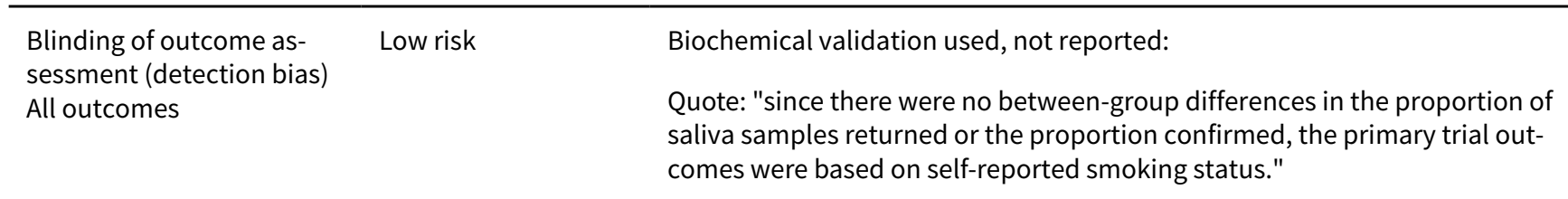

\begin{tabular}{ll}
\hline $\begin{array}{l}\text { Incomplete outcome data } \\
\text { (attrition bias) }\end{array}$ & Low risk \\
All outcomes & ers to follow-up 13\% at $12 \mathrm{~m}$, not different by group, losses included as smok-
\end{tabular}

All outcomes

Loss to follow-up $13 \%$ at $12 \mathrm{~m}$, not different by group, losses included as smok-

\section{McBride 2004}

\begin{tabular}{|c|c|c|}
\hline Methods & \multicolumn{2}{|c|}{$\begin{array}{l}\text { Setting: Army Medical Centre, USA } \\
\text { Recruitment: Pregnant women at first prenatal visit }\end{array}$} \\
\hline Participants & \multicolumn{2}{|c|}{583 pregnant current smokers and recent quitters (390 in relevant arms); av. age 24} \\
\hline Interventions & \multicolumn{2}{|c|}{$\begin{array}{l}\text { 1. Usual care: provider advice and S-H guide } \\
\text { 2. As } 1 \text {, plus } 6 \text { proactive TC calls, } 3 \text { in pregnancy, } 3 \text { postpartum within } 4 \mathrm{~m}+\text { late pregnancy relapse pre- } \\
\text { vention kit } \\
\text { 3. Partner-assisted intervention, not used in this review }\end{array}$} \\
\hline Outcomes & \multicolumn{2}{|c|}{$\begin{array}{l}\text { Abstinence at } 12 \mathrm{~m} \text { postpartum (7-day PP at all } 4 \text { follow-ups) } \\
\text { Validation: Saliva cotinine request, incomplete return, rates based on self-report }\end{array}$} \\
\hline Notes & \multicolumn{2}{|c|}{$\begin{array}{l}\text { Effect of TC as adjunct to brief advice } \\
\text { Effect at } 6 \mathrm{~m} \text { not sustained longer term. Mean number of calls received was } 5\end{array}$} \\
\hline \multicolumn{3}{|l|}{ Risk of bias } \\
\hline Bias & Authors' judgement & Support for judgement \\
\hline $\begin{array}{l}\text { Random sequence genera- } \\
\text { tion (selection bias) }\end{array}$ & Unclear risk & Randomised, method not described, stratified by smoking status \\
\hline $\begin{array}{l}\text { Allocation concealment } \\
\text { (selection bias) }\end{array}$ & Unclear risk & No details given \\
\hline $\begin{array}{l}\text { Blinding of outcome as- } \\
\text { sessment (detection bias) } \\
\text { All outcomes }\end{array}$ & Unclear risk & $\begin{array}{l}\text { Biochemical validation conducted but not used in outcome data. } \\
\text { Quote: "Saliva return rates did not differ by condition at either follow-up" but } \\
\text { rates of return low and level of misreport not specified }\end{array}$ \\
\hline $\begin{array}{l}\text { Incomplete outcome data } \\
\text { (attrition bias) } \\
\text { All outcomes }\end{array}$ & Low risk & $\begin{array}{l}\text { Loss to follow-up higher in Intervention ( } 22 \%) \text { than Control (16\%). Losses in- } \\
\text { cluded as smokers }\end{array}$ \\
\hline
\end{tabular}

McClure 2005

Methods Setting: Health Maintenance Organisation, USA


McClure 2005 (Continued)

Recruitment: Women with an abnormal cervical smear or colposcopy

\begin{tabular}{|c|c|c|}
\hline Participants & \multicolumn{2}{|c|}{275 women smokers, not selected for motivation to quit; av. age 33, av. cigs/day 14} \\
\hline Interventions & \multicolumn{2}{|c|}{$\begin{array}{l}\text { 1. Usual care, } \mathrm{S}-\mathrm{H} \text {, contact details for Free } \& \text { Clear, a covered benefit } \\
\text { 2. As } 1 \text {, plus up to } 4 \times 15 \text {-min proactive TC calls over } 6 \mathrm{~m}\end{array}$} \\
\hline Outcomes & \multicolumn{2}{|c|}{$\begin{array}{l}\text { Abstinence at } 12 \text { m (7-day PP) } \\
\text { Validation: Cotinine saliva strip test, but judged over-conservative so self-report used. Relative effect } \\
\text { not altered }\end{array}$} \\
\hline Notes & \multicolumn{2}{|c|}{ Effect of TC versus S-H only } \\
\hline \multicolumn{3}{|l|}{ Risk of bias } \\
\hline Bias & Authors' judgement & Support for judgement \\
\hline $\begin{array}{l}\text { Random sequence genera- } \\
\text { tion (selection bias) }\end{array}$ & Unclear risk & Randomised, method not described \\
\hline $\begin{array}{l}\text { Allocation concealment } \\
\text { (selection bias) }\end{array}$ & Unclear risk & No details given \\
\hline $\begin{array}{l}\text { Blinding of outcome as- } \\
\text { sessment (detection bias) } \\
\text { All outcomes }\end{array}$ & Low risk & $\begin{array}{l}\text { Bogus pipeline for short follow-up, biochemical validation at } 12 \mathrm{~m} \text {. Results } \\
\text { from saliva strip test judged overly conservative, hence self-report used in final } \\
\text { outcome data, but relative effect not altered }\end{array}$ \\
\hline $\begin{array}{l}\text { Incomplete outcome data } \\
\text { (attrition bias) } \\
\text { All outcomes }\end{array}$ & Unclear risk & $\begin{array}{l}\text { No information on numbers not reached at follow-up. All participants included } \\
\text { in analysis }\end{array}$ \\
\hline
\end{tabular}

McClure 2011

\begin{tabular}{ll}
\hline Methods & $\begin{array}{l}\text { Setting: Pacific Northwest, USA } \\
\text { Recruitment: Members of large regional health plan identified through automated records }\end{array}$ \\
\hline Participants & $\begin{array}{l}52 \text { adults with evidence of smoking in last year, depression in last } 2 \text { years, and without high levels of } \\
\text { physical activity. } 33 \% \text { M; av. age 44.5; av. cigs/day 10.6; av. FTND } 2.37\end{array}$ \\
\hline Interventions & $\begin{array}{l}\text { 1. Intervention: usual care + phone-based Step Up proactive counselling programme (1 motivational } \\
\text { call, } 9 \text { weekly CBT calls and } 2 \text { follow-up 'booster calls' according to participant need) }\end{array}$ \\
& $\begin{array}{l}\text { 2. Control: usual care treatment for depression, smoking and physical activity (incl. S-H material and } \\
\text { referral information for phone-based smoking cessation programme) }\end{array}$
\end{tabular}

Outcomes Self-reported abstinence at $6 \mathrm{~m}$ (7-day PP)

Validation: none

Notes

Pilot study of an intervention also addressing physical activity and depression

Number abstinent not provided and hence extrapolated from percentages given

\section{Risk of bias}


McClure 2011 (Continued)

\begin{tabular}{lll} 
Bias & Authors' judgement & Support for judgement \\
\hline $\begin{array}{l}\text { Random sequence genera- } \\
\text { tion (selection bias) }\end{array}$ & Unclear risk & $\begin{array}{l}\text { Quote: "randomly assigned," stratified by baseline antidepressant use". } \\
\text { Method of sequence generation not specified }\end{array}$ \\
\hline $\begin{array}{l}\text { Allocation concealment } \\
\text { (selection bias) }\end{array}$ & Unclear risk & Method not specified \\
\hline $\begin{array}{l}\text { Blinding of outcome as- } \\
\text { sessment (detection bias) } \\
\text { All outcomes }\end{array}$ & High risk & $\begin{array}{l}\text { Self-reported outcome, participants not blinded to treatment condition. Level } \\
\text { of personal contact differed between arms }\end{array}$ \\
\hline $\begin{array}{l}\text { Incomplete outcome data } \\
\text { (attrition bias) } \\
\text { All outcomes }\end{array}$ & Low risk & $\begin{array}{l}\text { Participants lost to follow-up counted as smokers, similar numbers lost in } \\
\text { each group (4/27 intervention, 2/25 control) }\end{array}$ \\
\hline
\end{tabular}

\section{McFall 1993}

$\begin{array}{ll}\text { Methods } & \text { Setting: Community, USA } \\ & \text { Recruitment: Registrants for a S-H TV programme who received manual or watched at least } 1 \text { pro- } \\ & \text { gramme }\end{array}$

\begin{tabular}{ll}
\hline Participants & 1745 smokers; $30 \% \mathrm{M}, 23 \%$ age $18-30,40 \%$ age 31 - 45, 30\% $45-64$ \\
\hline Interventions & $\begin{array}{l}\text { 1. TV programme and S-H manual (ALA Freedom From Smoking in 20 Days) } \\
\text { 2. As 1, plus } 10 \text { newsletters over } 6 \text { m following programme with details of hotline with taped messages } \\
\text { and counsellors }\end{array}$ \\
\hline Outcomes & $\begin{array}{l}\text { Abstinence at } 24 \mathrm{~m} \text { (7-day PP) } \\
\text { Validation: none }\end{array}$ \\
\hline Notes & Effect of access to hotline combined with S-H materials for maintenance of cessation \\
& Use of the hotline was low; only 7\% called and spoke to a counsellor
\end{tabular}

\section{Risk of bias}

\begin{tabular}{|c|c|c|}
\hline Bias & Authors' judgement & Support for judgement \\
\hline $\begin{array}{l}\text { Random sequence genera- } \\
\text { tion (selection bias) }\end{array}$ & Unclear risk & Randomised, method not described \\
\hline $\begin{array}{l}\text { Allocation concealment } \\
\text { (selection bias) }\end{array}$ & Unclear risk & No details given \\
\hline $\begin{array}{l}\text { Blinding of outcome as- } \\
\text { sessment (detection bias) } \\
\text { All outcomes }\end{array}$ & Unclear risk & $\begin{array}{l}\text { Self-reported outcomes from participants not blinded to treatment condition. } \\
\text { Unclear if level of personal contact differed between arms }\end{array}$ \\
\hline $\begin{array}{l}\text { Incomplete outcome data } \\
\text { (attrition bias) } \\
\text { All outcomes }\end{array}$ & Low risk & $\begin{array}{l}24 \% \text { lost in maintenance condition, } 27 \% \text { in control. MA includes only respon- } \\
\text { ders; Including losses would give less conservative effect }\end{array}$ \\
\hline
\end{tabular}


Metz 2007

\begin{tabular}{|c|c|c|}
\hline Methods & \multicolumn{2}{|c|}{$\begin{array}{l}\text { Setting: } 13 \text { rehabilitation centres, Germany } \\
\text { Recruitment: Recent smokers having rehabilitation, not formally selected for motivation }\end{array}$} \\
\hline Interventions & \multicolumn{2}{|c|}{$\begin{array}{l}\text { All participants had inpatient group therapy of } 7 \times 60 \text {-min sessions. } \sim 26 \% \text { abstinent at discharge } \\
\text { 1. Telephone boosters; } 5 \times \sim 10 \text {-min proactive calls over } 10 \text { weeks from female psychologists (not origi- } \\
\text { nal therapist) } \\
\text { 2. No boosters }\end{array}$} \\
\hline Outcomes & \multicolumn{2}{|c|}{$\begin{array}{l}\text { Abstinence at } 12 \text { m (7-day PP) } \\
\text { Validation: none }\end{array}$} \\
\hline Notes & \multicolumn{2}{|c|}{ Effect of TC as adjunct to intensive support } \\
\hline \multicolumn{3}{|l|}{ Risk of bias } \\
\hline Bias & Authors' judgement & Support for judgement \\
\hline $\begin{array}{l}\text { Random sequence genera- } \\
\text { tion (selection bias) }\end{array}$ & Unclear risk & Randomised, 1:2 ratio, method not described \\
\hline $\begin{array}{l}\text { Allocation concealment } \\
\text { (selection bias) }\end{array}$ & Unclear risk & No details given \\
\hline $\begin{array}{l}\text { Blinding of outcome as- } \\
\text { sessment (detection bias) } \\
\text { All outcomes }\end{array}$ & High risk & $\begin{array}{l}\text { Self-reported outcomes from participants not blinded to treatment condition. } \\
\text { Level of personal contact differed between arms }\end{array}$ \\
\hline
\end{tabular}

Miguez 2002

\begin{tabular}{ll}
\hline Methods & $\begin{array}{l}\text { Setting: Community, Spain } \\
\text { Recruitment: Volunteers interested in quitting }\end{array}$ \\
\hline Participants & 200 smokers; $62 \%$ M, av. age 35, av cigs/day 28 \\
\hline Interventions & $\begin{array}{l}\text { 1. Proactive TC, } 6 \text { x weekly 10-min calls. } 4 \text { on motivation and cessation, } 2 \text { on maintenance, + S-H } \\
\text { 2. S-H only. Personalised intro letter, manual and } 6 \text { similar mailings with self-monitoring and self-eval- } \\
\text { uation forms }\end{array}$ \\
\hline Outcomes & $\begin{array}{l}\text { Abstinence at } 12 \mathrm{~m} \text { (not even a puff since quitting) } \\
\text { Validation: CO at } 12 \mathrm{~m}\end{array}$ \\
\hline Notes & 10-year follow-up reported in 2008, not used in MA \\
\hline Risk of bias & Authors' judgement Support for judgement \\
\hline Bias &
\end{tabular}


Miguez 2002 (Continued)
Random sequence genera
Unclear risk
Randomised, method not described tion (selection bias)

\begin{tabular}{lll}
\hline $\begin{array}{l}\text { Allocation concealment } \\
\text { (selection bias) }\end{array}$ & Unclear risk & No details given \\
\hline $\begin{array}{l}\text { Blinding of outcome as- } \\
\text { sessment (detection bias) } \\
\text { All outcomes }\end{array}$ & Low risk & Biochemical validation used \\
\hline $\begin{array}{l}\text { Incomplete outcome data } \\
\text { (attrition bias) }\end{array}$ & Unclear risk & $\begin{array}{l}\text { No information on numbers not reached at follow-up. All participants included } \\
\text { All outcomes }\end{array}$
\end{tabular}

Miguez 2008

\begin{tabular}{ll}
\hline Methods & Setting: Community, Spain \\
& Recruitment: Volunteers interested in quitting
\end{tabular}

Participants 228 smokers of $\geq 10$ cigs/day; $54 \%$ M, av. age 37 , av. cigs/day $27,44 \%$ had prior year quit attempt

Interventions $\quad$ 1. Mailed S-H programme; 6 weekly manuals, quit date intended to be set at end of week 4

2. As $1 .+$ single proactive 5 - 10-min counsellor call in week 4 , to increase motivation and adherence

$\begin{array}{ll}\text { Outcomes } & \text { Abstinence at } 12 \mathrm{~m} \text { (sustained since end of treatment) } \\ \text { Validation: none ('bogus pipeline' warning) }\end{array}$

\section{Notes}

\section{Risk of bias}

\begin{tabular}{lll}
\hline Bias & Authors' judgement & Support for judgement \\
\hline $\begin{array}{l}\text { Random sequence genera- } \\
\text { tion (selection bias) }\end{array}$ & Unclear risk & Randomised, method not described \\
\hline $\begin{array}{l}\text { Allocation concealment } \\
\text { (selection bias) }\end{array}$ & Unclear risk & No details given \\
\hline $\begin{array}{l}\text { Blinding of outcome as- } \\
\text { sessment (detection bias) } \\
\text { All outcomes }\end{array}$ & Low risk & $\begin{array}{l}\text { Quote: "Telephone interviews were conducted by a trainer interviewer who } \\
\text { was blind with respect to the group to which each subject was assigned. To im- } \\
\text { prove the reliability of these self-reports of smoking status, all follow-up ques- } \\
\text { tionnaires and interviews commenced with a reminder that the subject might } \\
\text { at some point be asked to undergo a carbon monoxide test." }\end{array}$ \\
\hline
\end{tabular}

Incomplete outcome data Unclear risk Missing data treated as failure, no statement of numbers lost to follow-up
(attrition bias)

All outcomes

Miller 1997

$\begin{array}{ll}\text { Methods } & \text { Setting: Hospitals, USA } \\ \text { Recruitment: Inpatient smokers (excl those with no intention of quitting, or wishing to quit unaided) }\end{array}$


Miller 1997 (Continued)

Participants 1942 smokers (excludes deaths); $51 \%$ M, av. age 51, av cigs/day 20

All groups received standardised physician advice
1. Intensive intervention: 30 -min nurse face-to-face counselling, proactive TC, 4 at 48 hours post-dis-
charge, $7,21,90$ days, optional session for relapsers
2. Minimal: 30 -min counselling + 1 phone call at 48 hours
3. Usual care (not used in review)

$\begin{array}{ll}\text { Outcomes } & \text { Abstinence at } 12 \mathrm{~m} \text { (sustained at } 3 \mathrm{~m}, 6 \mathrm{~m}, 12 \mathrm{~m} \text { ) } \\ & \text { (Paper also reports } 12 \mathrm{~m} \text { PP confirmed and self-reported cessation rates) } \\ & \text { Validation: saliva cotinine }<15 \mathrm{ng} / \mathrm{ml} \text {, or family member verification }\end{array}$

Notes Effect of additional telephone follow-up. Not pooled.

\section{Risk of bias}

\begin{tabular}{lll}
\hline Bias & Authors' judgement & Support for judgement \\
\hline $\begin{array}{l}\text { Random sequence genera- } \\
\text { tion (selection bias) }\end{array}$ & Unclear risk & Randomised, method not described \\
\hline $\begin{array}{l}\text { Allocation concealment } \\
\text { (selection bias) }\end{array}$ & Low risk & Quote: "Nurses opened sealed envelopes in front of patients" \\
\hline $\begin{array}{l}\text { Blinding of outcome as- } \\
\text { sessment (detection bias) } \\
\text { All outcomes }\end{array}$ & Low risk & $\begin{array}{l}\text { Biochemical validation; verification by family member used when biochemical } \\
\text { validation not possible }\end{array}$ \\
\hline $\begin{array}{l}\text { Incomplete outcome data } \\
\text { (attrition bias) } \\
\text { All outcomes }\end{array}$ & Low risk & $\begin{array}{l}\text { Number lost to follow-up not specified, all randomised participants, excluding } \\
82 \text { deaths, included in analyses }\end{array}$ \\
\hline
\end{tabular}

\section{NCT00534404}

\begin{tabular}{ll}
\hline Methods & $\begin{array}{l}\text { Setting: USA } \\
\text { Recruitment: Quote: "Interested individuals completed a screening survey to determine eligibility. Fol- } \\
\text { lowing study consent, participants completed two emailed surveys over the next two days and a phone } \\
\text { confirmation call before being randomized. These check-ins confirmed the participant had valid con- } \\
\text { tact information and maintained their desire to quit smoking." }\end{array}$ \\
\hline Participants & $\begin{array}{l}2485 \text { adult smokers of } \geq 10 \text { cigs/day, willing to set a quit date within } 2 \text { to } 4 \text { weeks, willing to use a nico- } \\
\text { tine patch, 31\% } \mathrm{M}, \text { av. age } 44 .\end{array}$ \\
\hline Interventions & $\begin{array}{l}\text { 1. NRT patch (free 8-week) }+ \text { Internet (iQuit Smoking website) } \\
\text { 2. As 1, plus } 5 \text { sessions of TC after } 0,2,4,6 \text { and } 8 \text { weeks }\end{array}$ \\
\hline Outcomes & $\begin{array}{l}\text { Self-reported abstinence at } 9 \mathrm{~m}(6 \mathrm{~m} \text { prolonged) } \\
\text { Validation: none }\end{array}$ \\
\hline Notes & New for 2018 update \\
Funding: not reported
\end{tabular}

\section{Risk of bias}

Telephone counselling for smoking cessation (Review) 
NCT00534404 (Continued)

\begin{tabular}{|c|c|c|}
\hline Bias & Authors' judgement & Support for judgement \\
\hline $\begin{array}{l}\text { Random sequence genera- } \\
\text { tion (selection bias) }\end{array}$ & Unclear risk & Insufficient information provided on ClinicalTrials.gov website \\
\hline $\begin{array}{l}\text { Allocation concealment } \\
\text { (selection bias) }\end{array}$ & Unclear risk & Insufficient information provided on ClinicalTrials.gov website \\
\hline $\begin{array}{l}\text { Blinding of outcome as- } \\
\text { sessment (detection bias) } \\
\text { All outcomes }\end{array}$ & High risk & $\begin{array}{l}\text { Abstinence not biochemically validated. Level of personal contact differed be- } \\
\text { tween arms }\end{array}$ \\
\hline $\begin{array}{l}\text { Incomplete outcome data } \\
\text { (attrition bias) } \\
\text { All outcomes }\end{array}$ & Low risk & $\begin{array}{l}\text { Low percentage (19\%) of participants lost to follow-up and comparable across } \\
\text { arms }\end{array}$ \\
\hline
\end{tabular}

Nohlert 2014

Setting: Sweden; population-based
Recruitment: Tobacco user calls the quitline, the counsellor invites the user to participate in the study,
and if the user consents verbally, the registration form and baseline questionnaire are sent by mail. If
baseline questionnaire is returned the user is included in the study

Participants

1129 smokers, $22 \%$ M, age: $\leq 34: 20 \%, 35$ - 49 25\%, 50 - 64 39\%, $\geq 65$ 17\%, average cigs/day: 0: 27\%; 1 14: $34 \% ; \geq 15: 39 \%$. Participants were interested in quitting

Interventions Reactive quitline service: The study was performed within the normal run of the Sweedish national
tobacco quitline. Participants in this arm were not offered to be called back
2. Proactive quitline service: The study was performed within the normal run of the Swedish nation-
al tobacco quitline. Participants in this arm were offered to be called back. The first call was about 25
mins and subsequent calls were 5 - 10 mins, with a mean of 4.3 calls

\begin{tabular}{|c|c|}
\hline Outcomes & $\begin{array}{l}\text { Self-reported abstinence at } 12 \mathrm{~m} \text { ( } 6 \mathrm{~m} \text { continued) } \\
\text { Validation: none }\end{array}$ \\
\hline Notes & $\begin{array}{l}\text { New for } 2018 \text { update } \\
\text { Funding: "The study was supported by grants from the Swedish Heart and Lung Association, the } \\
\text { Swedish Heart Lung Foundation, the Swedish Cancer Society, the Swedish Research Council, the } \\
\text { Swedish Research Council for Health, Working Life and Welfare, and the County Council of Västman- } \\
\text { land, Sweden." }\end{array}$ \\
\hline & Declarations of interest: none declared \\
\hline
\end{tabular}

\section{Risk of bias}

\begin{tabular}{lll}
\hline Bias & Authors' judgement & Support for judgement \\
\hline $\begin{array}{ll}\text { Random sequence genera- } \\
\text { tion (selection bias) }\end{array}$ & High risk & Semi-randomised \\
& $\begin{array}{l}\text { Quote: "randomized to proactive service (even dates) and reactive service } \\
\text { (odd dates)" }\end{array}$ \\
\hline
\end{tabular}


Nohlert 2014 (Continued)

Allocation concealment High risk Quote: "As the randomization was performed at the time for the clients' first (selection bias) call, the intervention has started and was known by the clients when they decided to return the baseline questionnaire and thus be included in the study base"

\section{Blinding of outcome as- High risk} sessment (detection bias)

All outcomes
Abstinence not biochemically validated. Level of personal contact probably differed between arms

Incomplete outcome data High risk

(attrition bias)

Similar dropout across trial arms but $>50 \%$

All outcomes

\section{Ockene 1991}

\begin{tabular}{ll}
\hline Methods & $\begin{array}{l}\text { Setting: Primary care clinics, USA } \\
\text { Recruitment: Clinic attenders, not selected for interest in quitting }\end{array}$ \\
\hline Participants & $\begin{array}{l}1223 \text { smokers (excludes deaths and } 237 \text { who did not receive intervention); 43\% M, av. age 35, av. cigs/ } \\
\text { day } 23\end{array}$ \\
\hline Interventions & $2 \times 3$ factorial design, physician intervention \pm follow-up \\
(a) AO: Physician advice only \\
(b) Cl: Physician-provided patient-centered counselling, written agreement and schedule follow-up, \\
letter \\
(c). CI+NCG: as (b), plus informed of availability of free nicotine gum \\
$\begin{array}{l}\text { 1. Follow-up counselling by psychologist or health educator, } 3 \text { calls (1, 2, 3 m) approx } 10 \text { mins, behav- } \\
\text { ioural recommendations. Letters } \\
\text { 2. No follow-up }\end{array}$ \\
$\begin{array}{l}\text { Abstinence at } 6 \text { m (7-day PP). } 3 \text { m sustained abstinence rates not given by condition } \\
\text { Validation: none }\end{array}$ \\
\hline Outcomes & $\begin{array}{l}\text { Arm } 1 \text { vs 2, AO and Cl effect of TC in addition to physician intervention. NCG arm in pharmacotherapy } \\
\text { adjunct, both pooled in intensity and motivation subgroup analyses. } 12 \text {-m abstinence rates reported in } \\
\text { Ockene 1994, but not given by follow-up condition }\end{array}$
\end{tabular}

\section{Risk of bias}

\begin{tabular}{lll}
\hline Bias & Authors' judgement & Support for judgement \\
\hline $\begin{array}{l}\text { Random sequence genera- } \\
\text { tion (selection bias) }\end{array}$ & Unclear risk & Randomised, method not described \\
\hline $\begin{array}{l}\text { Allocation concealment } \\
\text { (selection bias) }\end{array}$ & Unclear risk & Allocated prior to physician encounter \\
\hline $\begin{array}{l}\text { Blinding of outcome as- } \\
\text { sessment (detection bias) } \\
\text { All outcomes }\end{array}$ & High risk & $\begin{array}{l}\text { Self-reported outcomes from participants not blinded to treatment condition. } \\
\text { Level of personal contact differed between arms }\end{array}$ \\
\hline $\begin{array}{l}\text { Incomplete outcome data } \\
\text { (attrition bias) } \\
\text { All outcomes }\end{array}$ & Low risk & $\begin{array}{l}19 \% \text { lost to follow-up, higher in telephone follow-up group. All included as } \\
\text { smokers in analysis }\end{array}$ \\
\hline
\end{tabular}


Orleans 1991

\begin{tabular}{ll} 
Methods & $\begin{array}{l}\text { Setting: Health Maintenance Organisation, USA } \\
\text { Recruitment: Largely through publicity in HMO magazine }\end{array}$ \\
\hline Participants & 2021 smokers of 3+ cigs/day, wanting to quit (1412 in relevant arms); 37\% M, av. age 44, av. cigs/day 26 \\
\hline Interventions & $\begin{array}{l}\text { 1. S-H manual, Quit Kit and ALA Lifetime of Freedom from Smoking } \\
\text { 2. Same materials as 1, plus } 2 \text { copies of a social support guide } \\
\text { 3. Same as 2, plus proactive TC }(6,18,34,60 \text { weeks) from a counsellor and invitation to call a quit line } \\
\text { 4. Control: Referral guide }\end{array}$ \\
\hline Outcomes & $\begin{array}{l}\text { Abstinence at } 16 \mathrm{~m} \text { (sustained for }>6 \mathrm{~m}) \text { obtained by blinded telephone interview } \\
\text { ported in analyses }\end{array}$
\end{tabular}

Notes

Arms 3 vs 1 and 2 combined, effect of telephone counselling compared to $\mathrm{S}-\mathrm{H}$ materials alone.

\section{Risk of bias}

\begin{tabular}{lll}
\hline Bias & Authors' judgement & Support for judgement \\
\hline $\begin{array}{l}\text { Random sequence genera- } \\
\text { tion (selection bias) }\end{array}$ & Unclear risk & $\begin{array}{l}\text { Randomised, method not described, stratified by living alone/not, advice to } \\
\text { quit in last } 12 \mathrm{~m} / \mathrm{not} \text {, and nicotine content of cig. brand }\end{array}$ \\
\hline $\begin{array}{l}\text { Allocation concealment } \\
\text { (selection bias) }\end{array}$ & Unclear risk & No details given \\
\hline $\begin{array}{l}\text { Blinding of outcome as- } \\
\text { sessment (detection bias) } \\
\begin{array}{l}\text { All outcomes } \\
\text { L }\end{array}\end{array}$ & Low risk & $\begin{array}{l}\text { Biochemical validation in sample at } 16 \mathrm{~m} \\
\text { Quote: "to improve the veracity of smoking self-report, all follow-up ques- } \\
\text { tionnaires and interviews began with a reminder that the subjects might be } \\
\text { asked for a saliva specimen for nicotine assessment, creating a sort of 'bogus } \\
\text { pipeline'" }\end{array}$ \\
\hline $\begin{array}{l}\text { Incomplete outcome data } \\
\text { (attrition bias) }\end{array}$ & Low risk & $\begin{array}{l}\text { Loss to follow-up 6\% at } 16 \text { m, did not differ across treatment groups. Analyses } \\
\text { based on respondents; including losses would marginally increase estimated } \\
\text { effect }\end{array}$ \\
\hline
\end{tabular}

\section{Orleans 1998}

\begin{tabular}{ll}
\hline Methods & Setting: Community, USA \\
& Recruitment: African-American smokers calling the NCIS telephone counselling line in response to tar- \\
& geted campaign
\end{tabular}

Participants

1422 African-American smokers; 36\% M, av. age not stated, 62\% in 20 - 39 age group, median cigs/day 20

Interventions

Reactive, for callers to quitline

1. Tailored TC and tailored 36-page Pathways to Freedom guide. Guide used African-American models and addressed specific obstacles. Personalised quitting plan

2. Standard NCIS TC and standard guide Clearing the Air

$\begin{array}{ll}\text { Outcomes } & \begin{array}{l}\text { Abstinence at } 6 \mathrm{~m} \text { (7-day PP) } \\ \text { Validation: none }\end{array}\end{array}$


(12-m abstinence also assessed in sample of 445 smokers and there were significant differences; $15.0 \%$ vs $8.8 \%$ using ITT)

\begin{tabular}{|c|c|c|}
\hline Notes & $\begin{array}{l}\text { Comparison between } \\
\text { counselling and S-H m } \\
\text { Median call length } 19\end{array}$ & $\begin{array}{l}\text { types of counselling. Also included in Cochrane Self-help review since effects of } \\
\text { terials cannot be separated } \\
\text { ins (interdecile range } 10-28 \mathrm{~min}) \text { for tailored, } 13 \mathrm{~min}(8-23) \text { for standard }\end{array}$ \\
\hline \multicolumn{3}{|l|}{ Risk of bias } \\
\hline Bias & Authors' judgement & Support for judgement \\
\hline $\begin{array}{l}\text { Random sequence genera- } \\
\text { tion (selection bias) }\end{array}$ & High risk & Pseudo-randomised by last digit of caller's contact phone number \\
\hline $\begin{array}{l}\text { Allocation concealment } \\
\text { (selection bias) }\end{array}$ & High risk & Potential for selection bias but unlikely given low contact \\
\hline $\begin{array}{l}\text { Blinding of outcome as- } \\
\text { sessment (detection bias) } \\
\text { All outcomes }\end{array}$ & Low risk & $\begin{array}{l}\text { Self-reported outcomes from participants not blinded to treatment condition, } \\
\text { but similar levels of personal contact in different study arms }\end{array}$ \\
\hline $\begin{array}{l}\text { Incomplete outcome data } \\
\text { (attrition bias) } \\
\text { All outcomes }\end{array}$ & Low risk & $\begin{array}{l}37 \% \text { lost to follow-up at } 6 \mathrm{~m} \text {. No differential dropout, losses included as smok- } \\
\text { ers }\end{array}$ \\
\hline
\end{tabular}

Osinubi 2003

\begin{tabular}{|c|c|c|}
\hline Methods & \multicolumn{2}{|c|}{$\begin{array}{l}\text { Setting: Occupational health service, USA } \\
\text { Recruitment: Asbestos-exposed workers and retirees attending medical screening, not selected for } \\
\text { motivation }\end{array}$} \\
\hline Participants & \multicolumn{2}{|c|}{58 smokers; 93\% M, av. age 52, av. cigs/day 22} \\
\hline Interventions & \multicolumn{2}{|c|}{$\begin{array}{l}\text { All participants received brief physician advice at screening } \\
\text { 1. Enrolment in Free \& Clear, proactive TC, } 5 \text { calls, hotline access, pharmacotherapy available } \\
\text { 2. Instructions to obtain support from personal physician, S-H materials and resources }\end{array}$} \\
\hline Outcomes & \multicolumn{2}{|c|}{ Self-reported abstinence at 6 m (30-day PP) } \\
\hline \multicolumn{3}{|l|}{ Notes } \\
\hline \multicolumn{3}{|l|}{ Risk of bias } \\
\hline Bias & Authors' judgement & Support for judgement \\
\hline $\begin{array}{l}\text { Random sequence genera- } \\
\text { tion (selection bias) }\end{array}$ & Unclear risk & Randomised, method not described \\
\hline $\begin{array}{l}\text { Allocation concealment } \\
\text { (selection bias) }\end{array}$ & Unclear risk & Sealed envelopes, not stated if opaque and numbered \\
\hline $\begin{array}{l}\text { Blinding of outcome as- } \\
\text { sessment (detection bias) } \\
\text { All outcomes }\end{array}$ & High risk & $\begin{array}{l}\text { Self-reported outcomes from participants not blinded to treatment condition. } \\
\text { Level of personal contact differed between arms }\end{array}$ \\
\hline
\end{tabular}


Osinubi 2003 (Continued)

Incomplete outcome data Low risk 32\% lost to follow-up, comparable across groups, losses included as smokers (attrition bias)

All outcomes

\section{Ossip-Klein 1991}

\begin{tabular}{ll}
\hline Methods & $\begin{array}{l}\text { Setting: } 10 \text { counties, USA } \\
\text { Recruitment: Media advertising, local sign-ons, brochures }\end{array}$ \\
\hline Participants & $\begin{array}{l}1813 \text { smokers planning to quit within } 3 \mathrm{~m} \text {; av. age 43, av. cigs/day } 28 \\
\text { Therapists (hotline): ex-smoker counsellors }\end{array}$ \\
\hline Interventions & $\begin{array}{l}\text { Reactive } \\
\text { 1. ALA S-H manuals } \\
\text { 2. as } 1, \text { plus materials promoting } 24-h o u r \text { hotline with daytime access to counsellors }\end{array}$ \\
\hline Outcomes & $\begin{array}{l}\text { Abstinence at } 18 \mathrm{~m} \text { (sustained from } 3 \text { m) } \\
\text { Validation: by significant other for } 90 \% \text { of claims, saliva cotinine for } 52 \% \text { of claims. Cotinine-validated }\end{array}$ \\
\hline rates used & $\begin{array}{l}\text { The authors report a range of analyses based on alternative measures of smoking status and using lo- } \\
\text { gistic regression to allow for cluster randomisation. The higher quit rate in the hotline counties was } \\
\text { consistent in all analyses. } 36 \% \text { called hotline, } 8.7 \% \text { spoke with counsellors }\end{array}$ \\
\hline
\end{tabular}

\section{Risk of bias}

\section{Bias Authors' judgement Support for judgement}

Random sequence genera- Unclear risk Matched pairs of counties assigned to condition in a restricted procedure to tion (selection bias) minimise media spill-over

\begin{tabular}{lll}
\hline $\begin{array}{l}\text { Allocation concealment } \\
\text { (selection bias) }\end{array}$ & Unclear risk & $\begin{array}{l}\text { Participant recruitment not linked to county assignment so selection bias un- } \\
\text { likely }\end{array}$ \\
\hline $\begin{array}{l}\text { Blinding of outcome as- } \\
\text { sessment (detection bias) } \\
\text { All outcomes }\end{array}$ & Low risk & Self-reported abstinence verified by significant other and/or saliva cotinine \\
\hline
\end{tabular}

Incomplete outcome data Low risk Follow-up over $90 \%$ at all points and did not differ by condition (attrition bias)

All outcomes

\section{Ossip-Klein 1997}

\begin{tabular}{ll} 
Methods & $\begin{array}{l}\text { Setting: Community, USA } \\
\text { Recruitment: Advertising for S-H cessation for over-60 yr-olds }\end{array}$ \\
\hline Participants & 177 smokers aged $\geq 60$, planning to quit in next $3 \mathrm{~m} ; 39 \%$ M, av. cigs/day 25 \\
\hline Interventions & $\begin{array}{l}\text { 1. S-H manual (Clear Horizons), access to } 24 \text {-hour hotline, } 2 \text { letters of support and hotline reminders } \\
\text { 2. As } 1 \text {, plus proactive TC, } 2 \text { calls at } 4 \text { and } 8 \text { weeks. Counsellors followed structured format to provide } \\
\text { strategies based on SoC }\end{array}$
\end{tabular}


Ossip-Klein 1997 (Continued)

Outcomes Abstinence at $6 \mathrm{~m}$ (7-day PP)

Validation: not biochemical. Significant others only. Refusals and non-confirmations classified as smokers

Notes $\quad 42 \%$ had called hotline and $17.5 \%$ spoken to counsellor by $6 \mathrm{~m}$

\section{Risk of bias}

\begin{tabular}{lll}
\hline Bias & Authors' judgement & Support for judgement \\
\hline $\begin{array}{l}\text { Random sequence genera- } \\
\text { tion (selection bias) }\end{array}$ & Unclear risk & Randomised, method not described \\
\hline $\begin{array}{l}\text { Allocation concealment } \\
\text { (selection bias) }\end{array}$ & Unclear risk & No details given \\
\hline $\begin{array}{l}\text { Blinding of outcome as- } \\
\text { sessment (detection bias) } \\
\text { All outcomes }\end{array}$ & Unclear risk & Validation by significant other, number refused/misreported not specified \\
\hline $\begin{array}{l}\text { Incomplete outcome data } \\
\text { (attrition bias) }\end{array}$ & Low risk & \\
All outcomes & & \\
\hline
\end{tabular}

\section{Peterson 2016}

$\begin{array}{ll}\text { Methods } & \text { Setting: Washington State, USA; High school-based } \\ & \text { Recruitment: High school smokers were identified by self-report using a study-administered baseline } \\ \text { classroom survey }\end{array}$
classroom survey

2151 smokers, $52.7 \%$ M, Age: $<16$ years old: $0.1 \% ; 16$ years old $30.5 \% ; 17$ years old: $62.0 \% ;>17$ years
old: $7.4 \% ;$ smokers were of variable motivation and wish for help with quitting
old: $7.4 \%$; smokers were of variable motivation and wish for help with quitting

Interventions
2. Proactive telephone intervention - 10 calls of about 15 mins each

\begin{tabular}{ll}
\hline Outcomes & $\begin{array}{l}\text { Self-reported abstinence at } 7 \text { years (6-year prolonged) } \\
\text { Validation: none }\end{array}$ \\
\hline
\end{tabular}

\begin{tabular}{ll}
\hline Notes & New for 2018 update \\
& Funding: "This study was supported by NCI grant R01-CA082569" \\
& Declarations of interest: none declared
\end{tabular}

\section{Risk of bias}

\begin{tabular}{lll}
\hline Bias & Authors' judgement & Support for judgement \\
\hline $\begin{array}{ll}\text { Random sequence genera- } \\
\text { tion (selection bias) }\end{array}$ & Low risk & $\begin{array}{l}\text { Quote: "A matched-pair randomization was performed via a computerized coin } \\
\text { flip for each of } 25 \text { pairs of high schools, using pair-matching of schools based } \\
\text { on number of smokers, smoking prevalence, fraction of students eligible for } \\
\text { free/reduced-priced meals, and average stage of readiness to quit, so that the } \\
\text { experimental and control conditions were balanced on these criteria" }\end{array}$ \\
& & \\
\hline
\end{tabular}


Peterson 2016 (Continued)

Allocation concealment $\quad$ Unclear risk
(selection bias)

Blinding of outcome as- High risk sessment (detection bias)

All outcomes
Abstinence not biochemically validated. Level of personal contact differed between arms

$\begin{array}{ll}\begin{array}{l}\text { Incomplete outcome data } \\ \text { (attrition bias) }\end{array} & \text { Low risk } \\ \text { All } & \begin{array}{l}\text { Even after } 7 \text { years percentage of participants lost to follow-up is small and } \\ \text { comparable between arms }\end{array}\end{array}$

All outcomes

comparable between arms

\section{Piper 2016}

\begin{tabular}{ll}
\hline Methods & Setting: Winsconsin, USA; primary care clinics \\
& Recruitment: Quote: "During clinic visits, clinical care staff (i.e. medical assistants) were prompted by \\
electronic health record technology to invite identified smokers to participate in a research program to \\
help them to quit smoking"
\end{tabular}

\section{Participants}

Interventions
637 smokers, $45 \%$ M, mean age 45.8 , average cigs/day 17.7 , participants were motivated to quit

1. Minimal phone counselling \pm preparation gum \pm preparation patch \pm in-person counselling \pm medication duration.

Quote: "Participants assigned to the minimal condition received one 10-minute session on the TQD that provided support and addressed motivation to quit, strategies for coping with craving and medication use."

2. Intense phone counselling \pm preparation gum \pm preparation patch \pm in-person counselling \pm medication duration

Quote: "Participants in the intensive condition received three 15-minute phone sessions (TQD, days 2 and 10). These calls emphasized intra-treatment social support, skill execution and avoidance of danger situations"

\section{Self-reported abstinence at 26 weeks (7-day PP)}

Validation: none

Notes New for 2018 update

Funding: "This research was supported by grants 9P50CA143188 and 1K05CA139871 from the National Cancer Institute to the University ofWisconsin Center for Tobacco Research and Intervention and by theWisconsin Partnership Program. L.M. C. is also supported by NIH grants P50DA10075 and R01DK097364. This work was carried out in part while T.R.S. was a Primary Care Research Fellow supported by a National Research Service Award (T32HP10010) from the Health Resources and Services Administration to the University of Wisconsin Department of Family Medicine. J.W.C. is also supported by Merit Review Award 101CX00056 from the US Department of Veterans Affairs. W.-Y.L. is also supported by NSF grant DMS-1305725."

Declarations of interest: none declared

\section{Risk of bias}


Piper 2016 (Continued)

Random sequence genera- Low risk Quote: "stratified permuted block randomization; we stratified by gender and tion (selection bias) clinic with a fixed block size of 32 based on the 32 unique treatment conditions (in random order within each block)"

\begin{tabular}{ll}
\hline $\begin{array}{l}\text { Allocation concealment } \\
\text { (selection bias) }\end{array}$ & Low risk
\end{tabular}

\begin{tabular}{lll}
\hline Blinding of outcome as- & High risk & $\begin{array}{l}\text { Abstinence not biochemically validated. Level of personal contact differed be- } \\
\text { tween arms }\end{array}$ \\
All outcomes &
\end{tabular}

All outcomes

$\begin{array}{ll}\text { Incomplete outcome data } & \text { Low risk } \\ \text { (attrition bias) } & 20 \%\end{array}$

All outcomes

Higher attrition in the intensive counselling arm but difference is less than

Alloutcomes

\section{Prochaska 1993}

\begin{tabular}{ll}
\hline Methods & $\begin{array}{l}\text { Setting: Community, USA } \\
\text { Recruitment: Advertisements for volunteers to test S-H materials, not selected for motivation }\end{array}$ \\
\hline Participants & $\begin{array}{l}756 \text { smokers (12\% precontemplation, } 58 \% \text { contemplation, 30\% preparation) (378 in relevant arms); } \\
38 \% \text { M, av. age 43, av. cigs/day } 27\end{array}$ \\
\hline Interventions & $\begin{array}{l}\text { 1. ALA S-H manuals } \\
\text { 2. Tailored manuals - } 5 \text { covering precontemplation, contemplation, action, maintenance, relapse. Par- } \\
\text { ticipants sent manual for their SoC and subsequent ones } \\
\text { 3. Interactive - in addition to tailored manuals, sent personally-tailored reports in response to ques- } \\
\text { tionnaires } \\
\text { 4. Proactive TC - short (15-min) calls at 0, } 1 \mathrm{~m}, 3 \mathrm{~m}, 6 \text { m. Materials as in } 3\end{array}$ \\
\hline
\end{tabular}

\begin{tabular}{ll}
\hline Outcomes & $\begin{array}{l}\text { Self-reported abstinence at } 18 \mathrm{~m} \text { (sustained at } 12 \mathrm{~m} \text { and } 18 \mathrm{~m} \text { ) } \\
\text { Validation: none. Participants asked for names of significant others but these not contacted }\end{array}$ \\
\hline Notes & $\begin{array}{l}\text { Arms } 4 \mathrm{vs} \mathrm{3,} \mathrm{TC} \text { vs S-H alone. Numbers randomised to groups and quit rates as shown in graphs ob- } \\
\text { tained from authors }\end{array}$ \\
\hline
\end{tabular}

\section{Risk of bias}

\begin{tabular}{lll}
\hline Bias & Authors' judgement & Support for judgement \\
\hline $\begin{array}{l}\text { Random sequence genera- } \\
\text { tion (selection bias) }\end{array}$ & Unclear risk & Randomised, method not described, stratified by SoC \\
\hline $\begin{array}{l}\text { Allocation concealment } \\
\text { (selection bias) }\end{array}$ & Unclear risk & No details given \\
\hline $\begin{array}{l}\text { Blinding of outcome as- } \\
\text { sessment (detection bias) } \\
\text { All outcomes }\end{array}$ & Low risk & $\begin{array}{l}\text { 'Bogus pipeline' approach; names of significant others asked for but not con- } \\
\text { tacted }\end{array}$ \\
\hline $\begin{array}{l}\text { Incomplete outcome data } \\
\text { (attrition bias) } \\
\text { All outcomes }\end{array}$ & Low risk & $\begin{array}{l}\text { Attrition at each assessment averaged 4.1\% - 7.1\% across all treatment condi- } \\
\text { tions, not significantly different. } 70 \% \text { provided data at every assessment. MA } \\
\text { uses numbers randomised, sensitivity analysis does not alter conclusions }\end{array}$ \\
\hline
\end{tabular}


Prochaska 2001

\begin{tabular}{|c|c|c|}
\hline Methods & \multicolumn{2}{|c|}{$\begin{array}{l}\text { Setting: Managed care organisation, USA } \\
\text { Recruitment: Active; smokers identified by survey of members. } 85 \% \text { recruited to a study, unselected for } \\
\text { motivation to quit }\end{array}$} \\
\hline Participants & \multicolumn{2}{|c|}{$\begin{array}{l}1447 \text { smokers ( } 723 \text { in comparisons used); } 38 \% \text { were precontemplators, } 44 \% \mathrm{M} \text {, av. age } 38 \text {, av. cigs/day } \\
20\end{array}$} \\
\hline Interventions & \multicolumn{2}{|c|}{$\begin{array}{l}\text { 1. Assessment only (completed questionnaires on } 4 \text { occasions) } \\
\text { 2. Expert System S-H. Tailored } 2 \text { - 3-page report at } 0,3 \mathrm{~m}, 6 \mathrm{~m} \text {, and SoC-matched manual } \\
\text { 3. As 2, plus proactive TC, short calls at } 0,3 \mathrm{~m}, 6 \mathrm{~m} \text {. Similar to Prochaska } 1993 \text { protocol but more em- } \\
\text { phasis on alternative targets for those unwilling to set quit date. } \\
\text { 4. As 3, plus computer-scheduled cig reduction }\end{array}$} \\
\hline Outcomes & \multicolumn{2}{|c|}{$\begin{array}{l}\text { Self-reported abstinence at } 18 \mathrm{~m} \text { (sustained for } 6 \mathrm{~m} \text { ). Other measures of abstinence also reported } \\
\text { Validation: None }\end{array}$} \\
\hline Notes & \multicolumn{2}{|c|}{ Arms 3 vs 2, TC vs S-H alone. Other arms compared in Self-help review } \\
\hline \multicolumn{3}{|l|}{ Risk of bias } \\
\hline Bias & Authors' judgement & Support for judgement \\
\hline $\begin{array}{l}\text { Random sequence genera- } \\
\text { tion (selection bias) }\end{array}$ & Unclear risk & Randomised, method not described \\
\hline $\begin{array}{l}\text { Allocation concealment } \\
\text { (selection bias) }\end{array}$ & Unclear risk & No details given \\
\hline $\begin{array}{l}\text { Blinding of outcome as- } \\
\text { sessment (detection bias) } \\
\text { All outcomes }\end{array}$ & High risk & $\begin{array}{l}\text { Abstinence not biochemically validated. Level of personal contact differed be- } \\
\text { tween arms }\end{array}$ \\
\hline $\begin{array}{l}\text { Incomplete outcome data } \\
\text { (attrition bias) } \\
\text { All outcomes }\end{array}$ & Low risk & $\begin{array}{l}\text { Greater loss to follow-up in TC ( } 44 \%) \text { than S-H ( } 38 \%) \text {. Denominators here in- } \\
\text { clude losses to follow-up and refusals. Author analysis suggests this treatment } \\
\text { of missing data is biased, but sensitivity analysis excluding losses and refusals } \\
\text { does not alter our MA conclusions }\end{array}$ \\
\hline
\end{tabular}

\section{Rabius 2004}

\begin{tabular}{ll}
\hline Methods & $\begin{array}{l}\text { Setting: Quitline, USA } \\
\text { Recruitment: Callers to quitline }\end{array}$ \\
\hline Participants & $\begin{array}{l}3522 \text { smokers willing to make a quit attempt within } 2 \text { weeks } \\
(\leq 25 />25): 39 \% / 33 \% \text { M, av. age } 22 / 44 \text {, av. cigs/day } 24 / 18\end{array}$ \\
\hline Interventions & $\begin{array}{l}\text { 1. } 3 \text { American Cancer Society S-H booklets } \\
\text { 2. As } 1 \text {, plus offer of } 5 \text { proactive TC calls, } 2 \text { before TQD, } 3 \text { within } 2 \text { weeks }\end{array}$ \\
\hline Outcomes & $\begin{array}{l}\text { Abstinence at } 6 \text { m (sustained). Only people abstinent at } 3 \text { m followed at } 6 \mathrm{~m} \\
\text { (reported in McAlister } 2004)\end{array}$ \\
\hline Notes & $58 \%$ did not complete more than 1 session of counselling (McAlister 2004)
\end{tabular}


Rabius 2004 (Continued)

Risk of bias

\begin{tabular}{|c|c|c|}
\hline Bias & Authors' judgement & Support for judgement \\
\hline $\begin{array}{l}\text { Random sequence genera- } \\
\text { tion (selection bias) }\end{array}$ & Unclear risk & Randomised, method not described \\
\hline $\begin{array}{l}\text { Allocation concealment } \\
\text { (selection bias) }\end{array}$ & Unclear risk & No details given \\
\hline $\begin{array}{l}\text { Blinding of outcome as- } \\
\text { sessment (detection bias) } \\
\text { All outcomes }\end{array}$ & Low risk & Small local sample biochemically tested, no responders disconfirmed \\
\hline $\begin{array}{l}\text { Incomplete outcome data } \\
\text { (attrition bias) } \\
\text { All outcomes }\end{array}$ & Low risk & $\begin{array}{l}\text { Loss to follow-up } 50 \% \text { in Intervention, } 55 \% \text { in Control (from McAlister 2004). } \\
\text { Differed by age, with higher loss in younger participants. All losses treated as } \\
\text { smokers }\end{array}$ \\
\hline
\end{tabular}

Rabius 2007

\begin{tabular}{|c|c|}
\hline Methods & $\begin{array}{l}\text { Setting: National Cancer Society quitline, USA } \\
\text { Recruitment: Callers to NCIS, interested in quitting }\end{array}$ \\
\hline Participants & 6322 smokers; 30\% M, av. age 43, median cigs/day 20 \\
\hline Interventions & $\begin{array}{l}1 / 4 \text { allocated to } \mathrm{S}-\mathrm{H} \text { control, remainder into } 3 \times 2 \text { factorial design } \\
\text { Counselling conditions: } \\
1.5 \text { sessions, } 210 \text { mins ( } 35 \text { - } 45 \text {-min calls } 10 \text { - } 14 \text { days pre-quit, } 2 \text { - } 3 \text { days pre-quit, } 1 \text { - } 2 \text { days, } 6 \text { - } 9 \text { days, } \\
13 \text { - } 16 \text { days post-quit) } \\
\text { 2. } 3 \text { sessions with } 105 \text { mins counselling (As } 1 \text {, omitting } 1 \text { st and last sessions) } \\
\text { 3. } 5 \text { sessions with } 50 \text { mins counselling (schedule as } 1,10 \text { mins duration) } \\
\text { Booster conditions: } 2 \times 15 \text {-min calls at } 4 \text { and } 8 \text { weeks after last counselling call }\end{array}$ \\
\hline Outcomes & $\begin{array}{l}\text { Abstinence at } 7 \mathrm{~m} \text { post-randomisation (PP) } \\
\text { Validation: none }\end{array}$ \\
\hline Notes & $\begin{array}{l}\text { All interventions pooled vs control, results of different intensities included in post hoc analyses and dis } \\
\text { cussed in more detail in text. }\end{array}$ \\
\hline
\end{tabular}

\section{Risk of bias}

\begin{tabular}{lll}
\hline Bias & Authors' judgement & Support for judgement \\
\hline $\begin{array}{l}\text { Random sequence genera- } \\
\text { tion (selection bias) }\end{array}$ & Low risk & Computer-generated random number sequence without stratification \\
\hline $\begin{array}{l}\text { Allocation concealment } \\
\text { (selection bias) }\end{array}$ & Unclear risk & No details given \\
\hline $\begin{array}{l}\text { Blinding of outcome as- } \\
\text { sessment (detection bias) } \\
\text { All outcomes }\end{array}$ & Unclear risk & $\begin{array}{l}\text { Self-reported outcomes from participants not blinded to treatment condition. } \\
\text { Varying levels of contact between arms in multifactorial trial }\end{array}$ \\
\hline $\begin{array}{l}\text { Incomplete outcome data } \\
\text { (attrition bias) }\end{array}$ & Low risk & $\begin{array}{l}\text { Loss to follow-up 50\%, similar in all groups. Analysis includes losses as smok- } \\
\text { ers }\end{array}$
\end{tabular}


Rabius 2007 (Continued)

All outcomes

Ramon 2013

\begin{tabular}{|c|c|}
\hline Methods & $\begin{array}{l}\text { Setting: Spain; smoking cessation outpatient clinics } \\
\text { Recruitment: smokers attending smoking cessation outpatient clinics }\end{array}$ \\
\hline Participants & $\begin{array}{l}600 \text { smokers, } 51.3 \% \text { M, mean age } 47.4 \text {, average cigs/day 25.3. Paticipants attended clinics to "receive } \\
\text { medical assistance" - they were interested in quitting }\end{array}$ \\
\hline \multirow[t]{2}{*}{ Interventions } & $\begin{array}{l}\text { 1. Individual counselling: "seven individual sessions at 3, 5, 7, 10, 12, 24, and } 52 \text { weeks after the pre-quit } \\
\text { session." }\end{array}$ \\
\hline & $\begin{array}{l}\text { 2. Telephone counselling + Individual Counseling: "individual counselling interventions at weeks 3, 5, } \\
\text { and } 12 \text { after the pre-quit session, telephone counselling at weeks 7, 10, and 24, and a control session at } \\
\text { the clinic at week 52." Sessions were between } 15 \text { and } 20 \text { mins }\end{array}$ \\
\hline \multirow[t]{2}{*}{ Outcomes } & Abstinence at 52 weeks (sustained from week 2 to 52 ) \\
\hline & Validation: $\mathrm{CO}$ concentrations of $<10 \mathrm{ppm}$ \\
\hline \multirow[t]{3}{*}{ Notes } & New for 2018 update \\
\hline & Funding: "This study was supported by a grant from the Spanish Health Institute, Carlos III PI080418." \\
\hline & $\begin{array}{l}\text { Declarations of interest: several authors "have received honoraria for conferences from manufacturers } \\
\text { of smoking cessation products." }\end{array}$ \\
\hline
\end{tabular}

\section{Risk of bias}

Bias Authors' judgement Support for judgement

Random sequence genera- Low risk tion (selection bias)
Quote: "used a computer-generated randomization system based on a permuted block randomization list where each block was used by one centre. An independent researcher in the coordination centre generated a random sequence, and centres were informed about smoker allocation after consent to participation during the pre-quit session."

Allocation concealment Low risk
(selection bias)
Quote: "used a computer-generated randomization system based on a permuted block randomization list where each block was used by one centre. An independent researcher in the coordination centre generated a random sequence, and centres were informed about smoker allocation after consent to participation during the pre-quit session."

\begin{tabular}{lll}
\hline $\begin{array}{l}\text { Blinding of outcome as- } \\
\text { sessment (detection bias) }\end{array}$ & Low risk & \\
$\begin{array}{l}\text { All outcomes } \\
\text { Incomplete outcome data }\end{array}$ & Low risk & Attrition was around 20\% and comparable across arms \\
$\begin{array}{l}\text { (attrition bias) } \\
\text { All outcomes }\end{array}$ & \\
\hline
\end{tabular}


Reid 1999a

\begin{tabular}{|c|c|c|}
\hline Methods & \multicolumn{2}{|c|}{$\begin{array}{l}\text { Setting: Community, Canada } \\
\text { Recruitment: Community volunteers }\end{array}$} \\
\hline Participants & \multicolumn{2}{|c|}{$\begin{array}{l}396 \text { smokers interested in quitting within } 30 \text { days, smoking } \geq 15 \text { cigs/day; } 52 \% \text { M, av. age } 38 \text {, av. cigs/ } \\
\text { day } 23-24\end{array}$} \\
\hline Interventions & \multicolumn{2}{|c|}{$\begin{array}{l}\text { 1. Nicotine patch ( } 15 \mathrm{mg} \times 8 \text { weeks, } 10 \mathrm{mg} \times 2 \text { weeks, } 5 \mathrm{mg} \times 2 \text { weeks) free, physician advice ( } \times 3 \text { 15-min, } \\
2 \text { weeks before, } 4 \text { weeks, } 12 \text { weeks after quit date) } \\
\text { 2. As } 1 \text {, plus proactive TC, nurse counsellors, stage-based, } 3 \text { sessions at 2, 6, } 13 \text { weeks }\end{array}$} \\
\hline Outcomes & \multicolumn{2}{|c|}{$\begin{array}{l}\text { Abstinence at } 12 \mathrm{~m} \text { (PP) } \\
\text { Validation: } \mathrm{CO} \text {, but self-reported rates reported. Only } 1 \text { disconfirmation }\end{array}$} \\
\hline Notes & \multicolumn{2}{|c|}{$\begin{array}{l}\text { Effect of adjunct TC compared to NRT and counselling alone } \\
\text { Similar counselling scripts to Orleans } 1991\end{array}$} \\
\hline \multicolumn{3}{|l|}{ Risk of bias } \\
\hline Bias & Authors' judgement & Support for judgement \\
\hline $\begin{array}{l}\text { Random sequence genera- } \\
\text { tion (selection bias) }\end{array}$ & Unclear risk & $\begin{array}{l}\text { Randomised using table of random numbers, stratified by gender and nicotine } \\
\text { dependence }\end{array}$ \\
\hline $\begin{array}{l}\text { Allocation concealment } \\
\text { (selection bias) }\end{array}$ & Unclear risk & Concealment unclear but physician blind to allocation \\
\hline $\begin{array}{l}\text { Blinding of outcome as- } \\
\text { sessment (detection bias) } \\
\text { All outcomes }\end{array}$ & Low risk & $\begin{array}{l}\text { 'Bogus pipeline' procedures used for early follow-ups; proportion of partici- } \\
\text { pants who provided breath samples did not differ between } 2 \text { groups; only } 1 \\
\text { misreport identified; adjustment of abstinence rates for validation did not af- } \\
\text { fect conclusions }\end{array}$ \\
\hline $\begin{array}{l}\text { Incomplete outcome data } \\
\text { (attrition bias) } \\
\text { All outcomes }\end{array}$ & Low risk & $15 \%$ lost/dropped out in each groups, included as smokers \\
\hline
\end{tabular}

\section{Reid 2007}

\begin{tabular}{ll}
\hline Methods & $\begin{array}{l}\text { Setting: Tertiary care cardiac hospital, Canada } \\
\text { Recruitment: Inpatients with CHD, not explicitly selected by motivation, 90\% of eligible enrolled }\end{array}$ \\
\hline Participants & 100 smokers; $68 \%$ M, av. age $54,48 \%$ quit attempt in previous year \\
\hline Interventions & $\begin{array}{l}\text { All participants received in-hospital brief counselling, access to NRT, S-H materials } \\
\text { 1. Interactive Voice Response (IVR) system contacted participants 3, } 14 \text { and } 30 \text { days post-hospital dis- } \\
\text { charge. Participants identified as needing support contacted by nurse counsellor for up to } 3 \times 20 \text {-min } \\
\text { sessions over } 8 \text { weeks } \\
\text { 2. Usual care }\end{array}$ \\
\hline Outcomes & $\begin{array}{l}\text { Abstinence at } 1 \text { year (PP) } \\
\text { Validation: none }\end{array}$ \\
\hline Notes & $\begin{array}{l}\text { Mean } 2.1 \text { IVR calls completed, 46\% received at least } 1 \text { counselling call, mean 1.8, so total calls cate- } \\
\text { gorised as } 4\end{array}$ \\
\hline
\end{tabular}

\section{Risk of bias}


Reid 2007 (Continued)

\begin{tabular}{lll} 
Bias & Authors' judgement & Support for judgement \\
\hline $\begin{array}{l}\text { Random sequence genera- } \\
\text { tion (selection bias) }\end{array}$ & Low risk & $\begin{array}{l}\text { Quote: "mediated through the Clinical Epidemiology Unit's data centre, using } \\
\text { a computer generated randomization list" Block size } 6\end{array}$ \\
\hline $\begin{array}{l}\text { Allocation concealment } \\
\text { (selection bias) }\end{array}$ & Low risk & $\begin{array}{l}\text { Quote: "Research staff were unaware of the treatment allocation prior to ran- } \\
\text { domization" }\end{array}$ \\
\hline $\begin{array}{l}\text { Blinding of outcome as- } \\
\text { sessment (detection bias) } \\
\text { All outcomes }\end{array}$ & High risk & $\begin{array}{l}\text { Self-reported outcomes from participants not blinded to treatment condition. } \\
\text { Level of personal contact differed between arms }\end{array}$ \\
\hline $\begin{array}{l}\text { Incomplete outcome data } \\
\text { (attrition bias) } \\
\text { All outcomes }\end{array}$ & Low risk & $\begin{array}{l}\sim 15 \% \text { lost to follow-up, similar between groups. 1 Control death excluded, oth- } \\
\text { ers included }\end{array}$
\end{tabular}

\section{Reid 2018}

$\begin{array}{ll}\text { Methods } & \text { Setting: Canada; hospital-based } \\ \text { Recruitment: Smokers admitted to the hospital were automatically referred to an in-house smoking } \\ \text { cessation programme }\end{array}$
cessation programme

$\begin{array}{ll}\text { Participants } & 410 \text { hospital-admitted CHD smokers, } 74.4 \% \mathrm{M} \text {, av. age } 54.2,16 \%<11 \text { cigs/day, } 33 \% 11-20 \text { cigs/day, } \\ & 40 \% 21-30 \text { cigs/day, } 11 \%>30 \text { cigs/day Not selected for motivation }\end{array}$

\begin{tabular}{ll}
\hline Outcomes & $\begin{array}{l}\text { Abstinence at } 52 \text { weeks (continuous abstinence) } \\
\text { Validation: } \mathrm{CO} \leq 4 \mathrm{ppm} \text { done in a random subsample with high verification rates after } 52 \text { weeks of fol- } \\
\text { low-up ( } 90 \%)\end{array}$ \\
\hline Notes & Few for 2018 update \\
& Funding: "Heart and Stroke Foundation of Ontario Grant \# NA5845" \\
& $\begin{array}{l}\text { Declarations of interest: "RDR and ALP have received speaking and/or consulting fees and research } \\
\text { grants from Pfizer and Johnson \& Johnson. KAM has received speaking fees from Pfizer. AGL is support- } \\
\text { ed by a Canadian Institutes of Health Research-Ottawa Model for Smoking Cessation Health Impact } \\
\text { Fellowship" }\end{array}$ \\
\hline
\end{tabular}

\section{Risk of bias}

\begin{tabular}{lll}
\hline Bias & Authors' judgement & Support for judgement \\
\hline $\begin{array}{l}\text { Random sequence genera- } \\
\text { tion (selection bias) }\end{array}$ & Low risk & Quote: "computer generated sequence" \\
\hline $\begin{array}{l}\text { Allocation concealment } \\
\text { (selection bias) }\end{array}$ & Unclear risk & Not described \\
\hline $\begin{array}{l}\text { Blinding of outcome as- } \\
\text { sessment (detection bias) }\end{array}$ & Low risk & $\begin{array}{l}\text { Validation of self-reports in a random subsample achieving high rates of veri- } \\
\text { fied abstinence }\end{array}$ \\
\hline
\end{tabular}


Reid 2018 (Continued)

All outcomes

Incomplete outcome data Low risk $\quad$ Similar percentage of participants lost to follow-up across arms ( $\sim 30 \%)$
(attrition bias)

(attrition bias)

All outcomes

\section{Rigotti 2006}

$\begin{array}{ll}\text { Methods } & \text { Setting: Prenatal care services, USA } \\ & \text { Recruitment: Pregnant women in a managed care plan or referred by a care provider, not selected by } \\ & \text { motivation }\end{array}$
motivation

\begin{tabular}{|c|c|}
\hline Participants & $\begin{array}{l}442 \text { pregnant women smoking at least } 1 \text { cig in previous } 7 \text { days; av. age } 29 \text {, av. cigs/day } 21 \text { prior to preg- } \\
\text { nancy, } 10 \text { at recruitment, } 84 \% \text { planned to quit }\end{array}$ \\
\hline Interventions & $\begin{array}{l}\text { All participants received brief counselling at enrolment call and mailed a pregnancy-tailored S-H book- } \\
\text { let } \\
\text { 1. Proactive counselling, up to } 90 \text { mins during pregnancy and } 15 \text { mins postpartum, + targeted written } \\
\text { materials } \\
\text { 2. Usual care }\end{array}$ \\
\hline
\end{tabular}

Outcomes Abstinence $3 \mathrm{~m}$ postpartum (sustained at end of pregnancy and $3 \mathrm{~m}$ )

Validation: saliva cotinine $\leq 20 \mathrm{ng} / \mathrm{mL}$

Notes Mean of 5 calls received, 4 in pregnancy, av. 68 mins in total

\section{Risk of bias}

\begin{tabular}{lll}
\hline Bias & Authors' judgement & Support for judgement \\
\hline $\begin{array}{l}\text { Random sequence genera- } \\
\text { tion (selection bias) }\end{array}$ & Low risk & $\begin{array}{l}\text { Quote: "computer-generated randomization list arranged in balanced blocks } \\
\text { of } 4 \text { and stratified by referral source" }\end{array}$ \\
\hline $\begin{array}{l}\text { Allocation concealment } \\
\text { (selection bias) }\end{array}$ & Low risk & $\begin{array}{l}\text { Quote: "... the application revealed the next assignment only after the smoker } \\
\text { had consented to participate in the study" }\end{array}$ \\
\hline $\begin{array}{l}\text { Blinding of outcome as- } \\
\text { sessment (detection bias) } \\
\text { All outcomes }\end{array}$ & Low risk & $\begin{array}{l}\text { Biochemical validation; those who failed biochemical validation or did not } \\
\text { provide a sample counted as smokers }\end{array}$ \\
\hline $\begin{array}{l}\text { Incomplete outcome data } \\
\text { (attrition bias) }\end{array}$ & Low risk & $\begin{array}{l}\text { 21 miscarriages excluded. 33\% Intervention, 28\% Control lost to follow-up, in- } \\
\text { cluded as smokers }\end{array}$ \\
\hline
\end{tabular}

Rimer 1994

\begin{tabular}{ll}
\hline Methods & $\begin{array}{l}\text { Setting: Community, USA } \\
\text { Recruitment: Volunteers from American Association for Retired Persons }\end{array}$ \\
\hline Participants & $\begin{array}{l}1867 \text { smokers aged } 50-75 \text { (12-m data based on } 1391,1225 \text { in relevant arms) interested in finding out } \\
\text { about quitting; } 37 \% \text { M, av age } 61, \text { av cigs/day } 27\end{array}$ \\
\hline Interventions & $\begin{array}{l}\text { 1. Standard S-H manual (not included in this review) } \\
\text { 2. S-H manual tailored for older smokers (Clear Horizons) }\end{array}$ \\
\hline
\end{tabular}


Rimer 1994 (Continued)

3. Tailored manual and $2 \times 10-15$-min proactive TC at $4-8$ weeks and $16-20$ weeks. Also access to a quitline

\begin{tabular}{|c|c|c|}
\hline Outcomes & \multicolumn{2}{|c|}{$\begin{array}{l}\text { Abstinence at } 12 \mathrm{~m} \text { (7-day PP) } \\
\text { Validation: none }\end{array}$} \\
\hline Notes & \multicolumn{2}{|c|}{ Arms 3 vs 2 . Preliminary $12 \mathrm{~m}$ results used } \\
\hline \multicolumn{3}{|l|}{ Risk of bias } \\
\hline Bias & Authors' judgement & Support for judgement \\
\hline $\begin{array}{l}\text { Random sequence genera- } \\
\text { tion (selection bias) }\end{array}$ & Unclear risk & Randomised, method not described \\
\hline $\begin{array}{l}\text { Allocation concealment } \\
\text { (selection bias) }\end{array}$ & Unclear risk & No details given \\
\hline $\begin{array}{l}\text { Blinding of outcome as- } \\
\text { sessment (detection bias) } \\
\text { All outcomes }\end{array}$ & High risk & $\begin{array}{l}\text { Self-reported outcomes from participants not blinded to treatment condition. } \\
\text { Level of personal contact differed between arms }\end{array}$ \\
\hline $\begin{array}{l}\text { Incomplete outcome data } \\
\text { (attrition bias) } \\
\text { All outcomes }\end{array}$ & Low risk & 75\% reached at $12 \mathrm{~m}$ with no treatment group differences in follow-up rate \\
\hline
\end{tabular}

\section{Rogers 2016}

\begin{tabular}{|c|c|}
\hline \multirow[t]{2}{*}{ Methods } & $\begin{array}{l}\text { Setting: NY, NJ, MA, VT, NH, RI, USA; } 6 \text { Veterans Health Administration (VHA) facilities in the U.S. North- } \\
\text { east }\end{array}$ \\
\hline & $\begin{array}{l}\text { Recruitment: Quote: "All smokers who saw a VHA mental health provider at participating sites were el- } \\
\text { igible for referral to the care coordination program by their usual mental health providers via an EMR } \\
\text { consult created for the study" }\end{array}$ \\
\hline Participants & $\begin{array}{l}577 \text { smokers, } 92 \% \mathrm{M} \text {, av. age } 54 \text {, av. cigs/day 15.9. Participants were referred from a VHA mental health } \\
\text { provider and were interested in quitting }\end{array}$ \\
\hline \multirow[t]{3}{*}{ Interventions } & 1. State quit-line counselling \\
\hline & $\begin{array}{l}\text { 2. Specialised proactive telephone counselling protocol developed by the study for mental health pa- } \\
\text { tients - } 10 \text { or fewer calls, weekly and for } 30-60 \text { mins }\end{array}$ \\
\hline & Participants in both groups also received mailed S-H materials and smoking cessation medications \\
\hline \multirow[t]{2}{*}{ Outcomes } & Self-reported abstinence at $6 \mathrm{~m}$ (30-day PP) \\
\hline & Validation: none \\
\hline \multirow[t]{3}{*}{ Notes } & New for 2018 update \\
\hline & $\begin{array}{l}\text { Funding: "This trial was funded by the U.S. Department of Veterans Affairs Health Services Research } \\
\text { and Development Quality Enhancement Research Initiative (\#SDP 07-034)." }\end{array}$ \\
\hline & Declarations of interest: none declared \\
\hline
\end{tabular}

\section{Risk of bias}


Rogers 2016 (Continued)

Bias Authors' judgement Support for judgement

Random sequence genera- High risk tion (selection bias)
Pseudo-randomised using social security number last digit (odd/even number). This resulted in nearly balanced groups except for the fact that participants in the specialised counselling arm smoked a significantly higher number of cigarettes than participants in the quitline arm

Allocation concealment High risk Unlikely to apply to this method of randomisation
(selection bias)

\begin{tabular}{|c|c|c|}
\hline $\begin{array}{l}\text { Blinding of outcome as- } \\
\text { sessment (detection bias) } \\
\text { All outcomes }\end{array}$ & High risk & $\begin{array}{l}\text { Abstinence not biochemically validated. Level of personal contact differed be- } \\
\text { tween arms }\end{array}$ \\
\hline
\end{tabular}

\begin{tabular}{l}
\hline $\begin{array}{l}\text { Incomplete outcome data Low risk } \\
\text { (attrition bias) } \\
\text { All outcomes }\end{array}$ \\
\hline
\end{tabular}

Schlam 2016

\begin{tabular}{ll}
\hline Methods & Setting: Winsconsin, USA; primary care clinics \\
& Recruitment: Recruited during primary care visits (11 primary care clinics in 2 healthcare systems). Ex- \\
& isting clinical care staff (i.e. medical assistants), prompted by electronic health record technology, in- \\
& vited identified smokers during clinic visits to participate in a research programme to help them quit \\
& smoking
\end{tabular}

\begin{tabular}{ll}
\hline Participants & 544 smokers, $41 \% \mathrm{M}$, av. age 46.2, av. cigs/day 18.6, motivated to quit \\
\hline Interventions & $\begin{array}{l}\text { 1. No maintenance (phone) counselling } \pm \text { extended medication } \pm \text { (on site) medication adherence coun- } \\
\text { selling } \pm \text { automated adherence calls } \pm \text { helping hand }(\mathrm{HH}) \text { with feedback and counselling }\end{array}$ \\
$\begin{array}{l}\text { 2. No automated adherence calls } \pm \text { extended medication } \pm \text { (on site) medication adherence counselling } \\
\pm \text { maintenance (phone) counselling } \pm \text { helping hand }(\mathrm{HH}) \text { with feedback and counselling (not used in } \\
\text { analysis) }\end{array}$ \\
$\begin{array}{l}\text { 3. Automated adherence calls } \pm \text { extended medication } \pm \text { (on site) medication adherence counselling } \\
\pm \text { maintenance (phone) counselling } \pm \text { helping hand }(\mathrm{HH}) \text { with feedback and counselling (not used in } \\
\text { analysis) }\end{array}$
\end{tabular}

4. Maintenance (phone) counselling \pm extended medication \pm (on site) medication adherence counselling \pm automated adherence calls \pm helping hand $(\mathrm{HH})$ with feedback and counselling $-8 \times 15$-min calls at weeks $3,4,6,8,10,14,18$ and 22

Quote: "All participants received a standard cessation intervention: 8 weeks of nicotine patch+nicotine gum and 50 minutes of counseling delivered over four sessions [in visits 1 week before and 1 week after the target quit day (TQD), and in calls on the TQD and at week 2]."

\begin{tabular}{ll}
\hline Outcomes & Self-reported abstinence at 52 weeks (7-day PP) \\
& Validation: none \\
\hline Notes & New for 2018 update \\
& Funding: "This research was supported by grants 9P50CA143188 and 1K05CA139871 from the Nation- \\
& al Cancer Institute to the University ofWisconsin Center for Tobacco Research and Intervention and \\
& by theWisconsin Partnership Program. L.M. C. is also supported by NIH grants P50DA10075 and R01D- \\
& K097364. This work was carried out in part while T.R.S. was a Primary Care Research Fellow supported
\end{tabular}


Schlam 2016 (Continued)

by a National Research Service Award (T32HP10010) from the Health Resources and Services Administration to the University of Wisconsin Department of Family Medicine. J.W.C. is also supported by Merit Review Award 101CX00056 from the US Department of Veterans Affairs. W.-Y.L. is also supported by NSF grant DMS-1305725."

Declarations of interest: none declared

\title{
Risk of bias
}

\begin{tabular}{lll}
\hline Bias & Authors' judgement & Support for judgement \\
\hline $\begin{array}{l}\text { Random sequence genera- } \\
\text { tion (selection bias) }\end{array}$ & Low risk & $\begin{array}{l}\text { Quote: "Participants were randomized to one of } 32 \text { unique experimental con- } \\
\text { ditions... via a database that used stratified, computer-generated, permuted } \\
\text { block randomization..." }\end{array}$ \\
\hline $\begin{array}{l}\text { Allocation concealment } \\
\text { (selection bias) }\end{array}$ & Low risk & $\begin{array}{l}\text { Quote: "Staff could not view the allocation sequence. The database did not re- } \\
\text { veal participants' treatment condition to staff until participants' eligibility was } \\
\text { confirmed; participants were blinded to treatment condition until they provid- } \\
\text { ed consent." }\end{array}$ \\
\hline
\end{tabular}

$\begin{array}{lll}\text { Blinding of outcome as- } & \text { High risk } & \begin{array}{l}\text { Abstinence not biochemically validated. Level of personal contact differed be- } \\ \text { sessment (detection bias) }\end{array} \\ \text { All outcomes } & \text { tween arms }\end{array}$

All outcomes

Incomplete outcome data Low risk

(attrition bias)

Attrition is much larger in Maintenance Counselling arm (51\%) than in No

All outcomes

\begin{abstract}
Maintenance Counselling arm (44\%)
\end{abstract}
Schuck 2014

$\begin{array}{ll}\text { Methods } & \text { Setting: Netherlands; school-based } \\ & \text { Recruitment: Quote: "Smoking parents were recruited through their children's primary schools across } \\ \text { the Netherlands. Primary schools were contacted by research assistants and asked to distribute study } \\ \text { invitation letters to parents through children." [...] "Parents registered to take part by mail, e-mail, tele- } \\ \text { phone or via a website." }\end{array}$

Participants 512 daily or weekly smokers and parents or caretakers of a child aged between 9 and 12 years. They were considering quitting smoking (currently or in the future). $47.5 \% \mathrm{M}$, av. age 42.2 , av. cigs/day 16.2

Interventions 1. "Standard Self-Help Brochure: Participants received a 40-page, colour-printed self-help brochure including didactic information on nicotine dependence and the health benefits of quitting smoking, tips and advice on how to initiate and maintain abstinence, instruction in the use of cognitive and behavioural skills to avoid triggers to smoke and cope with urges to smoke, and strategies for managing a lapse or relapse to smoking

2. Intensive Proactive Quitline Counselling + supplementary materials tailored to smoking parents; mean number of calls completed was 5.5 and these were scheduled for 10 days before quit day, 3 days, 1, 2, 4 weeks, 2, and 3 months after quit day."

Quote: "In addition, all participants received three accompanying booklets entitled Smoke-free parents which were designed for this study as tailored supplementary materials. Each booklet (four pages, colour-print) contained didactic information, tips and advice, motivational messages, as well as 'parent-relevant information'; e.g. effects of second-hand smoke (SHS) on children, strategies to manage parent-specific stressors]." 
Funding: "This work was supported by ZonMW, the Netherlands Organization for Health Care Research and Development (grant number: 50-50110-96-639)."

Declarations of interest: none reported

\section{Risk of bias}

\begin{tabular}{|c|c|c|}
\hline Bias & Authors' judgement & Support for judgement \\
\hline $\begin{array}{l}\text { Random sequence genera- } \\
\text { tion (selection bias) }\end{array}$ & Low risk & $\begin{array}{l}\text { Quote: "To ensure equal group sizes, allocation was performed in blocks of } \\
\text { 10. To ensure balance of key characteristics, stratified randomization was } \\
\text { used based on the stratifying variables gender, educational level (low: no high } \\
\text { school diploma/no vocational training, medium: vocational training or high } \\
\text { school diploma, high: college degree) and cigarettes per day (fewer than 10, } \\
\text { 10-20, } 21 \text { or more)." }\end{array}$ \\
\hline
\end{tabular}

\begin{tabular}{ll}
\hline $\begin{array}{l}\text { Allocation concealment } \\
\text { (selection bias) }\end{array}$ & $\begin{array}{l}\text { Quote: "Allocation of participants to trial conditions was conducted by an in- } \\
\text { dependent member of the research group using a computer-generated allo- } \\
\text { cation sequence." [...] "The independent researcher prepared a list of study } \\
\text { participants and their allocated treatment. Based on this list, the first author } \\
\text { prepared the mailings which informed study participants about the treatment } \\
\text { they would receive." }\end{array}$ \\
\end{tabular}

\begin{tabular}{lll}
\hline $\begin{array}{l}\text { Blinding of outcome as- } \\
\begin{array}{l}\text { sessment (detection bias) } \\
\text { All outcomes }\end{array}\end{array}$ & Low risk & $\begin{array}{l}\text { Biochemical validation not done in the entire sample, but just in a random } \\
\text { subset. However, verified abstinence rate of } 82 \% \text { (18 of 22) overall in the sub- } \\
\text { sample was acceptable, with no significant different across arms }\end{array}$ \\
\hline $\begin{array}{l}\text { Incomplete outcome data } \\
\text { (attrition bias) }\end{array}$ & Low risk & $\begin{array}{l}\text { Even though "There was a significant difference in the follow-up rate between } \\
\text { treatment groups }(85.5 \% \text { in the quitline condition and } 89.5 \% \text { in the self-help } \\
\text { condition, } X 2=4.98, P=0.03) ", \text { overall attrition was low }(11 \%) \text {. Furthermore } \\
\text { "Participants lost at follow-up did not differ on baseline characteristics com- } \\
\text { pared with the remaining participants, neither across nor within conditions } \\
\text { (all } P>0.05) . "\end{array}$ \\
&
\end{tabular}

Sherman 2017

Setting: California and Nevada, USA; Department of Veteran Affairs outpatient primary care clinics
Recruitment: Healthcare "providers were encouraged to refer any patient who smoked and was inter-
ested in quitting"

Participants 3120 smokers, $94 \%$ M, av. age 54.2, av. cigs/day 18.3. Participants were interested in quitting

Interventions
1. Reactive Self-Help: "Participants referred during a reactive week were mailed an invitational letter, and the co-ordinator waited for the patient to initiate a call. If patients in the reactive condition called, they only received medication co-ordination along with their self-help materials."

2. Proactive Self-Help: "Participants referred during a proactive week were sent self-help materials and telephoned by the care co-ordinator only to discuss medication."

3. Reactive Telephone Counselling: "Participants referred during a reactive week were mailed an invitational letter, and the co-ordinator waited for the patient to initiate a call." 
4. Proactive Telephone Counseling: "Participants referred during a proactive week were contacted by the care co-ordinator, who tried up to five times by phone over 2 weeks to reach them." 5 or fewer calls occurred per participant

"All patients referred received standard care from their primary care provider prior to referral, which typically included brief cessation advice. [...] Patients in both studies received cessation medication [...] 2 months of nicotine patches or 2 months of bupropion"

\begin{tabular}{ll}
\hline Outcomes & Self-reported abstinence at $6 \mathrm{~m}$ (7-day PP) \\
& Validation: none \\
\hline Notes & New for 2018 update \\
& Funding: "This work was supported by VA HSR\&D grant number \#IMV 04-088." \\
& Declarations of interest: none declared \\
\hline
\end{tabular}

\section{Risk of bias}

\begin{tabular}{lll}
\hline Bias & Authors' judgement & Support for judgement \\
\hline $\begin{array}{l}\text { Random sequence genera- } \\
\text { tion (selection bias) }\end{array}$ & High risk & $\begin{array}{l}\text { Quote: "We randomised all participating sites to either self-help or multises- } \\
\text { sion quitline counselling using a random number table." } \\
\text { Randomisation to proactive/reactive subarm was done by alternating calen- } \\
\text { dar week }\end{array}$ \\
\hline $\begin{array}{l}\text { Allocation concealment } \\
\text { (selection bias) }\end{array}$ & Unclear risk & No method to conceal allocation was mentioned \\
\hline $\begin{array}{l}\text { Blinding of outcome as- } \\
\text { sessment (detection bias) } \\
\text { All outcomes }\end{array}$ & High risk & $\begin{array}{l}\text { Abstinence not biochemically validated. Level of personal contact differed be- } \\
\text { tween arms }\end{array}$ \\
\hline $\begin{array}{l}\text { Incomplete outcome data } \\
\text { (attrition bias) } \\
\text { All outcomes }\end{array}$ & Low risk & Attrition was low, around $17 \%$ - $29 \%$ across arms \\
\hline
\end{tabular}

\section{Sims 2013}

Methods Setting: Wisconsin, USA

Recruitment: Young adult callers to the Wisconsin Tobacco Quit Line (WTQL)

\begin{tabular}{ll}
\hline Participants & $\begin{array}{l}410 \text { smokers age } 18-24 \text { years, smoked at least } 1 \text { cig in past } 30 \text { days and motivated to quit. } 42 \% \text { M; av. } \\
\text { age } 21.3 \text { years, av. cigs/day } 15\end{array}$
\end{tabular}

Interventions 1. S-H only, stage-based booklets

2. S-H + up to 4 proactive cessation counselling calls over 4 - 6 weeks through the WTQL

\begin{tabular}{ll}
\hline Outcomes & Abstinence at $6 \mathrm{~m}$ (7-day PP) \\
& Self-report
\end{tabular}

\section{Notes}


Sims 2013 (Continued)

Risk of bias

\begin{tabular}{lll}
\hline Bias & Authors' judgement & Support for judgement \\
\hline $\begin{array}{l}\text { Random sequence genera- } \\
\text { tion (selection bias) }\end{array}$ & Low risk & List of random numbers \\
\hline $\begin{array}{l}\text { Allocation concealment } \\
\text { (selection bias) }\end{array}$ & Unclear risk & No details given \\
\hline $\begin{array}{l}\text { Blinding of outcome as- } \\
\text { sessment (detection bias) }\end{array}$ & High risk & Abstinence not biochemically validated. Level of personal contact differed be- \\
All outcomes & & tween arms \\
\hline $\begin{array}{l}\text { Incomplete outcome data } \\
\text { (attrition bias) } \\
\text { All outcomes }\end{array}$ & Unclear risk & $\begin{array}{l}53 \% \text { not followed in Intervention, 50\% in Control. Missing treated as smoking. } \\
\text { Responder analysis did not change results }\end{array}$ \\
\hline
\end{tabular}

\section{Skov-Ettrup 2016}

Setting: Denmark; population-based
Recruitment: Quote: "Participants were recruited from two national health surveys: the Danish Health
Examination Survey (DANHES) (2007-08) and the Danish Health and Morbidity Survey (DHMS) (2010)
$\left[\begin{array}{l}\text { [...] The invitation letter was sent by e-mail or letter" }\end{array}\right.$

\begin{tabular}{ll}
\hline Participants & $\begin{array}{l}\text { 1810 smokers aged } 16 \text { and over, } 42 \% \mathrm{M} \text {, av. age } 51 \text {, av. cigs/day 16. Participants were willing to quit } \\
\text { smoking within the next } 12 \text { weeks }\end{array}$ \\
\hline Interventions & $\begin{array}{l}\text { 1. Self-help booklet: Participants received a 36-page booklet by letter. It was developed by the Danish } \\
\text { National Board of Health, and included advice on how to identify difficult situations and develop cop- } \\
\text { ing strategies at specific stages in the smoking cessation process. Setting a quit date was encouraged. } \\
\text { The Fagerström Test for Nicotine Dependence was also included along with information about pharma- } \\
\text { cotherapy }\end{array}$ \\
2. Reactive telephone counselling: A session lasted for approximately $13-15$ mins \\
3. Proactive telephone counselling: 5 counsellor-initiated sessions
\end{tabular}

\begin{tabular}{ll}
\hline Outcomes & Self-reported abstinence at $12 \mathrm{~m}$ (prolonged) \\
& Validation: none
\end{tabular}

$\begin{array}{ll}\text { Notes } & \text { New for } 2018 \text { update } \\ \text { Funding: "The study was funded by the Danish Cancer Society" } \\ \text { Declarations of interest: none reported }\end{array}$

\section{Risk of bias}

\begin{tabular}{lll}
\hline Bias & Authors' judgement & Support for judgement \\
\hline $\begin{array}{l}\text { Random sequence genera- } \\
\text { tion (selection bias) }\end{array}$ & Low risk & $\begin{array}{l}\text { Quote: "In order to assure equal group sizes, participants were sorted by ex- } \\
\text { act date and time of enrolment and a fixed sequence of four numbers was as- } \\
\text { signed repeatedly." Not truly random method but still groups are well-bal- } \\
\text { anced }\end{array}$ \\
\hline
\end{tabular}


Skov-Ettrup 2016 (Continued)

Allocation concealment Low risk Quote: "The procedure was conducted by a research assistant who was blind(selection bias) ed to the participants' names and ID numbers during the procedure." "there is little indication of bias related to the allocation procedure, as the participants were unknown to the person allocating them and a large number of participants were allocated at the same time."
Blinding of outcome as- High risk sessment (detection bias)

All outcomes
Abstinence not biochemically validated. Level of personal contact differed between arms

Incomplete outcome data Low risk $\quad$ Attrition was low, $\sim 20 \%$ and similar across arms
(attrition bias)

(attrition bias)

All outcomes

Smith 2004

\begin{tabular}{|c|c|}
\hline Methods & $\begin{array}{l}\text { Setting: } 10 \text { communities, Canada } \\
\text { Recruitment: Volunteers calling a quitline } \\
\text { Randomisation: Ccentralised, stratified by community, sequential envelope, random sequence }\end{array}$ \\
\hline Participants & 632 smokers intending to quit; $39 \% \mathrm{M}$, av. age $42,61 \%$ had prior use of NRT \\
\hline Interventions & $\begin{array}{l}\text { Factorial design comparing } 2 \text { intensities of TC and } 2 \text { types of } \mathrm{S}-\mathrm{H} \text { (collapsed in this review) } \\
\text { 1. } 50 \text {-min proactive TC, quit date set, } 2 \text { calls at } 2 \text { and } 7 \text { days post-TQD } \\
\text { 2. As } 1 \text {, plus } 4 \text { further calls at } 14,21,35,40 \text { days } \\
\text { 3. Control: S-H only }\end{array}$ \\
\hline Outcomes & $\begin{array}{l}\text { Self-reported abstinence at } 12 \mathrm{~m} \text { (sustained). Also at } 3 \mathrm{~m} \text { and } 6 \mathrm{~m} \text { follow-ups, also PP } \\
\text { Validation: none }\end{array}$ \\
\hline Notes & $\begin{array}{l}\text { All TC arms compared to S-H-only control } \\
\text { Results not reported by factorial groups; "no significant interactions or main effects at any follow-up"; } \\
\text { no data from authors, estimate used in test of intensity. Findings sensitive to choice of outcome, con- } \\
\text { trol PP rates increase over time } \\
76 \% \text { received at least } 1 \text { call, } 22 \% \text { of intensive condition received all calls, } 56 \% \text { of minimal condition re- } \\
\text { ceived both calls }\end{array}$ \\
\hline
\end{tabular}

\section{Risk of bias}

\begin{tabular}{lll}
\hline Bias & Authors' judgement & Support for judgement \\
\hline $\begin{array}{l}\text { Random sequence genera- } \\
\text { tion (selection bias) }\end{array}$ & Unclear risk & Randomised, stratified by community, method not described \\
\hline $\begin{array}{l}\text { Allocation concealment } \\
\text { (selection bias) }\end{array}$ & Low risk & Quote: "opening next in a series of envelopes' after enrolment" \\
\hline $\begin{array}{l}\text { Blinding of outcome as- } \\
\text { sessment (detection bias) } \\
\text { All outcomes }\end{array}$ & High risk & $\begin{array}{l}\text { Self-reported outcomes from participants not blinded to treatment condition. } \\
\text { Level of personal contact differed between arms }\end{array}$ \\
\hline $\begin{array}{l}\text { Incomplete outcome data } \\
\text { (attrition bias) } \\
\text { All outcomes }\end{array}$ & Low risk & $\begin{array}{l}\text { 30\% not available at 12 m, no difference across } 5 \text { groups, missing treated as } \\
\text { smoking }\end{array}$ \\
\hline
\end{tabular}


Smith 2013

\begin{tabular}{ll} 
Methods & $\begin{array}{l}\text { Seting: Quitline, USA } \\
\text { Recruitment: Quitline callers, motivated }\end{array}$ \\
\hline Participants & 987 smokers, > 10 cigs/day, willing to set quit date within 30 days: av. age 42, av. cigs/day 21 \\
\hline Interventions & $\begin{array}{l}\text { Factorial trial testing medication adherence counselling, } 2 \text { vs } 6 \text { weeks NRT, and nicotine patch alone vs } \\
\text { patch + gum }\end{array}$ \\
& $\begin{array}{l}\text { All participants received the same standard TC: } 4 \text { sessions over } 4 \text { weeks } \\
\text { Medication adherence counselling involved additional content at each call assessing and addressing } \\
\text { adherence }\end{array}$
\end{tabular}

\begin{tabular}{|c|c|c|}
\hline Outcomes & \multicolumn{2}{|c|}{$\begin{array}{l}\text { Abstinence at } 6 \mathrm{~m} \text { (30-day PP). 7-day PP also reported } \\
\text { Validation: none }\end{array}$} \\
\hline Notes & \multicolumn{2}{|c|}{ Not included in any MA as tested adjuncts to TC, not the efficacy of TC. Results reported narratively } \\
\hline \multicolumn{3}{|l|}{ Risk of bias } \\
\hline Bias & Authors' judgement & Support for judgement \\
\hline $\begin{array}{l}\text { Random sequence genera- } \\
\text { tion (selection bias) }\end{array}$ & Low risk & List of randomised numbers \\
\hline $\begin{array}{l}\text { Allocation concealment } \\
\text { (selection bias) }\end{array}$ & Unclear risk & No details given \\
\hline $\begin{array}{l}\text { Blinding of outcome as- } \\
\text { sessment (detection bias) } \\
\text { All outcomes }\end{array}$ & Low risk & $\begin{array}{l}\text { Abstinence not biochemically validated, but similar levels of personal contact } \\
\text { in different study arms }\end{array}$ \\
\hline $\begin{array}{l}\text { Incomplete outcome data } \\
\text { (attrition bias) } \\
\text { All outcomes }\end{array}$ & Unclear risk & $24 \%$ lost at 6-m follow-up, no difference across treatment groups \\
\hline
\end{tabular}

Solomon 2000

\begin{tabular}{ll}
\hline Methods & $\begin{array}{l}\text { Setting: Community, USA } \\
\text { Recruitment: Volunteers for free nicotine patch trial }\end{array}$ \\
\hline Participants & 214 women smokers, > 4 cigs/day, intending to quit in next 2 weeks; av. age 33, av cigs/day 24 \\
\hline Interventions & $\begin{array}{l}\text { 1. Free nicotine patch (dose based on smoking level) for up to } 10 \text { weeks } \\
\text { 2. Free patch plus proactive TC from woman ex-smoker, } 7 \text { hours training. Calls for up to } 3 \mathrm{~m} \text {, starting } \\
\text { pre-quit, quit day, day 4, average } 7\end{array}$ \\
\hline Outcomes & $\begin{array}{l}\text { Abstinence at } 6 \mathrm{~m} \text { (7-day at } 3 \mathrm{~m} \text { and } 6 \mathrm{~m}) \\
\text { Validation: CO } \leq 8 \text { ppm. }\end{array}$ \\
& ters $12 \%$ disconfirmation rate. Participants who did not provide samples remained classified as quit- \\
\hline
\end{tabular}


Solomon 2000 (Continued)

Notes
Intervention participants received an average of 7 calls. $95 \%$ received at least 1 . Participants could call Nicoderm support line, $21 \%$ of control vs $8 \%$ of intervention did so

\section{Risk of bias}

\begin{tabular}{lll}
\hline Bias & Authors' judgement & Support for judgement \\
\hline $\begin{array}{l}\text { Random sequence genera- } \\
\text { tion (selection bias) }\end{array}$ & Unclear risk & Randomised, method not described \\
\hline $\begin{array}{l}\text { Allocation concealment } \\
\text { (selection bias) }\end{array}$ & Unclear risk & No details given \\
\hline $\begin{array}{l}\text { Blinding of outcome as- } \\
\text { sessment (detection bias) } \\
\text { All outcomes }\end{array}$ & High risk & $\begin{array}{l}\text { Biochemical validation but } 7 \%-12 \% \text { disconfirmation rate. Differential rates of } \\
\text { return at } 6 \text { m (59\% of self-reported quitters in intervention group and } 67 \% \text { in } \\
\text { control). Participants who did not provide samples classified as quitters }\end{array}$ \\
\hline $\begin{array}{l}\text { Incomplete outcome data } \\
\text { (attrition bias) }\end{array}$ & Low risk & $\sim 27 \%$ lost in both groups, included as smokers \\
\hline \begin{tabular}{l} 
All outcomes \\
\hline
\end{tabular} & & \\
\hline
\end{tabular}

\section{Solomon 2005}

\begin{tabular}{ll}
\hline Methods & $\begin{array}{l}\text { Setting: Community, USA } \\
\text { Recruitment: Volunteers for free nicotine patch trial }\end{array}$ \\
\hline Participants & 330 women smokers > 4 cigs /day, intending to quit in next 2 weeks; av. age 34, av. cigs/day 24 \\
\hline Interventions & $\begin{array}{l}\text { 1. Free nicotine patch (dose based on smoking level) for up to } 10 \text { weeks } \\
\text { 2. Free patch plus proactive TC from F ex-smoker, } 7 \text { hrs training. Calls for up to } 4 \mathrm{~m}, \text { up to } 12 \mathrm{~m}, \text { starting } \\
\text { pre-quit, quit day, day } 4\end{array}$ \\
\hline Outcomes & $\begin{array}{l}\text { Abstinence at } 6 \mathrm{~m} \text { (30-day at } 3 \mathrm{~m} \text { and } 6 \mathrm{~m} \text { ) } \\
\text { Validation: none }\end{array}$ \\
\hline Notes & $\begin{array}{l}\text { Replication of Solomon 2000 with more extended telephone contact } \\
\text { Average number of calls } 8.2, \text { average duration } 10 \text { mins }\end{array}$ \\
\hline
\end{tabular}

\section{Risk of bias}

\begin{tabular}{lll}
\hline Bias & Authors' judgement & Support for judgement \\
\hline $\begin{array}{l}\text { Random sequence genera- } \\
\text { tion (selection bias) }\end{array}$ & Unclear risk & Randomised, method not described \\
\hline $\begin{array}{l}\text { Allocation concealment } \\
\text { (selection bias) }\end{array}$ & Unclear risk & No details given \\
\hline $\begin{array}{l}\text { Blinding of outcome as- } \\
\text { sessment (detection bias) } \\
\text { All outcomes }\end{array}$ & High risk & $\begin{array}{l}\text { Self-reported outcomes from participants not blinded to treatment condition. } \\
\text { Level of personal contact differed between arms }\end{array}$ \\
\hline $\begin{array}{l}\text { Incomplete outcome data } \\
\text { (attrition bias) } \\
\text { All outcomes }\end{array}$ & Low risk & $13 \%$ lost to follow-up in both groups, included as smokers \\
\hline
\end{tabular}


Sood 2009

\begin{tabular}{ll}
\hline Methods & $\begin{array}{l}\text { Setting: ALA Quitline, USA } \\
\text { Recruitment: Quitline callers }\end{array}$ \\
\hline Participants & 990 callers; 38\% M, av. age 43, av. cigs/day 22 \\
\hline Interventions & $\begin{array}{l}\text { 1. Reactive counselling } \\
\text { 2. Mailed S-H materials (Freedom from Smoking) }\end{array}$
\end{tabular}

\begin{tabular}{ll}
\hline Outcomes & Abstinence at $12 \mathrm{~m}(\mathrm{PP})$ \\
& Validation: Saliva cotinine only for convenience sample, refusals not recorded
\end{tabular}

Notes Test of different interventions for people calling a quitline. Comparison 2

\section{Risk of bias}

\begin{tabular}{|c|c|c|}
\hline Bias & Authors' judgement & Support for judgement \\
\hline $\begin{array}{l}\text { Random sequence genera- } \\
\text { tion (selection bias) }\end{array}$ & Low risk & Random-number list created by independent statistician \\
\hline $\begin{array}{l}\text { Allocation concealment } \\
\text { (selection bias) }\end{array}$ & Low risk & $\begin{array}{l}\text { Enrolment and assignment by researchers independent of helpline staff. Con- } \\
\text { cealment until assigned }\end{array}$ \\
\hline $\begin{array}{l}\text { Blinding of outcome as- } \\
\text { sessment (detection bias) } \\
\text { All outcomes }\end{array}$ & Unclear risk & $\begin{array}{l}\text { Quote: "Interviewer assessing outcomes was blinded"; biochemical validation } \\
\text { in a convenience sample ( } 16 / 28 \text { agreed); participants who did not agree to bio- } \\
\text { chemical validation but self-reported abstinence counted as abstinent }\end{array}$ \\
\hline $\begin{array}{l}\text { Incomplete outcome data } \\
\text { (attrition bias) } \\
\text { All outcomes }\end{array}$ & Low risk & $47 \%$ loss to follow-up, similar across groups, included as smokers \\
\hline
\end{tabular}

Sorensen 2007a

\begin{tabular}{ll}
\hline Methods & $\begin{array}{l}\text { Setting: Workplaces, USA } \\
\text { Recruitment: Members of LIUNA (construction workers union), included non-smokers }\end{array}$ \\
\hline Participants & $\begin{array}{l}231 \text { smokers completed baseline survey. Demographics for all participants followed up; 94\% M, av. age } \\
\text { Interventions }\end{array}$ \\
\hline $\begin{array}{l}\text { 1. Proactive counselling; up to } 6 \text { calls over } 3 \text { m (fruit and veg consumption also addressed), tailored } \\
\text { feedback report and tip sheets, NRT offered to those interested in quitting }\end{array}$ \\
\hline Outcomes & $\begin{array}{l}\text { Abstinence at } 6 \text { m (7-day PP) } \\
\text { Validation: none }\end{array}$ \\
\hline Notes & Baseline denominators confirmed by author \\
\hline Risk of bias & Authors' judgement Support for judgement \\
\hline Bias &
\end{tabular}


Sorensen 2007a (Continued)

Random sequence genera- Unclear risk $\quad$ Randomised, method not described
tion (selection bias)

\begin{tabular}{ll}
\hline $\begin{array}{l}\text { Allocation concealment } \\
\text { (selection bias) }\end{array}$ & Unclear risk details given
\end{tabular}

\begin{tabular}{lll}
\hline $\begin{array}{l}\text { Blinding of outcome as- } \\
\text { sessment (detection bias) } \\
\text { All outcomes }\end{array}$ & High risk & $\begin{array}{l}\text { Self-reported outcomes from participants not blinded to treatment condition. } \\
\text { Level of personal contact differed between arms }\end{array}$ \\
\hline $\begin{array}{l}\text { Incomplete outcome data } \\
\text { (attrition bias) }\end{array}$ & Low risk \\
\begin{tabular}{l} 
All outcomes \\
\hline
\end{tabular}
\end{tabular}

\section{Stotts 2002}

\begin{tabular}{ll}
\hline Methods & $\begin{array}{l}\text { Setting: Antenatal clinics, USA } \\
\text { Recruitment: Pregnant continuing smokers }\end{array}$ \\
\hline Participants & 269 pregnant smokers at week 28; av. age 28, approx $50 \%$ smoked < 60 cigs/week \\
\hline Interventions & $\begin{array}{l}\text { All participants had received brief counselling and } 7 \text { mailed S-H booklets in early pregnancy } \\
1.20 \text { - 30-min MI-based proactive TC call in 28th - 30th week of pregnancy, tailored letter, 2nd call } \\
\text { 2. No further contact }\end{array}$ \\
\hline Outcomes & $\begin{array}{l}\text { Abstinence or 'a few puffs' at } 6 \text { m postpartum } \\
\text { Validation: none postpartum, cotinine at week } 34\end{array}$ \\
\hline Notes & The common intervention in early pregnancy was not treated as face-to-face contact within the trial. \\
$55 \%$ received complete intervention
\end{tabular}

\section{Risk of bias}

\begin{tabular}{lll}
\hline Bias & Authors' judgement & Support for judgement \\
\hline $\begin{array}{l}\text { Random sequence genera- } \\
\text { tion (selection bias) }\end{array}$ & Unclear risk & Randomised, method not described \\
\hline $\begin{array}{l}\text { Allocation concealment } \\
\text { (selection bias) }\end{array}$ & Unclear risk & No details given \\
\hline $\begin{array}{l}\text { Blinding of outcome as- } \\
\text { sessment (detection bias) } \\
\text { All outcomes }\end{array}$ & Unclear risk & $\begin{array}{l}\text { Although no biochemical validation postpartum, cotinine in subsample at } \\
\text { week 34; no differences between experimental and control groups; }\end{array}$ \\
& $\begin{array}{l}\text { Quote: "the urine samples appeared not to have been collected in a systemati- } \\
\text { cally biased manner." } \\
\text { Level of misreport and refusal not specified }\end{array}$ \\
\hline
\end{tabular}

Incomplete outcome data Unclear risk $\quad 39 \%$ lost at follow-up in both groups, assumed to be smoking
(attrition bias)

All outcomes 
Sumner 2016

Setting: Illinois and Missouri, USA; worksite employees \& spouses
Recruitment: Quote: "Participants called a toll free number (866-902-QUIT) to initiate enrolment. [...]
Both organizations promoted Call-2-Quit through multiple channels including health fairs, employee
web sites, employee news, promotional posters, fliers, and department managers. Each organization
promoted Call-2-Quit to help smokers adapt to tobacco control policies implemented during the trial.
In 2006, the hospital system implemented health insurance discounts of $\$ 10 / m o n t h$ for employees who
committed, during open enrolment in November, to pursue several health promoting activities. Smok-
ers obtained the discount by "enrolling" in a qualifying smoking
cessation program, such as Call-2-Quit"

Participants

518 employee and spouse smokers, 34\% M, av. age 46.5, av. cigs/day 12.9. Participants were seeking treatment as they called the toll-free number

Interventions

1. Directive telephone coaching - Directive coaching included the following distinctive features:

- Calls scheduled about 1 week apart, except calls \#4 and \#7

- Fixed topic schedule

2. Nondirective telephone coaching - Nondirective coaching included these distinctive features:

- 7 calls planned over 90 days, as convenient to smoker and coach

- Quit date set according to individual preference

- Coach offers topics at each call, smoker selects 1, or may choose a novel topic

There were up to 7 weekly calls, for 15 - 20 mins each

Outcomes Self-reported abstinence at $12 \mathrm{~m}$ (7-day PP)

Validation: mailed saliva cotinine assays or witnessed cheek swabs attempted, but low return rate

$\begin{array}{ll}\text { Notes } & \text { New for } 2018 \text { update } \\ \text { Funding: "The Centers for Disease Control grant number R01 DP000098 funded this study." } \\ \text { Declarations of interest: none declared }\end{array}$

\section{Risk of bias}

\begin{tabular}{|c|c|c|}
\hline Bias & Authors' judgement & Support for judgement \\
\hline $\begin{array}{l}\text { Random sequence genera- } \\
\text { tion (selection bias) }\end{array}$ & Low risk & $\begin{array}{l}\text { Quote: "New families were randomized to directive or nondirective coaching } \\
\text { mode in a 1:1 ratio, based on a randomization table, when the first member } \\
\text { enrolled. Consent to randomization was required to participate." }\end{array}$ \\
\hline $\begin{array}{l}\text { Allocation concealment } \\
\text { (selection bias) }\end{array}$ & Low risk & $\begin{array}{l}\text { Quote: "After baseline data were entered, members of a previously random- } \\
\text { ized family were assigned to the family coaching mode." }\end{array}$ \\
\hline $\begin{array}{l}\text { Blinding of outcome as- } \\
\text { sessment (detection bias) } \\
\text { All outcomes }\end{array}$ & Low risk & $\begin{array}{l}\text { Outcome validation attempted but low return rate. Similar levels of personal } \\
\text { contact in different study arms }\end{array}$ \\
\hline $\begin{array}{l}\text { Incomplete outcome data } \\
\text { (attrition bias) } \\
\text { All outcomes }\end{array}$ & High risk & $\begin{array}{l}\text { After } 12 \text { months of follow-up the proportion lost to follow-up was larger than } \\
\text { half the initial sample, although similar across arms }\end{array}$ \\
\hline
\end{tabular}

Methods Setting: Group Health Co-operative, USA


Swan 2003 (Continued)

Recruitment: Volunteers for a trial of medication

\begin{tabular}{|c|c|c|}
\hline Participants & \multicolumn{2}{|c|}{1524 smokers $\geq 10$ cigs/day; $43 \%$ M, av. age 45 , av. cigs/day $23,44 \%$ history of depression } \\
\hline Interventions & \multicolumn{2}{|c|}{$\begin{array}{l}\text { Proactive } \\
\text { Factorial design, } 300 \mathrm{mg} / \text { day and } 150 \mathrm{mg} / \text { day bupropion doses collapsed. Prescription was mailed. No } \\
\text { face-to-face contact during enrolment or treatment } \\
\text { 1. Free \& Clear proactive TC ( } 4 \text { brief calls), access to quitline and S-H materials } \\
\text { 2. Zyban Advantage Program (ZAP) tailored S-H materials, single telephone call after TQD, access to } \\
\text { Zyban (bupropion) support line }\end{array}$} \\
\hline Outcomes & \multicolumn{2}{|c|}{$\begin{array}{l}\text { Abstinence at } 12 \mathrm{~m} \text { (7-day PP) } \\
\text { Validation: none }\end{array}$} \\
\hline Notes & \multicolumn{2}{|c|}{$\begin{array}{l}\text { Compares different intensities of TC. No dose/behavioural treatment interaction at } 12 \mathrm{~m} \text { so bupropion } \\
\text { arms collapsed }\end{array}$} \\
\hline \multicolumn{3}{|l|}{ Risk of bias } \\
\hline Bias & Authors' judgement & Support for judgement \\
\hline $\begin{array}{l}\text { Random sequence genera- } \\
\text { tion (selection bias) }\end{array}$ & Low risk & Randomisation procedure built into study database \\
\hline $\begin{array}{l}\text { Allocation concealment } \\
\text { (selection bias) }\end{array}$ & Low risk & Procedure ensured concealment \\
\hline $\begin{array}{l}\text { Blinding of outcome as- } \\
\text { sessment (detection bias) } \\
\text { All outcomes }\end{array}$ & High risk & $\begin{array}{l}\text { Self-reported outcomes from participants not blinded to treatment condition. } \\
\text { Level of personal contact differed between arms }\end{array}$ \\
\hline $\begin{array}{l}\text { Incomplete outcome data } \\
\text { (attrition bias) } \\
\text { All outcomes }\end{array}$ & Low risk & Loss to follow-up at $12 \mathrm{~m} 17 \%$ Intervention, $12 \%$ Control, treated as smokers \\
\hline
\end{tabular}

\section{Swan 2010}

\begin{tabular}{ll}
\hline Methods & Setting: Community, Idaho and Washington, USA \\
& Recruitment: Community advertising, physician referral, and quitline callers \\
\hline Participants & $\begin{array}{l}1202 \text { adult current smokers of at least } 10 \text { cigs/day in past year and } 5 \text { cigs/day in past week, motivated to } \\
\text { quit. } 33.1 \% \text { M; av. age } 47.3 ; \text { av. cigs/day } 19.7 ; \text { av.FTND } 4.9\end{array}$
\end{tabular}

Interventions All participants received: 12-week course of varenicline; 5 - 10-min orientation call; S-H materials; access to toll-free support line for ad hoc calls

1. Telephone counselling. Proactive; from quitline counsellor using MI techniques; max 5 calls

2. Web programme with standardised content and interactive tools modelled on those used in phone intervention

3. 1+2. Phone counsellors had access to info participants entered online

\begin{tabular}{ll}
\hline Outcomes & Abstinence at $6 \mathrm{~m}$ (30-day PP) (abstinence at $3 \mathrm{~m}, 7$-day PP also reported) \\
& Validation: none
\end{tabular}


Swan 2010 (Continued)

Notes

Number abstinent not provided, estimated from percentages given in published report

TC and TC+web had similar outcomes so pooled $1+3$ vs 2

\section{Risk of bias}

\begin{tabular}{lll}
\hline Bias & Authors' judgement & Support for judgement \\
\hline $\begin{array}{l}\text { Random sequence genera- } \\
\text { tion (selection bias) }\end{array}$ & Low risk & $\begin{array}{l}\text { Quote: "Group assignment was randomly allocated using an automated algo- } \\
\text { rithm built into the study database" }\end{array}$ \\
\hline $\begin{array}{l}\text { Allocation concealment } \\
\text { (selection bias) }\end{array}$ & Low risk & Central computerised allocation, see above \\
\hline $\begin{array}{l}\text { Blinding of outcome as- } \\
\text { sessment (detection bias) } \\
\text { All outcomes }\end{array}$ & High risk & $\begin{array}{l}\text { Self-reported outcome measure used from participants not blinded to treat- } \\
\text { ment condition. Level of personal contact differed between arms }\end{array}$ \\
\hline $\begin{array}{l}\text { Incomplete outcome data } \\
\text { (attrition bias) } \\
\text { All outcomes }\end{array}$ & Low risk & $\begin{array}{l}\text { Participants lost to follow-up counted as smokers in ITT analysis; equal losses } \\
\text { between groups (103 Web, 107 Phone, 100 Web + phone) }\end{array}$ \\
\hline
\end{tabular}

Thomas 2016

\begin{tabular}{|c|c|}
\hline Methods & $\begin{array}{l}\text { Setting: Minnesota, Ohio, Texas, Wisconsin, USA; higher education students } \\
\text { Recruitment: Quote: "e-mails and promotional postcards direct-mailed to all enrolled students" }\end{array}$ \\
\hline Participants & $\begin{array}{l}1217 \text { adult undergraduate smokers willing to set a quit date approximately } 1 \text { month from study eligibil- } \\
\text { ity assessment, } 45 \% \mathrm{M} \text {, av. age } 26.2 \text {, av. cigs/day } 11.5\end{array}$ \\
\hline Interventions & $\begin{array}{l}\text { 1. No TC } \pm \text { single/multiple contests } \\
\text { 2. TC } \pm \text { single/multiple contests: } 6 \text { telephone-administered Motivation and problem solving (MAPS) } \\
\text { counselling sessions during the } 12 \text { week treatment, each over } 20 \text { minutes, } 10 \text { days prior to quit date, } \\
\text { and at the discretion of the participant }\end{array}$ \\
\hline Outcomes & $\begin{array}{l}\text { Abstinence at } 6 \text { months (continuous) } \\
\text { Validation: Biochemical verification using urine, using NicCheck and (if NicCheck was negative) NicAlert } \\
\text { test strips to verify self-reported abstinence. Also, Quote: "if a participant reported that he or she had } \\
\text { used NRT within the past } 7 \text { days, the sample was sent instead to the laboratory for analysis of concen- } \\
\text { trations of anatabine/anabasine" }\end{array}$ \\
\hline
\end{tabular}

Notes

New for 2018 update

Funding: "This study was funded by the National Heart, Lung, and Blood Institute (5R01-

HL094183-04S1, J.L.T., Principle Investigator)."

Declarations of interest: none reported

\section{Risk of bias}

\begin{tabular}{lll}
\hline Bias & Authors' judgement & Support for judgement \\
\hline $\begin{array}{l}\text { Random sequence genera- } \\
\text { tion (selection bias) }\end{array}$ & Unclear risk & Not stated \\
\hline \hline
\end{tabular}

Telephone counselling for smoking cessation (Review) 
Thomas 2016 (Continued)

\begin{tabular}{lll}
$\begin{array}{l}\text { Allocation concealment } \\
\text { (selection bias) }\end{array}$ & Unclear risk & Not stated \\
\hline $\begin{array}{l}\text { Blinding of outcome as- } \\
\text { sessment (detection bias) } \\
\text { All outcomes }\end{array}$ & Low risk & $\begin{array}{l}\text { Not blinded but biochemical validation so differential misreport judged un- } \\
\text { likely }\end{array}$ \\
\hline $\begin{array}{l}\text { Incomplete outcome data } \\
\text { (attrition bias) } \\
\text { All outcomes }\end{array}$ & Low risk & $\begin{array}{l}\text { Around } 19 \% \text { of participants did not complete or were lost to follow-up (simi- } \\
\text { lar } n \text { lost to follow-up in each arm }(1.47 / 306 ; 2.50 / 309 ; 3 / 67 / 296 ; 4.71 / 306) . \\
\text { Authors tested impact in sensitivity analyses and state it did not affect conclu- } \\
\text { sions }\end{array}$
\end{tabular}

Thompson 1993

\begin{tabular}{ll} 
Methods & $\begin{array}{l}\text { Setting: Workplace and community, USA } \\
\text { Recruitment: Callers to a hotline, initially from 4 workplaces, targeting blue-collar workers, widened } \\
\text { to general community to meet targets. Callers gave oral consent and baseline assessment of smoking } \\
\text { characteristics prior to randomisation }\end{array}$ \\
\hline Participants & $\begin{array}{l}382 \text { (341 smokers, } 41 \text { recent quitters). Most in contemplation or action SoC, 24\% 'blue-collar', 41\% M, } \\
\text { av. age } 41, \text { av. cigs/day } 18 \text { - } 22\end{array}$ \\
\hline Interventions & $\begin{array}{l}\text { 1. Callers to hotline received general information based on fact sheets, and sent S-H material } \\
\text { 2. Callers were given information based on stage, and encouraged to take next step in cessation } \\
\text { process. Script tailored to blue-collar workers using focus groups }\end{array}$ \\
\hline Outcomes & $\begin{array}{l}\text { Abstinence at } 6 \text { m (PP) (subset followed to } 12 \text { m) } \\
\text { Validation: saliva samples sought but not tested. Surrogates asked to confirm status }\end{array}$ \\
\hline Notes & $\begin{array}{l}\text { Comparison between stage-based and non-specific brief counselling } \\
\text { The stage-model counselling was based on the approach used by the NCIS. Kinne } 1991 \text { gives data } \\
\text { about call rates from original target worksites. Average call length } 34 \text { mins for stage-based, } 20 \text { mins for } \\
\text { standard }\end{array}$ \\
\hline
\end{tabular}

\section{Risk of bias}

\begin{tabular}{lll}
\hline Bias & Authors' judgement & Support for judgement \\
\hline $\begin{array}{l}\text { Random sequence genera- } \\
\text { tion (selection bias) }\end{array}$ & Unclear risk & Randomised, method not described \\
\hline $\begin{array}{l}\text { Allocation concealment } \\
\text { (selection bias) }\end{array}$ & Unclear risk & No details given \\
\hline $\begin{array}{l}\text { Blinding of outcome as- } \\
\text { sessment (detection bias) } \\
\begin{array}{l}\text { All outcomes } \\
\text { Incomplete outcome data }\end{array}\end{array}$ & Low risk & Saliva samples sought but not tested; surrogates asked to confirm status \\
$\begin{array}{l}\text { (attrition bias) } \\
\text { All outcomes }\end{array}$ & \\
\hline
\end{tabular}


Tzelepis 2011a

Methods
Setting: Community, New South Wales, Australia
$\begin{aligned} & \text { Recruitment: Active telephone recruitment (cold-calling) of NSW residents, motivation to quit not re- } \\ & \text { quired }\end{aligned}$

\begin{tabular}{ll}
\hline Participants & 1562 adult daily smokers. 50\% M, av. cigs/day 19.4, av. age 45 \\
\hline Interventions & $\begin{array}{l}1.6 \text { proactive counselling calls for smokers willing to quit within } 1 \mathrm{~m}, 4 \text { for those not willing using MI } \\
\text { techniques. Those who relapsed and set new quit date within a month offered additional } 5 \text { calls; those } \\
\text { relapsed but did not set quit date offered a call in } 1 \mathrm{~m} \text {. Those initially not willing to quit who became } \\
\text { motivated to quit offered additional } 5 \text { support calls. Standard S-H materials }\end{array}$
\end{tabular}

\section{S-H materials only}

Outcomes Self-reported abstinence at $13 \mathrm{~m}$ (prolonged for $12 \mathrm{~m}$ with $1 \mathrm{~m}$ grace period). Other prolonged and PP rates at $4,7,13 \mathrm{~m}$ also reported

Validation: none

Notes $\quad 7.8 \%$ of control group called quitline during study period.

\section{Risk of bias}

\begin{tabular}{lll}
\hline Bias & Authors' judgement & Support for judgement \\
\hline $\begin{array}{l}\text { Random sequence genera- } \\
\text { tion (selection bias) }\end{array}$ & Low risk & Quote: "random number generator" \\
\hline $\begin{array}{l}\text { Allocation concealment } \\
\text { (selection bias) }\end{array}$ & Low risk & $\begin{array}{l}\text { Quote: "computer assisted telephone interview used a random number gener- } \\
\text { ator created by an independent programmer to allocate the smoker" }\end{array}$ \\
\hline $\begin{array}{l}\text { Blinding of outcome as- } \\
\text { sessment (detection bias) }\end{array}$ & High risk & $\begin{array}{l}\text { Self-reported outcome measure used, participants not blinded to treatment } \\
\text { condition. Level of personal contact differed between arms }\end{array}$ \\
\hline $\begin{array}{l}\text { Incomplete outcome data } \\
\text { (attrition bias) }\end{array}$ & Unclear risk & $\begin{array}{l}\text { Participants lost to follow-up counted as smokers; similar numbers in both } \\
\text { All outcomes }\end{array}$ \\
\hline
\end{tabular}

Vander Weg 2016

\begin{tabular}{ll} 
Methods & Setting: USA; rural setting \\
& $\begin{array}{l}\text { Recruitment: People meeting basic eligibility criteria were sent a letter offering them participation in } \\
\text { the trial, to which they could respond by returning a self-addressed postcard or contacting study staff } \\
\text { by phone. Those expressing interest were mailed an informed consent document and baseline ques- } \\
\text { tionnaire, which included Vander Weg et al. BMC Public Health (2016) 16:811 Page } 2 \text { of } 11 \text { screening } \\
\text { items to assess for eligibility for the supplemental behavioral counselling modules (described below) }\end{array}$ \\
\hline Participants & $\begin{array}{l}63 \text { rural Veteran daily cigarette smokers who were interested in quitting, } 87.3 \% \text { M, av. age } 56.8, \text { av. cigs/ } \\
\text { day } 24.7\end{array}$ \\
\hline $\begin{array}{l}\text { 1. Referral to state tobacco quitline: Referred by fax to the tobacco quitline for their state of residence. } \\
\text { Quitlines subsequently contacted participants to initiate treatment }\end{array}$ \\
$\begin{array}{l}\text { 2. Tailored telephone counselling: Combines counselling on tobacco use and related issues including } \\
\text { depressive symptoms, risky alcohol use, and weight concerns. } 6 \text { calls, } 1 \text { per week, for } 20 \text { - } 30 \text { mins }\end{array}$
\end{tabular}


Vander Weg 2016 (Continued)

The approach to pharmacotherapy was the same for both groups - NRT, bupropion, varenicline

\begin{tabular}{ll}
\hline Outcomes & Self-reported abstinence at $6 \mathrm{~m}$ (7-day PP) \\
& Validation: none \\
\hline Notes & New for 2018 update \\
& $\begin{array}{l}\text { Funding: "The work reported in this manuscript was funded by the Department of Veterans Affairs Of- } \\
\text { fice of Rural Health (Project number 12-CR6)." } \\
\text { Declarations of interest: none declared }\end{array}$
\end{tabular}

\section{Risk of bias}

\begin{tabular}{|c|c|c|}
\hline Bias & Authors' judgement & Support for judgement \\
\hline $\begin{array}{l}\text { Random sequence genera- } \\
\text { tion (selection bias) }\end{array}$ & Low risk & $\begin{array}{l}\text { Quote: "randomly assigned to treatment conditions based on a computer-gen- } \\
\text { erated algorithm on a 1:1 allocation ratio using simple randomization without } \\
\text { blocking. The computerized random allocation sequence was generated by } \\
\text { the study data manager." }\end{array}$ \\
\hline $\begin{array}{l}\text { Allocation concealment } \\
\text { (selection bias) }\end{array}$ & Unclear risk & Not described \\
\hline $\begin{array}{l}\text { Blinding of outcome as- } \\
\text { sessment (detection bias) } \\
\text { All outcomes }\end{array}$ & High risk & $\begin{array}{l}\text { Abstinence not biochemically validated. Level of personal contact differed be- } \\
\text { tween arms }\end{array}$ \\
\hline $\begin{array}{l}\text { Incomplete outcome data } \\
\text { (attrition bias) } \\
\text { All outcomes }\end{array}$ & Low risk & $\begin{array}{l}\text { Dropout was twice as high in the tailored intervention as in the standard to- } \\
\text { bacco quitline group }\end{array}$ \\
\hline
\end{tabular}

Velicer 2006

\begin{tabular}{ll}
\hline Methods & Setting: Community, USA \\
& Recruitment: Proactive approach to smokers at Veterans Administration Medical Centre. Passive con- \\
sent by mail then phone screening, not selected for motivation
\end{tabular}

Participants
2054 smokers (1009 in relevant arms); 76\% M, av. age 51, 40\% precontemplators, $40 \%$ contemplators, $20 \%$ preparers

Interventions
1. Stage-based S-H manuals; participants sent manual for current stage and next stage. (not used in this review)
2. As 1 , plus 6 -week nicotine patch if in appropriate stage, reassessed for NRT eligibility at 6 and $10 \mathrm{~m}$ (not used in this review)
3. As 2, plus 1 expert system written feedback report
4. As 3, plus regular automated TC (pre-recorded voice files tailored to responses). People receiving NRT had weekly calls in month 1 , biweekly in month 2 , then monthly to month 6 . People not receiving NRT had monthly calls. Participants could also initiate calls

\begin{tabular}{ll}
\hline Outcomes & $\begin{array}{l}\text { Self-reported abstinence at } 30 \mathrm{~m} \text { (sustained for } 6 \mathrm{~m} \text { ) } \\
\text { Validation: none }\end{array}$ \\
\hline Notes & $\begin{array}{l}\text { Comparison of arms } 4 \text { vs } 3 \text { for proactive TC. In NRT eligible groups } 350(67 \%) \text { received NRT at baseline } \\
\text { and } 448(86 \%) \text { received NRT at some point, so classified as adjunct to pharmacotherapy, and in }>6 \text { call } \\
\text { category }\end{array}$ \\
\hline
\end{tabular}


Velicer 2006 (Continued)

Risk of bias

\begin{tabular}{lll}
\hline Bias & Authors' judgement & Support for judgement \\
\hline $\begin{array}{l}\text { Random sequence genera- } \\
\text { tion (selection bias) }\end{array}$ & Low risk & Computer-based random-number generator \\
\hline $\begin{array}{l}\text { Allocation concealment } \\
\text { (selection bias) }\end{array}$ & Low risk & $\begin{array}{l}\text { Allocation done after completion of survey. randomised participants who did } \\
\text { not return consent form are excluded from further analyses }\end{array}$ \\
\hline $\begin{array}{l}\text { Blinding of outcome as- } \\
\text { sessment (detection bias) } \\
\text { All outcomes }\end{array}$ & High risk & $\begin{array}{l}\text { Self-reported outcomes from participants not blinded to treatment condition. } \\
\text { Level of personal contact differed between arms }\end{array}$ \\
\hline $\begin{array}{l}\text { Incomplete outcome data } \\
\text { (attrition bias) }\end{array}$ & Low risk & $\begin{array}{l}\text { 39\% lost includes 8\% refused by 30 m, no significant differences between } \\
\text { gll outcomes }\end{array}$ \\
\hline
\end{tabular}

\title{
Warner 2016
}

Setting: Olmsted County, MN, USA; hospital-based
Recruitment: Identified through electronic medical records. Study personnel then approached the po-
tential participants to confirm eligibility

Participants 600 adult smokers, $51 \%$ M, av. age 46.3, av. cigs/day 14.4

Interventions

\begin{abstract}
1. Brief ( ${ }^{5}$-min) cessation advice: Quote: "Consisted of the first four of the 5A's (Ask, Advise, Assess, Assist, and Arrange), including advice and brief assistance in reviewing tips to help maintain abstinence using a brochure. The brochure included the study quitline number but did not specifically encourage its use."

2. Brief ( 5 -minute) quitline facilitation intervention: Quote: "A single brief quitline facilitation intervention (also 5 minutes in duration, slightly modified from that piloted in the authors' prior studies of presurgical patients) was delivered. Based on principles of Social Cognitive Therapy, it included advice to quit and quitline information. Its purpose was to facilitate quitline utilization, not to provide assistance with quitting, but to overcome cognitive barriers to quitline utilization. A written brochure that included information about the quitline and a wallet-sized "quit-card" were provided. If patients were amenable, study personnel then contacted the quitline provider, preferably by direct phone call ("warm handoff") to enroll the patient for quitline services and arrange for an initial counseling call. If this direct contact could not be made, faxed referrals were sent to the quitline provider. Based on early experiences that it was difficult for the quitline to re-contact patients while in hospital, the goal was to complete the first counseling session immediately after the in-hospital quitline intake. Subsequent counseling sessions were scheduled by quitline counselors."
\end{abstract}

NRT was offered to all participants: free 2-week supply of nicotine patches

\begin{tabular}{ll}
\hline Outcomes & Abstinence at $6 \mathrm{~m}$ (7-day PP) \\
& Validation: Urine anabasine levels $<2 \mathrm{ng} / \mathrm{mL}$ \\
\hline Notes & New for 2018 update \\
& Funding: "This work was supported by grant RC-2012-0001 from ClearWay Minnesota." \\
& Declarations of interest: none reported \\
\hline
\end{tabular}


Warner 2016 (Continued)

Risk of bias

\begin{tabular}{lll}
\hline Bias & Authors' judgement & Support for judgement \\
\hline $\begin{array}{l}\text { Random sequence genera- } \\
\text { tion (selection bias) }\end{array}$ & Low risk & $\begin{array}{l}\text { Quote: "using dynamic randomization allocation based on the Mayo Clinic } \\
\text { Study Data Management System, a proprietary web application for data entry } \\
\text { and management. Randomization was stratified based on nursing unit to en- } \\
\text { sure the number of subjects assigned to each of the two intervention groups } \\
\text { remained balanced within that unit, enhancing the homogeneity of admitting } \\
\text { diagnoses between groups" }\end{array}$ \\
&
\end{tabular}

\begin{tabular}{l}
$\begin{array}{l}\text { Allocation concealment } \\
\text { (selection bias) }\end{array}$ \\
\hline
\end{tabular}

\begin{tabular}{ll}
\hline Blinding of outcome as- & Low risk \\
sessment (detection bias) & \\
All outcomes & \\
\hline
\end{tabular}

Incomplete outcome data Low risk Low attrition $30 \%$ and comparable across arms

(attrition bias)

All outcomes

\begin{tabular}{ll} 
Wu 2017 & \\
\hline Methods & $\begin{array}{l}\text { Setting: Beijing, China; } 2 \text { Endocrinology and Acupuncture out-patient clinics of a general hospital } \\
\text { Recruitment: Asked all people who attended the clinic for participation in the study }\end{array}$ \\
\hline Participants & $\begin{array}{l}369 \text { adult smokers who smokers } 10 \text { or more cigs/day and were not interested in quitting, } 100 \% \text { M, av. } \\
\text { age } 40,43 \% 10-19 \text { cigs/day, } 57 \% \geq 20 \text { cigs/day }\end{array}$ \\
\hline Interventions & $\begin{array}{l}\text { 1. Exercise and diet advice (EDA) control group } \\
\text { 2. Smoking-reduction intervention (SRI) group }\end{array}$ \\
& $\begin{array}{l}\text { Both groups received a single face-to-face brief advice ( } 1 \text { min) }+5 \times \text { TC follow-up sessions of the same } \\
\text { duration ( } 1 \text { min) after } 1 \text { week, and after } 1,3,6 \text { and } 12 \text { m }\end{array}$ \\
\hline Outcomes & $\begin{array}{l}\text { Abstinence at } 12 \text { m (7-day PP) } \\
\text { Validation: Exhaled CO level < } 6 \text { ppm }\end{array}$ \\
\hline New for 2018 update \\
Funding: "This study was supported by a research grant from the National Natural Science Founda- \\
tion of China ( 81373080$)$, a research grant from the Beijing Municipal Science and Technology Commis- \\
sion (Z121107001012070) and Clinical Research Grants from the Chinese PLA General Hospital (2013FC- \\
TSYS-1021 and MJ201447)." \\
Declarations of interest: none reported
\end{tabular}

\section{Risk of bias}

\begin{tabular}{lll}
\hline Bias & Authors' judgement & Support for judgement \\
\hline $\begin{array}{l}\text { Random sequence genera- } \\
\text { tion (selection bias) }\end{array}$ & Low risk & $\begin{array}{l}\text { Quote: "A research assistant of the project generated the random numbers for } \\
\text { group assignment using a computer" }\end{array}$ \\
\hline $\begin{array}{l}\text { Allocation concealment } \\
\text { (selection bias) }\end{array}$ & Low risk & $\begin{array}{l}\text { Quote: "After written consent, a trained counsellor who was not involved in } \\
\text { preparing the randomization sequence opened a serially numbered, opaque }\end{array}$ \\
\hline
\end{tabular}

Telephone counselling for smoking cessation (Review) 
Wu 2017 (Continued)

and sealed envelope with a card inside indicating intervention or control and randomly allocated the participant accordingly, thus ensuring allocation concealment"

\begin{tabular}{|c|c|c|}
\hline $\begin{array}{l}\text { Blinding of outcome as- } \\
\text { sessment (detection bias) } \\
\text { All outcomes }\end{array}$ & Low risk & $\begin{array}{l}\text { Biochemically-validated outcome. Validation rate achieved } 43.2 \% \text { by February } \\
2017 \text { ( } 45.8 \% \text { in the SRI group and } 38.5 \% \text { in the EDA control group) }\end{array}$ \\
\hline $\begin{array}{l}\text { Incomplete outcome data } \\
\text { (attrition bias) } \\
\text { All outcomes }\end{array}$ & Low risk & $\begin{array}{l}\text { Percentage of participants lost to follow-up was around } 30 \% \text { and similar } \\
\text { across groups. There were no differences between those who completed and } \\
\text { those who were lost to follow-up }\end{array}$ \\
\hline
\end{tabular}

Young 2008

\begin{tabular}{ll}
\hline Methods & $\begin{array}{l}\text { Setting: General practices, Australia } \\
\text { Recruitment: People attending for routine consultations, not selected for motivation }\end{array}$ \\
\hline Participants & 318 smokers; $47 \% \mathrm{M}$, av. age 37, modal cigs/day $11-20,56 \%$ in contemplation/precontemplation \\
\hline Interventions & $\begin{array}{l}\text { 1. GP offered referral; telephone call from a nurse trained in cessation within } 3 \text { days. } 5 \text { As counselling } \\
\text { framework. If willing to make a quit attempt mailed quit kit, encouraged to buy NRT, phoned again on } \\
\text { TQD, } 1 \text { week, } 3 \text { weeks } \\
\text { 2. Usual care (GPs given quit kits to distribute to participants) }\end{array}$ \\
\hline Outcomes & $\begin{array}{l}\text { Abstinence at } 12 \mathrm{~m} \text { (PP) } \\
\text { Validation: none }\end{array}$ \\
\hline Notes & $\begin{array}{l}\text { We classified control as minimal intervention rather than brief intervention, MA not sensitive to classi- } \\
\text { fication. Referral was to a research nurse not to a dedicated quitline. } 5 \text { control participants received in- } \\
\text { tervention, analysed with controls as ITT }\end{array}$ \\
\hline
\end{tabular}

\section{Risk of bias}

\begin{tabular}{lll}
\hline Bias & Authors' judgement & Support for judgement \\
\hline $\begin{array}{l}\text { Random sequence genera- } \\
\text { tion (selection bias) }\end{array}$ & Low risk & $\begin{array}{l}\text { Questionnaires randomly ordered and coded prior to delivery to the practice } \\
\text { by selecting sequential numbers from a computer-generated random-number } \\
\text { list. }\end{array}$ \\
\hline $\begin{array}{l}\text { Allocation concealment } \\
\text { (selection bias) }\end{array}$ & Unclear risk & $\begin{array}{l}\text { Participants (including non-smokers) completed the precoded questionnaire } \\
\text { before the consultation. GP identified allocation from unobtrusive marks on } \\
\text { questionnaire, could not influence allocation. But unclear whether selection } \\
\text { bias by recruiters, given imbalance in numbers }\end{array}$ \\
\hline
\end{tabular}

\begin{tabular}{lll}
\hline $\begin{array}{l}\text { Blinding of outcome as- } \\
\text { sessment (detection bias) }\end{array}$ & High risk & $\begin{array}{l}\text { Self-reported outcomes from participants not blinded to treatment condition. } \\
\text { Level of personal contact differed between arms }\end{array}$ \\
All outcomes &
\end{tabular}

$\begin{aligned} & \text { Incomplete outcome data } \\ & \text { (attrition bias) }\end{aligned}$
L Low risk $\quad 31 \%$ Intervention, 41\% Control lost to follow-up, included as smokers

All outcomes 


\section{Zhu 1996}

\begin{tabular}{ll}
\hline Methods & Setting: Quitline, USA \\
Recruitment: Callers to a quitline
\end{tabular}

\begin{tabular}{ll}
\hline Participants & $\begin{array}{l}3030 \text { smokers calling smokers' helpline and were ready to quit in next week; 43\% M, av. age 36, av. cigs/ } \\
\text { day } 20\end{array}$ \\
\hline Interventions & $\begin{array}{l}\text { 1. S-H materials only } \\
\text { 2. S-H materials and } 50 \text {-min pre-quit TC } \\
\text { 3. As 2, plus up to } 5 \text { further sessions of TC at } 1,3,7,14 \text { and } 30 \text { days }\end{array}$ \\
\hline Outcomes & Abstinence at $13 \mathrm{~m}$ (sustained for $12 \mathrm{~m}$ ) \\
Validation: Cotinine $<10 \mathrm{mg} / \mathrm{nl}$ in a convenience sample \\
Notes & $\begin{array}{l}\text { Arms } 2 \text { and } 3 \text { vs } 1 . \text { Arms } 3 \text { vs } 2 \text { in effect of multiple sessions } \\
\text { Approx } 65 \% \text { of single session and } 67 \% \text { of multisession group received some counselling. Multisession } \\
\text { participants received } 4 \text { calls on average }\end{array}$
\end{tabular}

\section{Risk of bias}

\begin{tabular}{lll}
\hline Bias & Authors' judgement & Support for judgement \\
\hline $\begin{array}{l}\text { Random sequence genera- } \\
\text { tion (selection bias) }\end{array}$ & High risk & Pseudo-random, according to last 2 digits of telephone number \\
\hline $\begin{array}{l}\text { Allocation concealment } \\
\text { (selection bias) }\end{array}$ & High risk & Potential for selection bias but unlikely, given low contact \\
\hline $\begin{array}{l}\text { Blinding of outcome as- } \\
\text { sessment (detection bias) } \\
\text { All outcomes }\end{array}$ & Low risk & $\begin{array}{l}\text { Biochemical validation in a convenience sample. Disconfirmation rate not } \\
\text { used to correct data, but refusal and misreport rates similar in all groups }\end{array}$ \\
\hline $\begin{array}{l}\text { Incomplete outcome data } \\
\text { (attrition bias) } \\
\text { All outcomes }\end{array}$ & Low risk & $12 \%-16 \%$ lost to follow-up at 13 m, included as smokers \\
\hline
\end{tabular}

\section{Zhu 2002}

\begin{tabular}{ll}
\hline Methods & $\begin{array}{l}\text { Setting: Quitline, USA } \\
\text { Recruitment: Callers to a quitline }\end{array}$ \\
\hline Participants & $\begin{array}{l}3282 \text { smokers calling quitline, ready to quit within } 1 \text { week and wanting counselling; 44\% M, av. age 38, } \\
\text { av. cigs/day } 20\end{array}$ \\
\hline Interventions & $\begin{array}{l}\text { 1. S-H pack, motivational materials, counselling provided if smoker made contact to request it } \\
\text { Self-efficacy, social support, planning, relapse prevention } 3 \text { m. Included quitting history, motivation, }\end{array}$ \\
\hline Outcomes & $\begin{array}{l}\text { Self-reported abstinence at } 13 \text { m (sustained for } 12 \text { m) } \\
\text { Validation: none }\end{array}$ \\
\hline Notes & $\begin{array}{l}\text { Authors also analysed subgroups of controls who did and did not seek counselling. 32\% of Control and } \\
72 \% \text { of Intervention group received counselling }\end{array}$ \\
\hline
\end{tabular}

\section{Risk of bias}


Zhu 2002 (Continued)

\begin{tabular}{lll} 
Bias & Authors' judgement & Support for judgement \\
\hline $\begin{array}{l}\text { Random sequence genera- } \\
\text { tion (selection bias) }\end{array}$ & Unclear risk & $\begin{array}{l}\text { Randomised, method not described. 60/40 split. Only randomised when coun- } \\
\text { selling demand exceeded capacity }\end{array}$ \\
\hline $\begin{array}{l}\text { Allocation concealment } \\
\text { (selection bias) }\end{array}$ & Unclear risk & No details given \\
\hline $\begin{array}{l}\text { Blinding of outcome as- } \\
\text { sessment (detection bias) } \\
\text { All outcomes }\end{array}$ & High risk & $\begin{array}{l}\text { Self-reported outcomes from participants not blinded to treatment condition. } \\
\text { Level of personal contact differed between arms }\end{array}$ \\
\hline $\begin{array}{l}\text { Incomplete outcome data } \\
\text { (attrition bias) } \\
\text { All outcomes }\end{array}$ & Low risk & $\sim 30 \%$ lost to follow-up at $13 \mathrm{~m}$ in both groups, included as smokers \\
\hline
\end{tabular}

Zhu 2012

\begin{tabular}{|c|c|}
\hline Methods & $\begin{array}{l}\text { Setting: Quitline, USA } \\
\text { Recruitment: Callers to a quitline }\end{array}$ \\
\hline Participants & $\begin{array}{l}2278 \text { Chinese-, Korean- and Vietnamese-speaking daily smokers, ready to quit within } 1 \mathrm{~m} ; 90 \% \mathrm{M} \text {; agec } \\
18 \text { - } 75 \text { (approx. } 45 \% 25 \text { - } 44 \text { and } 45 \% 45 \text { - 64); av. cigs/day } 15.6\end{array}$ \\
\hline Interventions & $\begin{array}{l}\text { 1. S-H pack, culturally-tailored, translated into Chinese, Korean and Vietnamese } \\
\text { 2. S-H pack + proactive TC; Social Learning Theory; MI; CBT techniques. } 30 \text { - } 40 \text { mins, pre-quit, up to } 5 \\
\text { relapse prevention calls ( } 10 \text { - } 15 \text { min) } 0,3,7,14,30 \text { days }\end{array}$ \\
\hline
\end{tabular}

Outcomes

Prolonged abstinence at $7 \mathrm{~m}$ post-intervention, $1 \mathrm{~m}$ grace period immediately post-quit

Validation: none (but saliva samples collected)

Notes Number abstinent at $6 \mathrm{~m}$ not specified; data used in MA calculated back from percentages

\section{Risk of bias}

\begin{tabular}{lll}
\hline Bias & Authors' judgement & Support for judgement \\
\hline $\begin{array}{l}\text { Random sequence genera- } \\
\text { tion (selection bias) }\end{array}$ & Low risk & $\begin{array}{l}\text { Quote: "randomly assigned...using blocks of 20 to keep a balance of language } \\
\text { and sex...Random assignment tables for each strata were created using SAS } \\
9.2 . "\end{array}$ \\
\hline $\begin{array}{l}\text { Allocation concealment } \\
\text { (selection bias) }\end{array}$ & Low risk & $\begin{array}{l}\text { Quote: "The allocation was done by the computer so that staff were blinded to } \\
\text { group assignment until the intake call" }\end{array}$ \\
\hline $\begin{array}{l}\text { Blinding of outcome as- } \\
\text { sessment (detection bias) } \\
\text { All outcomes }\end{array}$ & Low risk & $\begin{array}{l}\text { Self-reported outcomes but saliva samples collected. No statistically signifi- } \\
\text { cant differences in saliva sample return rates at } 7 \text { m between intervention and } \\
\text { control groups and between self-reported quitters and non-quitters }\end{array}$ \\
\hline $\begin{array}{l}\text { Incomplete outcome data } \\
\text { (attrition bias) } \\
\begin{array}{ll}\text { All outcomes } \\
\hline\end{array}\end{array}$ & Low risk & $\begin{array}{l}\text { Simlar rate of dropouts in both groups (18\% in 1, 16\% in 2). Participants lost to } \\
\text { follow-up included as smokers in outcome data }\end{array}$ \\
\hline
\end{tabular}


Zwar 2015

\begin{tabular}{|c|c|}
\hline Methods & $\begin{array}{l}\text { Setting: Australia; community-based } \\
\text { Recruitment: Patients were approached in the waiting room of participating practices by trained re- } \\
\text { search assistants over a 2-week period and assessed for eligibility }\end{array}$ \\
\hline Participants & 2390 adult smokers, $46 \%$ M, av. age 42.8 , av. cigs/day 17.1 \\
\hline \multirow[t]{4}{*}{ Interventions } & $\begin{array}{l}\text { 1. Usual care: In control group practices, the GPs were asked to assess participants' willingness to quit } \\
\text { and offer assistance in accordance with their usual practice. This could include advice within the prac- } \\
\text { tice, referral to Quitline or both, but no provision was made to facilitate either. }\end{array}$ \\
\hline & $\begin{array}{l}\text { 2. Quit with practice nurse: Individual face-to-face counselling with nurse. Quit kits (a printed resource } \\
\text { used by Quitlines nationally) were also distributed to participants. Nurses were also supported by } 3 \\
\text { proactive telephone calls from an experienced counsellor. }\end{array}$ \\
\hline & $\begin{array}{l}\text { 3. Quitline referral: GPs were asked to assess the participants' willingness to quit and to offer brief ad- } \\
\text { vice. } \\
\text { Participants with interest in quitting were offered referral to the Quitline and, if they agreed, GP com- } \\
\text { pleted a fax referral form to Quitline. On receiving a GP referral, the Quitline telephoned the participant } \\
\text { to offer services to meet their needs. Participants expressing interest in quitting and willing to engage } \\
\text { with the Quitline counselling service were offered a series of free evidence-based proactive call-back } \\
\text { counselling/advice sessions. }\end{array}$ \\
\hline & All were offered, according to clinical practice guidelines, free patches of NRT for 8 weeks \\
\hline \multirow[t]{2}{*}{ Outcomes } & Self-reported abstinence at $12 \mathrm{~m}$ (sustained $\geq 10 \mathrm{~m}$ ) \\
\hline & Validation: none \\
\hline \multirow[t]{3}{*}{ Notes } & New for 2018 update \\
\hline & Funding: "Australian National Health and Medical Research Council Project Grant (568617)" \\
\hline & Declarations of interest: none declared \\
\hline
\end{tabular}

\section{Risk of bias}

\begin{tabular}{lll}
\hline Bias & Authors' judgement & Support for judgement \\
\hline $\begin{array}{l}\text { Random sequence genera- } \\
\text { tion (selection bias) }\end{array}$ & Unclear risk & Method of randomisation not described \\
\hline $\begin{array}{l}\text { Allocation concealment } \\
\text { (selection bias) }\end{array}$ & Low risk & $\begin{array}{l}\text { Quote: "patients were given a card indicating their enrolment and the alloca- } \\
\text { tion group of the practice to take into the GP consultation" }\end{array}$ \\
\hline $\begin{array}{l}\text { Blinding of outcome as- } \\
\text { sessment (detection bias) } \\
\text { All outcomes }\end{array}$ & High risk & $\begin{array}{l}\text { Abstinence not biochemically validated, but similar levels of personal contact } \\
\text { in different study arms }\end{array}$ \\
\hline $\begin{array}{l}\text { Incomplete outcome data } \\
\text { (attrition bias) } \\
\begin{array}{l}\text { All outcomes } \\
\hline\end{array}\end{array}$ & Low risk & Similar \% of lost to follow-up across arms \\
\hline
\end{tabular}

AHRQ: Agency for Healthcare Research and Quality; ACT: Acceptance and Commitment therapy; ALA: American Lung Association; av: average; CHD: chronic heart disease; CBT: cognitive behavioural therapy; CO: carbon monoxide; COPD: chronic obstructive pulmonary disease; F: female; FTND: Fagerström Test for Nicotine Dependence; HMO: health maintenance organisation; hrs: hours; HTN: hypertension; ITT: intention-to-treat (analysis); m: months; M: male; MA: meta-analysis; MI: motivational interviewing; NCIS: National Cancer Information 
Service; NRT: nicotine replacement therapy; PP: point prevalence; ppm: parts per million; SES: socio-economic status; S-H: Self-help materials; SHS: Second-hand smoking; SoC: Stage of change; TC: Telephone counselling; TQD: Target quit date

Characteristics of excluded studies [ordered by study ID]

\begin{tabular}{ll}
\hline Study & Reason for exclusion \\
\hline Abroms 2014 & Text message intervention which encouraged participants to call a quitline \\
\hline Ahijevych 1995 & $\begin{array}{l}\text { Pilot study with } 12 \text { weeks follow-up, after which the advice and control groups were offered the in- } \\
\text { tervention. The intervention was } 4 \mathrm{x} \text { weekly mailings and telephone calls from a lay facilitator. }\end{array}$ \\
\hline Alonso-Perez 2007 & Not a fully randomised trial. Smokers assigned to behavioural condition by clinic attended \\
\hline Amos 1995 & $\begin{array}{l}\text { Not a controlled trial. Callers to a workplace helpline set up in conjunction with a non-smoking pol- } \\
\text { icy were followed up. } 16 \% \text { of smokers reported they had quit } 3 \text { m later, } 28 \% \text { of those who had tried } \\
\text { to quit. It was estimated that between } 3 \text { and 3.3\% of smokers in the company had called in the first } \\
3 \mathrm{~m}\end{array}$
\end{tabular}

\begin{tabular}{|c|c|}
\hline An 2008 & Intervention was to increase clinic referrals to a quitline. No smoking outcomes \\
\hline Asfar 2010 & $\begin{array}{l}\text { Previously listed as ongoing. Compared proactive with reactive telephone counselling but the NRT } \\
\text { dosage provided varied between arms }\end{array}$ \\
\hline Augustine 2015 & Effect of TC cannot be evaluated independently of NRT \\
\hline Baker 2015 & Telephone compared to face-to-face counselling \\
\hline Balanda 1999 & $\begin{array}{l}\text { Callers to a helpline were randomised to } 1 \text { of } 2 \mathrm{~S}-\mathrm{H} \text { materials. No counselling was given. Follow-up } \\
\text { only } 1 \mathrm{~m} \text { after receipt of materials. There was no difference in cessation rates between the booklet } \\
\text { groups. }\end{array}$ \\
\hline Berndt 2014 & Effect of TC cannot be evaluated independently of NRT \\
\hline Bernstein 2018 & Insufficient length of follow-up (3 months) \\
\hline Best 1977 & $\begin{array}{l}\text { Allocation not stated to be random. Telephone follow-up compared to group behavioural treat- } \\
\text { ment with aversive smoking only. }\end{array}$ \\
\hline Bliksrud 2002 & Not a randomised trial \\
\hline Bock 2008 & All participants received brief TC calls. Intervention was a face-to-face motivational interview \\
\hline Borland 1989 & Not a controlled trial. Evaluation of calls to a helpline \\
\hline Borland 2004 & $\begin{array}{l}\text { All participants called a quitline, test of different S-H materials. Included in Cochrane Review of S-H } \\
\text { (Livingstone-Banks 2019a) }\end{array}$ \\
\hline Boyle 2004 & Intervention for smokeless tobacco use, not smoking \\
\hline Boyle 2008 & Intervention for smokeless tobacco use, not smoking \\
\hline Brandon 2000 & $\begin{array}{l}\text { Focus on preventing relapse. See Cochrane Review on relapse prevention (Livingstone-Banks } \\
\text { 2019b) }\end{array}$ \\
\hline Bronshtein 2016 & No data on smoking cessation \\
\hline
\end{tabular}




\begin{tabular}{ll}
\hline Study & Reason for exclusion \\
\hline Brunner-Frandsen 2010 & Intervention condition included intensive face-to-face counselling as well as telephone contact \\
\hline Buchanan 2004 & Multicomponent intervention, only 12 weeks follow-up \\
\hline Buller 2012 & $\begin{array}{l}\text { Previously listed as ongoing. Compares an online intervention against telephone counselling with } \\
\text { self-help }\end{array}$ \\
\hline Burns 2010 & Not randomised; historical and non-equivalent controls \\
\hline Bush 2012 & $\begin{array}{l}\text { Evaluated a counselling component to address cessation-related weight concerns. Will be evaluat- } \\
\text { ed in Cochrane Review of interventions for preventing weight gain after smoking cessation (Farley } \\
\text { 2012) }\end{array}$ \\
\hline Bush 2016 & $\begin{array}{l}\text { Evaluated a counselling component to address cessation-related weight concerns. Will be evaluat- } \\
\text { ed in Cochrane Review of interventions for preventing weight gain after smoking cessation (Farley } \\
\text { 2012) }\end{array}$
\end{tabular}

\begin{tabular}{|c|c|}
\hline Carlin-Menter 2011 & Only 3 months follow-up \\
\hline Carlini 2008 & Intervention to increase re-enrolment in quitline services. No smoking outcomes \\
\hline Carlini 2012 & Intervention was IVR to re-engage relapsed smokers, no cessation outcomes \\
\hline Carreras 2007 & Not a randomised trial. Compared intensive counselling delivered face-to-face or by telephone \\
\hline Cheung 2013 & Participants in quitline arm could choose between email, telephone or sms contacts \\
\hline Cheung 2017 & Participants in quitline arm could choose between email, telephone or sms contacts \\
\hline Choi 2014 & Addition of Tobacco Tactics website to nurse-delivered TC plus NRT \\
\hline Conway 2004 & $\begin{array}{l}\text { Focus on preventing relapse. See Cochrane Review on relapse prevention (Livingstone-Banks } \\
\text { 2019b) }\end{array}$ \\
\hline Cooper 2004 & $\begin{array}{l}\text { Trial identified from a paper reporting secondary outcomes. Compared } 3 \text { levels of behavioural in- } \\
\text { tervention in a primary care setting. Full results have not been published and not available }\end{array}$ \\
\hline Cummings 1988 & $\begin{array}{l}\text { Callers to a helpline were randomised to one of } 4 \text { different S-H programmes or an information con- } \\
\text { trol. No counselling was given. }\end{array}$ \\
\hline Cummings 1989 & $\begin{array}{l}\text { Does not measure smoking cessation. Assesses impact of a media campaign to get women smok- } \\
\text { ers with young children to call a quit line. Call rates compared in media markets with and without a } \\
\text { campaign. }\end{array}$ \\
\hline Cummings $2006 a$ & Not a randomised trial. Evaluated impact of free NRT as adjunct to telephone support \\
\hline Cummings 2010 & $\begin{array}{l}\text { Not a randomised trial. Evaluated impact of different amounts of free NRT as adjunct to telephone } \\
\text { support }\end{array}$ \\
\hline Cummings 2011 & $\begin{array}{l}\text { All participants eligible for same telephone counselling intervention; test of different amounts of } \\
\text { NRT }\end{array}$ \\
\hline Curry 2003 & Telephone component cannot be evaluated independently of face-to-face counselling \\
\hline Danaher 2011 & Study of smokeless tobacco users only \\
\hline
\end{tabular}




\begin{tabular}{ll}
\hline Study & Reason for exclusion \\
\hline Danaher 2015 & Study of smokeless tobacco smokers \\
\hline Davis 1992 & $\begin{array}{l}\text { All participants were women with young children who called a hotline and received same stage- } \\
\text { based counselling. They were randomised to receive } 3 \text { different S-H guides. See Cochrane Review } \\
\text { of S-H (Livingstone-Banks 2019a) }\end{array}$ \\
\hline De Azevedo 2010 & $\begin{array}{l}\text { Telephone component cannot be evaluated independently of face-to-face counselling. The inter- } \\
\text { vention included in-hospital motivational interviewing as well as post-discharge telephone con- } \\
\text { tact, and was compared to usual care }\end{array}$ \\
\hline DeBusk 1994 & $\begin{array}{l}\text { Telephone component cannot be evaluated independently of face-to-face counselling. The inter- } \\
\text { vention included in-hospital physician advice and counselling by a nurse as well as post-discharge } \\
\text { telephone contact, and was compared to usual care }\end{array}$
\end{tabular}

\begin{tabular}{|c|c|}
\hline Decker 1989 & $\begin{array}{l}\text { Not random or pseudo-random. Interventions ran sequentially. Participants receiving mailed ma- } \\
\text { terials had access to a hotline }\end{array}$ \\
\hline Dent 2009 & $\begin{array}{l}\text { Single telephone call was the brief intervention control for a 3-session group-based pharma- } \\
\text { cist-conducted intervention }\end{array}$ \\
\hline Dubren 1977 & $\begin{array}{l}\text { Recent quitters were randomised to access to recorded messages, not a counsellor. Short fol- } \\
\text { low-up ( } 4 \text { weeks) }\end{array}$ \\
\hline Edelman 2014 & No data on smoking cessation \\
\hline Fellows 2016 & $\begin{array}{l}\text { Multicomponent intervention including TC, individual and group counselling and an interactive } \\
\text { web-based programme }\end{array}$ \\
\hline Fu 2016 & $\begin{array}{l}\text { TC as an adjunct of NRT. However, NRT is offered in a different manner in the TC arm (free) and usu- } \\
\text { al care arm (discounted price) }\end{array}$ \\
\hline Garvey 2012 & $\begin{array}{l}\text { Compares } 3 \text { different lengths of telephone and face-to-face cognitive behavioural counselling ( } 3,6 \\
\text { and } 12 \text { months duration) }\end{array}$ \\
\hline Gianos 2015 & Telephone component cannot be evaluated independently of text messaging \\
\hline Gies 2008 & $\begin{array}{l}\text { Only 3-m follow-up. Comparison between } 1 \text { and } 4 \text { telephone follow-ups as adjunct to face-to-face } \\
\text { counselling. } 19 \text { participants per group }\end{array}$ \\
\hline Glasgow 2009 & Intervention aimed at reduction in cigarette use for people not wishing to attempt cessation \\
\hline Gong 2016 & Insufficient length of follow-up (12 weeks) \\
\hline Gordon 2010 & $\begin{array}{l}\text { Telephone component cannot be evaluated independently of face-to-face counselling delivered by } \\
\text { dental practitioner }\end{array}$ \\
\hline Gritz 2012 & $\begin{array}{l}\text { Intervention used cell phone. Will be evaluated in Cochrane Review of mobile phone-based inter- } \\
\text { ventions for smoking cessation (Whittaker 2016) }\end{array}$ \\
\hline Haas 2015 & Multicomponent intervention that includes TC and free NRT versus usual care \\
\hline Hackbarth 2006 & Insufficient detail in abstract to include, no full report identified \\
\hline Hammett 2018 & Effect of TC cannot be evaluated independently of NRT \\
\hline
\end{tabular}




\begin{tabular}{ll}
\hline Study & Reason for exclusion \\
\hline Han 2010 & $\begin{array}{l}\text { Study of } 2 \text { different frequencies of telephone counselling for high blood pressure, including smok- } \\
\text { ing cessation counselling. Smoking cessation not reported as an outcome, unclear if smoking ces- } \\
\text { sation measured }\end{array}$ \\
\hline
\end{tabular}

\begin{tabular}{|c|c|}
\hline Harris 2015 & TC arm compared to a web-based intervention \\
\hline Hasuo 2004 & $\begin{array}{l}\text { Telephone component cannot be evaluated independently of face-to-face counselling. The inter- } \\
\text { vention included in-hospital counselling by a nurse }\end{array}$ \\
\hline Hawkes 2013 & No data on smoking \\
\hline Hennrikus 2002 & $\begin{array}{l}\text { Included in previous updates of this review. Excluded in } 2018 \text { update due to TC being compared to } \\
\text { group counselling }\end{array}$ \\
\hline Hokanson 2006 & $\begin{array}{l}\text { Telephone component cannot be evaluated independently of face-to-face counselling and offer of } \\
\text { pharmacotherapy }\end{array}$ \\
\hline Holtrop 2005 & The purpose of the telephone call was to encourage participants to enrol in quitline services \\
\hline Johnson 1999 & $\begin{array}{l}\text { Telephone component cannot be evaluated independently of face-to-face counselling. The inter- } \\
\text { vention included in-hospital counselling by a nurse. Quasi-random design }\end{array}$ \\
\hline Joseph 2011 & Complex intervention; all participants received telephone counselling \\
\hline Katz 2004 & $\begin{array}{l}\text { Included in previous updates of this review. Excluded in } 2018 \text { update due to the fact that the effect } \\
\text { of TC cannot be evaluated independently of NRT }\end{array}$ \\
\hline Keten 2013 & Insufficient length of follow-up \\
\hline Killen 2008 & Main intervention component was face-to-face support. Telephone contact in both arms \\
\hline Kim 2016 & $\begin{array}{l}\text { TC compared with videoconferencing among Korean-American women. This study will be covered } \\
\text { in a new Cochrane review about real-time video counselling for smoking cessation (see Tzelepis } \\
2017 \text { ) }\end{array}$ \\
\hline
\end{tabular}

Kim 2017

TC compared with videoconferencing among women living with HIV. This study will be covered in a new Cochrane review about real-time video counselling for smoking cessation (see Tzelepis 2017)

\begin{tabular}{ll}
\hline Klesges 2015 & Effect of TC cannot be evaluated independently of NRT \\
\hline Koffman 1998 & $\begin{array}{l}\text { 3 worksites allocated to different interventions. No way to distinguish variation due to worksite } \\
\text { from effect of intervention }\end{array}$ \\
\hline Lando 1996 & $\begin{array}{l}\text { Previously included, recruited only recent quitters so now covered in Cochrane Review of relapse } \\
\text { prevention (Livingstone-Banks 2019b) }\end{array}$
\end{tabular}

The intervention included 1 session of face-to-face counselling with telephone follow-up. Results, which did not show any intervention effect, are given in Bobo 1998

\section{Lichtenstein 2002b}

Linder 2014
No long-term outcomes yet reported

Effect of TC cannot be evaluated independently of NRT 


\begin{tabular}{|c|c|}
\hline Study & Reason for exclusion \\
\hline Lindinger 2012 & Not randomised. Compared participants accepting proactive calls to those choosing only 1 session \\
\hline Little 2009 & $\begin{array}{l}\text { Systems change intervention; trained dental staff in to assess, advise and refer to telephone coun- } \\
\text { selling }\end{array}$ \\
\hline Mahabee-Gittens 2008 & Quitline referral confounded with brief advice, only 3 m follow-up \\
\hline Manfredi 1999 & $\begin{array}{l}\text { The intervention included the opportunity of a motivational telephone call following provider ad- } \\
\text { vice and S-H components. Follow-up was only } 5-8 \text { weeks }\end{array}$ \\
\hline Manfredi 2011 & Smoking status not measured \\
\hline Mayer 2010 & Trial of a relapse prevention intervention; participants were abstinent at time of randomisation \\
\hline McAfee 2008 & All participants had same quitline counselling \\
\hline McBride 2002 & $\begin{array}{l}\text { The focus of the intervention was on genetic susceptibility feedback. Effect of telephone support } \\
\text { cannot be evaluated independently }\end{array}$ \\
\hline McClure 2018 & Telephone component cannot be evaluated independently of website and text messaging \\
\hline McDaniel 2015 & $\begin{array}{l}\text { This study includes exclusively recent quitters. This falls within the scope of a separate review on } \\
\text { preventing relapse (Hajek 2009). }\end{array}$ \\
\hline McGrath 2014 & Insufficient length of follow-up ( 3 months) \\
\hline Mermelstein 2003 & $\begin{array}{l}\text { Compares } 2 \text { telephone-based interventions for preventing relapse following group therapy. Now } \\
\text { included in Cochrane Review of relapse prevention (Livingstone-Banks 2019b) }\end{array}$ \\
\hline Miller 2009 & $\begin{array}{l}\text { Trial of NRT as opposed to telephone support; same telephone support intervention offered to } \\
\text { both groups }\end{array}$ \\
\hline Morris 2011 & All participants received telephone counselling and NRT, test of additional group counselling \\
\hline Mullen 2016 & No data on smoking abstinence \\
\hline Nair 2017 & Insufficient length of follow-up (1 month) \\
\hline Ockene 1992 & Telephone support could not be evaluated independently of combined intervention \\
\hline Oddone 2017 & The outcome of this trial is enrolment of veterans in smoking cessation services \\
\hline Owen 2000 & Not a controlled trial. Survey of callers to UK quitline. \\
\hline Papadakis 2013 & Insufficient length of follow-up \\
\hline Parker 2007 & Trial in pregnant women \\
\hline Partin 2006 & $\begin{array}{l}\text { Telephone intervention purpose was to assess smoking status, interest in making another quit at- } \\
\text { tempt, quit challenges, and treatment preferences, not to assist cessation per se }\end{array}$ \\
\hline Patten 2009 & $\begin{array}{l}\text { Intervention was telephone counselling for non-smokers wanting to help a smoker. Outcome was } \\
\text { calls by smoker to quitline, not cessation }\end{array}$ \\
\hline
\end{tabular}




\begin{tabular}{|c|c|}
\hline Study & Reason for exclusion \\
\hline Patten 2011 & $\begin{array}{l}\text { Intervention was telephone counselling for non-smokers wanting to help a smoker. Outcome was } \\
\text { calls by smoker to quitline, not cessation }\end{array}$ \\
\hline Peng 2011 & Short follow-up \\
\hline Peterson 2009 & $\begin{array}{l}\text { School as unit of randomisation. Telephone counselling confounded by other school-based initia- } \\
\text { tives }\end{array}$ \\
\hline Peterson 2015 & Telephone counselling cannot be evaluated independently of telehealth counselling \\
\hline Platt 1997 & $\begin{array}{l}\text { Not a controlled trial. A panel sample of callers to the Scottish Smokeline was followed up for } 1 \\
\text { year. } 607 \text { ( } 71 \% \text { of original sample) were reached. }\end{array}$ \\
\hline Prue 1983 & $\begin{array}{l}\text { The amount and timing of telephone contact is unclear. The main component was a S-H pro- } \\
\text { gramme, compared to a waiting list control. Total of } 40 \text { participants }\end{array}$ \\
\hline Racelis 1998 & Intervention addressed multiple risk factors, number of smokers enrolled not specified \\
\hline Ratner 2004 & Telephone support could not be evaluated independently of face-to-face counselling \\
\hline Reid 1999b & $\begin{array}{l}\text { Not a controlled trial. Followed } 258 \text { nicotine patch purchasers who enrolled for support pro- } \\
\text { gramme of } 4 \text { calls from a trained nurse counsellor. }\end{array}$ \\
\hline Richter 2015 & $\begin{array}{l}\text { Traditional TC compared with telemedicine. This study will be covered in a new Cochrane Review } \\
\text { about real-time video counselling for smoking cessation (see Tzelepis 2017) }\end{array}$ \\
\hline Rigotti 2014 & Effect of TC cannot be evaluated independently of NRT \\
\hline Rigotti 2016 & Effect of TC cannot be evaluated independently of pharmacotherapy \\
\hline Rigotti 2017 & Effect of TC cannot be evaluated independently of pharmacotherapy \\
\hline Ringen 2002 & Not randomised. Smokers chose intensity of support \\
\hline Rodgers 2005 & $\begin{array}{l}\text { Intervention used mobile phone (including text messaging). To be covered by separate Cochrane } \\
\text { Review (Whittaker 2016) }\end{array}$ \\
\hline Rogers 2018 & Telephone component cannot be evaluated independently of NRT \\
\hline Roski 2003 & $\begin{array}{l}\text { Included in previous updates of this review. Excluded in } 2018 \text { update due to TC being compared to } \\
\text { financial incentives }\end{array}$ \\
\hline Rothemich 2010 & Systems change intervention; referral to quitline was only 1 component \\
\hline Schiebel 2007 & $\begin{array}{l}\text { Small }(n=39) \text { feasibility study in Emergency Department. Very low rate of follow-up especially for } \\
\text { sustained abstinence outcome }(2 / 39 \text { reached at both follow-ups) }\end{array}$ \\
\hline Schneider 1995 & $\begin{array}{l}\text { Evaluated a telephone support system. All smokers recruited had access to the interactive pro- } \\
\text { gramme. Random subsets were selected for access to messages about nicotine gum, sent a re- } \\
\text { minder to call, or sent a user's manual }\end{array}$ \\
\hline Segan 2011 & Study of phone counselling for relapse prevention \\
\hline Sharifirad 2012 & Telephone component cannot be evaluated independently of NRT \\
\hline Sherman 2008 & Abstinence data given only for intervention group \\
\hline
\end{tabular}




\begin{tabular}{|c|c|}
\hline Study & Reason for exclusion \\
\hline Sherman 2016 & Effect of TC cannot be evaluated independently of NRT \\
\hline Shiffman 2000 & Follow-up 12 weeks. \\
\hline Sidhu 2015 & $\begin{array}{l}\text { Multicomponent intervention which included telephone counselling, a pedometer, supporting } \\
\text { written materials and a self-monitoring diary }\end{array}$ \\
\hline Simon 1997 & $\begin{array}{l}\text { Telephone component cannot be evaluated independently of face-to-face counselling. The inter- } \\
\text { vention included brief counselling and NRT }\end{array}$ \\
\hline Simon 2003 & $\begin{array}{l}\text { Telephone component cannot be evaluated independently of face-to-face counselling. The inter- } \\
\text { vention included in-hospital nurse counselling as well as post-discharge telephone contact, and } \\
\text { was compared to a minimal intervention }\end{array}$ \\
\hline Sivarajan 2004 & Telephone component could not be evaluated independently of combined intervention \\
\hline Sorensen $2007 b$ & $\begin{array}{l}\text { Telephone intervention was a 10-min reminder call, } 2 \mathrm{~m} \text { after face-to-face advice to quit prior to } \\
\text { surgery. Outcomes combined with an arm given reminder at a face-to-face meeting }\end{array}$ \\
\hline Stevens 1993 & $\begin{array}{l}\text { Telephone component cannot be evaluated independently of face-to-face counselling. The inter- } \\
\text { vention included in-hospital physician advice and counselling by a nurse as well as post-discharge } \\
\text { telephone contact, and was compared to usual care }\end{array}$ \\
\hline Stoltzfus 2011 & Not a controlled trial. Pre-test/post-test study of different referral methods \\
\hline Strong 2012 & All participants had same basic counselling intervention. Test of a mood management component \\
\hline Sutton 2007 & $\begin{array}{l}\text { All participants had same counselling intervention. Test of tailored written materials, see Cochrane } \\
\text { self-help Review (Livingstone-Banks 2019a) }\end{array}$ \\
\hline Szklo 2010 & Not an evaluation of counselling; compared 2 strategies to encourage calls to a quitline \\
\hline Taylor 1990 & $\begin{array}{l}\text { Telephone component cannot be evaluated independently of face-to-face counselling. The inter- } \\
\text { vention included in-hospital physician advice and counselling by a nurse, as well as post-discharge } \\
\text { telephone contact, and was compared to usual care }\end{array}$ \\
\hline Terazawa 2001 & Telephone component could not be evaluated independently of combined intervention \\
\hline Terry 2011 & Not randomised; comparison of work-based intervention programmes \\
\hline Toll 2010 & Only $3 \mathrm{~m}$ follow-up \\
\hline Tseng 20162015 & Insufficient length of follow-up (12 weeks) \\
\hline Urso 2003 & Only 12 weeks follow-up \\
\hline Van der Meer 2010 & All participants received telephone counselling. Test of a mood management component \\
\hline Vidrine 2006 & $\begin{array}{l}\text { Intervention used mobile phone (including text messaging). To be covered by separate Cochrane } \\
\text { Review (Whittaker 2016) }\end{array}$ \\
\hline Wadland 1999 & $\begin{array}{l}\text { Not randomised. The treated groups were recruited by different means and given different inter- } \\
\text { ventions, both of which included telephone counselling by nurses or counsellors }\end{array}$ \\
\hline Wadland 2001 & Only $3 \mathrm{~m}$ follow-up \\
\hline
\end{tabular}




\begin{tabular}{|c|c|}
\hline Study & Reason for exclusion \\
\hline Wadland 2007 & Trial of methods for clinic referral to quitline support. No quitting outcomes \\
\hline Walker 2011a & Recruitment by quitline, but test of providing samples of NRT \\
\hline Walker 2011b & Recruitment by quitline, but test of nicotine-free cigarettes as an adjunct to NRT \\
\hline Wang 2017 & $\begin{array}{l}\text { Comparison of different leaflets/booklets. One of the arms also includes referral to the quitline and } \\
\text { other smoking cessation services }\end{array}$ \\
\hline Warner 2011 & $\begin{array}{l}\text { Comparison of physician-provided general help to quit smoking with intervention primarily aimed } \\
\text { at facilitating quitline use. Both groups had same access to quitline }\end{array}$ \\
\hline Weaver 2015 & Multicomponent intervention which includes NRT, telephone and face-to-face counselling \\
\hline Westman 1993 & Telephone component cannot be evaluated independently of face-to-face counselling \\
\hline Wetter 2007 & Only 12 weeks follow-up \\
\hline Wewers 2017 & TC compared to face-to-face counselling \\
\hline Willemsen 2008 & Uncontrolled evaluation. Quitline callers followed up at 1 year \\
\hline Wolfenden 2008a & Quitline component was part of a comprehensive intervention including face-to-face support \\
\hline Zanis 2011 & Only 12 weeks follow-up \\
\hline Zawertailo 2013 & Not randomised; uses a concurrent matched control \\
\hline Zhu 2000 & $\begin{array}{l}\text { Not an RCT. All participants called the California Smokers' Helpline and received } 1 \text { session of coun- } \\
\text { selling and planned to use NRT. Those who chose to receive further counselling were compared to } \\
\text { those who did not }\end{array}$ \\
\hline
\end{tabular}

$\mathrm{Cl}$ : confidence interval; m: month(s); IVR: interactive voice response; NRT: nicotine replacement therapy; S-H: self-help; TC: telephone counselling; TQD: target quit date

\section{Characteristics of ongoing studies [ordered by study ID]}

Argyropoulou 2005

\begin{tabular}{ll}
\hline Trial name or title & Smoking cessation: data for two years from two different interventions \\
\hline Methods & $\begin{array}{l}\text { 9-week open-label bupropion phase } 300 \mathrm{mg} \text { daily and NRT for } 3 \text { weeks combined with behavioural } \\
\text { support; smokers randomised in } 2 \text { groups, follow-up for 3, 6, } 12 \text { and } 24 \text { months }\end{array}$ \\
\hline Participants & No information \\
\hline Interventions & Group A: 7 weekly one-to-one counselling sessions; Group B: telephone counselling \\
\hline Outcomes & PP and continuous abstinence \\
\hline
\end{tabular}

Starting date

\section{Contact information}

\section{Notes}


Humfleet 2012

\begin{tabular}{ll}
\hline Trial name or title & Reaching and treating lesbian, gay, bisexual, and transgender (LGBT) cigarette smokers \\
\hline Methods & Randomised, open-label, factorial (4 arm) \\
\hline Participants & $\geq 18$ years; identify as LGBT \\
\hline Interventions & $\begin{array}{l}\text { 1) self-help manual; 2) mail-based self-help plus internet-based smoking treatment; 3) self-help } \\
\text { manual + telephone counselling; 4) self-help manual plus internet-based Intervention plus tele- } \\
\text { phone counselling }\end{array}$
\end{tabular}

\begin{tabular}{ll}
\hline Outcomes $\quad$ Primary: smoking status at 3, 6 and 12 months post-enrolment \\
\hline
\end{tabular}

Starting date February 2008

Contact information

Notes

\section{Mak 2015}

\begin{tabular}{ll}
\hline Trial name or title & Acceptance and commitment therapy for smoking cessation in the primary care setting (ACT) \\
\hline Methods & RCT, parallel assignment, double masking \\
\hline Participants & $\begin{array}{l}\text { Aged } 18 \text { years and older, currently smoking at least } 1 \text { cigarette a day in the past } 30 \text { days, Hong Kong } \\
\text { residents, able to communicate in Cantonese, currently residing in Hong Kong and expecting to } \\
\text { continue to do so for the next } 6 \text { months, have access to a telephone }\end{array}$ \\
\hline Interventions & $\begin{array}{l}\text { 2 telephone ACT counselling sessions, minimal face-to-face ACT counselling, printed self-help } \\
\text { leaflet on smoking cessation }\end{array}$ \\
\hline Outcomes & $\begin{array}{l}\text { Primary outcome: self-reported 7-day point prevalence } \\
\text { Secondary outcome: validated abstinence }\end{array}$ \\
\hline Starting date & July 2012 \\
\hline Contact information & Www.researchgate.net/profile/Yim_Mak; www.researchgate.net/profile/Alice_Loke \\
\hline Notes & Only protocol and baseline results have been published so far \\
\hline
\end{tabular}

\begin{tabular}{ll} 
NCT00311948 & \\
\hline Trial name or title & Telephone and web-based teen tobacco cessation in HMOs \\
\hline Methods & RCT, parallel assignment, single (Investigator) masking \\
\hline Participants & 600 teenagers \\
\hline Interventions & Telephone counselling plus interactive website \\
\hline
\end{tabular}


NCT00311948 (Continued)

Outcomes Self-reported 30 days point prevalence assessed at 12 months

\begin{tabular}{ll}
\hline Starting date & March 2006 \\
\hline Contact information & hollisja@chr.mts.kpnw.org
\end{tabular}

\section{Notes}

\section{NCT00851357}

\begin{tabular}{ll}
\hline Trial name or title & Telephone counseling and the distribution of nicotine patches to smokers \\
\hline Methods & RCT, factorial assignment, quadruple masking \\
\hline Participants & 4200 adults residing in California including English and Spanish speakers \\
\hline Interventions & Telephone counselling \pm nicotine patch \pm self-help \pm placebo \\
\hline Outcomes & 6 months continuous abstinence assessed after 7 months of follow-up \\
\hline Starting date & February 2009 \\
\hline Contact information & szhu@ucsd.edu \\
\hline Notes &
\end{tabular}

\section{NCT01892813}

Trial name or title Dissemination of a tailored tobacco quitline for rural veteran smokers

\begin{tabular}{|c|c|}
\hline Methods & RCT, Parallel Assignment, Double Masking \\
\hline Participants & $\begin{array}{l}411 \text { rural veteran smokers, older than } 18 \text {, receive primary care from the lowa City VA Health Care } \\
\text { System or an affiliated community-based outpatient clinic (CBOC), live in a non-metropolitan area } \\
\text { (based on Rural-Urban Commuting Area Codes (RUCA)), willing to make an attempt to quit smoking } \\
\text { in the next } 30 \text { days, capable of providing informed consent, have access to a telephone (land line or } \\
\text { cell phone) and have a stable residence. }\end{array}$ \\
\hline
\end{tabular}

\begin{tabular}{ll}
\hline Interventions & Tailored tobacco quitline for rural veteran smokers \\
\hline Outcomes & 30-day abstinence assessed after 6 months of follow-up \\
\hline Starting date & July 2013 \\
\hline Contact information & mark-vanderweg@uiowa.edu \\
\hline
\end{tabular}

\section{Notes}


NCT01893502

\begin{tabular}{|c|c|}
\hline Trial name or title & Smoke-free randomised controlled trial \\
\hline Methods & RCT, parallel assignment, single masking \\
\hline Participants & $\begin{array}{l}11 \text { Singaporean current smokers among outpatients, including hospital employees, who provide } \\
\text { informed consent for enrolment in the smoking cessation programme }\end{array}$ \\
\hline Interventions & Proactive telephone counselling weekly for 6 months \\
\hline Outcomes & 7-day point prevalence assessed after 6 months of follow-up \\
\hline Starting date & June 2013 \\
\hline Contact information & kay_choong_see@nuhs.edu.sg \\
\hline \multicolumn{2}{|l|}{ Notes } \\
\hline \multicolumn{2}{|l|}{ NCT02157610 } \\
\hline Trial name or title & Smoking cessation for cervical cancer survivors \\
\hline Methods & $\mathrm{RCT}$, parallel assignment, open-label \\
\hline Participants & 350 women with a history of cervical cancer \\
\hline Interventions & Self-help + nicotine patch + referral to Oklahome quitline +6 behavioural counselling calls \\
\hline Outcomes & Smoking abstinence after 18 months of follow-up \\
\hline Starting date & January 2015 \\
\hline Contact information & Jennifer-vidrine@ouhsc.edu \\
\hline Notes & Recruiting \\
\hline
\end{tabular}

\section{NCT02397369}

Trial name or title

Evaluation of efficacy of different methods of tobacco cessation interventions among BEST employees in Mumbai

\begin{tabular}{ll}
\hline Methods & RCT, 4 arms, double masking \\
\hline Participants & 4000 Mumbai male BEST employees \\
\hline Interventions & Telephonic counselling \\
\hline Outcomes & Tobacco cessation after 1 year of follow-up \\
\hline Starting date & March 2015 \\
\hline Contact information & $\begin{array}{l}\text { www.researchgate.net/profile/Sharmila_Pimple } \\
\text { gauravi2005@yahoo.co.in }\end{array}$
\end{tabular}


NCT02397369 (Continued)

Notes Recruiting

NCT02421991

\begin{tabular}{ll}
\hline Trial name or title & Telephone-delivered interventions for smoking cessation (TALK) \\
\hline Methods & RCT, parallel assignment, single masking \\
\hline Participants & 1168 American adult smokers \\
\hline Interventions & Telephone counselling (ACT) 5 weeks \\
\hline Outcomes & 30-day point prevalence abstinence after 12 months of follow-up \\
\hline Starting date & 2 November 2015 \\
\hline Contact information & jbricker@fredhutch.org \\
\hline
\end{tabular}

Notes

NCT03002883

\begin{tabular}{ll}
\hline Trial name or title & STAND Community College tobacco cessation trial \\
\hline Methods & RCT, 3 arms, open-label \\
\hline Participants & 113 Californian adult smokers \\
\hline Interventions & Usual care + referral to quitline \\
\hline Outcomes & Biochemically-validated smoking cessation after 6 months of follow-up \\
\hline Starting date & September 2014 \\
\hline Contact information & ektong@ucdavis.edu \\
\hline Notes & Cannot find a full-text report \\
\hline
\end{tabular}

\section{NCT03194958}

\begin{tabular}{ll}
\hline Trial name or title & Helping poor smokers quit \\
\hline Methods & RCT, factorial design, double masking \\
\hline Participants & 2000 Missouri resident adult smokers \\
\hline Interventions & Specialised quitline services \pm basic needs navigator \\
\hline Outcomes & 7-day point prevalence abstinence after 6 months of follow-up \\
\hline
\end{tabular}


NCT03194958 (Continued)

\begin{tabular}{ll} 
Starting date & 5 June 2017 \\
\hline Contact information & mkreuter@wustl.edu \\
\hline Notes & Recruiting
\end{tabular}

NCT03236025

\begin{tabular}{ll}
\hline Trial name or title & $\begin{array}{l}\text { A video-led smoking cessation intervention in helping male smokers who is planning to have a ba- } \\
\text { by to quit }\end{array}$ \\
\hline Methods & RCT, parallel assignment, single masking \\
\hline Participants & 888 male adult Chinese-speaking Hong Kong-resident smokers \\
\hline Interventions & Telephone counselling + pamphlet \\
\hline Outcomes & Self-reported 7-day point prevalence quit rate after 6 months of follow-up \\
\hline Starting date & $\begin{array}{l}\text { 1 June 2017 } \\
\text { Www.researchgate.net/profile/Ho_Li2 } \\
\text { william3@hku.hk }\end{array}$ \\
\hline Notes & Recruiting
\end{tabular}

\section{NCT03538938}

\begin{tabular}{ll}
\hline Trial name or title & Improving quitline support study (IQS) \\
\hline Methods & RCT, factorial design, single masking \\
\hline Participants & 1600 Winsconsin-resident adult smokers \\
\hline Interventions & 4-call quitline counselling \pm NRT \pm text messaging \pm financial incentives \\
\hline Outcomes & 7-day point prevalence abstinence after 6 months of follow-up \\
\hline Starting date & 7 June 2018 \\
\hline Contact information & $\begin{array}{l}\text { www.researchgate.net/profile/Danielle_Mccarthy } \\
\text { demccarthy@ctri.wisc.edu }\end{array}$ \\
\hline Notes & Enrolling \\
\hline
\end{tabular}

\section{NTR6092}

$\begin{array}{ll}\text { Trial name or title } & \begin{array}{l}\text { Recruitment strategies for an effective smoking cessation programme for parents (De implemen- } \\ \text { tatie van een effectieve interventie om te stoppen met roken voor ouders) }\end{array}\end{array}$


NTR6092 (Continued)

\begin{tabular}{ll} 
Methods & RCT, parallel assignment, single masking \\
\hline Participants & 144 smoking parents of children younger than 12 \\
\hline Interventions & Proactive telephone counselling based on Ml and cognitive-behavioural skill building \\
\hline Outcomes & $\begin{array}{l}\text { 7-day point prevalence abstinence after } 12 \text { months of follow-up } \\
\text { Prolonged abstinence (at least } 6 \text { months) after 12-months of follow-up }\end{array}$ \\
\hline Starting date & 15 September 2016 \\
\hline Contact information & tscheffers@trimbos.nl \\
\hline Notes & Enroling
\end{tabular}

\section{Salgado Garcia 2018}

\begin{tabular}{ll}
\hline Trial name or title & Planning a change easily (PACE) \\
\hline Methods & RCT, 4 arms \\
\hline Participants & US adult smokers not ready to quit \\
\hline Interventions & Motivational Interviewing Telephone Counseling \\
\hline Outcomes & $\begin{array}{l}\text { 7-day point prevalence after } 12 \text { months of follow-up } \\
\text { Prolonged abstinence after } 12 \text { months of follow-up } \\
\text { Biochemically validated (saliva cotinine) abstinence after } 12 \text { months of follow-up }\end{array}$ \\
\hline Starting date & fsalgado@uthsc.edu \\
\hline Contact information & Only protocol published so far \\
\hline Notes &
\end{tabular}

Sienkiewicz-Jarosz 2015

\begin{tabular}{ll}
\hline Trial name or title & Antismoking interventions in stroke patients - Polish perspective \\
\hline Methods & RCT, 3 arms \\
\hline Participants & 198 participants with first ischaemic stroke \\
\hline Interventions & $\begin{array}{l}\text { 4 telephone calls } 6 \text { weeks after discharge from hospital + brief (20-min) counselling by physician } \\
1 \text { telephone call } 7 \text { days post-stroke + brief (20-min) counselling by physician }\end{array}$ \\
\hline Outcomes & Smoking cessation rate after 12 months of follow-up \\
\hline Starting date & www.researchgate.net/profile/Halina_Sienkiewicz-Jarosz \\
\hline Contact information & \\
\hline
\end{tabular}


Sienkiewicz-Jarosz 2015 (Continued)

Notes

Conference abstract. First author contacted but no response received

DATA AND ANALYSES

Comparison 1. Interventions for callers to quitlines - effect of additional proactive calls

\begin{tabular}{llllll}
\hline Outcome or subgroup title & No. of studies & $\begin{array}{l}\text { No. of partici- } \\
\text { pants }\end{array}$ & Statistical method & Effect size \\
\hline 1 Cessation at longest follow-up & 14 & 32484 & $\begin{array}{l}\text { Risk Ratio (M-H, Random, 95\% } \\
\text { Cl) }\end{array}$ & $1.38[1.19,1.61]$ \\
\hline
\end{tabular}

Analysis 1.1. Comparison 1 Interventions for callers to quitlines - effect of additional proactive calls, Outcome 1 Cessation at longest follow-up.

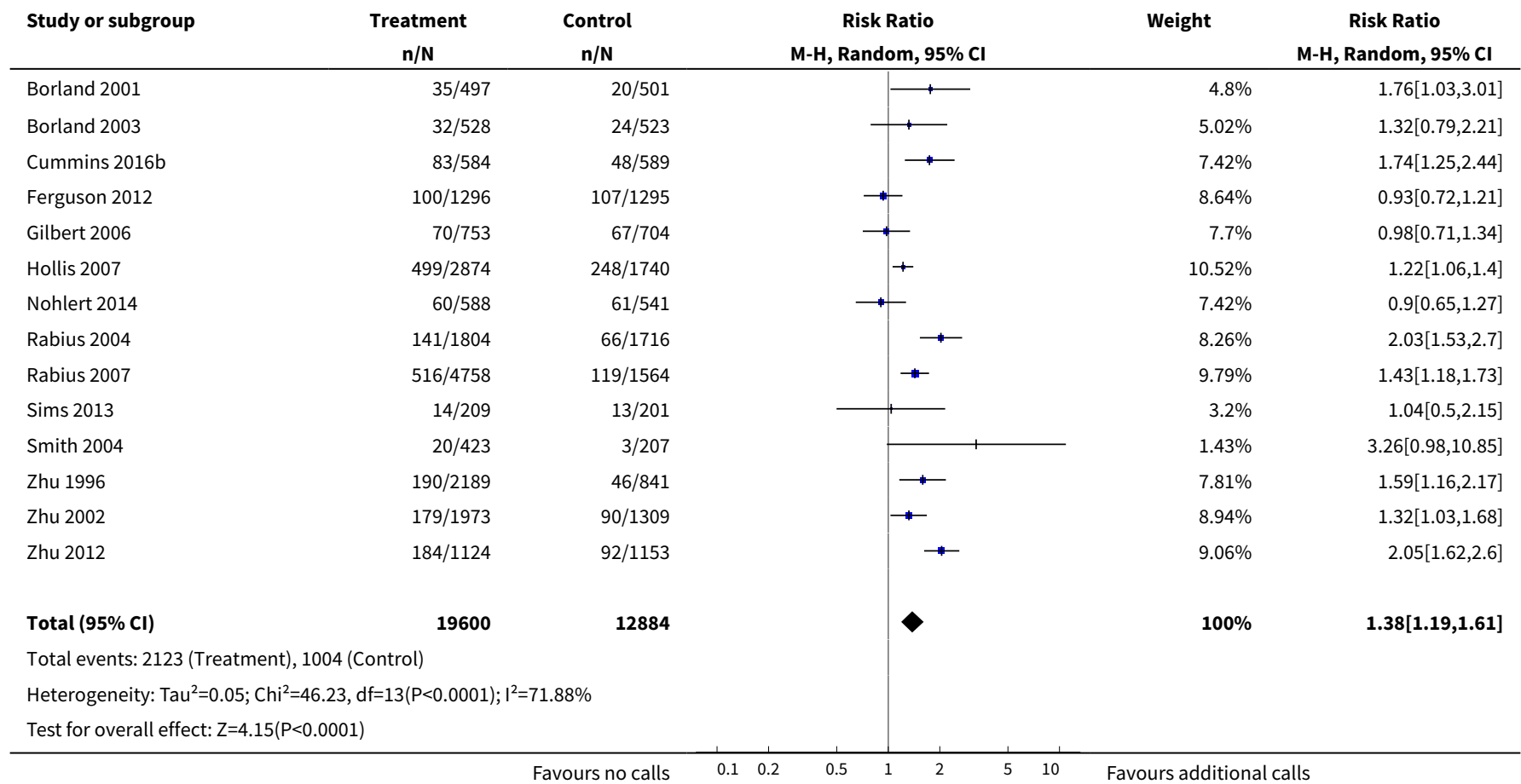

\section{Comparison 2. Interventions for callers to quitlines - comparison of different intensities}

\begin{tabular}{lllll}
\hline Outcome or subgroup title & No. of studies & $\begin{array}{l}\text { No. of partici- } \\
\text { pants }\end{array}$ & Statistical method & Effect size \\
\hline 1 Cessation at longest follow-up & 3 & & $\begin{array}{l}\text { Risk Ratio (M-H, Random, 95\% } \\
\text { Cl) }\end{array}$ & Subtotals only \\
\hline
\end{tabular}

Telephone counselling for smoking cessation (Review) 


\begin{tabular}{lllll}
\hline Outcome or subgroup title & No. of studies & $\begin{array}{l}\text { No. of partici- } \\
\text { pants }\end{array}$ & Statistical method & Effect size \\
\hline 1.1 Seven versus three phone calls & 1 & 1908 & $\begin{array}{l}\text { Risk Ratio (M-H, Random, 95\% } \\
\text { Cl) }\end{array}$ & $1.44[1.09,1.89]$ \\
\hline 1.2 Five versus three phone calls & 1 & 3669 & $\begin{array}{l}\text { Risk Ratio (M-H, Random, 95\% } \\
\text { Cl) }\end{array}$ & $1.28[1.00,1.64]$ \\
\hline 1.3 Seven versus five phone calls & 1 & & Risk Ratio (M-H, Random, 95\% & $1.12[0.93,1.36]$ \\
\hline 1.4 Five versus two phone calls & 1 & 3939 & $\begin{array}{l}\text { Risk Ratio (M-H, Random, 95\% } \\
\text { Cl) }\end{array}$ & $1.05[0.89,1.23]$ \\
\hline 1.5 Five versus one phone call & 1 & 2874 & $\begin{array}{l}\text { Risk Ratio (M-H, Random, 95\% } \\
\text { Cl) }\end{array}$ & $1.32[1.01,1.74]$ \\
\hline
\end{tabular}

\section{Analysis 2.1. Comparison 2 Interventions for callers to quitlines - comparison of different intensities, Outcome 1 Cessation at longest follow-up.}

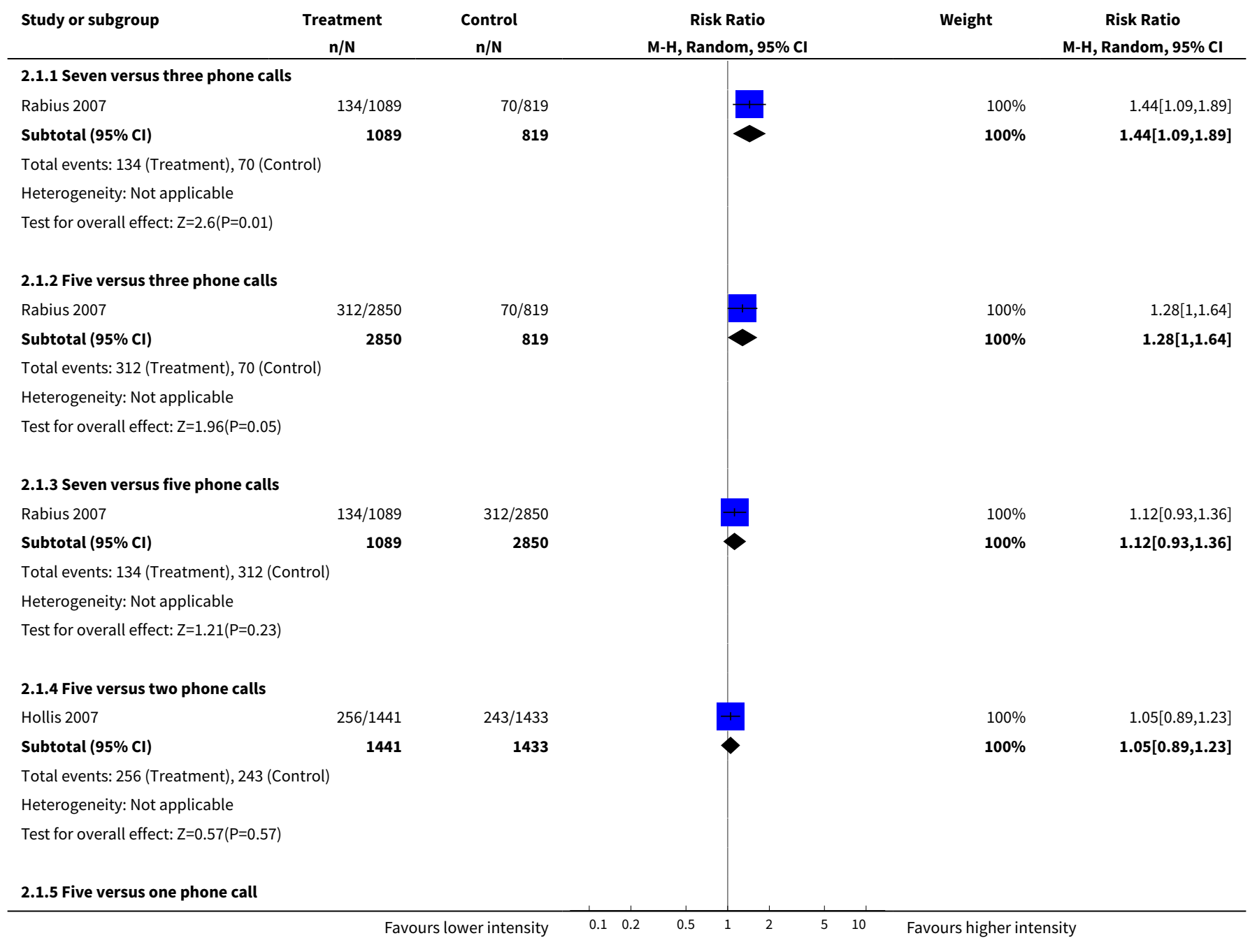




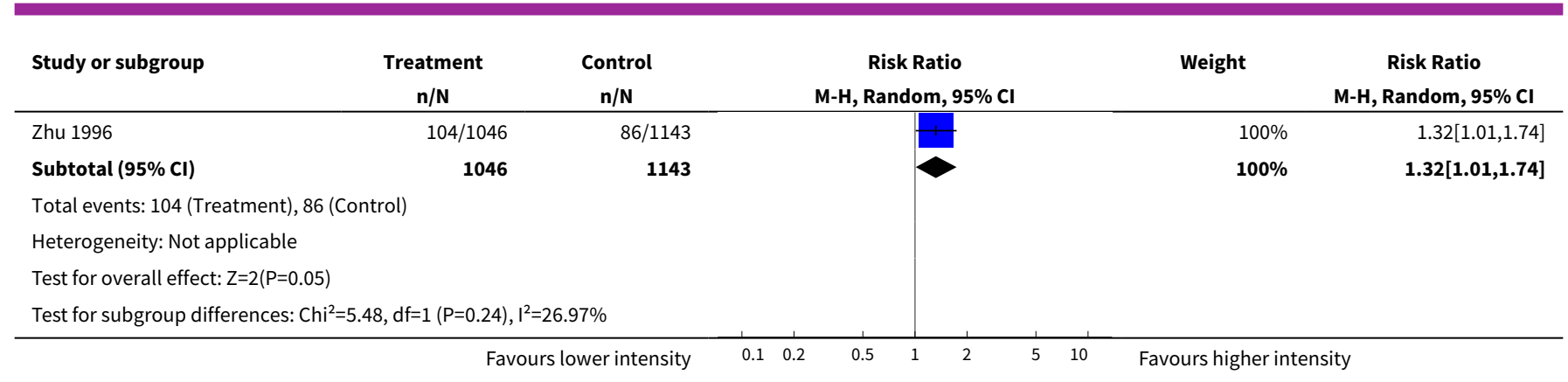

Comparison 3. Interventions for callers to quitlines - subgroups by counseling intensity

\begin{tabular}{lllll}
\hline Outcome or subgroup title & No. of studies & $\begin{array}{l}\text { No. of partici- } \\
\text { pants }\end{array}$ & Statistical method & Effect size \\
\hline $\begin{array}{l}1 \text { Cessation at longest fol- } \\
\text { low-up }\end{array}$ & 14 & 32484 & Risk Ratio (M-H, Random, 95\% Cl) & $1.37[1.20,1.57]$ \\
\hline 1.1 Two sessions or fewer & 2 & 3867 & Risk Ratio (M-H, Random, 95\% Cl) & $1.22[1.02,1.46]$ \\
\hline 1.2 Three to six sessions & 11 & 22612 & Risk Ratio (M-H, Random, 95\% Cl) & $1.38[1.17,1.63]$ \\
\hline 1.3 Seven sessions or more & 4 & 6005 & Risk Ratio (M-H, Random, 95\% Cl) & $1.49[0.98,2.25]$ \\
\hline
\end{tabular}

Analysis 3.1. Comparison 3 Interventions for callers to quitlines - subgroups by counseling intensity, Outcome 1 Cessation at longest follow-up.

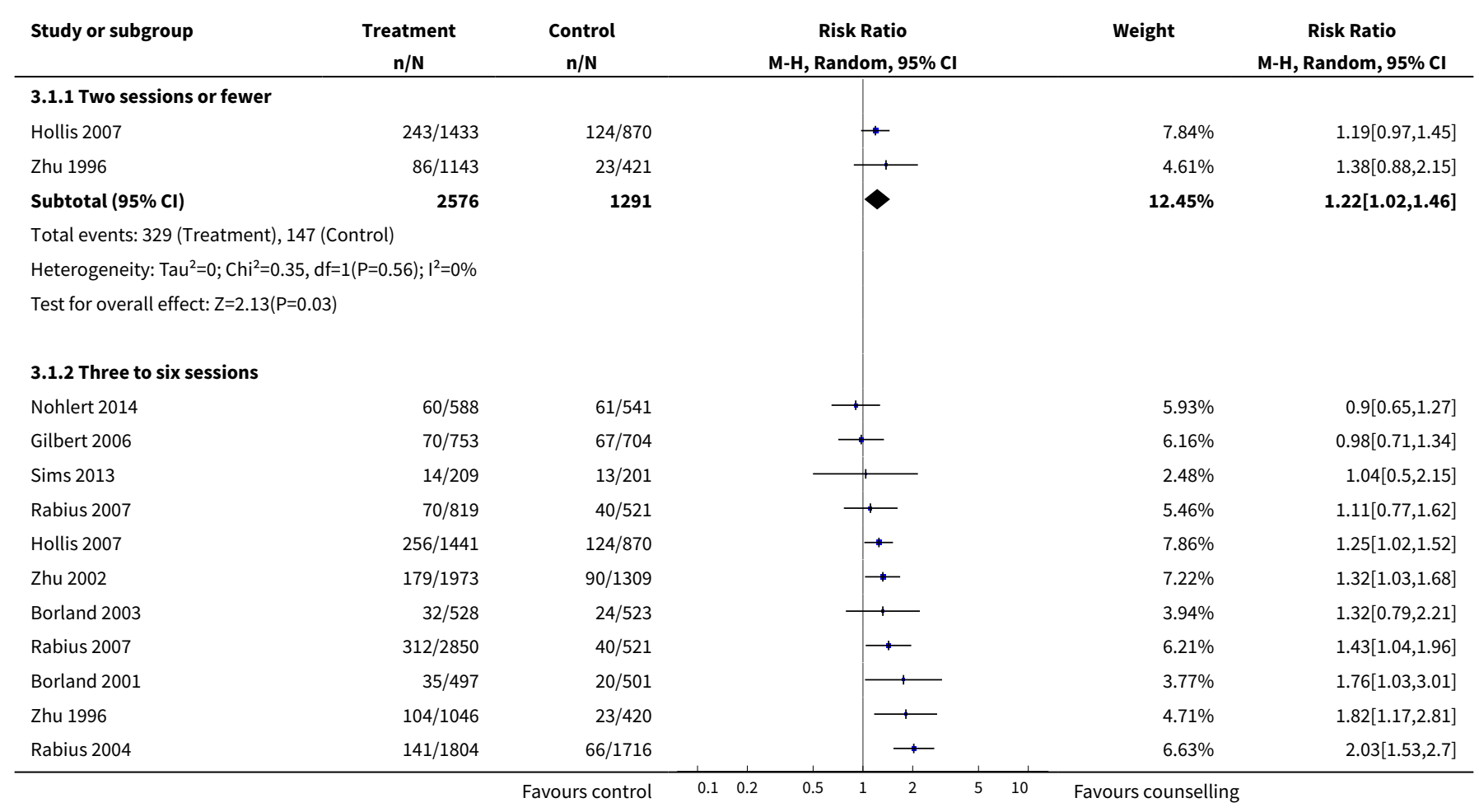




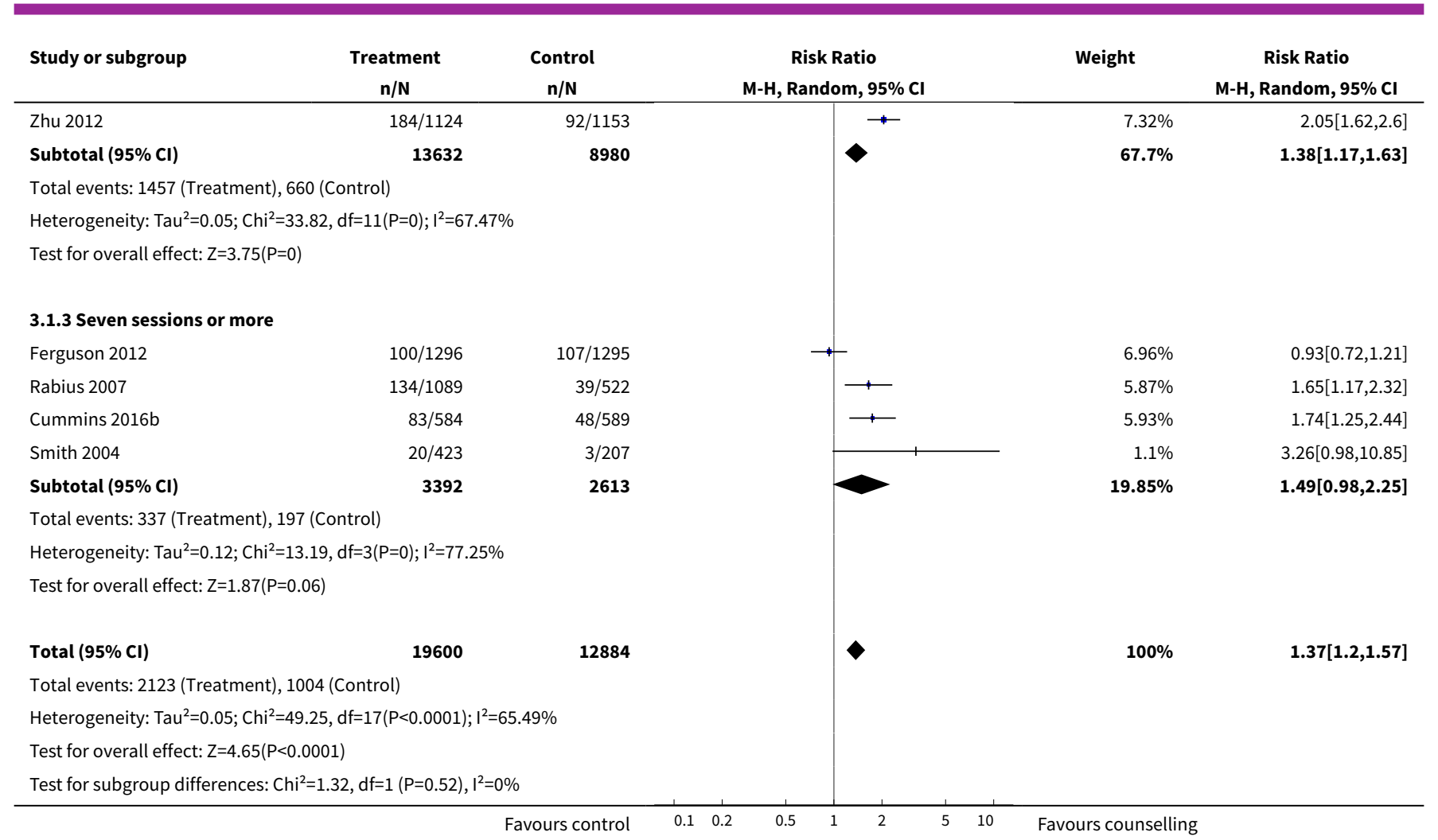

\section{Comparison 4. Interventions for callers to quitlines - comparison of different support at initial call}

\begin{tabular}{|c|c|c|c|c|}
\hline Outcome or subgroup title & No. of studies & $\begin{array}{l}\text { No. of partici- } \\
\text { pants }\end{array}$ & Statistical method & Effect size \\
\hline 1 Cessation at longest follow-up & 5 & & $\begin{array}{l}\text { Risk Ratio (M-H, Random, } \\
95 \% \mathrm{Cl} \text { ) }\end{array}$ & $\begin{array}{l}\text { Totals not select- } \\
\text { ed }\end{array}$ \\
\hline $\begin{array}{l}1.1 \text { Reactive counselling vs self-help } \\
\text { materials }\end{array}$ & 1 & & $\begin{array}{l}\text { Risk Ratio (M-H, Random, } \\
95 \% \mathrm{Cl} \text { ) }\end{array}$ & $0.0[0.0,0.0]$ \\
\hline $\begin{array}{l}\text { 1.2 Tailored counselling versus stan- } \\
\text { dard counselling }\end{array}$ & 1 & & $\begin{array}{l}\text { Risk Ratio (M-H, Random, } \\
95 \% \mathrm{Cl} \text { ) }\end{array}$ & $0.0[0.0,0.0]$ \\
\hline $\begin{array}{l}\text { 1.3 Stage-based counselling versus } \\
\text { general information }\end{array}$ & 1 & & $\begin{array}{l}\text { Risk Ratio (M-H, Random, } \\
95 \% \mathrm{Cl} \text { ) }\end{array}$ & $0.0[0.0,0.0]$ \\
\hline 1.4 ACT + NRT versus CBT + NRT & 1 & & $\begin{array}{l}\text { Risk Ratio (M-H, Random, } \\
95 \% \mathrm{Cl} \text { ) }\end{array}$ & $0.0[0.0,0.0]$ \\
\hline $\begin{array}{l}\text { 1.5 Motivational Interviewing TC versus } \\
\text { standard TC }\end{array}$ & 1 & & $\begin{array}{l}\text { Risk Ratio (M-H, Random, } \\
95 \% \mathrm{Cl})\end{array}$ & $0.0[0.0,0.0]$ \\
\hline
\end{tabular}


Analysis 4.1. Comparison 4 Interventions for callers to quitlines - comparison of different support at initial call, Outcome 1 Cessation at longest follow-up.

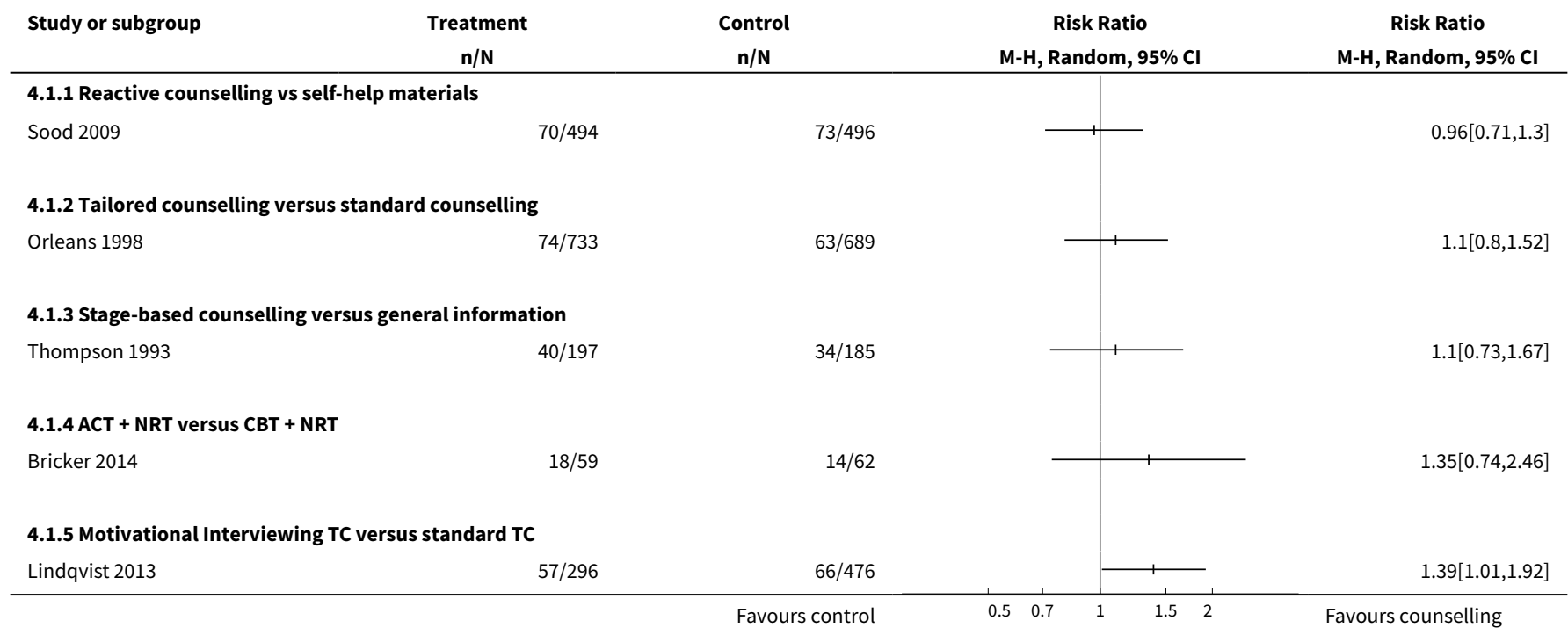

\section{Comparison 5. Offer of counselling via quitlines/helplines/hotlines}

\begin{tabular}{|c|c|c|c|c|}
\hline Outcome or subgroup title & No. of studies & $\begin{array}{l}\text { No. of partici- } \\
\text { pants }\end{array}$ & Statistical method & Effect size \\
\hline 1 Cessation at longest follow-up & 7 & & $\begin{array}{l}\text { Risk Ratio (M-H, Random, } \\
95 \% \mathrm{Cl} \text { ) }\end{array}$ & Subtotals only \\
\hline $\begin{array}{l}\text { 1.1 Hotline and self-help materials com- } \\
\text { pared to minimal intervention }\end{array}$ & 2 & 3327 & $\begin{array}{l}\text { Risk Ratio (M-H, Random, } \\
95 \% \mathrm{Cl})\end{array}$ & $1.62[1.16,2.25]$ \\
\hline $\begin{array}{l}1.2 \text { Hotline and self-help materials for } \\
\text { cessation maintenance compared to } \\
\text { nothing }\end{array}$ & 1 & 1311 & $\begin{array}{l}\text { Risk Ratio (M-H, Random, } \\
95 \% \mathrm{Cl} \text { ) }\end{array}$ & $0.86[0.70,1.06]$ \\
\hline $\begin{array}{l}1.3 \text { Reactive or proactive counselling vs } \\
\text { provider counselling }\end{array}$ & 4 & 7780 & $\begin{array}{l}\text { Risk Ratio (M-H, Random, } \\
95 \% \mathrm{Cl} \text { ) }\end{array}$ & $1.40[1.07,1.84]$ \\
\hline $\begin{array}{l}\text { 1.4 Proactive counselling vs reactive } \\
\text { counselling }\end{array}$ & 2 & 2908 & $\begin{array}{l}\text { Risk Ratio (M-H, Random, } \\
95 \% \mathrm{Cl} \text { ) }\end{array}$ & $2.06[0.58,7.31]$ \\
\hline 1.5 Proactive counselling vs self-help & 2 & 2498 & $\begin{array}{l}\text { Risk Ratio (M-H, Random, } \\
95 \% \mathrm{Cl} \text { ) }\end{array}$ & $1.42[0.76,2.63]$ \\
\hline 1.6 Reactive counselling vs self-help & 2 & 2364 & $\begin{array}{l}\text { Risk Ratio (M-H, Random, } \\
95 \% \mathrm{Cl} \text { ) }\end{array}$ & $0.78[0.44,1.40]$ \\
\hline
\end{tabular}


Analysis 5.1. Comparison 5 Offer of counselling via quitlines/ helplines/hotlines, Outcome 1 Cessation at longest follow-up.

\begin{tabular}{lcr} 
Study or subgroup & $\begin{array}{c}\text { Treatment } \\
\mathbf{n} / \mathbf{N}\end{array}$ & $\begin{array}{c}\text { Control } \\
\mathbf{n} / \mathbf{N}\end{array}$ \\
\hline $\begin{array}{l}\mathbf{5 . 1 . 1} \text { Hotline and self-help materials compared to minimal interven- } \\
\text { tion }\end{array}$ & $56 / 894$ & $34 / 919$ \\
Ossip-Klein 1991 & $37 / 836$ & $20 / 678$ \\
Zwar 2015 & $\mathbf{1 7 3 0}$ & $\mathbf{1 5 9 7}$ \\
Subtotal (95\% Cl) & \\
Total events: 93 (Treatment), 54 (Control) & \\
Heterogeneity: Tau $^{2}=0 ; \mathrm{Chi}^{2}=0.12, \mathrm{df}=1(\mathrm{P}=0.73) ;\left.\right|^{2}=0 \%$ & \\
Test for overall effect: $\mathrm{Z}=2.87(\mathrm{P}=0)$ &
\end{tabular}

\subsubsection{Hotline and self-help materials for cessation maintenance com-} pared to nothing

McFall 1993

$\begin{array}{rr}180 / 873 & 105 / 438 \\ \mathbf{8 7 3} & \mathbf{4 3 8}\end{array}$

Subtotal $(95 \% \mathrm{Cl})$

438

Total events: 180 (Treatment), 105 (Control)

Heterogeneity: Not applicable

Test for overall effect: $Z=1.4(P=0.16)$

5.1.3 Reactive or proactive counselling vs provider counselling

$\begin{array}{lrr}\text { Joyce } 2008 & 326 / 1690 & 412 / 2605 \\ \text { Rogers } 2016 & 49 / 270 & 38 / 307 \\ \text { Sherman } 2017 & 157 / 1069 & 120 / 934 \\ \text { Skov-Ettrup 2016 } & 33 / 452 & 8 / 453 \\ \text { Subtotal (95\% Cl) } & \mathbf{3 4 8 1} & \mathbf{4 2 9 9}\end{array}$

Total events: 565 (Treatment), 578 (Control)

Heterogeneity: $\mathrm{Tau}^{2}=0.05 ; \mathrm{Chi}^{2}=10.94, \mathrm{df}=3(\mathrm{P}=0.01) ; \mathrm{I}^{2}=72.58 \%$

Test for overall effect: $Z=2.42(P=0.02)$

5.1.4 Proactive counselling vs reactive counselling

$\begin{array}{lr}\text { Sherman } 2017 & 157 / 1069 \\ \text { Skov-Ettrup } 2016 & 33 / 452 \\ \text { Subtotal (95\% Cl) } & \mathbf{1 5 2 1}\end{array}$

1521

Total events: 190 (Treatment), 128 (Control)

Heterogeneity: $\mathrm{Tau}^{2}=0.76 ; \mathrm{Chi}^{2}=10.26, \mathrm{df}=1(\mathrm{P}=0) ; \mathrm{I}^{2}=90.25 \%$

Test for overall effect: $Z=1.12(P=0.26)$

\subsubsection{Proactive counselling vs self-help}

Sherman 2017

$157 / 1069$

$33 / 452$

Skov-Ettrup 2016

1521

Subtotal $(95 \% \mathrm{Cl})$

Total events: 190 (Treatment), 87 (Control)

Heterogeneity: $\mathrm{Tau}^{2}=0.15 ; \mathrm{Chi}^{2}=3.9, \mathrm{df}=1(\mathrm{P}=0.05) ; \mathrm{I}^{2}=74.34 \%$

Test for overall effect: $Z=1.1(P=0.27)$

5.1.6 Reactive counselling vs self-help

Sherman 2017

Skov-Ettrup 2016

$120 / 934 \quad 71 / 525$

$120 / 934$

$8 / 453$

1387

Subtotal $(95 \% \mathrm{Cl})$

Risk Ratio

M-H, Random, $95 \% \mathrm{Cl}$
Risk Ratio M-H, Random, $95 \% \mathrm{Cl}$

Total events: 128 (Treatment), 87 (Control)

Heterogeneity: $\mathrm{Tau}^{2}=0.11 ; \mathrm{Chi}^{2}=2.06, \mathrm{df}=1(\mathrm{P}=0.15) ; \mathrm{I}^{2}=51.38 \%$

Test for overall effect: $\mathrm{Z}=0.83(\mathrm{P}=0.41)$

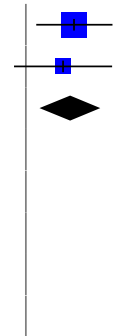

$62.27 \%$

$1.69[1.12,2.57]$

$37.73 \%$

$1.5[0.88,2.56]$

$100 \%$

$1.62[1.16,2.25]$
$0.86[0.7,1.06]$

$100 \%$

$\mathbf{0 . 8 6}[0.7,1.06]$
1.22[1.07,1.39]

$1.47[0.99,2.17]$

$1.14[0.92,1.43]$

4.13[1.93,8.85]

$1.4[1.07,1.84]$
$1.14[0.92,1.43]$

4.13[1.93,8.85]

$45.88 \%$

$100 \%$ 


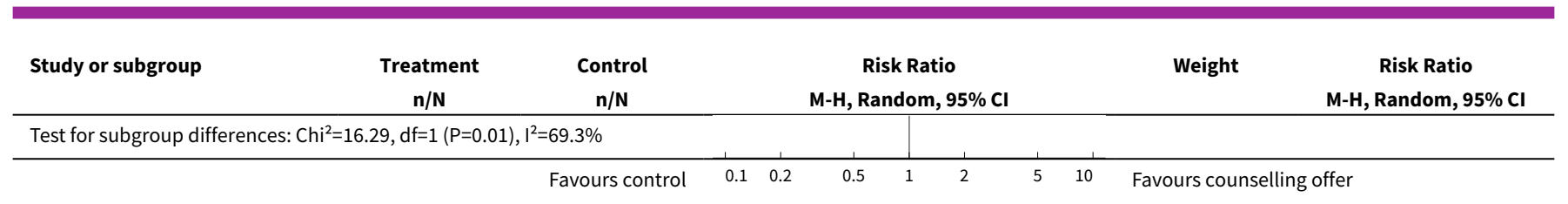

\section{Comparison 6. Interventions for smokers not calling quitlines - subgroups by baseline support}

\begin{tabular}{|c|c|c|c|c|}
\hline Outcome or subgroup title & No. of studies & $\begin{array}{l}\text { No. of partici- } \\
\text { pants }\end{array}$ & Statistical method & Effect size \\
\hline 1 Cessation at longest follow-up & 65 & 41233 & $\begin{array}{l}\text { Risk Ratio (M-H, Random, } \\
95 \% \mathrm{Cl} \text { ) }\end{array}$ & $1.25[1.15,1.35]$ \\
\hline $\begin{array}{l}\text { 1.1 Adjunct to self-help or minimal in- } \\
\text { tervention }\end{array}$ & 35 & 22917 & $\begin{array}{l}\text { Risk Ratio (M-H, Random, } \\
95 \% \mathrm{Cl})\end{array}$ & $1.35[1.16,1.57]$ \\
\hline $\begin{array}{l}\text { 1.2 Adjunct to brief intervention or } \\
\text { counselling }\end{array}$ & 12 & 4234 & $\begin{array}{l}\text { Risk Ratio (M-H, Random, } \\
95 \% \mathrm{CI})\end{array}$ & $1.30[1.12,1.50]$ \\
\hline 1.3 Adjunct to pharmacotherapy & 18 & 12865 & $\begin{array}{l}\text { Risk Ratio (M-H, Random, } \\
95 \% \mathrm{CI})\end{array}$ & $1.14[1.03,1.26]$ \\
\hline $\begin{array}{l}\text { 1.4 Adjunct to incentives for smoking } \\
\text { cessation }\end{array}$ & 1 & 1217 & $\begin{array}{l}\text { Risk Ratio (M-H, Random, } \\
95 \% \mathrm{Cl} \text { ) }\end{array}$ & $1.05[0.67,1.65]$ \\
\hline
\end{tabular}

Analysis 6.1. Comparison 6 Interventions for smokers not calling quitlines - subgroups by baseline support, Outcome 1 Cessation at longest follow-up.

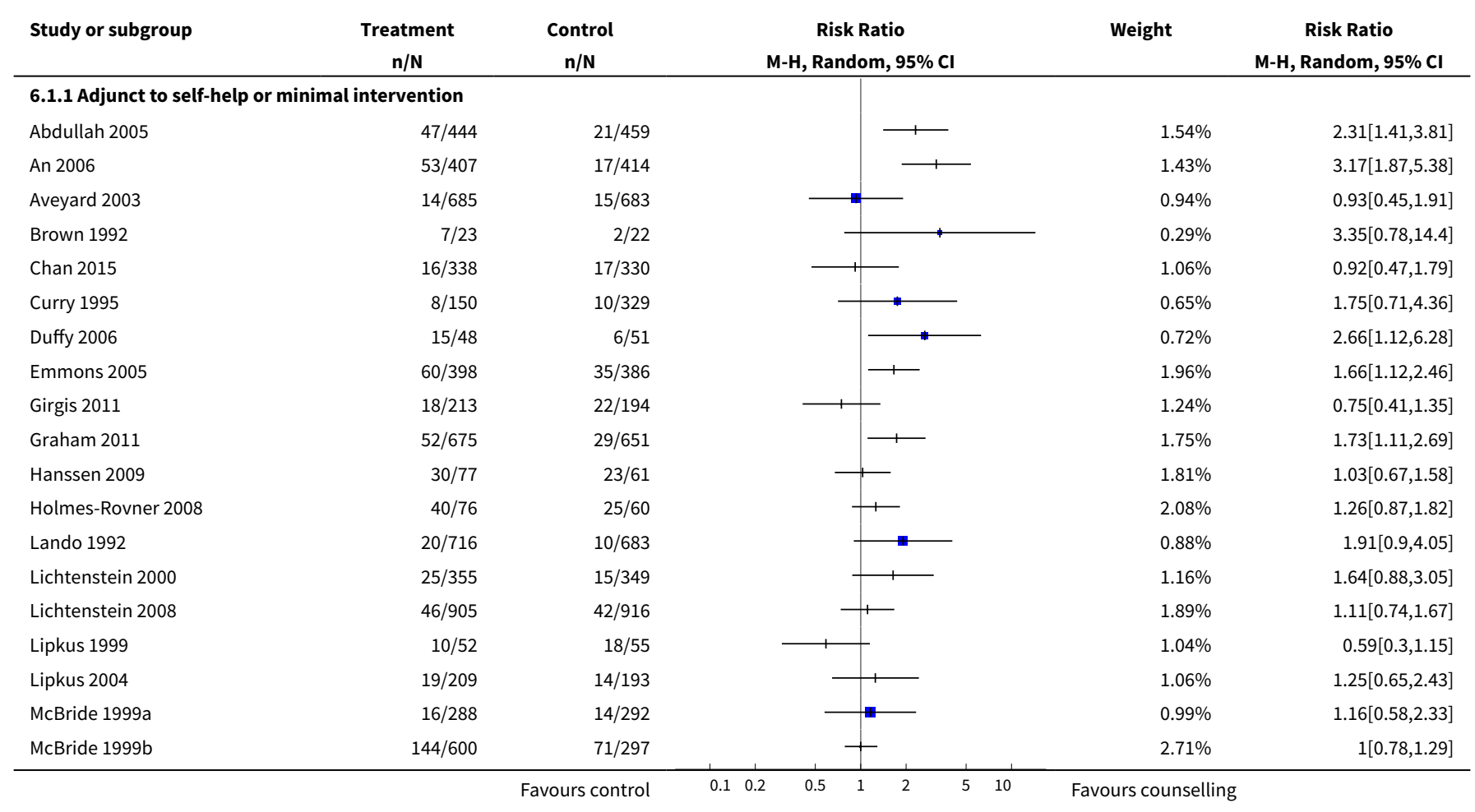




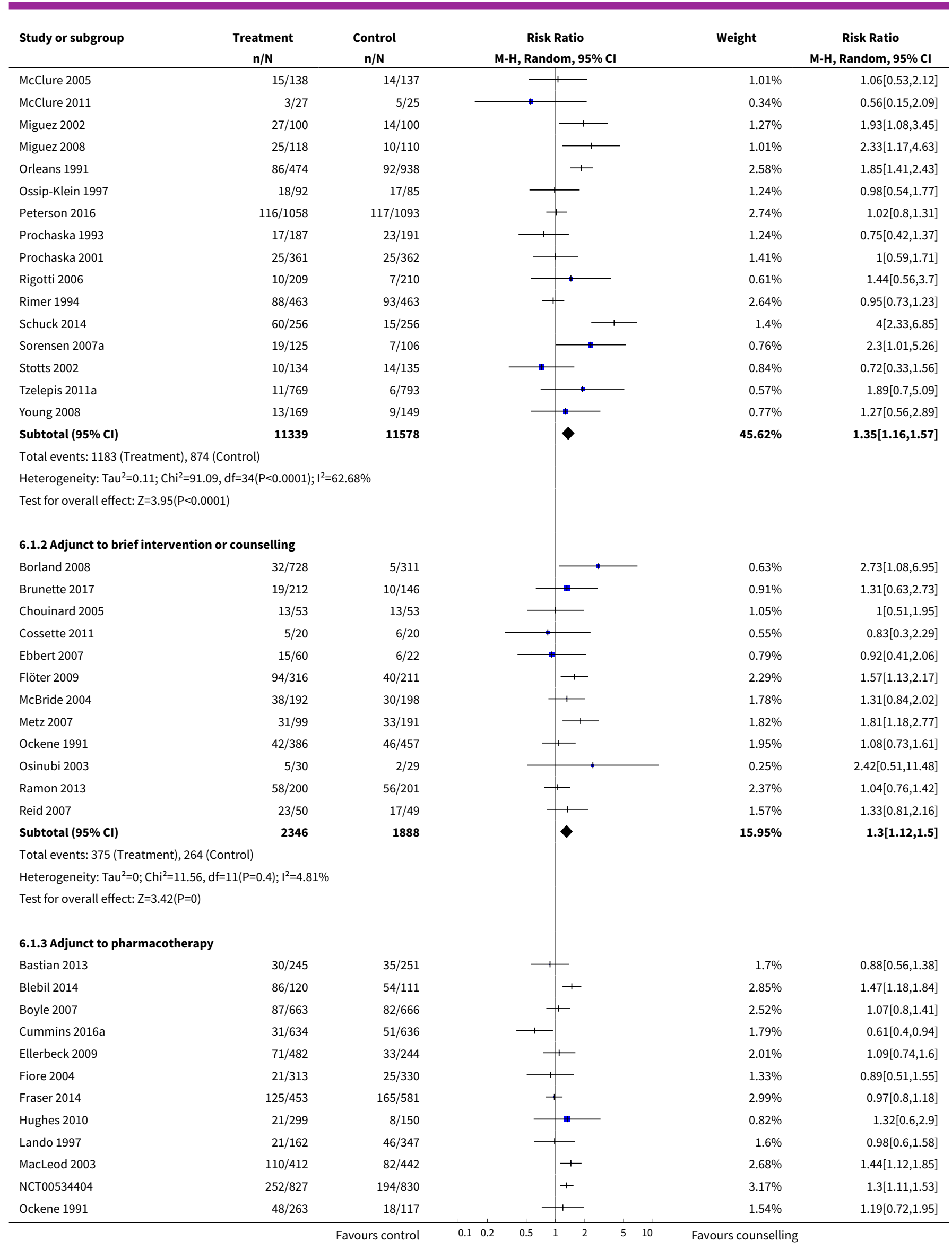

Telephone counselling for smoking cessation (Review) 


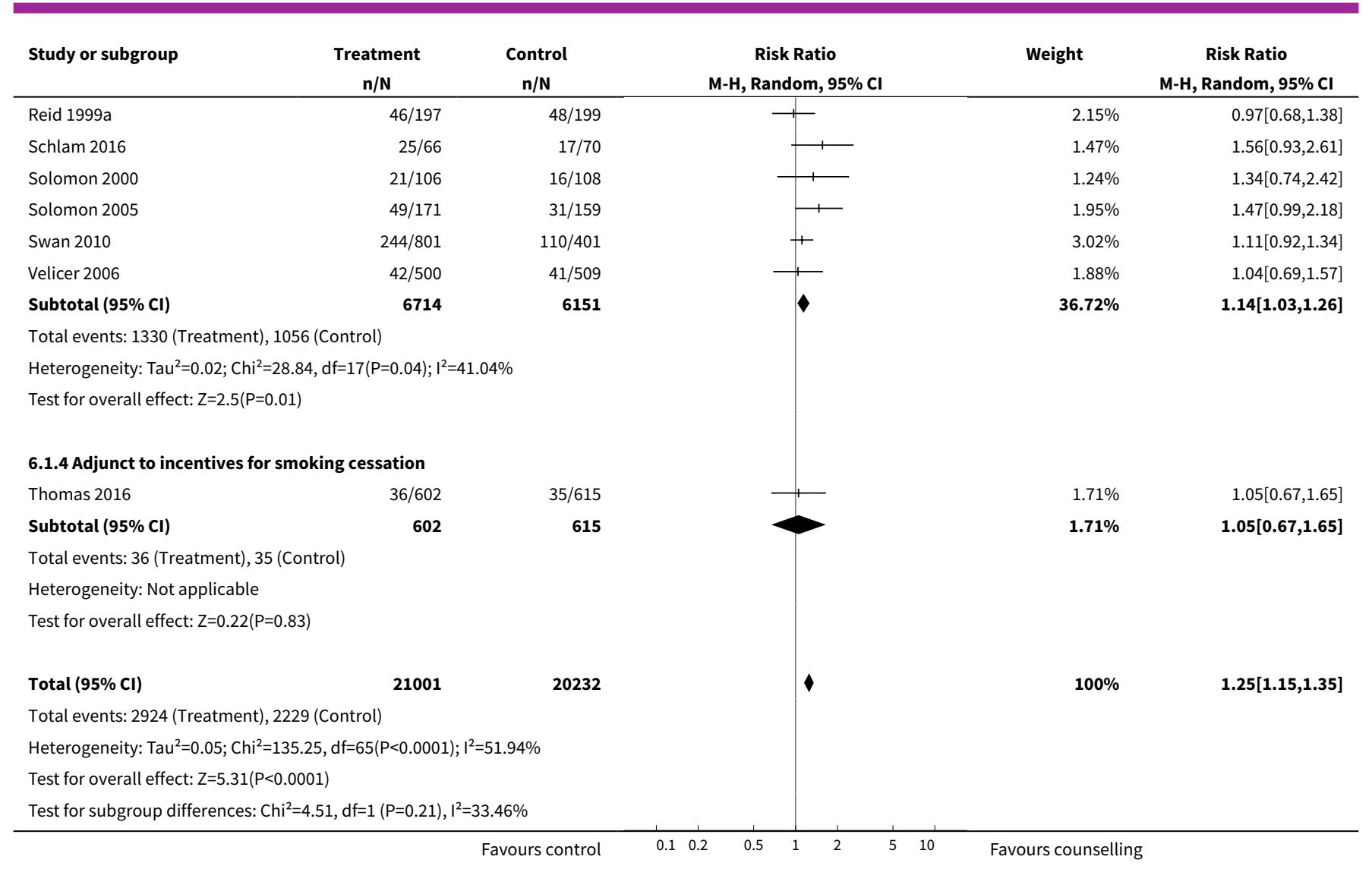

Comparison 7. Interventions for smokers not calling quitlines - intense versus minimal telephone counselling

\begin{tabular}{lllll}
\hline Outcome or subgroup title & No. of studies & $\begin{array}{l}\text { No. of partici- } \\
\text { pants }\end{array}$ & Statistical method & Effect size \\
\hline 1 Cessation at longest follow-up & 3 & 2602 & $\begin{array}{l}\text { Risk Ratio (M-H, Random, 95\% } \\
\text { Cl) }\end{array}$ & 1.27 [1.12, 1.44] \\
\hline
\end{tabular}

Analysis 7.1. Comparison 7 Interventions for smokers not calling quitlines - intense versus minimal telephone counselling, Outcome 1 Cessation at longest follow-up.

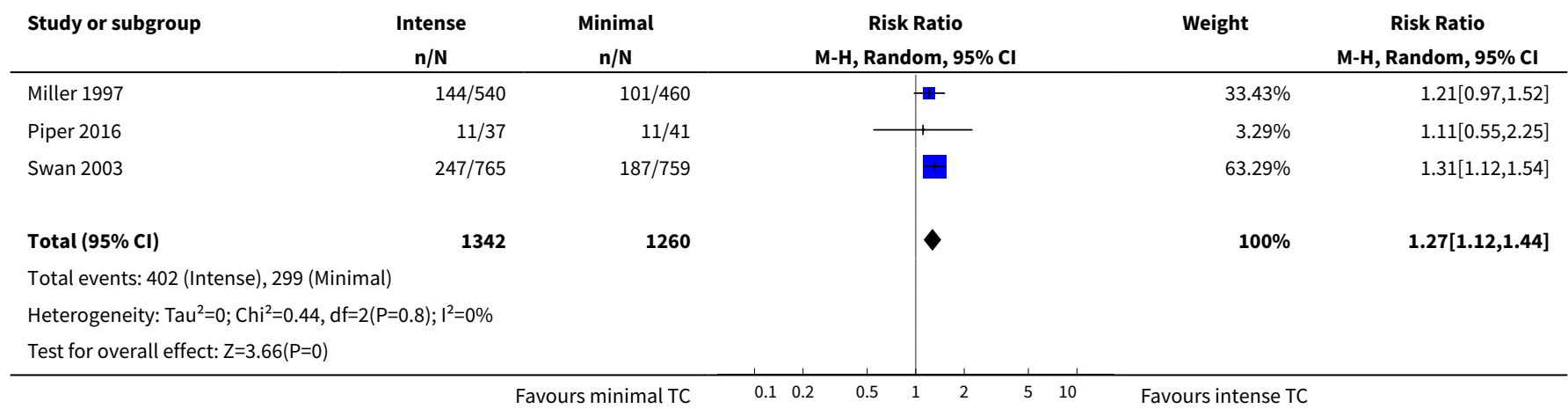


Comparison 8. Interventions for smokers not calling quitlines - subgroups by counseling intensity

\begin{tabular}{llllll}
\hline Outcome or subgroup title & No. of studies & $\begin{array}{l}\text { No. of partici- } \\
\text { pants }\end{array}$ & Statistical method & Effect size \\
\hline $\begin{array}{lllll}1 \text { Cessation at longest fol- } \\
\text { low-up }\end{array}$ & 65 & 41233 & Risk Ratio (M-H, Random, 95\% Cl) & $1.25[1.15,1.35]$ \\
\hline 1.1 Two sessions or fewer & 9 & 6274 & Risk Ratio (M-H, Random, 95\% Cl) & $1.09[0.86,1.40]$ \\
\hline 1.2 Three to six sessions & 44 & 26686 & Risk Ratio (M-H, Random, 95\% Cl) & $1.29[1.18,1.42]$ \\
\hline 1.3 Seven sessions or more & 13 & 8273 & Risk Ratio (M-H, Random, 95\% Cl) & $1.22[0.98,1.51]$ \\
\hline
\end{tabular}

Analysis 8.1. Comparison 8 Interventions for smokers not calling quitlines subgroups by counseling intensity, Outcome 1 Cessation at longest follow-up.

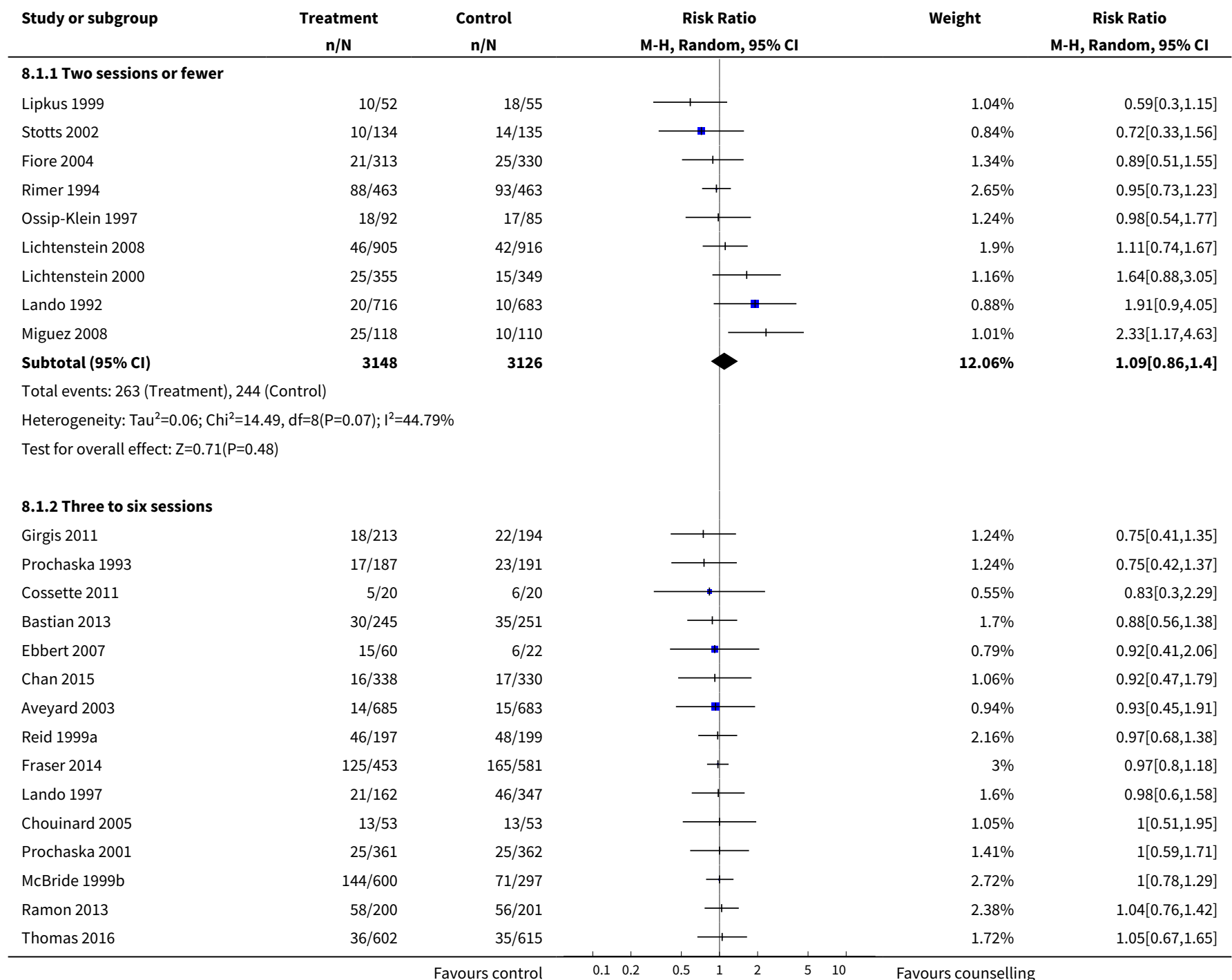




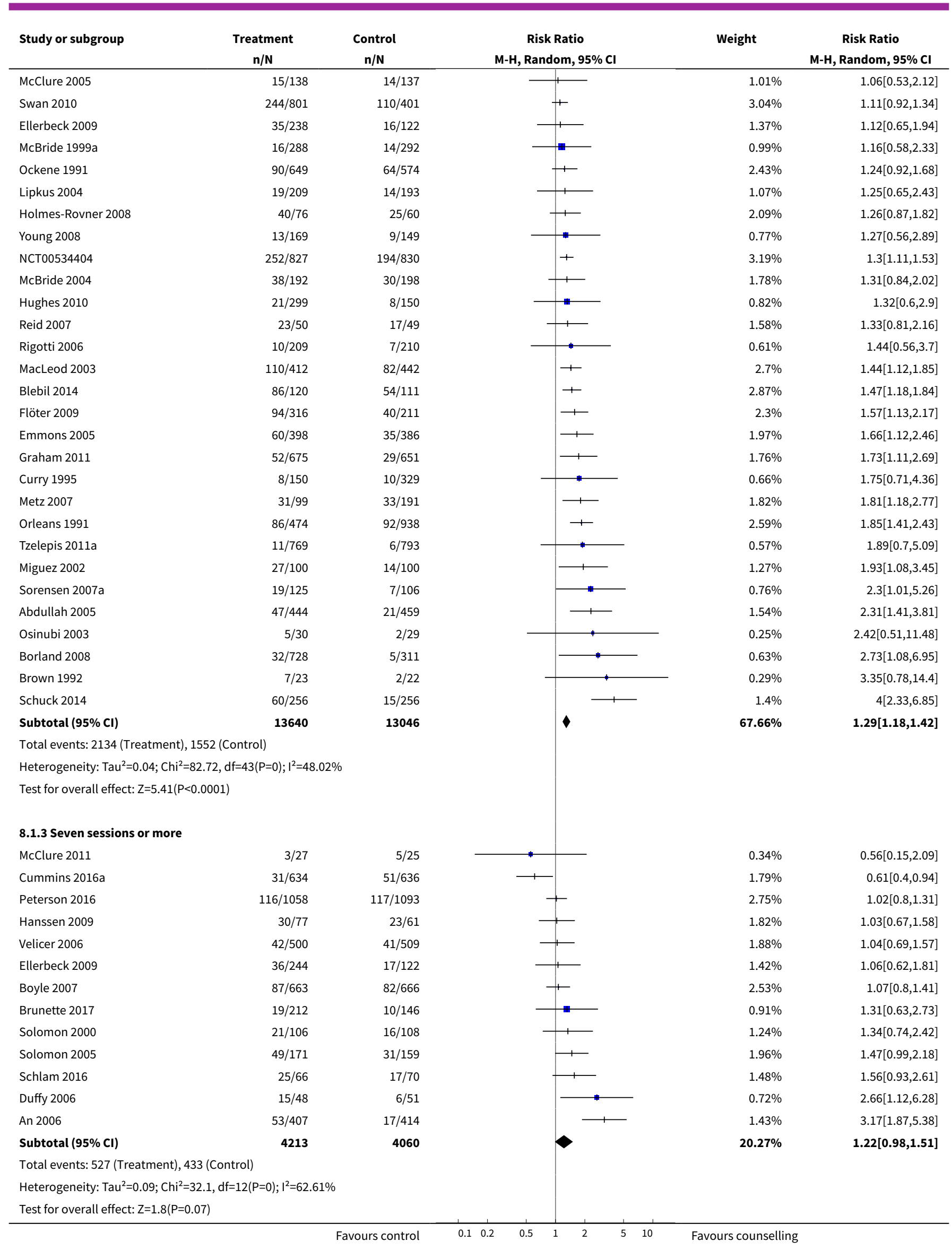

Telephone counselling for smoking cessation (Review) 


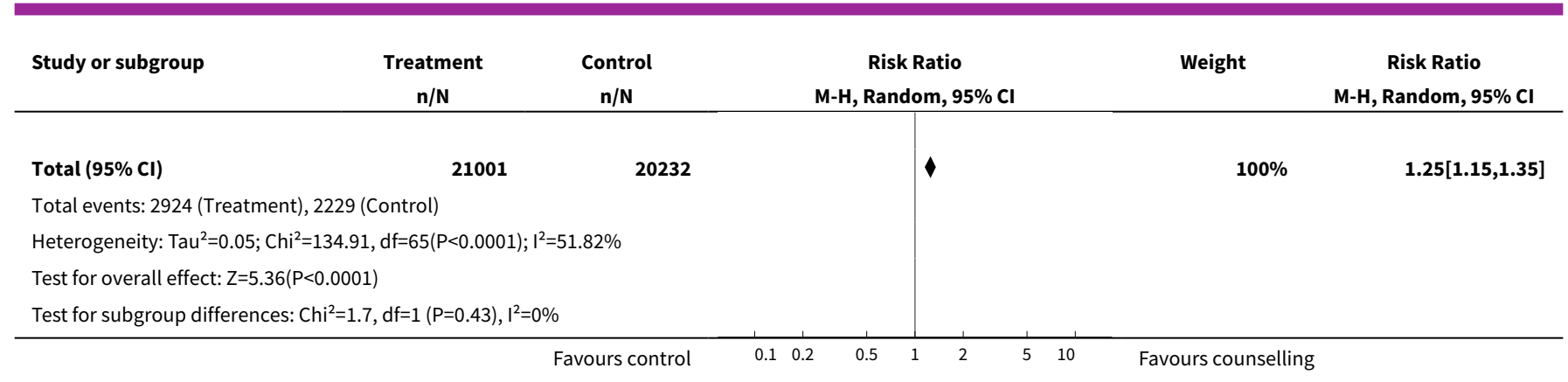

Comparison 9. Interventions for smokers not calling quitlines - subgroups by motivation

\begin{tabular}{lllll}
\hline Outcome or subgroup title & No. of studies & $\begin{array}{l}\text { No. of partici- } \\
\text { pants }\end{array}$ & Statistical method & Effect size \\
\hline 1 Cessation at longest follow-up & 65 & 41233 & $\begin{array}{l}\text { Risk Ratio (M-H, Random, 95\% } \\
\text { Cl) }\end{array}$ & 1.25 [1.15, 1.36] \\
\hline $\begin{array}{l}1.1 \text { Selected for motivation/interest } \\
\text { in quitting }\end{array}$ & 26 & 17877 & $\begin{array}{l}\text { Risk Ratio (M-H, Random, 95\% } \\
\text { Cl) }\end{array}$ & $1.31[1.15,1.49]$ \\
\hline 1.2 Not selected for motivation & 39 & 23356 & $\begin{array}{l}\text { Risk Ratio (M-H, Random, 95\% } \\
\text { Cl) }\end{array}$ & 1.20 [1.09, 1.33] \\
\hline
\end{tabular}

\section{Analysis 9.1. Comparison 9 Interventions for smokers not calling quitlines - subgroups by motivation, Outcome 1 Cessation at longest follow-up.}

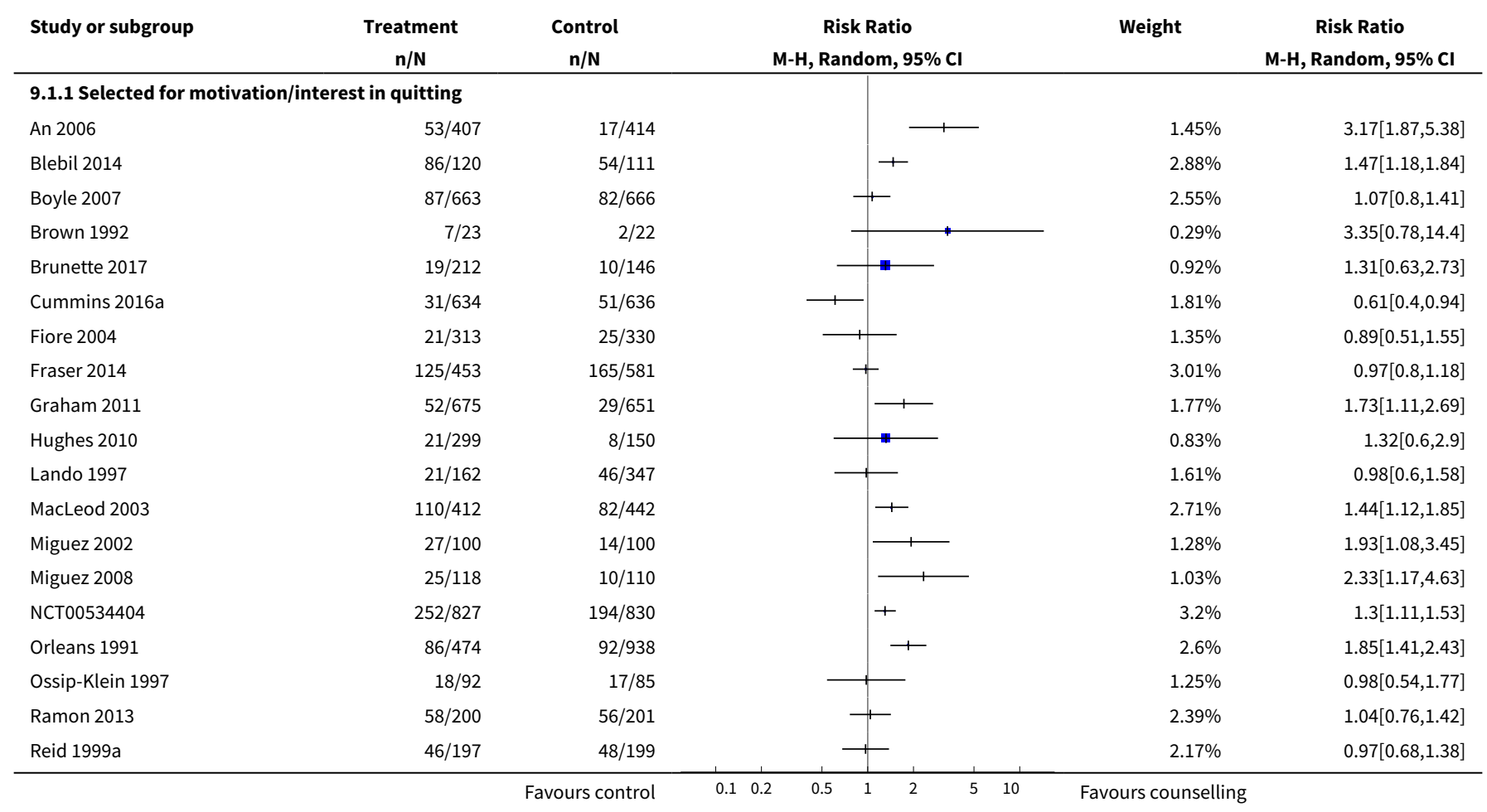




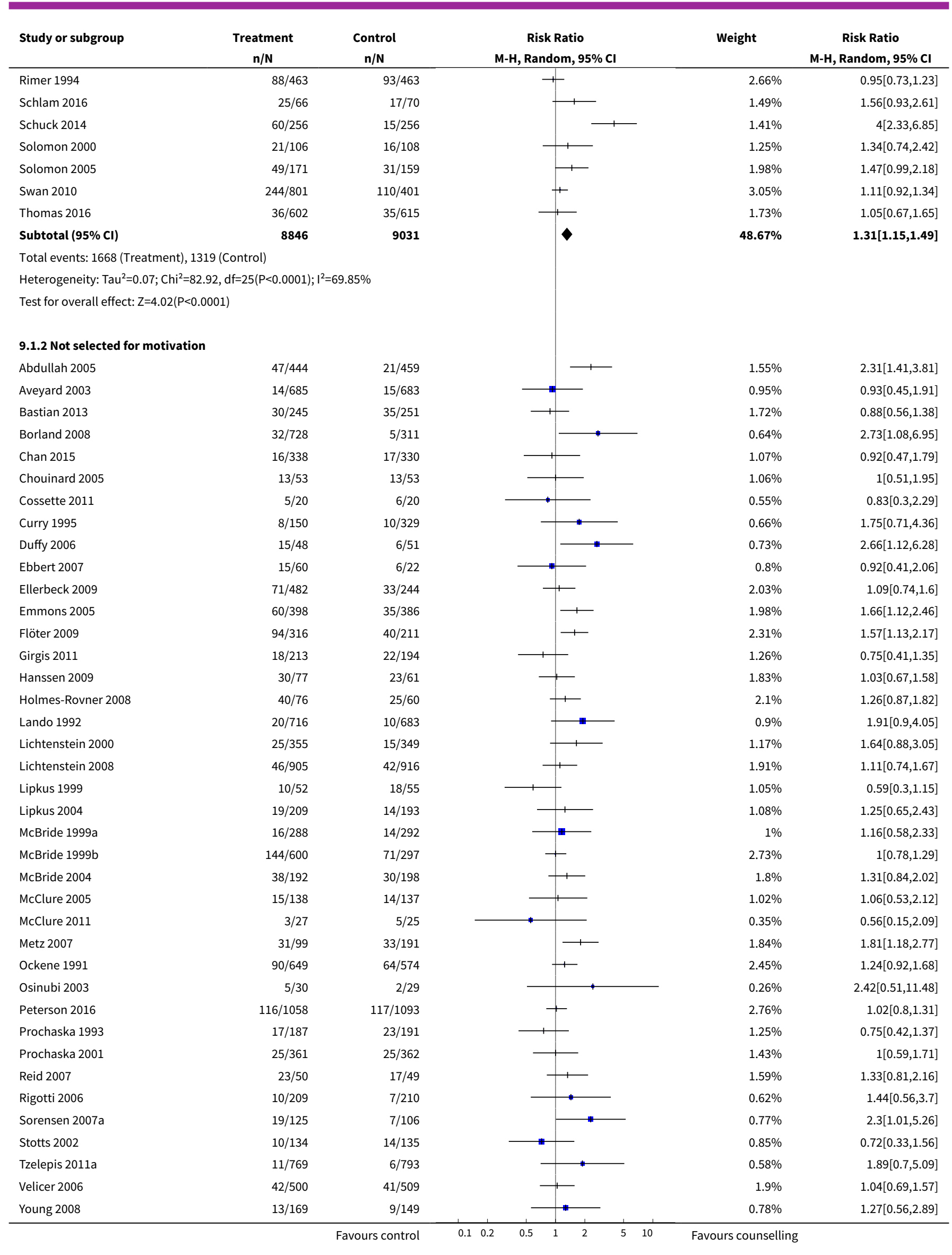

Telephone counselling for smoking cessation (Review) 


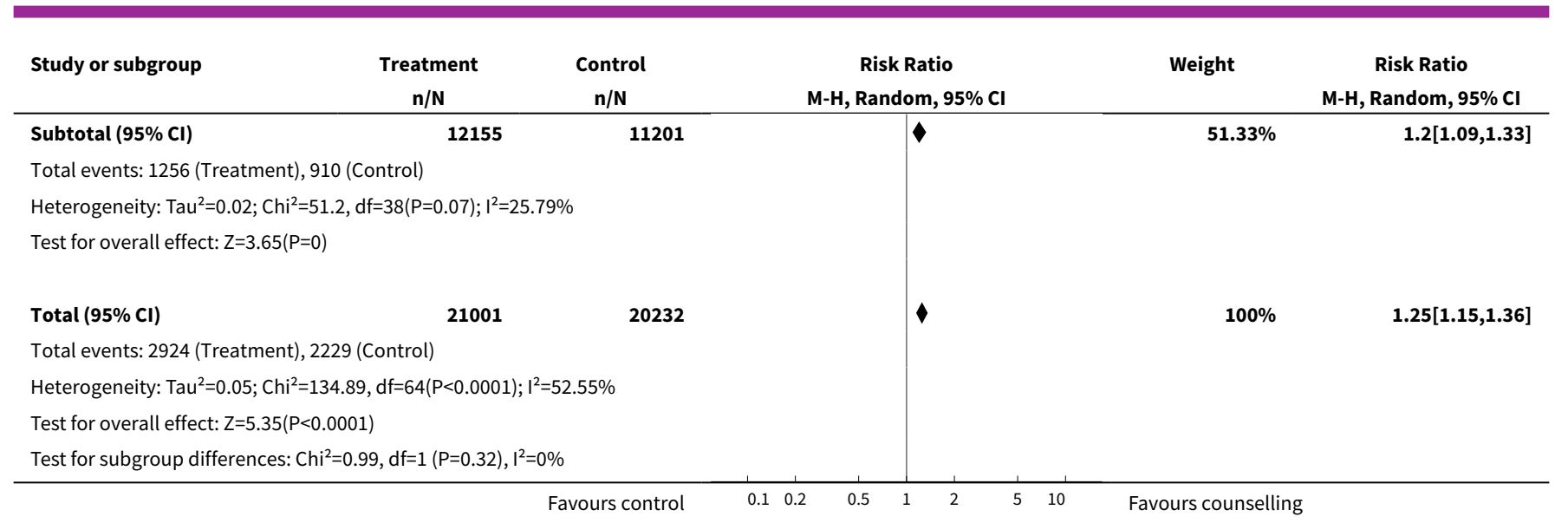

\section{Comparison 10. Other studies}

\begin{tabular}{|c|c|c|c|c|}
\hline Outcome or subgroup title & No. of studies & $\begin{array}{l}\text { No. of partici- } \\
\text { pants }\end{array}$ & Statistical method & Effect size \\
\hline 1 Cessation at longest follow-up & 10 & & $\begin{array}{l}\text { Risk Ratio (M-H, Random, } \\
95 \% \mathrm{Cl} \text { ) }\end{array}$ & Subtotals only \\
\hline $\begin{array}{l}\text { 1.1 Family-supported vs standard tele- } \\
\text { phone counseling }\end{array}$ & 1 & 471 & $\begin{array}{l}\text { Risk Ratio (M-H, Random, } \\
95 \% \mathrm{Cl} \text { ) }\end{array}$ & $1.02[0.72,1.45]$ \\
\hline $\begin{array}{l}\text { 1.2 Parental focused telephone counsel- } \\
\text { ing vs nutrition counseling }\end{array}$ & 1 & 327 & $\begin{array}{l}\text { Risk Ratio (M-H, Random, } \\
95 \% \mathrm{Cl} \text { ) }\end{array}$ & $2.01[0.97,4.17]$ \\
\hline $\begin{array}{l}\text { 1.3 Brief motivational vs standard tele- } \\
\text { phone counseling }\end{array}$ & 1 & 374 & $\begin{array}{l}\text { Risk Ratio (M-H, Random, } \\
95 \% \mathrm{Cl})\end{array}$ & $2.63[1.12,6.14]$ \\
\hline $\begin{array}{l}\text { 1.4 Smoking reduction vs brief motiva- } \\
\text { tional telephone counseling }\end{array}$ & 1 & 371 & $\begin{array}{l}\text { Risk Ratio (M-H, Random, } \\
95 \% \mathrm{Cl})\end{array}$ & $0.88[0.47,1.68]$ \\
\hline $\begin{array}{l}\text { 1.5 Smoking reduction vs standard tele- } \\
\text { phone counseling }\end{array}$ & 1 & 375 & $\begin{array}{l}\text { Risk Ratio (M-H, Random, } \\
95 \% \mathrm{Cl})\end{array}$ & $2.32[0.98,5.52]$ \\
\hline $\begin{array}{l}1.6 \text { Nondirective vs directive telephone } \\
\text { coaching }\end{array}$ & 1 & 518 & $\begin{array}{l}\text { Risk Ratio (M-H, Random, } \\
95 \% \mathrm{Cl})\end{array}$ & $1.15[0.82,1.62]$ \\
\hline $\begin{array}{l}\text { 1.7 Tailored telephone counseling vs } \\
\text { state tobacco quitline referral }\end{array}$ & 1 & 63 & $\begin{array}{l}\text { Risk Ratio (M-H, Random, } \\
95 \% \mathrm{Cl} \text { ) }\end{array}$ & $1.03[0.47,2.25]$ \\
\hline $\begin{array}{l}\text { 1.8 Brief quitline facilitation vs brief ces- } \\
\text { sation advice }\end{array}$ & 1 & 600 & $\begin{array}{l}\text { Risk Ratio (M-H, Random, } \\
95 \% \mathrm{Cl} \text { ) }\end{array}$ & $1.62[0.96,2.72]$ \\
\hline $\begin{array}{l}\text { 1.9 Smoking-reduction vs exercise \& diet } \\
\text { telephone counseling }\end{array}$ & 1 & 369 & $\begin{array}{l}\text { Risk Ratio (M-H, Random, } \\
95 \% \mathrm{Cl} \text { ) }\end{array}$ & $2.86[0.93,8.81]$ \\
\hline $\begin{array}{l}\text { 1.10 Medication adherence vs standard } \\
\text { telephone counseling }\end{array}$ & 1 & 987 & $\begin{array}{l}\text { Risk Ratio (M-H, Random, } \\
95 \% \mathrm{Cl} \text { ) }\end{array}$ & $0.98[0.83,1.15]$ \\
\hline $\begin{array}{l}\text { 1.11 Automated telephone follow-up vs } \\
\text { standard care }\end{array}$ & 1 & 440 & $\begin{array}{l}\text { Risk Ratio (M-H, Random, } \\
95 \% \mathrm{Cl} \text { ) }\end{array}$ & $1.22[0.92,1.60]$ \\
\hline
\end{tabular}




\begin{tabular}{lllll}
\hline Outcome or subgroup title & No. of studies & $\begin{array}{l}\text { No. of partici- } \\
\text { pants }\end{array}$ & Statistical method & Effect size \\
\hline $\begin{array}{l}1.12 \text { Coverage for telephone counseling } \\
\text { and pharmacotherapy vs pharmacothera- } \\
\text { py alone }\end{array}$ & 1 & 266 & $\begin{array}{l}\text { Risk Ratio (M-H, Random, } \\
95 \% \mathrm{Cl})\end{array}$ & $0.68[0.38,1.18]$ \\
\hline
\end{tabular}

Analysis 10.1. Comparison 10 Other studies, Outcome 1 Cessation at longest follow-up.

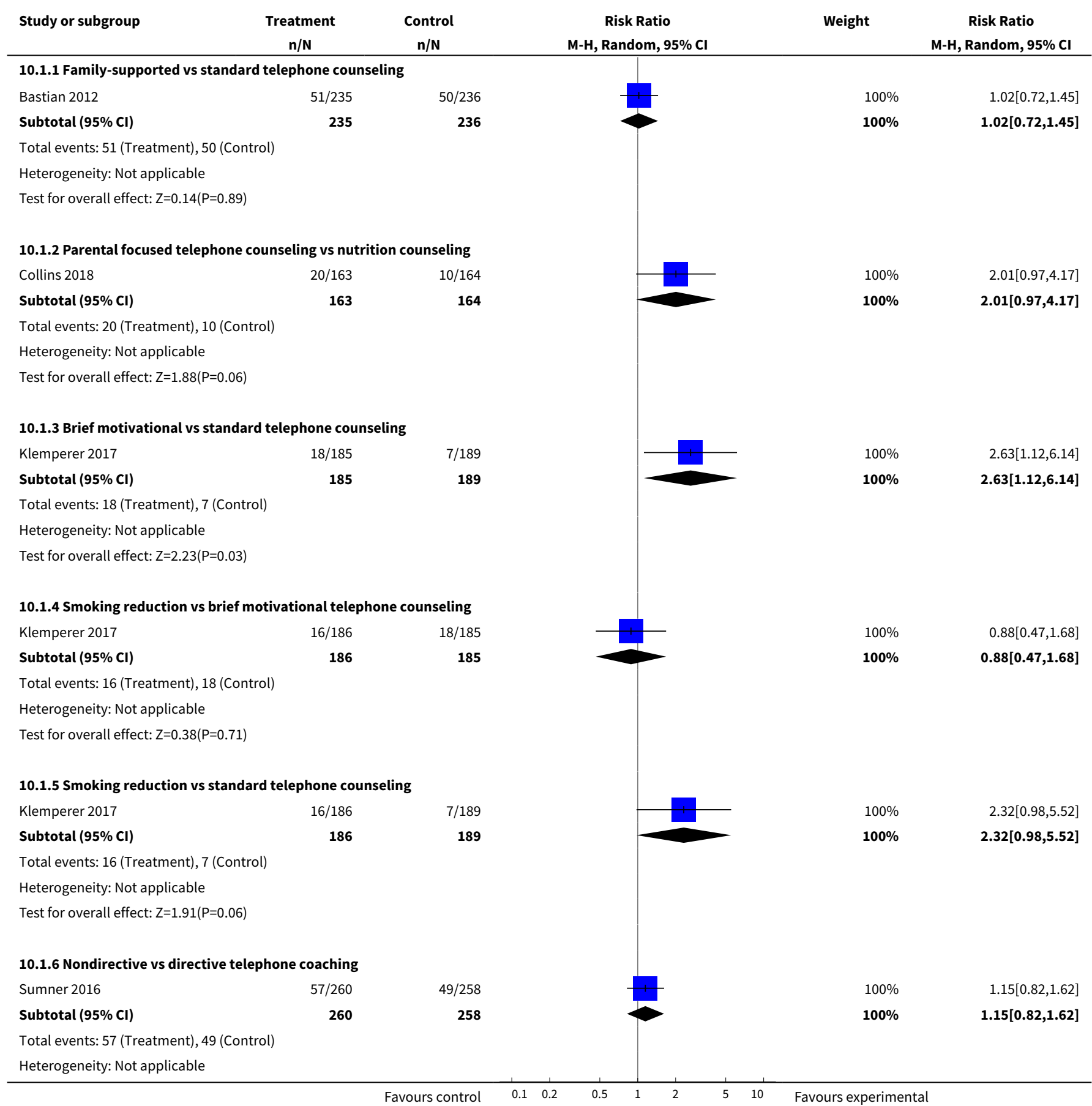




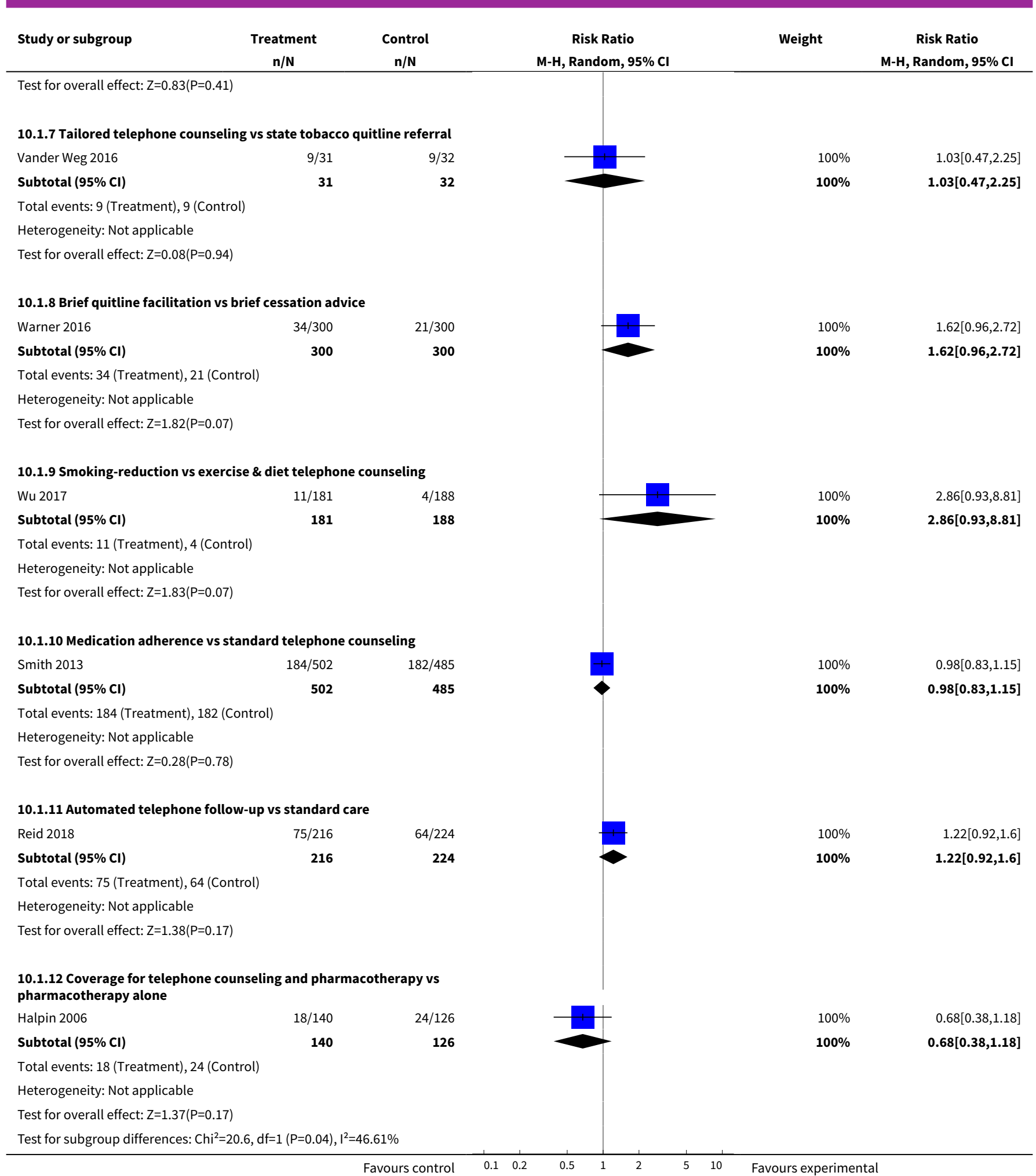

Telephone counselling for smoking cessation (Review) 


\section{APPEN DICES}

\section{Appendix 1. Specialised Register Search Strategy}

Searched using CRS (Cochrane Register of Studies software)

\#1 MeSH DESCRIPTOR Hotlines

\#2 (telephone* OR phone* OR quitline* OR helpline):TI,XKY,MH,EMT,KW

$\# 3$ (quitline* OR helpline): $A B$

\#4 ((telephone ${ }^{\star}$ NEAR counsel $\left.{ }^{\star}\right)$ OR (phone NEAR counsel $\left.\left.{ }^{\star}\right)\right): A B$

\#5 \#1 OR \#2 OR \#3 OR \#4

MH - MeSH descriptor. EMT - Embase descriptor. KW \& XKY - other keywords including those assigned as part of Tobacco addiction group coding

\section{Appendix 2. Results of meta-regression}

Mixed-Effects Model ( $k=67$; tau² estimator: $\mathrm{DL})$

$\mathrm{I}^{2}$ (residual heterogeneity/unaccounted variability): $49.91 \%$

$\mathrm{R}^{2}$ (amount of heterogeneity accounted for): $0.87 \%$

\section{Test for Residual Heterogeneity:}

$\mathrm{QE}(\mathrm{df}=61)=121.7906, \mathrm{p}$-value $<0.0001$

Test of Moderators (all coefficient included):

$\mathrm{QM}(\mathrm{df}=5)=10.4926, \mathrm{p}$-value $=0.0264$

\begin{tabular}{|c|c|c|c|c|c|}
\hline Parameter & $\beta$ & $(95 \% \mathrm{Cl})$ & RRCa & $(95 \% \mathrm{Cl})$ & $P$ value \\
\hline Intercept & -0.17 & $(-0.45$ to 0.12$)$ & 0.85 & (0.64 to 1.13 ) & 0.25 \\
\hline Baseline Support & - & - & - & - & - \\
\hline Pharmacotherapy & 0 & Reference & 1.00 & Reference & \\
\hline Self-help & 0.30 & (0.10 to 0.51$)$ & 1.35 & (1.10 to 1.67$)$ & $<0.01$ \\
\hline Brief intervention & 0.31 & (0.05 to 0.58$)$ & 1.37 & (1.05 to 1.79$)$ & 0.02 \\
\hline Incentives & -0.12 & $(-0.75$ to 0.51$)$ & 0.89 & (0.47 to 1.67$)$ & 0.71 \\
\hline Per each additional call & 0.02 & $(-0.02$ to 0.05$)$ & 1.02 & (0.98 to 1.05$)$ & 0.29 \\
\hline Selected for motivation & - & - & - & - & - \\
\hline No & 0.00 & Reference & 1.00 & Reference & - \\
\hline Yes & 0.23 & (0.04 to 0.42 ) & 1.26 & (1.04 to 1.52$)$ & 0.02 \\
\hline
\end{tabular}

aRRC: Relative Risk Change compared to reference category (categorical moderators) and no change in units (continuous moderator).

WHAT'S NEW 


\begin{tabular}{lll}
\hline Date & Event & Description \\
\hline 30 October 2018 & $\begin{array}{l}\text { New citation required but conclusions } \\
\text { have not changed }\end{array}$ & $\begin{array}{l}30 \text { new studies added, no major change to conclusions. Addition- } \\
\text { al authors: WM and JMOM }\end{array}$ \\
\hline 3 May 2018 & New search has been performed & Searches updated \\
\hline
\end{tabular}

\section{HISTORY}

Protocol first published: Issue 4, 2000

Review first published: Issue 2, 2001

\begin{tabular}{|c|c|c|}
\hline Date & Event & Description \\
\hline 23 October 2013 & Amended & Information added to ongoing studies tables. \\
\hline 20 June 2013 & New search has been performed & Searches updated \\
\hline 20 June 2013 & $\begin{array}{l}\text { New citation required but conclusions } \\
\text { have not changed }\end{array}$ & $\begin{array}{l}\text { Twelve new studies added, no major change to conclusions. Ad- } \\
\text { ditional author JHB. }\end{array}$ \\
\hline 12 May 2009 & New search has been performed & $\begin{array}{l}\text { Updated for issue } 3,2009 \text {. Nineteen new studies, no change to } \\
\text { conclusions, strengthened evidence of effect overall and for } \\
\text { some subgroups. }\end{array}$ \\
\hline 4 August 2008 & Amended & Converted to new review format. \\
\hline 11 April 2006 & $\begin{array}{l}\text { New citation required but conclusions } \\
\text { have not changed }\end{array}$ & $\begin{array}{l}\text { Updated for Issue 3, } 2006 \text {. Twenty two new studies, studies of re- } \\
\text { lapse prevention now excluded. Comparisons reorganised, addi- } \\
\text { tional subgroup analyses. }\end{array}$ \\
\hline 14 October 2002 & $\begin{array}{l}\text { New citation required but conclusions } \\
\text { have not changed }\end{array}$ & $\begin{array}{l}\text { Updated for Issue } 1,2003 \text {. Four new trials, of which } 3 \text { contribute } \\
\text { to meta-analysis. No major changes to conclusions }\end{array}$ \\
\hline
\end{tabular}

\section{CONTRIBUTIONS OF AUTHORS}

JH-B became an author from 2013 and contributed to extracting data and updating the text.

WM became an author in 2018 and contributed to titles, abstracts, and full-text screening, data extraction, meta-analyses, and updating the text.

JMOM became an author in 2018 and contributed to titles, abstracts, and full-text screening, data extraction, meta-analyses, metaregression and updating the text.

\section{DECLARATIONS OF INTEREST}

WM: none known.

JOM: none known.

JHB: none known.

\section{SOURCES OF SUPPORT}

\section{Internal sources}

- National Institute for Health Research (NIHR) School for Primary Care Research, UK.

- Department of Primary Care Health Sciences, University of Oxford, UK. 
- NIHR Community Healthcare Medtech and In Vitro Diagnostics Cooperative (MIC), UK.

Partly funded the work of JMOM

- NIHR Biomedical Research Centre, Oxford, UK.

Partly funded the work of JMOM

\section{External sources}

- NHS Research \& Development Programme, UK.

\section{DIFFERENCES BETWEEN PROTOCOLAND REVIEW}

As of the 2018 update of the review, we changed the meta-analyses from a fixed-effect to a random-effects model, in line with new Cochrane Tobacco Addiction Group policy, to account for the expected variability in the interventions delivered.

For this update, we added two new post hoc subgroup analyses, looking at baseline support provided and intensity of counselling, operationalised as the number of phone calls offered.

\section{N DEX TERMS}

\section{Medical Subject Headings (MeSH)}

*Telephone; Counseling [ ${ }^{*}$ methods]; Hotlines; Randomized Controlled Trials as Topic; Smoking Cessation [ ${ }^{*}$ methods] [ ${ }^{*}$ statistics \& numerical data]

\section{MeSH check words}

Adult; Female; Humans; Male; Middle Aged; Pregnancy 